\title{
CAMILA LORENZ
}

\section{Caracterização molecular e morfológica de Anopheles cruzii e Anopheles homunculus (Diptera; Culicidae) da Mata Atlântica do Estado de São Paulo}

Dissertação apresentada ao Departamento de Parasitologia do Instituto de Ciências Biomédicas da Universidade de São Paulo, para obtenção do Título de Mestre em Ciências. 


\section{CAMILA LORENZ}

\section{Caracterização molecular e morfológica de Anopheles cruzii e Anopheles homunculus (Diptera; Culicidae) da Mata Atlântica do Estado de São Paulo}

Dissertação apresentada ao Departamento de Parasitologia do Instituto de Ciências Biomédicas da Universidade de São Paulo, para obtenção do Título de Mestre em Ciências.

Área de Concentração: Biologia da Relação Patógeno-Hospedeiro

Orientador: Prof. Dr. Lincoln Suesdek

Versão corrigida. A versão original eletrônica encontra-se disponível tanto na Biblioteca do ICB quanto na Biblioteca Digital de Teses e Dissertações da USP (BDTD). 
DADOS DE CATALOGAÇÃO NA PUBLICAÇÄO (CIP)

Serviço de Biblioteca e Informação Biomédica do

Instituto de Ciências Biomédicas da Universidade de São Paulo

reproduçäo näo autorizada pelo autor

Lorenz, Camila.

Caracterização molecular e morfológica de Anopheles cruzii e Anopheles homunculus (Diptera; Culicidae) da Mata Atlântica do Estado de São Paulo / Camila Lorenz. -- São Paulo, 2012.

Orientador: Prof. Dr. Lincoln Suesdek Rocha.

Dissertação (Mestrado) - Universidade de São Paulo. Instituto de Ciências Biomédicas. Departamento de Parasitologia. Área de concentração: Biologia da Relação Patógeno-Hospedeiro. Linha de pesquisa: Genética populacional e morfometria geométrica de vetores.

Versão do título para o inglês: Morphological and molecular characterization of Anopheles cruzii and Anopheles homunculus (Dptera; Culicidae) in the Atlantic Forest of São Paulo.

1. Anopheles 2. Malária 3. Evolução 4. Asa 5. Genética de populações 6. Sazonalidade I. Rocha, Prof. Dr. Lincoln Suesdek II. Universidade de São Paulo. Instituto de Ciências Biomédicas. Programa de Pós-Graduação em Parasitologia III. Título. 
Candidato(a):

Título da

Orientador(a):
Camila Lorenz.

Caracterização molecular e morfológica de Anopheles cruzii e Anopheles homunculus (Diptera; Culicidae) da Mata Atlântica do Estado de São Paulo.

Prof. Dr. Lincoln Suesdek Rocha.

A Comissão Julgadora dos trabalhos de Defesa da Dissertação de Mestrado, em sessão pública realizada a considerou
( ) Aprovado(a)
( ) Reprovado(a)

Examinador(a): Assinatura:

Nome:

Instituição:

Examinador(a): Assinatura:

Nome:

Instituição:

Presidente: Assinatura:

Nome:

Instituição: 


\section{CERTIFICADO DE ISENÇÃO}

Certificamos que o Protocolo CEP-ICB N $\mathrm{N}^{\circ} 475 / 11$ referente ao projeto intitulado: "Caracterização molecular e morfológica de Anopheles homunculus e Anopheles cruzii da mata atlântica do estado de São Paulo (Kerteszia; Deptera; Culicidae)" sob a responsabilidade de Camila Lorenz, foi analisado na presente data pela CEUA - COMISSÃO DE ÉTICA NO USO DE ANIMAIS e pela CEPSH- COMISSÃO DE ÉTICA EM PESQUiSA COM SERES HUMANOS, tendo sido deliberado que o referido projeto não utilizará animais que estejam sob a égide da lei 11.794 de 8 de outubro de 2008, nem envolverá procedimentos regulados pela Resolução CONEP nº196 de 1996.

São Paulo, 17 de agosto de 2011.
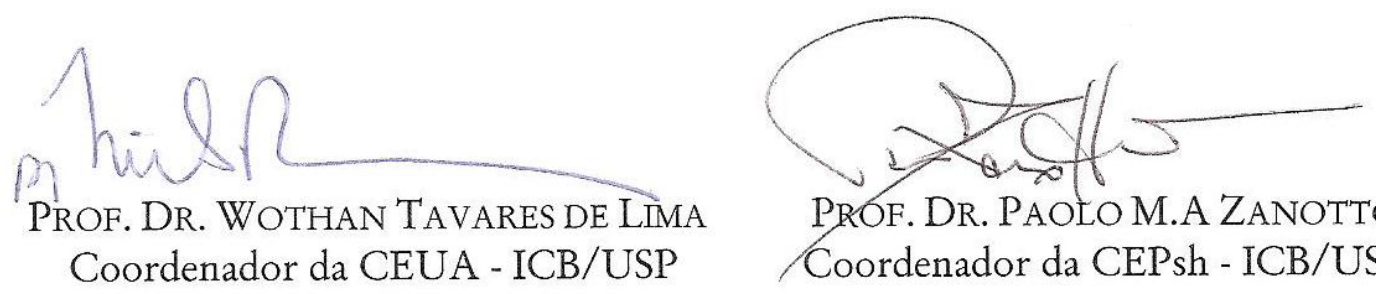

PROF. DR. PAOLO M.A ZANOTTO Coordenador da CEPsh - ICB/USP 
Dedico este trabalbo

was mens quesidas pais Solange e Domingas com todo amor e gratidãa,

e wo men irmão leowardo que me acompanhou nessa trajetória. 


\section{AGRADECIMENTOS}

Ao meu orientador Prof. Dr. Lincoln Suesdek, por acreditar na minha capacidade, pela imensa contribuição na minha formação acadêmica, profissional e humana. Pelo apoio, orientação e amizade.

À Profa. Dra. Maria Anice Mureb Sallum pela contribuição durante todo o percurso da dissertação, pelas valiosas sugestões e pelos espécimes cedidos para a realização de parte do trabalho.

Ao biólogo Aristides Fernandes pelo auxílio na identificação dos espécimes e ao Dr. Paulo Roberto Urbinatti pela ajuda com as fotos dos culicídeos.

À equipe da USP em Pariquera-Açu: Décio Wach, Jair Donizete da Silva, Francisco Alves dos Santos, Rui de Lima e Luiz Carlos de Oliveira, cuja assistência foi essencial para realização das coletas de campo.

Aos membros da minha banca de qualificação: Prof. Dr. Mauro T. Marrelli, Prof. Dr. Carlos Eduardo Winter e Profa. Dra. Margareth de Lara Capurro-Guimarães pelas sugestões.

Aos doutores Jean-Pierre Dujardin e Leandro Rabelo Monteiro pelos ensinamentos de morfometria geométrica.

Aos colegas, funcionários e pesquisadores do Laboratório de Parasitologia do Instituto Butantan pela troca de experiências, ajuda, convívio e descontração.

Aos colegas da Faculdade de Saúde Pública Denise Sant'ana, Ivy Luizi de Sá, Sandra Nagaki e Bruna Demari pela companhia em congressos e pela amizade.

Aos amigos do lab: Paloma, Vivian, Flávia, Carol, Stella, Fábio e Edu pela amizade, pelos momentos de aprendizado e descontração e por me proporcionarem um ambiente super agradável para trabalhar. Obrigada!

À doutoranda Paloma de Oliveira Vidal, pela imensa ajuda no meu trabalho, paciência e disponibilidade para me ensinar técnicas morfométricas e genéticas.

Ao Conselho Nacional de Desenvolvimento Científico e Tecnológico (CNPq) pela concessão da bolsa.

Ao meu irmão e demais familiares, por tudo que representam em minha vida.

Aos meus queridos pais, pelo exemplo de vida, conselhos, amizade, ensinamentos, amor e carinho irrestritos. Por sempre estarem ao meu lado, em toda e qualquer situação com palavras de incentivo e coragem. E pelos puxões de orelha quando necessários.

Ao homem que trouxe as primeiras mudas de café para o Brasil, sem o qual não seria possível terminar essa dissertação... 
"A natureza nunca nos engana; somos sempre nós que nos enganamos."

Jean Jacques Rousseau 


\section{RESUMO}

Lorenz C. Caracterização molecular e morfológica de Anopheles cruzii e Anopheles homunculus (Diptera; Culicidae) da Mata Atlântica do estado de São Paulo. [dissertação (Mestrado em Biologia da Relação Patógeno-Hospedeiro)]. São Paulo: Instituto de Ciências Biomédicas, Universidade de São Paulo; 2012.

Registros de casos autóctones de malária têm sido reportados na Mata Atlântica do sudeste brasileiro. Na região litorânea do Estado de São Paulo, Anopheles (Kerteszia) cruzii e Anopheles (Kerteszia) homunculus são, respectivamente, vetores principal e secundário de Plasmodium sp. Essas duas espécies de anofelinos são de difícil identificação taxonômica, sobretudo as fêmeas. Tal dificuldade tem possivelmente levado à subestimação da importância vetorial de An. homunculus. Ambas têm ciclos de vida associados a coleções hídricas de bromélias. Esses anofelinos, embora habitem um largo intervalo altitudinal (entre 5 e 263 metros), apresentam afinidades diferenciais aos microambientes da mata atlântica. Devido a esse contexto, o objetivo do trabalho foi obter diagnose alar para An. cruzii e An. homunculus além de caracterizar morfológica e geneticamente as populações em perspectiva sazonal, temporal e microambiental. Utilizando a morfometria geométrica foi possível distinguir as espécies An. cruzii e An. homunculus. Há também acentuado dimorfismo sexual de forma alar nas duas espécies. As populações de An. cruzii analisadas em perspectiva sazonal apresentaram diferenciação no formato alar. O gene CO-I mostrou-se altamente polimórfico com apenas dois compartilhamentos entre essas populações, porém com baixo nível de divergência genética ( $\mathrm{Fst}=0,003$, $\Phi \mathrm{st}=0,007)$. Populações de $A n$. homunculus do inverno também apresentaram alta diferenciação no formato e tamanho alar em relação às do verão. Entretanto nesta espécie o gene CO-I parece estar mais conservado do que em An. cruzii. As populações de An. cruzii do morro e planície também apresentaram variação no formato alar. O tamanho do centróide nos indivíduos do morro foi ligeiramente maior em todas as comparações. Houve compartilhamento de apenas um haplótipo entre populações do morro e planície. Há evidência de alguma estruturação populacional $(F s t=0,125, \Phi s t=0,121)$ e baixo número de migrantes $(\mathrm{Nm}=1,67)$ entre os esses microambientes altitudinais em Julho/2012. As comparações temporais tanto em An. cruzii como em An. homunculus mostraram evidente diferenciação morfológica, ou seja, os caracteres das asas são acusativos de microevolução. Houve altos valores de diferenciação genética intrapopulacional em todos os grupos amostrados $(79,6 \%$ a $99,3 \%)$ e a diversidade haplotípica foi acima de 0,97 em todas as populações de An. cruzii analisadas, com poucos haplótipos compartilhados entre as amostras sazonais e geográficas. Os marcadores morfológicos e moleculares utilizados neste estudo parecem evoluir em velocidades diferentes, pois os valores Qst são maiores que os Fst em todas as populações. Os resultados sugerem que existe regionalismo associado à paisagem nas populações de $A n$. cruzii do morro e planície, embora sejam geograficamente próximas. Há substituição populacional em curto período de tempo, demonstrado pelo alto número de haplótipos diferentes e formato alar entre inverno e verão.

Palavras-chave: Morfometria geométrica alar. Microevolução. Gene mitocondrial. Microambientes. Sazonalidade. Culicidae. 
Lorenz C. Morphological and molecular characterization of Anopheles cruzii and Anopheles homunculus (Diptera; Culicidae) in the Atlantic Forest of São Paulo state. [Masters thesis (Biology of Host-Pathogen Relationship)]. São Paulo: Instituto de Ciências Biomédicas, Universidade de São Paulo; 2012.

Records of autochthonous malaria cases have been reported in the Atlantic Forest of Southeastern Brazil. In the coastal region of the state of São Paulo, Anopheles (Kerteszia) cruzii and Anopheles (Kerteszia) homunculus are, respectively, the primary and secondary vectors of Plasmodium $s p$. These two species are difficult of taxonomic identification, especially females. This difficulty has possibly led to underestimation of the importance of vector Anopheles homunculus. Both have life cycles associated with water collections of bromeliads. These anophelines, although inhabit a wide altitudinal range (from 5 to 263 meters), exhibit differential affinities to the microenvironments of the Atlantic Forest. Due to this context, the aim of this research was to obtain wing diagnosis for An. cruzii and An. homunculus, besides morphological and genetically characterize the populations in seasonal, temporal and microenvironmental perspectives. Using geometric morphometrics was possible to distinguish between species $A n$. cruzii and An. homunculus. There is also pronounced sexual dimorphism of wing shape in both species. Populations of $A n$. cruzii analyzed presented differentiation in wing shape. The CO-I gene was highly polymorphic with only two shares between these populations, but with low level of genetic divergence ( $F s t=0,003 ; \Phi s t=0,007)$. Populations of $A n$. homunculus of winter also showed high differentiation alar in shape and size to those of the summer. However, in this species, CO-I gene appears to be more conserved than An. cruzii. Populations of An. cruzii of hill and plain also showed variation in wing shape. The centroid size among individuals of the hill was slightly higher in all comparisons. There was only one haplotype sharing between specimens of hill and plain. There is some evidence of population subdivision ( $F s t=0,125$; $\Phi s t=0,121)$ and low number of migrants $(\mathrm{Nm}=1,67)$ between the microenvironments analyzed in July 2012. The temporal comparisons in both An. cruzii and An. homunculus shown apparent morphological differentiation; the characters of the wings are accusatives of microevolution. There were high values of genetic differentiation within populations sampled in all groups (79,6\% to $99,3 \%)$, and haplotype diversity was high in all $A n$. cruzii populations analyzed with few shared haplotypes among seasonal and geographical samples. The morphological and molecular markers used in this study seem to evolve at different speeds, because the values of Qst are greater than Fst in all populations. The results suggest that regionalism is associated with the landscape in populations of $A n$. cruzii of hill and plain, although they are geographically close. There is a significant population replacement in a short period of time, demonstrated by the high number of different haplotypes and wing shape between winter and summer.

Keywords: Morphometric geometrics. Microevolution. Mitochondrial gene. Microenvironments. Seasonality. Culicidae. 


\section{LISTA DE ABREVIATURAS E SIGLAS}

$\begin{array}{ll}\text { DNA } & \text { ácido desoxirribonucleico } \\ \mathrm{COI} & \text { gene citocromo oxidase subunidade I } \\ \mathrm{pb} & \text { pares de bases de DNA } \\ \mathrm{PCR} & \text { reação de polimerização em cadeia } \\ \mathrm{VC} & \text { variável canônica } \\ \mathrm{NaCl} & \text { cloreto de sódio } \\ \text { EDTA } & \text { do inglês ethylene diamine tetra acetic acid } \\ \mathrm{SDS} & \text { dodecil sulfato de sódio } \\ \text { Dntp } & \text { desoxirribonucleotídeos fosfatados } \\ \mathrm{MgCl} 2 & \text { cloreto de magnésio } \\ \mathrm{RCF} & \text { do inglês relative centrifugal force } \\ \mathrm{Fst} & \text { índice que mede a diferenciação genética } \\ \phi S \mathrm{St} & \text { índice que mede a diferenciação genética por AMOVA } \\ \text { Qst } & \text { índice que mede a diferenciação morfológica quantitativa } \\ \mathrm{Nm} & \text { número de migrantes } \\ \text { AMOVA } & \text { análise de variância molecular }\end{array}$




\section{LISTA DE ILUSTRAÇÕES}

Figura 1 - Incidência de casos de malária

Figura 2 - Bromélias do gênero Vriesia e Nidularium 22

Figura 3 - Vista dorsal de uma larva de Anopheles cruzii e An. homunculus. .24

Figura 4 - Mapa da distribuição das espécies Kerteszia encontradas no Brasil.......27

Figura 5 - Mapa do Estado de São Paulo evidenciando a região de Cananéia. .34

Figura 6 - Pupa de Anopheles cruzii. 36

Figura 7 - Fêmea adulta de Anopheles cruzii.

Figura 8 - Foto da asa de An. cruzii com os marcos anatômicos. .38

Quadro 1 - Indivíduos Anopheles cruzii e An. homunculus utilizados nas comparações genéticas .40

Figura 9 - Esquema demonstrando a região do gene CO-I onde os primers UEA-7 e UEA-10 se hibridizaram

Figura 10 - Padrão de fragmentos do gene COI de Anopheles cruzii. .42

Figura 11 - Dimorfismo sexual de Anopheles cruzii. 46

Figura 12 - Distâncias de Mahalanobis entre machos e fêmeas de Anopheles cruzii.

Figura 13 - Dimorfismo sexual de Anopheles homunculus .48

Figura 14 - Variação sazonal do formato alar em fêmeas de An. cruzii. .49

Figura 15 - Variação sazonal do formato alar em machos de An. cruzii. .50 
Figura 16 - Consensos alares de fêmeas e machos de An. cruzii no inverno e verão.

Figura 17 - Variação sazonal do tamanho alar em machos e fêmeas de An. cruzii.

Figura 18 - Rede de haplótipos de An. cruzii coletados no inverno e verão 52

Figura 19 - Dendrograma dos haplótipos de Anopheles cruzii coletados no inverno e verão.

Figura 20 - Variação sazonal do formato alar em fêmeas de An. homunculus 54

Figura 21 - Variação sazonal do formato alar em machos de An. homunculus 55

Figura 22 - Consensos alares de fêmeas e machos de An. homunculus no inverno e verão. .55

Figura 23 - Variação sazonal do tamanho alar em machos e fêmeas de An. homunculus.

Figura 24 - Rede de haplótipos de Anopheles homunculus coletados no inverno e verão.

Figura 25 - Dendrograma dos haplótipos de Anopheles homunculus coletados no inverno e verão

Figura 26 - Variação microambiental do formato alar em fêmeas de An. cruzii em Janeiro/2009.

Figura 27 - Variação microambiental do formato alar em machos de An. cruzii em Janeiro/2009.

Figura 28 - Consensos alares de fêmeas e machos de An. cruzii no morro e planície em Janeiro/2009

Figura 29 - Variação microambiental do tamanho alar em machos e fêmeas de An. cruzii em Janeiro/2009 
Figura 30 - Variação microambiental do formato alar em fêmeas de An. cruzii em Janeiro/2012.

Figura 31 - Variação microambiental do formato alar em machos de An. cruzii em Janeiro/2012.

Figura 32 - Variação microambiental do tamanho alar em machos e fêmeas de An. cruzii em Janeiro/2012

Figura 33 - Consensos alares de fêmeas e machos de An. cruzii no morro e planície em Janeiro/2012

Figura 34 - Rede de haplótipos de Anopheles cruzii coletados no morro e planície em Janeiro/2012

Figura 35 - Dendrograma dos haplótipos de Anopheles cruzii coletados no morro e planície em Janeiro/2012

Figura 36 - Variação microambiental do formato alar em fêmeas de An. cruzii em Julho/2012

Figura 37 - Variação microambiental do formato alar em machos de An. cruzii em Julho/2012

Figura 38 - Variação microambiental do tamanho alar em machos e fêmeas de An. cruzii em Julho/2012

Figura 39 - Consensos alares de fêmeas e machos de An. cruzii no morro e planície em Julho/2012

Figura 40 - Rede de haplótipos de Anopheles cruzii coletados no morro e planície em Julho/2012

Figura 41 - Dendrograma dos haplótipos de Anopheles cruzii coletados no morro e planície em Julho/2012

Figura 42 - Variação temporal do formato alar em fêmeas de An. cruzii coletadas no morro em 2009 e 2012.

Figura 43 - Variação temporal do formato alar em machos de An. cruzii coletados no morro em 2009 e 2012 
Figura 44 - Variação temporal do tamanho alar em machos e fêmeas de An. cruzii coletados no morro em 2009 e 2012

Figura 45 - Consensos alares de fêmeas e machos de An. cruzii coletados no morro em 2009 e 2012

Figura 46 - Variação temporal do formato alar em fêmeas de An. cruzii coletadas na planície em 2009 e 2012

Figura 47 - Variação temporal do formato alar em machos de An. cruzii coletadas na planície em 2009 e 2012

Figura 48 - Variação temporal do tamanho alar em machos e fêmeas de An. cruzii coletados na planície em 2009 e 2012

Figura 49 - Consensos alares de fêmeas e machos de An. cruzii coletados na planície em 2009 e 2012

Figura 50 - Variação temporal do formato alar em fêmeas de An. homunculus em 2009 e 2012

Figura 51 - Variação temporal do formato alar em machos de An. homunculus em 2009 e 2012

Figura 52 - Variação temporal do tamanho alar em machos e fêmeas de An. homunculus em 2009 e 2012

Figura 53 - Consensos alares de fêmeas e machos de An. homunculus em 2009 e 2012

Figura 54 - Correlação do tamanho do centróide com precipitação e temperatura em machos de An. cruzii.

Figura 55 - Correlação do tamanho do centróide com precipitação e temperatura em fêmeas de An. cruzii.

Quadro A.1 - Sítios variáveis dos haplótipos de An. cruzii encontrados no inverno x verão e morro x planície em Janeiro/2012

Quadro A.2 - Sítios variáveis dos haplótipos de An. cruzii encontrados no morro e planície em Julho/2012 
Quadro A.3 - Sítios variáveis dos haplótipos de An. homunculus encontrados no inverno e verão. 


\section{LISTA DE TABELAS}

Tabela 1 - Indivíduos Anopheles cruzii utilizados para Morfometria Geométrica.

Tabela 2 - Indivíduos Anopheles homunculus utilizados para Morfometria Geométrica.

Tabela 3 - Dados relacionados ao dimorfismo sexual de Anopheles cruzii

Tabela 4 - Dados relacionados ao dimorfismo sexual de Anopheles homunculus.

Tabela 5 - Dados genéticos da comparação Inverno x Verão de Anopheles cruzii.

Tabela 6 - Valores de diferenciação genética e número de migrantes da comparação Inverno x Verão de Anopheles cruzii

Tabela 7 - Dados genéticos da comparação Inverno x Verão de Anopheles homunculus

Tabela 8 - Valores de diferenciação genética e número de migrantes da comparação Inverno x Verão de Anopheles homunculus .58

Tabela 9 - Dados genéticos da comparação Morro X Planície de Anopheles cruzii em Janeiro/2012

Tabela 10 - Valores de diferenciação genética e número de migrantes da comparação Morro X Planície de Anopheles cruzii em Janeiro/2012

Tabela 11 - Dados genéticos da comparação Morro X Planície de Anopheles cruzii em Julho/2012

Tabela 12 - Valores de diferenciação genética e número de migrantes da comparação Morro X Planície de Anopheles cruzii em Julho/2012.

Tabela 13 - Tamanhos do centróide, distâncias de Mahalanobis e índices de reclassificação de machos e fêmeas de Anopheles cruzii

Tabela 14 - Tamanhos do centróide, distâncias de Mahalanobis e índices de reclassificação de machos e fêmeas de Anopheles homunculus. 


\section{SUMÁRIO}

1 INTRODUÇÃO

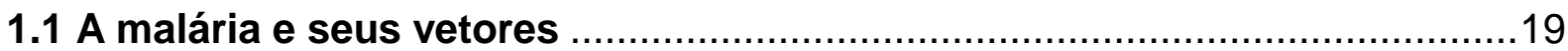

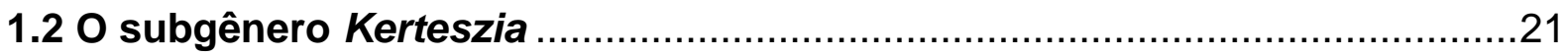

1.3 As espécies Anopheles cruzii e Anopheles homunculus..........................23

1.3.1 Aspectos taxonômicos e variabilidade morfológica .......................................23

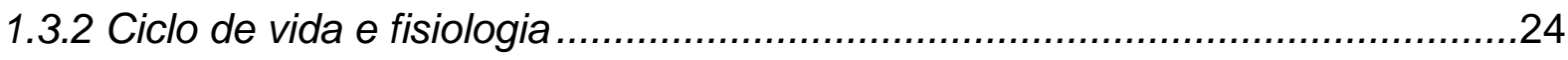

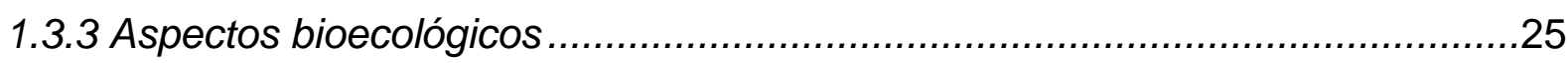

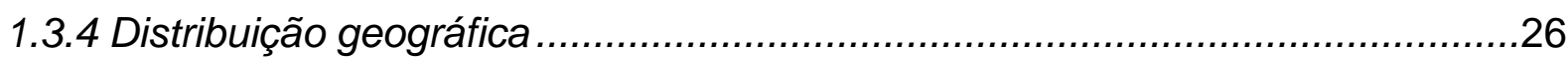

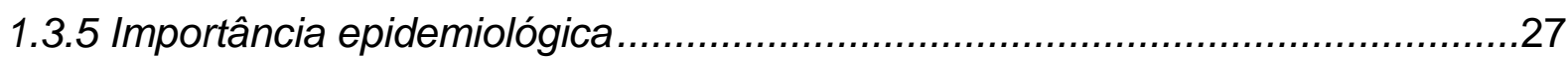

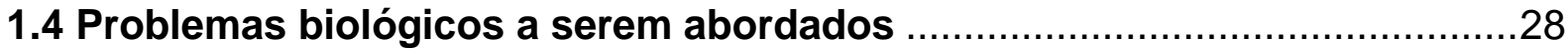

1.5 Métodos para caracterização populacional em Culicidae ...........................29

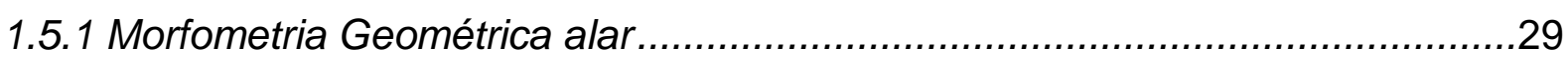

1.5.2 Marcadores mitocondriais - citocromo oxidase (COI)...................................30

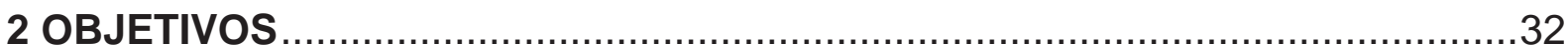

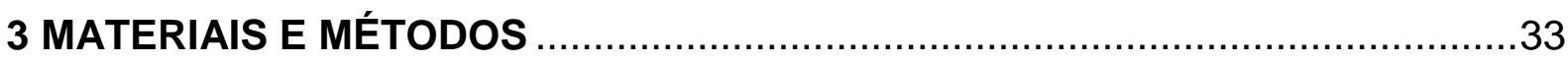

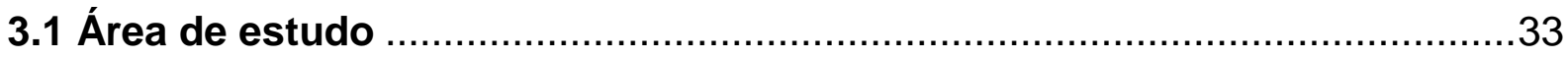

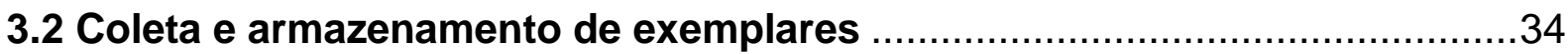

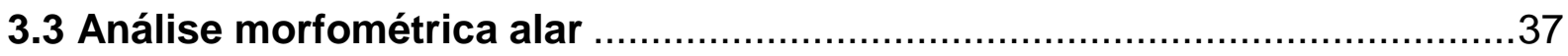

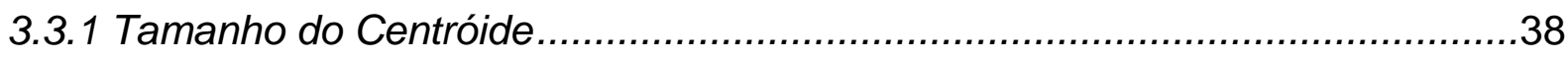

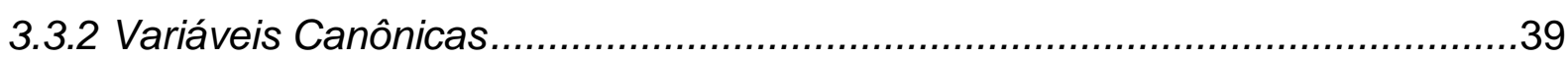

3.4 Análises do gene mitocondrial citocromo-oxidade (COI) ...........................39

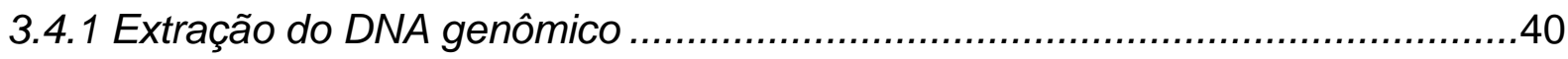

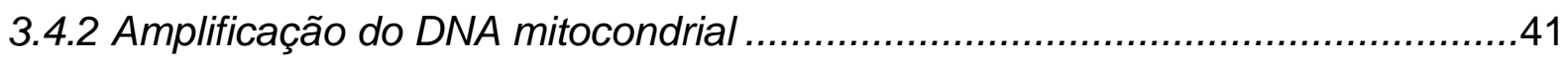

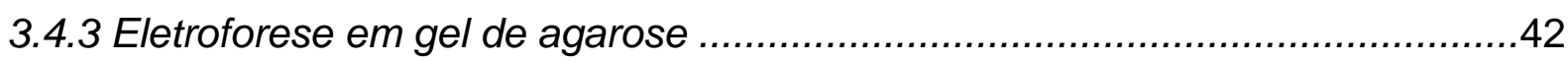

3.4.4 Purificação do produto da PCR e Sequenciamento ......................................42

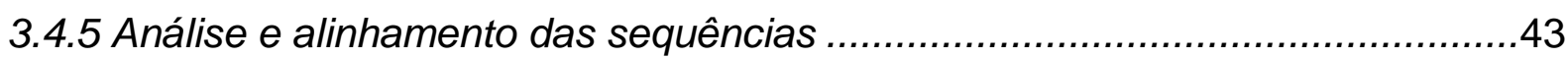

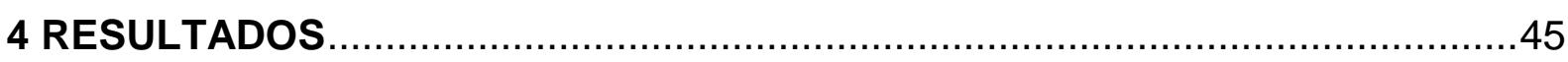

4.1 Diagnose entre as espécies Anopheles cruzii e An. homunculus...............45

4.2 Dimorfismo sexual - Morfometria Geométrica Alar ...................................45

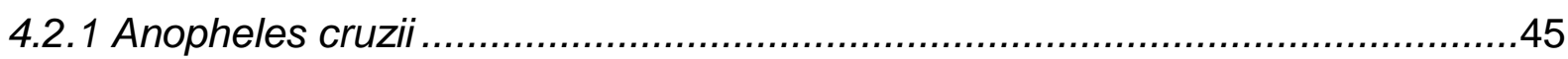

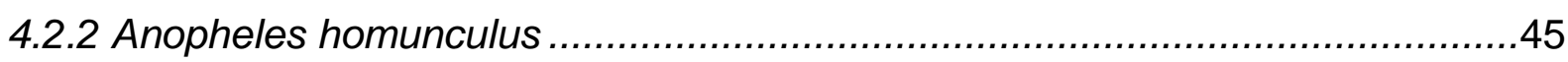

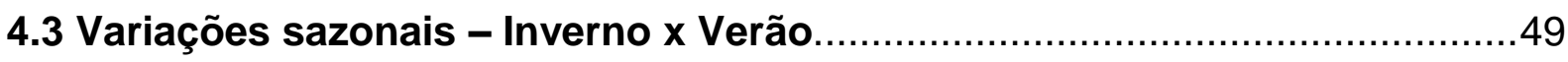

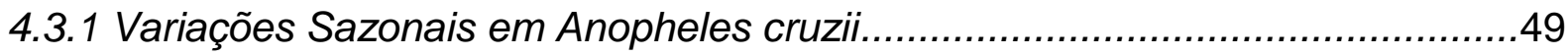

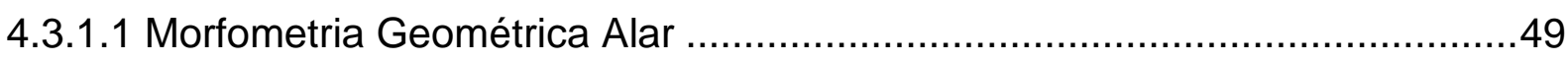

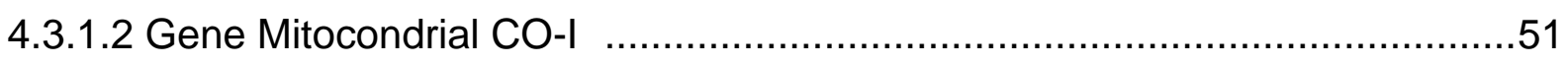

4.3.2 Variações Sazonais em Anopheles homunculus........................................54 


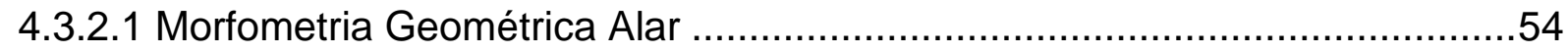

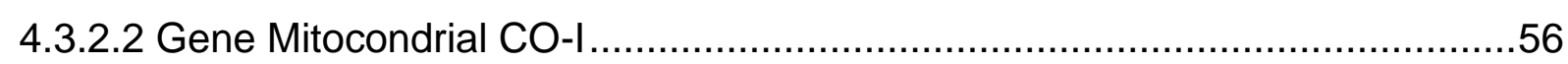

4.4 Variações altitudinais em An. cruzii - Morro x Planície .................................58

4.4.1 Variações Altitudinais em Janeiro/2009......................................................58

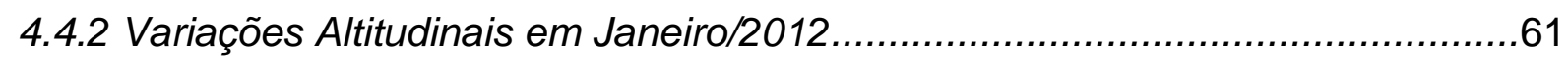

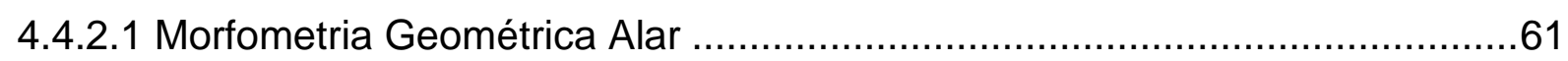

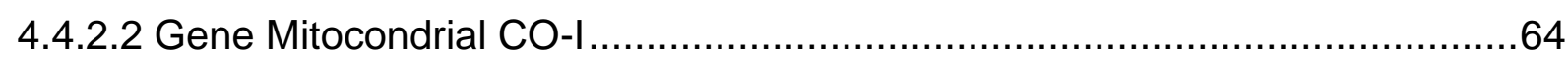

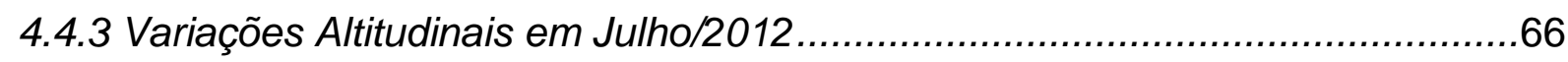

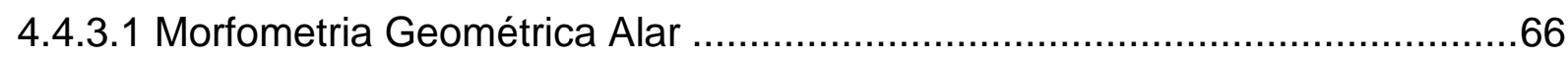

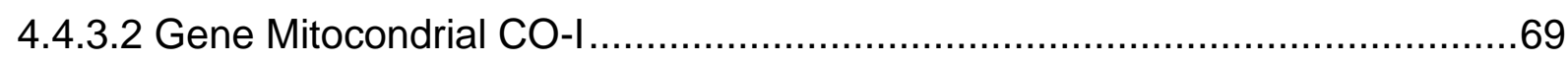

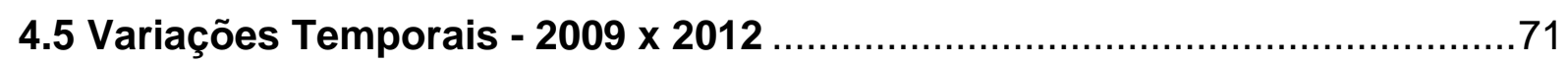

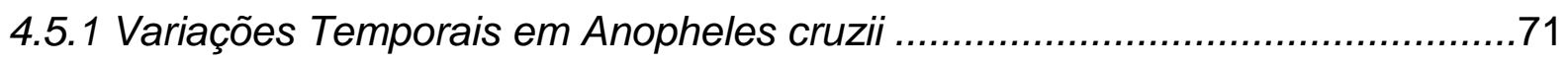

4.5.1.1 Variações Temporais no microambiente morro .........................................71

4.5.1.2 Variações Temporais no microambiente planície .......................................74

4.5.2 Variações Temporais em Anopheles homunculus ........................................77

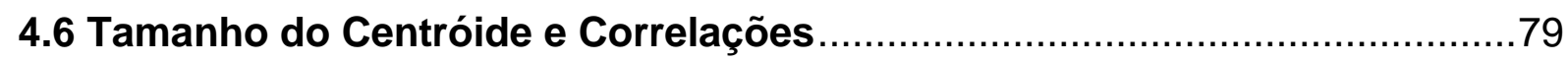

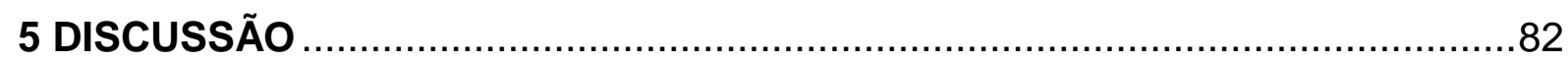

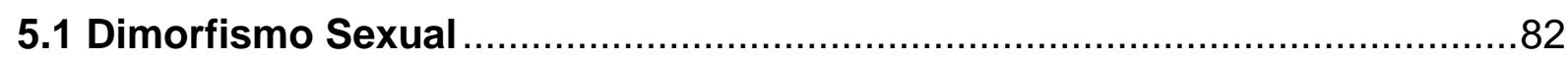

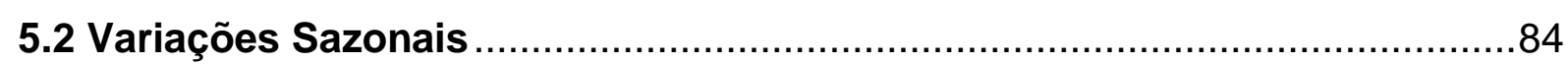

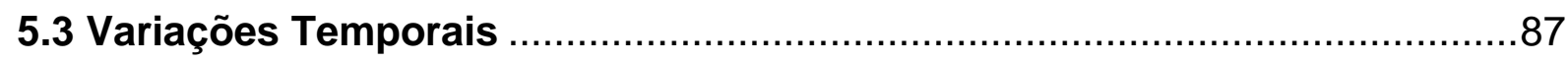

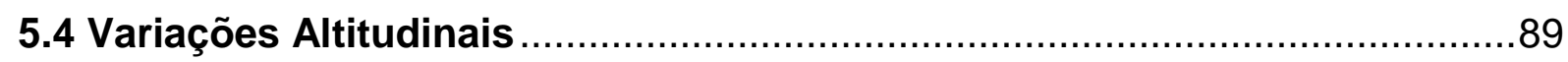

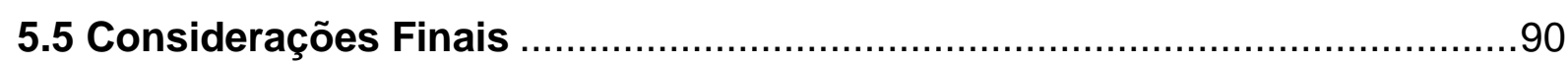

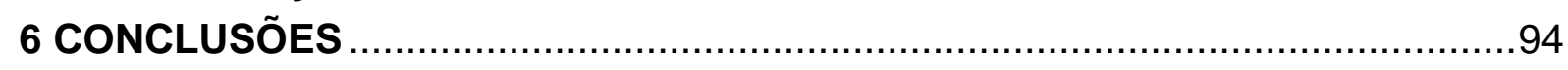

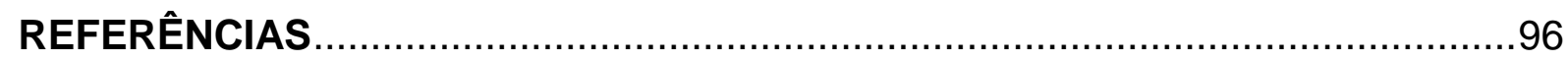

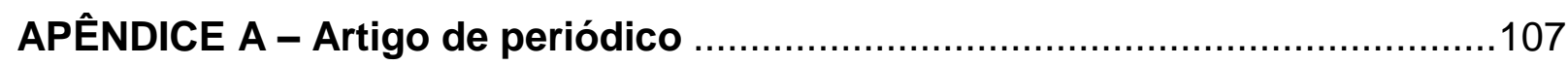

APÊNDICE B - Quadros de haplótipos …...............................................118 


\section{INTRODUÇÃO}

\subsection{A malária e seus vetores}

A malária é uma doença parasitária conhecida desde tempos remotos e vem atingindo a humanidade presumivelmente há milhares de anos. Tem maior ocorrência em áreas tropicais e subtropicais, entretanto causa mais prejuízos nos países em desenvolvimento. A doença é causada por protozoários do gênero Plasmodium e transmitida ao hospedeiro vertebrado pela picada da fêmea infectada do mosquito culicídeo do gênero Anopheles (Lima, 2010). A enfermidade caracteriza-se por acessos febris de 24,48 ou 72 horas, causando problemas no fígado e um quadro de anemia nesse hospedeiro vertebrado (Service, 1996).

Estima-se que mais de $40 \%$ da população mundial corre o risco de adquirir a malária (Figura 1). Em apenas um ano, há aproximadamente 300 milhões de novos casos e um milhão de mortes em todo o mundo (Brasil, 2010). No Brasil, o quadro epidemiológico dessa doença é preocupante, porque o número de casos foi superior a 300.000 no ano de 2009. Deste número, 99,9\% ocorreram na região amazônica (Brasil, 2010).

Figura 1 - Incidência de casos de malária a cada 1000 habitantes (2006)

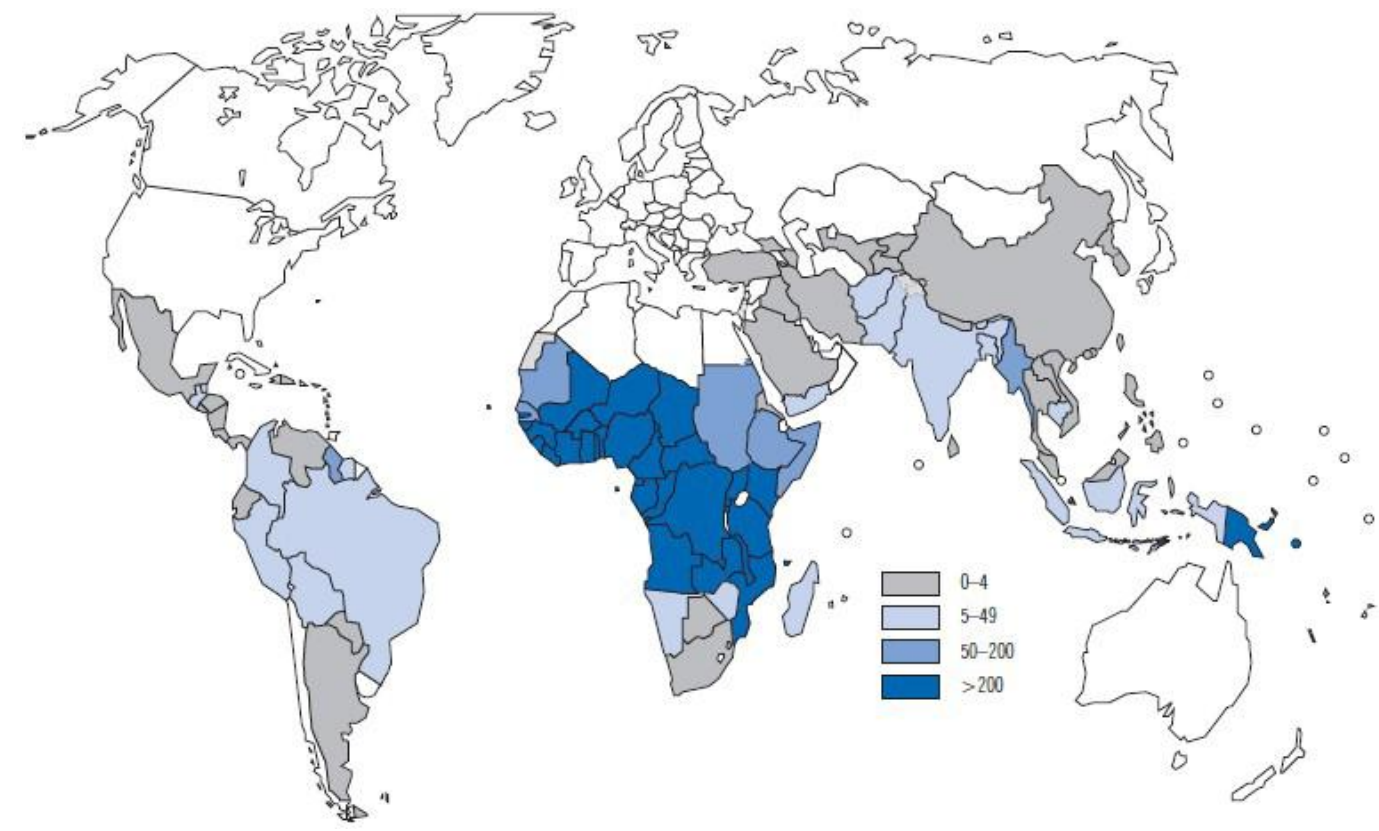

(Fonte: World Malaria Report, WHO, 2008) 
Atualmente são conhecidas aproximadamente 500 espécies da subfamília Anophelinae, mas apenas 70 delas são vetoras do Plasmodium. Destas, somente cerca de 20 são envolvidas com malária humana (Service, 1996). Para que um mosquito seja considerado um vetor importante de malária humana, é preciso que ele se alimente preferencialmente de sangue humano (antropofilia) e que seu ciclo de vida seja cronologicamente compatível com a história natural do parasita (Marrelli, 2000). A densidade demográfica de uma população e a proporção de picadas infectantes sobre os humanos também são fatores considerados para determinar a capacidade vetorial de um mosquito numa determinada região (Dye, 1986). As espécies do gênero Anopheles de uma forma geral apresentam ampla distribuição geográfica (Consoli, Lourenço-de-Oliveira, 1994). Com o aumento das populações humanas que vem ocorrendo nas áreas endêmicas aliado a fatores como desmatamento e exploração de minerais, essa distribuição pode ser afetada favorecendo o aumento dos índices de malária (Walsh et al., 1993).

Há duas categorias para designar a eficiência de um vetor na transmissão de Plasmodium: vetor principal (ou primário), que são as espécies responsáveis pelas transmissões em zonas endêmicas, e vetores auxiliares (ou secundários), os quais apresentam a capacidade de transmissão do plasmódio apenas em determinadas circunstâncias, como o aumento significativo de sua população em uma respectiva área (Forattini, 2002). Consoli e Lourenço-de-Oliveira (1994) designam as características de vetores secundários: hábitos exofílicos e zoofílicos, mas que na ausência de hospedeiros preferenciais ou em épocas de elevada densidade podem se alimentar com sangue humano e, ocasionalmente, participam da transmissão da doença (Moutinho, 2010). Também é possível verificar se uma mesma espécie é vetorialmente designada primária e auxiliar, conforme a área de estudo analisada: o An. rangeli, por exemplo, que no Brasil é considerado um vetor auxiliar, tem no entanto um importante papel na transmissão da malária em outros países da América do Sul (Quinõnes et al., 2006).

No Brasil, as principais espécies anofelinas envolvidas com a transmissão de malária pertencem à família Culicidae, divididas em dois subgêneros: Nyssorhynchus (Anopheles darlingi, An aquasalis, An. nuneztovari, An. oswaldoi, An. triannulatus e complexo An. albitarsis) (Marrelli et al., 1999; Tadei, Dutary-Tatcher, 2000) e Kerteszia (An. cruzii e An. bellator) (Ramirez, Dessen, 1994), sendo que An. 
cruzii e An. darlingi são considerados vetores primários da doença (Ferreira, Luz, 2003).

Estratégias para o controle dos vetores da malária e de outros culicídeos têm sido desenvolvidas há décadas, como os métodos químicos (inseticidas) e biológico como por exemplo a introdução de predadores ou mosquitos geneticamente modificados (Forattini, 2002). No entanto, a eficiência desses métodos depende, em parte, de um fator intrínseco, particular de cada espécie: sua microevolução. Entende-se por "microevolução" o conjunto de mudanças evolutivas ocorridas em níveis taxonômicos intraespecíficos, ou seja, envolvendo populações (Futuyma, 1997; Ridley, 2003). Os processos microevolutivos ocorrem de forma dinâmica nas populações como resultado da combinação de fatores abióticos e bióticos. Os padrões genotípicos, fenotípicos e cariotípicos resultantes desses processos irão depender da atuação da seleção natural ou da deriva genética. Tudo isso é influenciado pelo fluxo gênico entre as populações e pode culminar numa diferenciação ou convergência de algum caráter nos indivíduos envolvidos (Futuyma, 1997; Ridley, 2003). Visto isso, pode-se compreender que a mobilidade geográfica das populações de anofelinos interfere em seu fluxo gênico e, consequentemente, é uma questão muito importante na sua evolução.

Com a sucessão das várias gerações de mosquitos, pode ocorrer a fixação de caracteres, resultando em resistência a inseticidas, aumento da antropofilia, alterações da capacidade vetorial, tolerância a poluentes ou qualquer outra adaptação favorável ao aumento da população. Consequentemente, faz-se necessário estudar esses processos e padrões de microevolução em Culicidae para auxiliar os mecanismos de controle.

\subsection{0 subgênero Kerteszia}

O gênero Anopheles, pertencente à família Culicidae, possui espécies que se encontram amplamente distribuídas por toda a região sul-americana, a leste dos Andes, na Colômbia, Venezuela, Bolívia, Peru, Paraguai, Argentina, Brasil e nas Guianas (Consoli, Lourenço-de-Oliveira, 1994). Sua distribuição ocorre em regiões de baixas altitudes, geralmente associada aos cursos d'água e florestas do interior, mas há também presença no litoral. A transmissão autóctone da malária que ocorre 
fora da região amazônica se faz principalmente nas regiões de serra do mar, com mata atlântica. Essa situação acontece devido à forte presença de mosquitos do subgênero Kerteszia nessas áreas, grupo de anofelinos que obtêm seu desenvolvimento nas águas acumuladas em axilas de bromélias (com exceção de An. bambusicolus que se desenvolve nos internódios do bambu) (Sallum et al., 2008).

Os indivíduos agrupados no subgênero Kerteszia possuem algumas peculiaridades que os separam dos demais anofelinos, como seus hábitos "bromelícolos" (Figura 2). As condições atmosféricas são fundamentais para a constância da sua ocorrência, seus habitats são extremamente específicos e dependentes do biótopo.

Figura 2 - Bromélias do gênero Vriesia (esquerda) e Nidularium (direita) utilizadas para oviposição de anofelinos do subgênero Kerteszia.

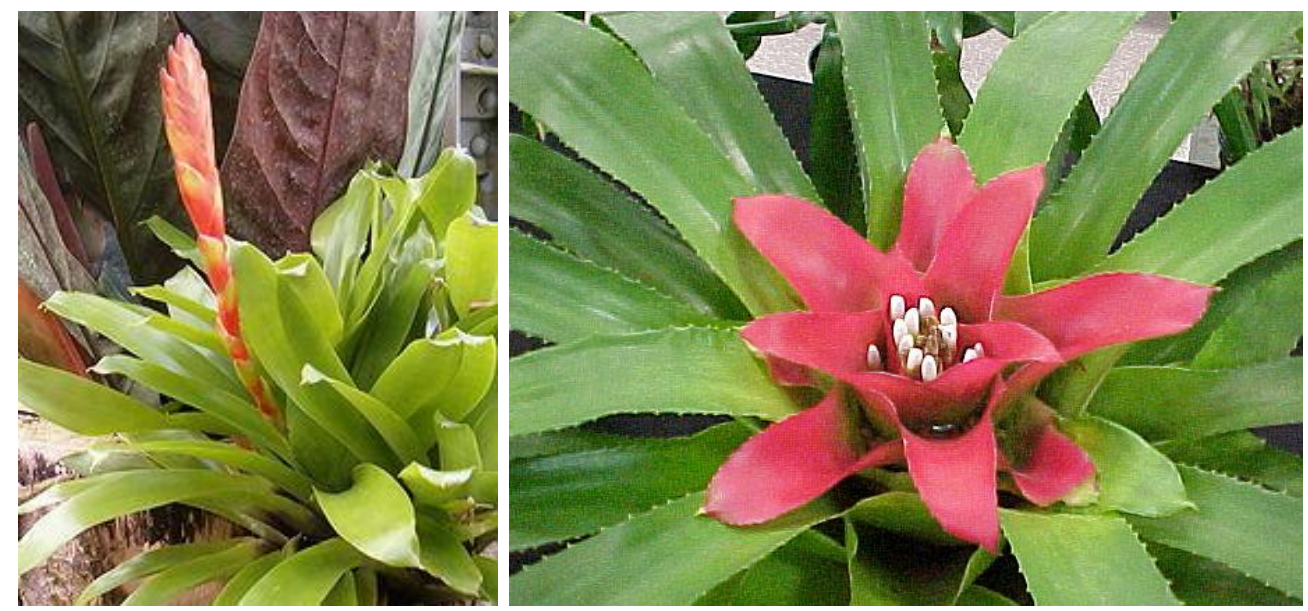

(Fonte: Karl Slatner, 2012)

Os três habitats preferencialmente ocupados pelas três espécies principais desse subgênero (An. cruzii, An. homunculus e An. bellator) para oviposição são: bromeliáceas encontradas na mata estabelecida em planície quaternária, no qual se encontra An. cruzii; as grandes áreas montanhosas do maciço atlântico, principalmente nos biótopos das comunidades situadas nos vales, encontra-se a espécie An. homunculus; e nas bromeliáceas de restinga e rupestres predomina 0 An. bellator (Veloso et al., 1956).

A transmissão autóctone de malária extra-amazônica ocorre em vários estados brasileiros, principalmente naqueles associados ao sistema de Serra do Mar e coincide com a distribuição geográfica de An. cruzii. Ele é o principal vetor de 
malária no sudeste do país (Arruda et al., 1986) por isso faz-se necessário o estudo mais aprofundado dessa espécie.

\subsection{As espécies Anopheles cruzii e Anopheles homunculus}

\subsubsection{Aspectos taxonômicos e variabilidade morfológica}

Indivíduos adultos, principalmente fêmeas, e pupas de An. cruzii e An. homunculus são muito parecidos morfologicamente, sendo difícil a identificação mediante características taxonômicas tradicionais (Calado, Navarro-Silva, 2005). Alguns autores ainda consideram a hipótese de ambas pertencerem a um grupo de espécies morfologicamente e filogeneticamente próximas (Rosa-Freitas et al., 1998). De acordo com estudos recentes desenvolvidos por Peixoto et al. (2009), utilizando análises genéticas, An. cruzii é na verdade um complexo de pelo menos duas espécies crípticas, onde uma ocorre na Bahia e outra na região sudeste do Brasil. $\mathrm{Na}$ literatura, alguns registros de ocorrência de An. cruzii são duvidosos e podem ter sido confundidos com outras espécies do subgênero Kerteszia, justamente por esse problema na identificação (Calado, Navarro-Silva, 2005). As duas espécies ocorrem em simpatria no estado de São Paulo, Paraná e Santa Catarina (Calado, NavarroSilva, 2005).

De acordo com Wilkerson e Peyton (1991), as fêmeas dessas espécies podem ser diferenciadas morfologicamente através dos caracteres presentes nos palpos maxilares. Martins (1958) ainda aponta que as fêmeas de An. cruzii possuem tegumento abdominal com coloração vermelha uniforme ou vermelha com regiões mais claras; enquanto que $A n$. homunculus apresenta esse tegumento com manchas escuras e claras, mas nunca avermelhadas. Para a diferenciação de larvas, Lima (1952) constata que em An. cruzii o segmento anal é pouco quitinizado e o tegumento possui cor amarelada ou avermelhada. Por outro lado, as larvas de An. homunculus apresentam segmento anal com alto grau de quitinização e coloração do tegumento escura (Figura 3) (Calado, Navarro-Silva, 2005). 
Figura 3 - Vista dorsal de uma larva de Anopheles cruzii (esquerda) e An. homunculus (direita).

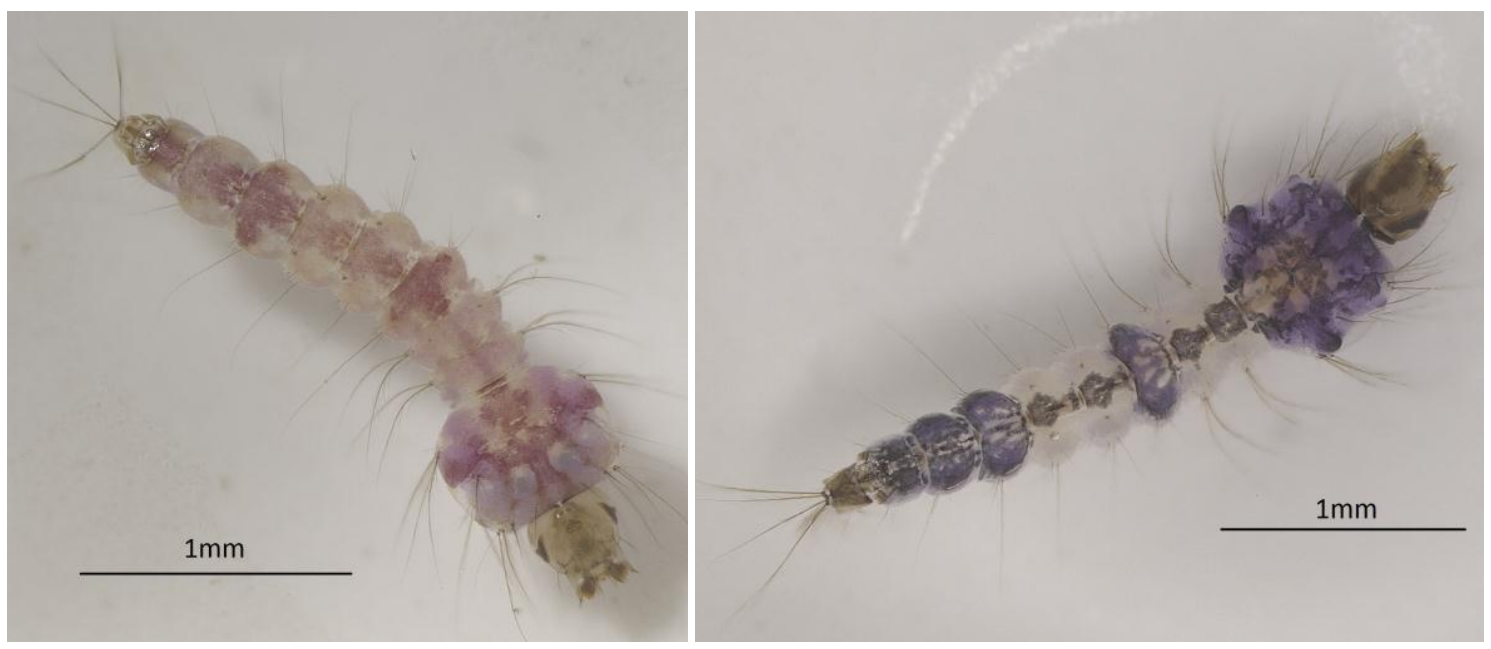

Entretanto, todas essas características morfológicas citadas são de difícil interpretação e muito subjetivas. A identificação externa é também muitas vezes prejudicada pelo alto grau de variabilidade observada nesses caracteres diagnósticos e pela perda ou danificação das partes do corpo do inseto na hora da captura (Calado, Navarro-Silva, 2005). Por isso é útil abordar simultaneamente vários parâmetros de identificação, não só os morfológicos, mas também os moleculares e genéticos. Dessa forma, a possibilidade de correlacionar os dados fenotípicos e genotípicos também estará aumentada.

\subsubsection{Ciclo de vida e tempo de sobrevivência}

As espécies do gênero Anopheles possuem ovos que medem cerca de 0.5 $\mathrm{mm}$ de comprimento e são dotados de flutuadores laterais que permitem sua permanência na superfície da água (Calado, 2005). Em condições de laboratório uma fêmea de An. cruzii pode por, em média, 30 ovos em cada postura (Kakitani, 1992). Em ambiente natural foi observado um pequeno número de larvas de uma mesma espécie por criadouro (Forattini et al., 1961), o que sugere que as fêmeas ovopositam em pequenas quantidades como possível estratégia para evitar a competição por recursos (Calado, 2005).

As condições ambientais determinam o período de desenvolvimento dos mosquitos, podendo variar bastante dependendo da época do ano. Em laboratório foi observado que o tempo de duração do ovo ao adulto é de aproximadamente 35 
dias para An. cruzii (Wilkerson, Peyton, 1991). Os fatores ambientais, como temperatura e umidade, também podem alterar a taxa de sobrevivência de várias espécies de anofelinos. No ambiente natural, foi observado que o período de sobrevivência das fêmeas de An. cruzii varia de 35 a 56 dias (Ferreira et al., 1969a).

Do ponto de vista epidemiológico, o tempo de sobrevida dos mosquitos vetores e sua densidade populacional são fatores importantes a serem considerados, visto que estão intimamente relacionados com a transmissão de doenças (Bona, 2008). Devido as suas peculiaridades biológicas, os anofelinos Kerteszia têm sua densidade populacional aumentada no período de chuvas e temperaturas elevadas (Calado, 2005; Forattini et al., 1996; Forattini, 2002; Guimarães et al., 2000a)

\subsubsection{Aspectos bioecológicos}

As fêmeas de An. cruzii realizam a hematofagia preferencialmente durante os crepúsculos matutino e vespertino e nas primeiras horas da noite, mas também podem picar durante o dia (Coutinho et al., 1943). Essa espécie é exofílica, e possui maior frequência dentro da mata (Guimarães et al., 2000), no entanto podem invadir domicílios em algumas áreas. O repasto sanguíneo é realizado em ambiente antrópico, porém após efetuá-lo as fêmeas abandonam o ambiente à procura de abrigo no ambiente natural circundante (Calado, 2005; Consolim et al., 1979; Forattini et al., 2000). Em relação à escolha do hospedeiro An. cruzii apresenta bastante ecletismo, podendo alimentar-se do homem, outros mamíferos e aves (Deane, 1986).

No município de Guaratuba (PR), estudos de Ferreira et al. (1969b) comprovaram a capacidade de dispersão de até 1000m em An. cruzii. Esse dado é muito importante do ponto de vista epidemiológico, já que o alcance de vôo dos mosquitos vetores está diretamente relacionado com seu potencial de dispersão, ampliando o território sujeito à ocorrência de doenças em humanos ou animais (Bona, 2008).

An. cruzii possui um grande ecletismo vertical na mata, e movimenta-se do dossel para o solo e vice-versa com grande facilidade, porém apresenta diferentes graus de acrodendrofilia nas regiões do Brasil. Por exemplo, na Floresta da 
Cantareira (SP) essa espécie apresenta comportamento tipicamente acrodendrófilo, enquanto em Joinville (SC) é eclética, obtendo alimento próximo ao solo e em diversos níveis da mata (Deane et al., 1984; Deane, 1992). Essas peculiaridades levantam suspeitas em relação ao status taxonômico dessas populações.

As formas larvárias de An. cruzii são observadas em vários habitats diferentes, desde o nível do mar até $600 \mathrm{~m}$ de altitude, e em bromélias com diferentes capacidades hídricas que variam desde $5 \mathrm{ml}$ até mais de 2 litros, presentes tanto no solo até o nível das mais altas árvores do dossel (Veloso et al., 1956).

Ainda pouco se sabe sobre a ecologia de An. homunculus, já que a espécie possivelmente foi subestimada devido aos erros em sua identificação. No entanto, sabe-se que An. homunculus é comumente encontrado nas regiões mais úmidas e inferiores da mata, tendo sua condição ótima somente em biótopos situados abaixo de $5 \mathrm{~m}$ de altura, e geralmente em bromélias com pequeno volume de água (Veloso et al., 1956).

\subsubsection{Distribuição geográfica}

A distribuição atual de An. cruzii limita-se ao sistema montanhoso que caracteriza a Mata Atlântica, desde o estado de Sergipe até a região sul do Brasil, incluindo parte da região argentina representada pelas províncias de Chaco e Missiones (Figura 4) (Forattini, 2002).

O primeiro registro de An. homunculus foi em Santa Catarina em 1943 (Forattini et al., 1970). Em 2008, Sallum et al. notificaram a presença desta espécie no estado do Espírito Santo. Seto (1992) também reportou a existência de An. homunculus em Peruíbe, mas a baixa frequência nas coletas indica que ela seja rara nessa região. A existência de poucos registros de An. homunculus no Brasil pode ser devido à sua difícil identificação (Sallum et al., 2008), já que as fêmeas adultas dessa espécie se confundem com as de An. cruzii. O diagnóstico diferencial entre essas duas espécies era realizado somente por caracteres da genitália externa do macho (Lima, 1952). 
Figura 4 - Mapa reproduzido de Forattini (2002) mostrando a distribuição geográfica das principais espécies de Kerteszia encontradas no Brasil.

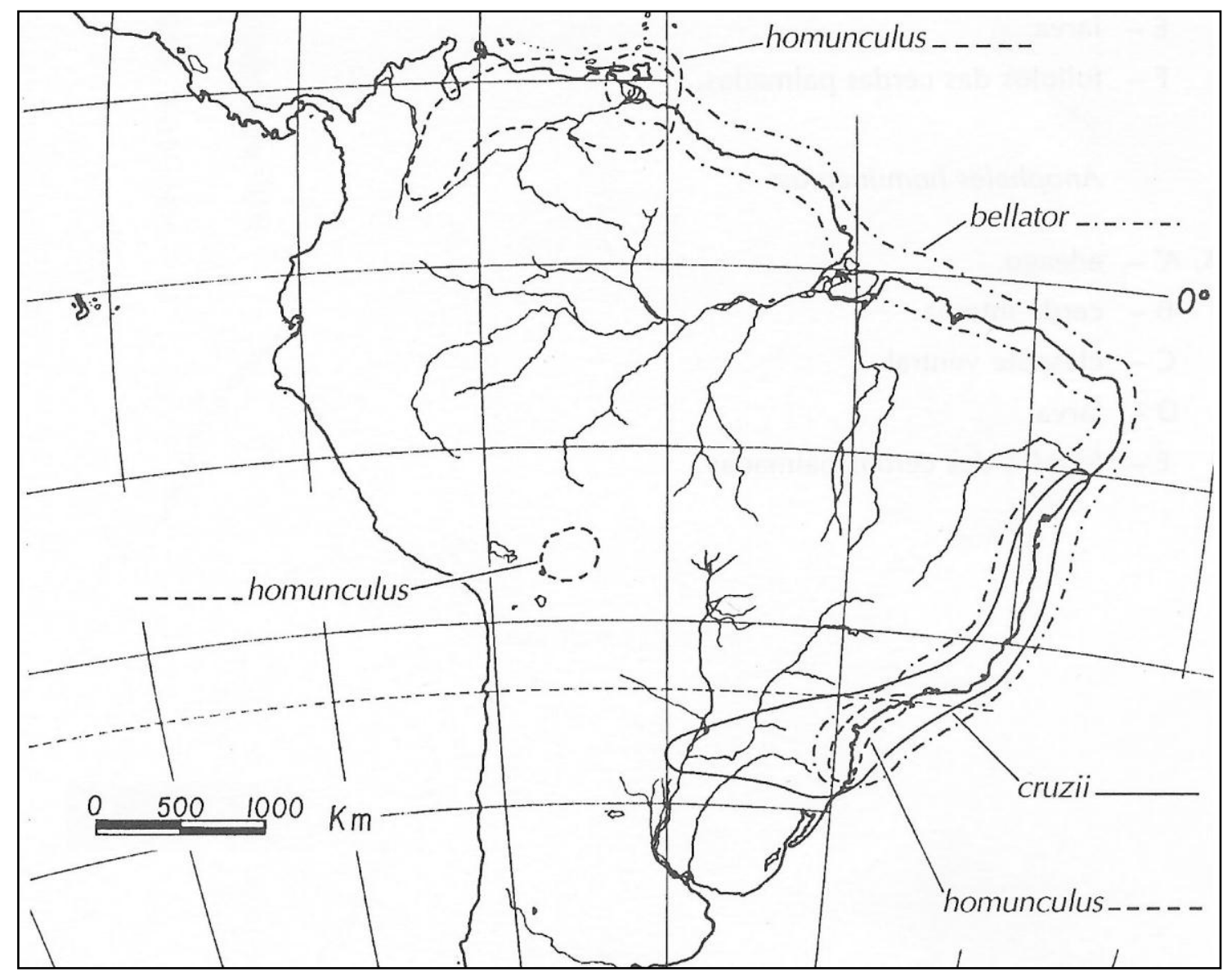

\subsubsection{Importância epidemiológica}

An. cruzii é vetor primário de Plasmodium spp. nos litorais sul e sudeste do Brasil, principalmente nos estados do Paraná, Santa Catarina e São Paulo, sendo encontrado diversas vezes infectado por oocistos e esporozoítos (Amaral, 1942; Coutinho et al. 1943; Rachou, Ferreira, 1966b). Ele também está envolvido com a manutenção de malária assintomática em áreas de Mata Atlântica do estado de São Paulo e Rio de Janeiro (Branquinho et al., 1997; Carvalho et al., 1998). Nos estudos de Branquinho et al. (1997) foi verificado que as amostras de An. cruzii dos municípios de Juquitiba e São Vicente (SP) apresentavam infecção por Plasmodium vivax clássico $(0.149 \%)$, Plasmodium vivax VK247 $(0.086 \%)$ e por Plasmodium brasilianum-malariae. De acordo com esses autores, embora os índices de infecção encontrados tenham sido considerados baixos, a alta densidade de mosquitos e sua 
voracidade podem compensar esse fato. Além da malária humana, An. cruzii é considerado vetor de Plasmodium simium e Plasmodium brasilianum, ambos agentes causadores de malária simiana (Calado, 2005; Deane, 1992). An. homunculus também é um importante transmissor de plasmódios humanos em áreas do sudeste brasileiro e em Trinidad (Forattini, 1962), sendo considerado vetor secundário da malária nessas regiões (Rezende et al., 2009).

\subsection{Problemas biológicos a serem abordados}

Como An. cruzii e An. homunculus são morfologicamente semelhantes é possível que os registros referidos à primeira espécie possam estar contemplando indivíduos da segunda espécie que foram identificados de forma equivocada. Obviamente, a identificação correta das espécies é fundamental tanto para o reconhecimento dos vetores envolvidos na transmissão de patógenos como para o desenvolvimento de estratégias eficientes de controle (Sallum et al., 2008). Faz-se necessário o desenvolvimento de métodos diagnósticos mais simples, rápidos e que estejam ao alcance do maior número de profissionais da saúde para diferenciar essas duas espécies anofelinas, visto que An. cruzii é um importante vetor de malária no sudeste.

Além da questão da diagnose específica, outro problema biológico envolvendo essas espécies desperta atenção. Nas áreas de Mata Atlântica do sul e do sudeste brasileiro, Ramírez e Dessen (1994, 2000a, b) analisaram populações de seis localidades e as dividiram em An. cruzii A, B e C. Esta denominação baseou-se nos padrões diferentes de bandas do cromossomo politênico $X$. De acordo com as autoras, o padrão A foi o único encontrado em Aldeia dos Índios (Peruíbe, SP) e o B, em São Francisco do Sul (SC). Os padrões A e B ocorreram em simpatria nas regiões de Guaratuba (SP) e Cananéia (SP). Em Juquitiba (SP) e Boracéia (SP), foram registrados os padrões $\mathrm{A}$ e $\mathrm{C}$. Adicionalmente, as autoras afirmam haver uma clara relação entre altitude e as diferentes formas cromossômicas. An. cruzii B foi predominante nas regiões planas de Mata Atlântica, próximas ao nível do mar, enquanto que a forma $A$, em região com elevação de 200 metros (Aldeia dos Índios). De acordo com o exposto, podemos levantar a hipótese de que as populações de 
An. cruzii da planície e do morro, no município de Cananéia, possam também apresentar diferenças genéticas em sua composição.

No município de Cananéia (Estado de São Paulo), onde An. cruzii e An. homunculus ocorrem em simpatria, estudos de Marques (2012) demonstram que elas possuem preferências diferenciais quanto à altitude de seu habitat na Mata Atlântica. Naqueles estudos, foram amostrados três microambientes do local definidos pela altitude (planície, encosta e morro) com acompanhamento mensal ao longo de um ano. Considerando-se que cada espécie tem preferência por uma faixa de altitude ao invés de outra, é possível que o fluxo gênico intrapopulacional de cada espécie não seja equitativamente distribuído ao longo desse transecto altitudinal. $A$ elucidação desta questão poderia ser muito informativa para o entendimento da dinâmica de transmissão de Plasmodium sp. no local. É possível ainda que os padrões de fluxo gênico sejam diferenciais ao longo do ano ou que as populações sofram alterações ou substituições demográficas nesse ínterim. A estabilidade da variabilidade genética nas populações dessas espécies não é conhecida ainda, mas quando for, poderá auxiliar na compreensão epidemiológica da malária na região.

\subsection{Métodos para caracterização populacional em Culicidae}

\subsubsection{Morfometria Geométrica alar}

Quando se trata de insetos, a caracterização morfológica de estruturas complexas e de variabilidade individual é difícil e sujeita à subjetividade. Nesses casos é útil ter-se um método que permita a percepção e a quantificação dessas variações entre indivíduos, como a morfometria. Trata-se de uma formalização matemática das diferenças entre as formas geométricas de objetos.

A morfometria geométrica, em especial, permite um estudo estatístico multivariado das estruturas biológicas (Monteiro, Reis, 1999), ou seja, considera simultaneamente várias características de uma estrutura corporal complexa. Nos insetos, a principal estrutura-alvo dessa análise são as asas, pois possuem uma estrutura bidimensional e as nervuras alares se cruzam formando pontos, ideais para uma comparação morfométrica. Há estudos na literatura que indicam ser possível separar espécies dentro de complexos através da morfometria geométrica, 
assim como também seria possível distinguir indivíduos da mesma espécie em diferentes populações (Dujardin 2008; Jirakanjanakit, Dujardin, 2005; Vidal et al., 2011). Variações morfológicas clinais e geográficas podem também ser descritas quantitativamente a partir de dados morfométricos das asas, como recentemente efetuado no culicídeo Culex quinquefasciatus (Morais et al., 2010)

Para a análise da forma alar, geralmente faz-se uma sobreposição de Procrustes e posterior estudo de componentes principais ("relative warps"), que excluem a variação do tamanho isométrico e definem a variação populacional dos formatos nas asas. Para a descrição de tamanho alar utiliza-se o vetor tamanho do centróide, que formalmente é a raiz quadrada da soma dos quadrados das distâncias de cada ponto anatômico do centróide na configuração total (Rohlf, 1993). É uma estratégia para sintetizar o tamanho da asa numa única variável (Dujardin, 2008).

Em Culicidae, futuramente os caracteres morfométricos alares poderão eventualmente auxiliar em estudos comportamentais, visto que as características das asas geralmente estão relacionadas a outras particularidades biológicas do mosquito, como eficiência no vôo, produção de sons alares de corte pré-cópula e até fecundidade (Brogdon, 1994). Além disso, a morfometria alar é um método rápido, barato e os dados provenientes de sua análise podem ser utilizados por outros profissionais da saúde em vigilância sanitária epidemiológica (Dujardin, 2008).

\subsubsection{Marcadores mitocondriais - citocromo oxidase subunidade I (COI)}

O DNA mitocondrial vem sendo cada vez mais utilizado como marcador em estudos de filogeografia e diagnose de espécies crípticas. Isso ocorre porque ele possui rápida taxa evolutiva, apresenta herança exclusivamente materna e raramente sofre recombinação (Matioli, 2001). O gene mitocondrial COI, que codifica a subunidade I da enzima citocromo oxidase, está presente em centenas de cópias por células e têm pouca variação intraespecífica (Cywiska et al., 2006), sendo um bom marcador para populações. Esse gene tem sido apontado também como indicador taxonômico, havendo autores que defendem seu emprego como fiel diagnóstico de espécies, a chamada iniciativa "barcodes" ou código de barras (Moritz, Cicero, 2004). 
Alguns estudos como o de Lehr et al. (2005) revelam que a partir do gene mitocondrial $\mathrm{CO}$ foi possível distinguir espécies crípticas do complexo An. albitarsis, por exemplo. Já foram analisadas 32 espécies de Anophelinae neotropicais e a partir do gene COI pode-se distinguir indivíduos até o nível de espécie (Sallum et al., 2002). Recentes estudos acusaram a existência de 21 haplótipos (Devicari, 2010) de $\mathrm{COI}$ com variabilidade intra e interpopulacional em Aedes scapularis. Aqueles resultados indicam que tal gene pode apresentar-se diverso em culicídeos e reforça a ideia de que este é um bom marcador genético populacional.

Com isso, é muito provável que seja possível diferenciar genética e morfologicamente as populações aqui amostradas, já que os marcadores foram validados em vários outros estudos populacionais com Culicidae. 


\section{OBJETIVOS}

- Identificar caracteres da geometria alar que sejam diagnósticos para as espécies Anopheles cruzii e Anopheles homunculus;

- comparar os padrões genéticos (marcador COI) e morfológicos (asa) em perspectiva sazonal, amostrando populações de An. cruzii e An. homunculus nos períodos de inverno e verão;

- comparar os padrões morfológicos da asa em perspectiva temporal (2009 e 2012), pretendendo analisar o grau de microevolução das espécies An. cruzii e An. homunculus;

- descrever as variações altitudinais intraespecíficas de An. cruzii quanto à geometria alar e ao gene mitocondrial COI em região de mata atlântica (Cananéia, $\mathrm{SP}$ ) amostrando dois microambientes (planície e morro); 


\section{MATERIAIS E MÉTODOS}

\section{1 Área de estudo}

O município de Cananéia (SP) está situado em um remanescente de Mata Atlântica (Figura 5) e em 1999 recebeu pela Organização das Nações Unidas para a Educação, a Ciência e a Cultura (UNESCO) o título de Patrimônio Natural da Humanidade, devido à importância ecológica de seu complexo estuarino lagunar (Prefeitura Municipal de Cananéia, 2008). A região está associada ao sistema de Serra do Mar, que é onde são registrados a maioria dos casos autóctones de malária no sudeste (Sallum et al., 2008). Segundo Forattini (1986), o ambiente úmido de floresta primária presente em Cananéia propicia condições favoráveis para várias espécies da família Bromeliaceae. Esse fato está diretamente relacionado ao aparecimento de anofelinos do subgênero Kerteszia na região. De acordo com dados na literatura, as espécies An. cruzii e An. homunculus ocorrem em simpatria nesta região, portanto é um local adequado para os objetivos do presente estudo.

Segundo o Centro de Pesquisas Meteorológicas e Climáticas aplicadas à Agricultura (CEPAGRI, 2009), a região de Cananéia apresenta temperatura média anual de $24{ }^{\circ} \mathrm{C}$ e precipitação média de $2.794 \mathrm{~mm}$. O sítio de coleta situa-se no bairro de Aroeira $\left(24^{\circ} 53^{\prime} 06^{\prime \prime}\right.$ S / 47 $51^{\circ} 01^{\prime}$ "W), sendo considerado formação Submontana da Floresta Ombrófila Densa, que pode se estender até $400 \mathrm{~m}$ de altitude. $O$ dossel é irregular e as árvores podem alcançar até $30 \mathrm{~m}$ de altura (Marques, 2010). 
Figura 5 - Mapa do estado de São Paulo evidenciando a região de Cananéia

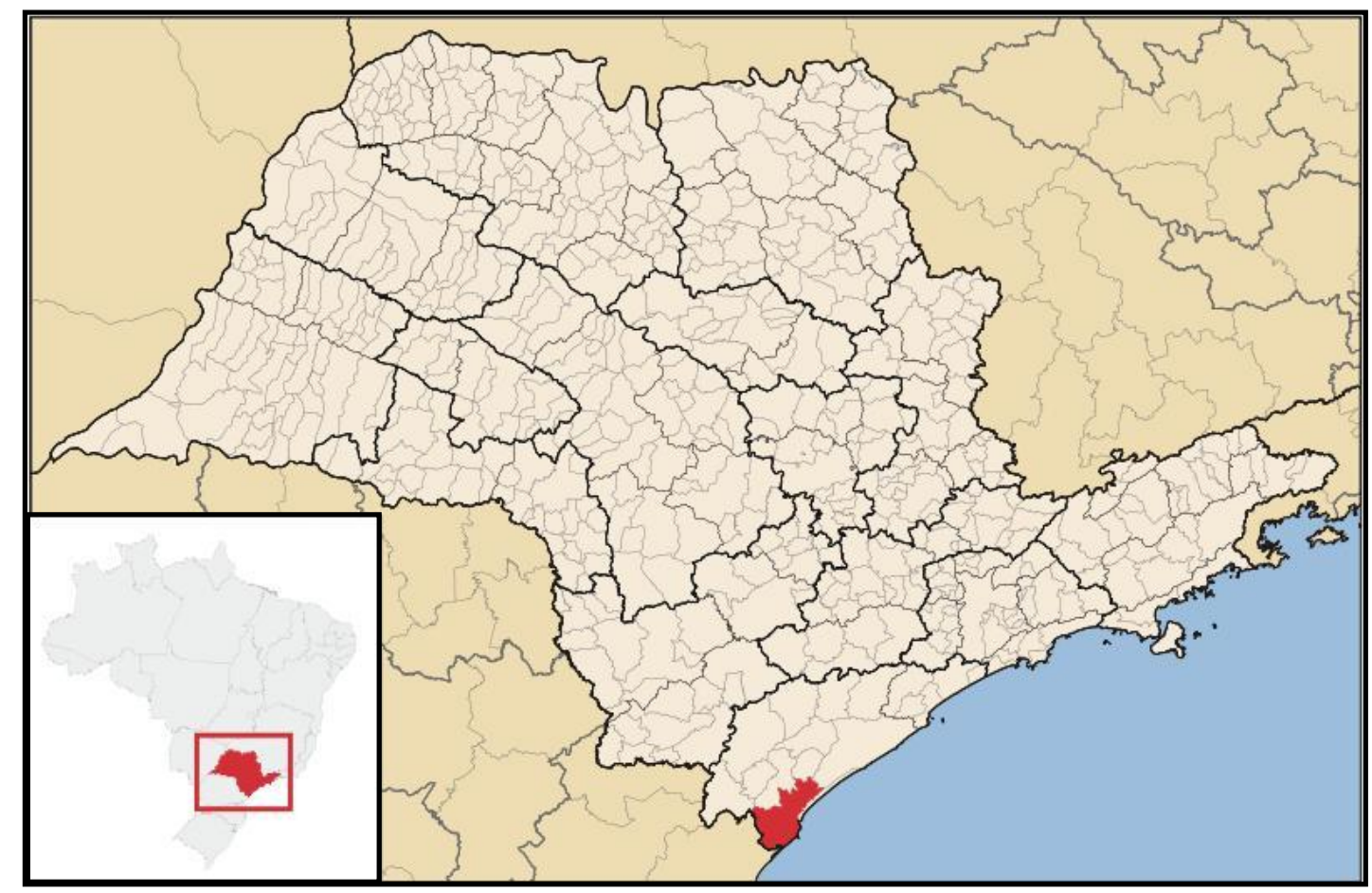

(Fonte: Instituto Geográfico Cartográfico, 2012)

\subsection{Coleta e armazenamento de exemplares}

As larvas de An. cruzii e An. homunculus foram capturadas no conteúdo hídrico acumulado nas axilas de bromélias terrestres, rupestres e epífitas, estas situadas até três metros do nível do solo. Foram amostradas bromélias nas épocas de inverno e verão em dois ambientes distintos: planície e morro (Tabelas 1 e 2). Os espécimes de An. cruzii e An. homunculus coletados por Marques (2010) também foram aproveitados neste trabalho para comparações temporais dos anos de $2009 \mathrm{x}$ 2012. 
Tabela 1 - Dados relacionados às coletas das populações de Anopheles cruzii utilizados nas análises de Morfometria Geométrica.

\begin{tabular}{|c|c|c|c|c|c|}
\hline Data da coleta & $\begin{array}{l}\text { Temp. } \\
\text { média } \\
\left({ }^{\circ} \mathrm{C}\right)\end{array}$ & $\begin{array}{c}\text { Precipitação } \\
(\mathrm{mm})\end{array}$ & Ambiente & Sexo & $\mathrm{N}^{\circ}$ de amostras \\
\hline \multirow{4}{*}{$\begin{array}{c}\text { Janeiro/Fevereiro } \\
(2009)^{*}\end{array}$} & \multirow{4}{*}{24,9} & \multirow{4}{*}{19,1} & \multirow{2}{*}{ Planície } & $\mathrm{F}$ & 28 \\
\hline & & & & $M$ & 21 \\
\hline & & & \multirow{2}{*}{ Morro } & $F$ & 26 \\
\hline & & & & M & 22 \\
\hline \multirow{3}{*}{ Julho/2011 } & \multirow{3}{*}{17,6} & \multirow{3}{*}{25,3} & \multirow{3}{*}{ Planície } & $F$ & 42 \\
\hline & & & & & \\
\hline & & & & M & 33 \\
\hline \multirow{4}{*}{ Janeiro/2012 } & \multirow{4}{*}{23,2} & \multirow{4}{*}{67,3} & \multirow{2}{*}{ Planície } & $\mathrm{F}$ & 26 \\
\hline & & & & M & 34 \\
\hline & & & \multirow{2}{*}{ Morro } & $\mathrm{F}$ & 24 \\
\hline & & & & $\mathrm{M}$ & 22 \\
\hline \multirow{4}{*}{ Julho/2012 } & \multirow{4}{*}{17,5} & \multirow{4}{*}{46,0} & \multirow{2}{*}{ Planície } & $\mathrm{F}$ & 51 \\
\hline & & & & $M$ & 46 \\
\hline & & & \multirow{2}{*}{ Morro } & $F$ & 52 \\
\hline & & & & $M$ & 42 \\
\hline
\end{tabular}

*Dados cedidos por Marques, 2010.

Tabela 2 - Dados relacionados às coletas das populações de Anopheles homunculus utilizados nas análises de Morfometria Geométrica.

\begin{tabular}{cccccc}
\hline Data da coleta & $\begin{array}{c}\text { Temp. } \\
\left.\text { média ( }{ }^{\circ} \mathbf{C}\right)\end{array}$ & $\begin{array}{c}\text { Precipitação } \\
(\mathbf{m m})\end{array}$ & Ambiente & Sexo & $\begin{array}{c}\mathbf{N}^{\circ} \text { de } \\
\text { amostras }\end{array}$ \\
\hline $\begin{array}{c}\text { Janeiro/Fevereiro } \\
(\mathbf{2 0 0 9 )})^{*}\end{array}$ & 24,9 & 19,1 & Morro & $\mathrm{F}$ & 20 \\
\hline Janeiro/2012 & 23,2 & 67,3 & Morro & F & 21 \\
\hline Julho/2012 & 17,6 & & M & 24 \\
\hline
\end{tabular}

*Dados cedidos por Marques, 2010. 
A planície é caracterizada pela proximidade com o mangue, com elevação que varia de 5 a 20 metros acima do nível do mar. As coletas realizadas no ambiente morro foram realizadas adentrando-se mais no continente, entre 81 e 263 metros acima do nível do mar. Dados relativos à temperatura média e precipitação foram obtidos por meio de consulta ao banco de dados da Estação de Cananéia do Centro Integrado de Informações Agrometeorológicas (CIIAGRO, 2012).

Para a coleta das formas imaturas, foi retirado o conteúdo hídrico da planta com a utilização de uma bomba de sucção manual como proposta por Lozovei e Silva (1999). A grande maioria das formas imaturas coletadas eram ovos ou larvas nos estágios iniciais L1 ou L2. Esse conteúdo hídrico foi acondicionado em recipientes plásticos individuais devidamente rotulados com os dados de cada microambiente (planície e morro). No laboratório, os imaturos de An. cruzii e $A n$. homunculus foram separados e mantidos em recipiente com água destilada, sendo alimentados com comida para peixe até atingir a fase de pupa (Figura 6). Nesse período todos os indivíduos ficaram submetidos a condições semelhantes de temperatura, quantidade de oxigênio, comida e espaço no criadouro. Após emergir, os adultos (Figura 7) eram sacrificados e mantidos secos em freezer de $\quad-80^{\circ} \mathrm{C}$. As asas direitas dos exemplares foram retiradas e armazenadas para posterior montagem em lâminas microscópicas.

Figura 6 - Pupa de Anopheles cruzii em vista lateral.

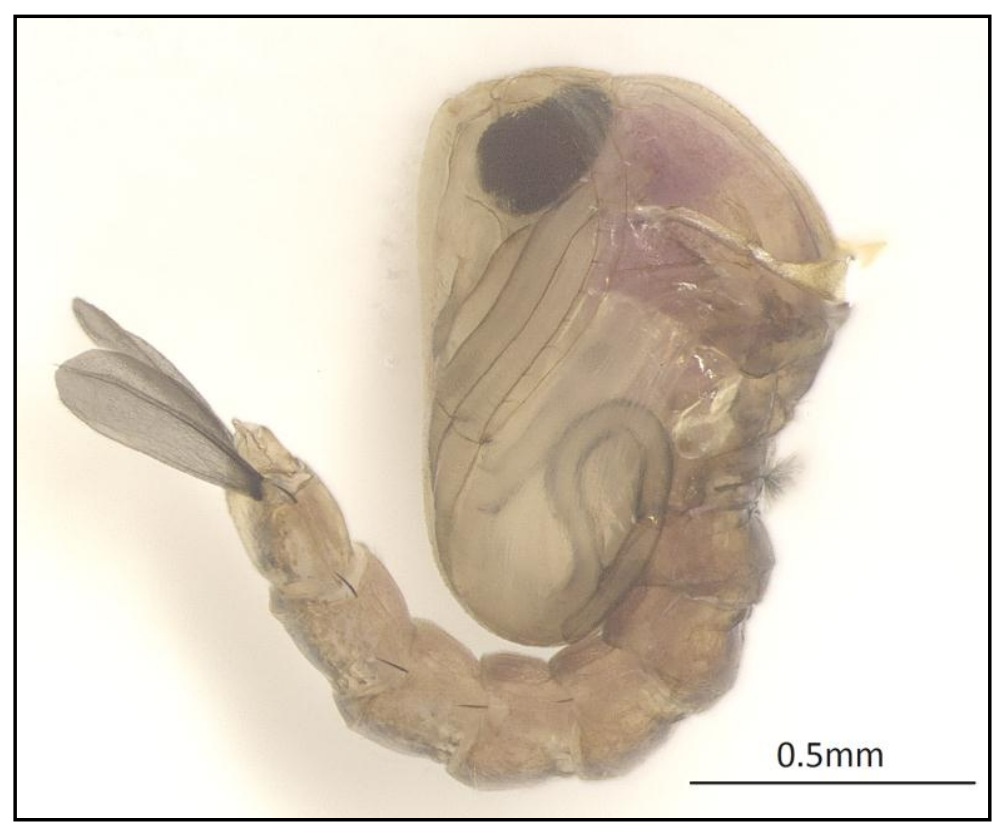


Figura 7 - Fêmea adulta de Anopheles cruzii em vista lateral.

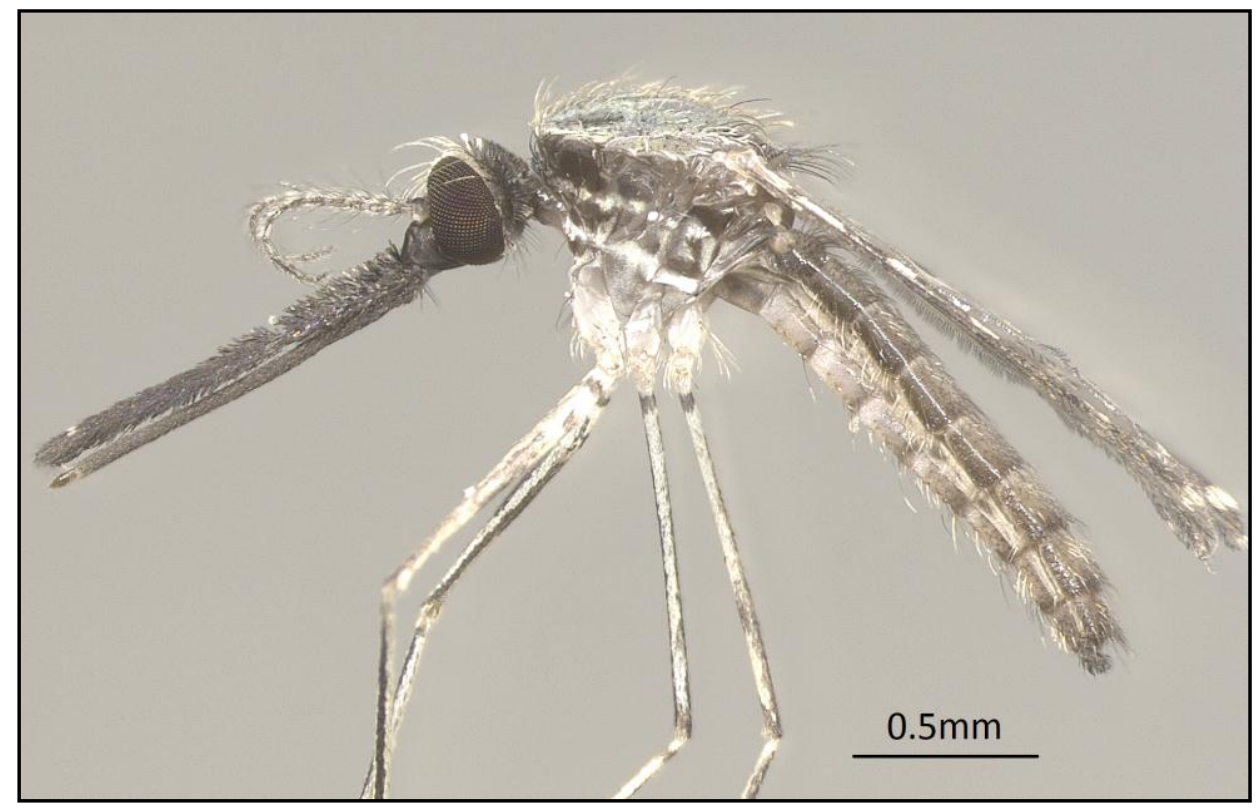

\subsection{Análise morfométrica alar}

Foram utilizados os métodos descritos por Rocha (2005) para as análises de morfometria geométrica alar. As asas direitas de machos e fêmeas foram clarificadas em potassa ( $\mathrm{KOH}$ a $20 \%$ ) por 8 horas e coradas com fucsina ácida. Foi utilizado um pincel com álcool para auxiliar na remoção das cerdas da asa. A seguir foram montadas entre lâmina e lamínula com bálsamo do Canadá. As imagens dessas asas foram capturadas pela câmera fotográfica digital Leica 320 acoplada a um microscópio estereoscópico Leica S6. Com o auxílio do software TpsDig v.2 (Rohlf, 2005) foram tomadas as coordenadas posicionais de cada um dos 18 pontos anatômicos sobre um plano cartesiano (Figura 8). Sobre esses dados foram calculados os tamanhos de centróide, as variáveis canônicas e as distâncias de Mahalanobis utilizando os programas TpsUtil 1.26 (Rohlf, 2004), TpsRelw 1.36 (Rohlf, 2003a), TpsRegr 1.28 (Rohlf, 2003b) e Statistica 7.0 (STATSOFT, 2004). Foi retirado o efeito alométrico em todas as análises de forma através da regressão entre os componentes de forma e o tamanho do centróide. O índice Qst, análogo ao Fst genético, também foi calculado para quantificar a diferenciação no formato e tamanho alar entre as populações. Para isso utilizou-se os programas TET e COV (JP Dujardin - http://www.mpl.ird.fr/morphometrics/). 


\subsubsection{Tamanho do Centróide}

Os tamanhos dos centróides e a construção dos gráficos descritores dos centróides foram obtidos a partir dos softwares TpsRelw 1.36 (Rohlf, 2004) e Statistica 7.0 (STATSOFT, 2004), sendo utilizados nas comparações intra e interpopulacionais e interespecíficas das amostras. Para testar a normalidade das distribuições amostrais foi empregado o teste de Kolmogorov-Smirnov; e para comparações múltiplas dos tamanhos dos centróides utilizou-se a análise de variância ANOVA e teste post-hoc de Tukey-Kramer.

Figura 8 - Acima, foto da asa de um exemplar de An. cruzii. No meio, asa após preparação química com potassa e coloração de fucsina, evidenciando os marcos anatômicos utilizados. Abaixo, conformação alar obtida com a ligação dos 18 pontos.

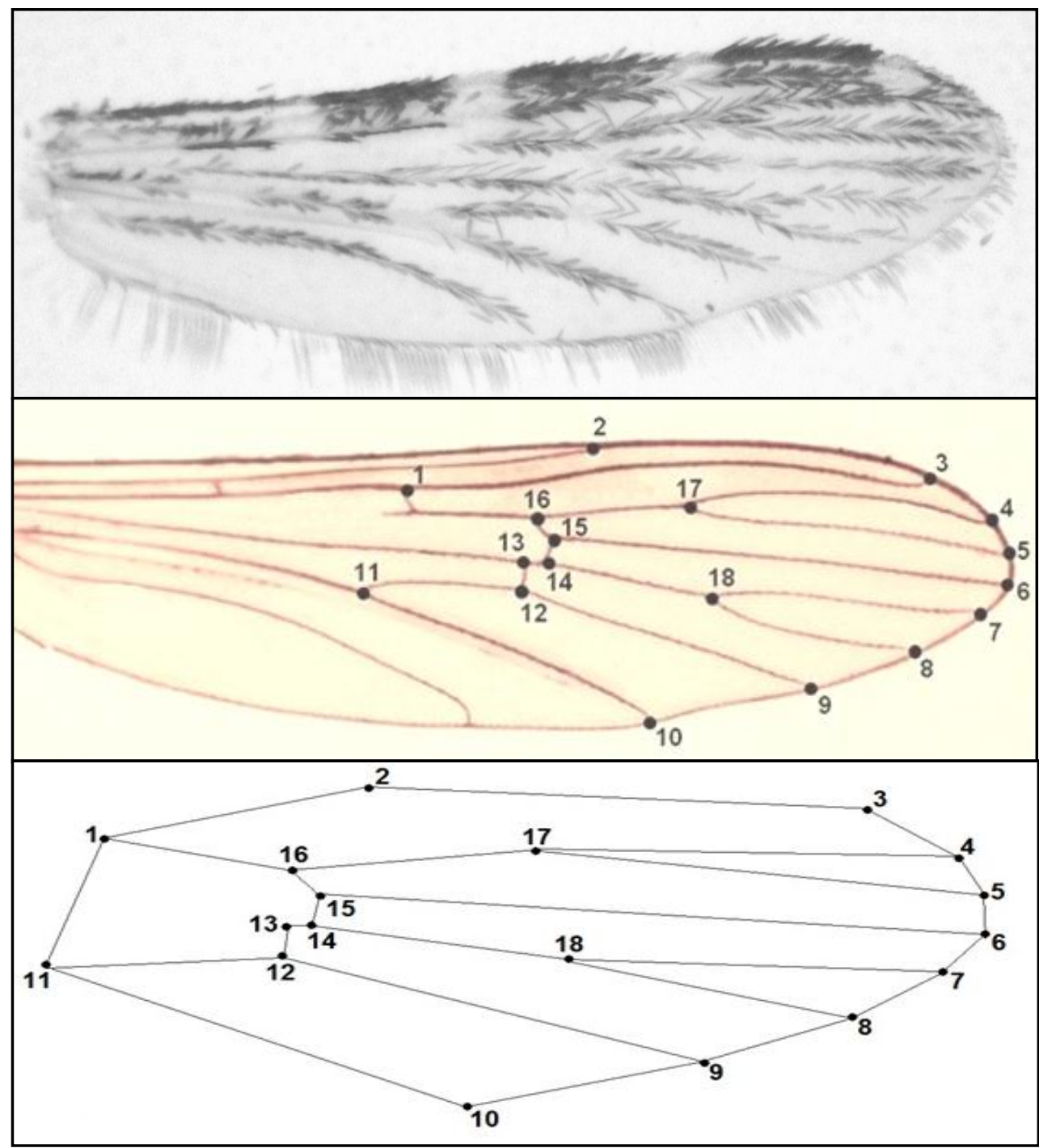




\subsubsection{Variáveis Canônicas}

Por definição, as variáveis canônicas são variáveis latentes que sumarizam as diferenças entre as amostras classificadas a priori, sob uma perspectiva multivariada (Monteiro, Reis, 1999). Elas foram obtidas com os softwares MorphoJ 1.02 e Statistica 7.0. Tabelas de relative warps (Rohlf, 2003a) foram geradas no programa TpsRelw para cada comparação e utilizadas no Statistica para as análises canônicas. Entre as variáveis canônicas obtidas em cada comparação, foram consideradas para interpretação apenas a primeira e a segunda (VC1 e VC2), pois segundo Monteiro e Reis (1999) elas são as mais informativas. Para representar a distribuição dos indivíduos no morfoespaço de variáveis canônicas, foram plotados gráficos de dispersão de pontos ou histogramas. Esses gráficos ilustram as características biológicas analisadas: dimorfismo sexual, diferenciação populacional e diferenciação específica entre An. cruzii e An. homunculus.

Derivadas dessas análises, as distâncias de Mahalanobis foram calculadas através do software MorphoJ 1.02 para avaliar o grau de similaridade relativo entre as amostras. Testes de reclassificação também foram realizados para todas as comparações populacionais realizadas (macho $x$ fêmea, inverno $x$ verão, morro $x$ planície, 2009 x 2012) utilizando o programa MorphoJ. Nesse tipo de teste cada espécime é retirado da análise, uma nova classificação é realizada com os indivíduos restantes e em seguida esse espécime é reinserido para averiguar em qual grupo ele é classificado; trata-se de um teste com validação (cross-validated). A confiabilidade da reclassificação é representada com um valor percentual.

\subsection{Análises do gene mitocondrial citocromo-oxidade subunidade I (COI)}

Para as análises genéticas, foram utilizados no mínimo 15 indivíduos de cada população, conforme ilustrado na Tabela 3. Machos e fêmeas foram analisados juntos. Nas comparações entre inverno e verão, foram utilizados somente indivíduos da planície de An. cruzii e somente indivíduos do morro de An. homunculus. 
Quadro 1 - Número de indivíduos de Anopheles cruzii e An. homunculus utilizados em cada comparação genética.

\begin{tabular}{|c|c|}
\hline Anopheles cruzii & Anopheles homunculus \\
\hline JAN/2012 (26) X JUL/2011 (24) & \\
\hline PLANÍCIE (26) X MORRO (20)* & JAN/2012 (16) X JUL/2012 (15) \\
\hline PLANÍCIE (21) X MORRO (21)** & \\
\hline
\end{tabular}

- Comparações inverno x verão; • Comparações altitudinais;

*Somente indivíduos do verão (janeiro/2012). ${ }^{* *}$ Somente indivíduos do inverno (julho/2012).

\subsubsection{Extração do DNA genômico}

Foram utilizados os exemplares adultos conservados em freezer $-80{ }^{\circ} \mathrm{C}$ para extração de DNA genômico e análises de DNA mitocondrial. A extração de DNA foi feita individualmente para cada mosquito, de acordo com o método de Jowett (1986), descrito a seguir:

Aquelas amostras conservadas em freezer $-80{ }^{\circ} \mathrm{C}$ foram maceradas em solução de homogeneização [Tris- $\mathrm{HCl} 10$ mM (pH=7,5), $\mathrm{NaCl} 60$ mM, EDTA 50 mM]. Aos homogeneizados foi adicionada a solução de lise [SDS 1,25\%, Tris- $\mathrm{HCl} 0,3 \mathrm{M}$ (ph=9,0), EDTA 0,1 M, sacarose $5 \%$, proteinase $\mathrm{K}$ a $100 \mu \mathrm{g} / \mathrm{ml}$. Toda essa mistura foi incubada a $65^{\circ} \mathrm{C}$ durante 1 hora, para "lise" das células e para a ação da proteinase $\mathrm{K}$ (clivar as proteínas em peptídeos menores).

Prossegue-se com uma incubação a $4{ }^{\circ} \mathrm{C}$ durante 45 minutos e logo após uma centrifugação a $12.000 \mathrm{~g}$ a $4 \stackrel{\circ}{\circ}$. Posteriormente, se formaram duas fases na mistura. O precipitado (peptídeos) foi descartado, e o sobrenadante (ácidos nucléicos e sais) foi transferido para outro microtubo e misturado com 2 volumes de etanol 100\%, visando a precipitação do DNA. Após 5 minutos de incubação à temperatura ambiente, as amostras foram novamente centrifugadas a $12.000 \mathrm{~g}$ à temperatura ambiente, durante 5 minutos. O sobrenadante foi descartado e adicionou-se $1 \mathrm{ml}$ de etanol $70 \%$ ao precipitado, submetendo a mistura a uma última centrifugação à temperatura ambiente e $12.000 \mathrm{~g}$ por 5 minutos. O precipitado final 
foi seco e ressuspendido em $20 \mu \mathrm{l}$ de $\mathrm{H}_{2} \mathrm{O}$ milli-Q (Millipore) para cada amostra, que foram armazenadas a $-20^{\circ} \mathrm{C}$.

\subsubsection{Amplificação do DNA mitocondrial}

Para obter inúmeras cópias do fragmento do gene COI presente no DNA mitocondrial foi utilizado o método da PCR (polymerase chain reaction). As reações foram preparadas utilizando as seguintes concentrações finais das soluções: $1 \mathrm{X}$ da solução estoque do tampão 10X (Tris-KCL $20 \mathrm{mM}, \mathrm{pH}=8,4$ ), 0,4 mM de dNTP (10 $\mathrm{mM}$ ), 2,5 mM de $\mathrm{MgCl} 2$ (50 mM), 0,5 $\mu \mathrm{M}$ de cada um dos iniciadores (forward e reverse), 0,5 $\mu \mathrm{l}$ de Taq polimerase e água estéril para completar o volume final de $20 \mu \mathrm{l}$ de reação para cada tubo de $0,2 \mathrm{ml}$. Os iniciadores (primers) usados na amplificação do gene mitocondrial COI foram publicados por Zhang e Hewitt (1996), e possuem as sequências descritas no Genbank: UEA 7: 5'TACAGTTGGAATAGACGTTGATAC-3' para a fita forward e UEA 10: 5'TCCAATGCACTAATCTGCCATATTA-3' para a fita reverse. O tamanho do fragmento final amplificado foi de aproximadamente 600 pb. O primer UEA-7 foi anelado na porção final do gene CO-I e não engloba a região de barcode (início do gene CO-I utilizado para identificar espécies); já o primer UEA-10 foi anelado fora da porção do gene CO-I, como demonstrado no esquema da Figura 9. O ciclo de amplificação do DNA de An. cruzii constituiu em: Temperatura inicial de $95{ }^{\circ} \mathrm{C}$ durante $3 \mathrm{~min}$, seguidos por 40 ciclos de $94{ }^{\circ} \mathrm{C}$ durante $40 \mathrm{~s}, 52{ }^{\circ} \mathrm{C}$ por $40 \mathrm{~s}$ (annealing), $72{ }^{\circ} \mathrm{C}$ por 1 min e o ciclo de extensão final de $72{ }^{\circ} \mathrm{C}$ por $10 \mathrm{~min}$. Para An. homunculus foi utilizado o mesmo ciclo de amplificação, exceto a temperatura de anneling que foi de $47^{\circ} \mathrm{C}$.

Figura 9 - Esquema demonstrando a região do gene CO-I onde os primers UEA-7 e UEA-10 se hibridizaram.

\begin{tabular}{|l|l|l|l|l|l|l|l|}
\hline ND2 & Trp & Cys & Tyr & & LEA-7 & \\
\hline
\end{tabular}




\subsubsection{Eletroforese em gel de agarose}

As extrações de DNA e as amplificações do gene mitocondrial foram conferidas qualitativamente através de uma eletroforese em agarose, seguindo descrição de Sambrook et al. (1989). Ela foi realizada numa cuba transversal a 8V por cm de gel em TAE $1 \mathrm{X}$ como tampão de corrida, utilizando $2 \mu \mathrm{l}$ do material amplificado, $1 \mu \mathrm{l}$ de azul de bromofenol e $1 \mu \mathrm{l}$ de gel red $1 \mathrm{X}$. Um marcador de massa molecular $(1 \mu \mathrm{l})$ foi usado como padrão de comparação. Os géis foram visualizados através de um foto-documentador digital UVP sob radiação ultravioleta de $300 \mathrm{~nm}$ (Figura 9).

Figura 10 - Padrão de fragmentos do gene COI amplificado através de PCR de indivíduos Anopheles cruzii, visualizados em gel de agarose através do fotodocumentador. Marcador 100 pb DNA Ladder (Invitrogen $\AA$ ).

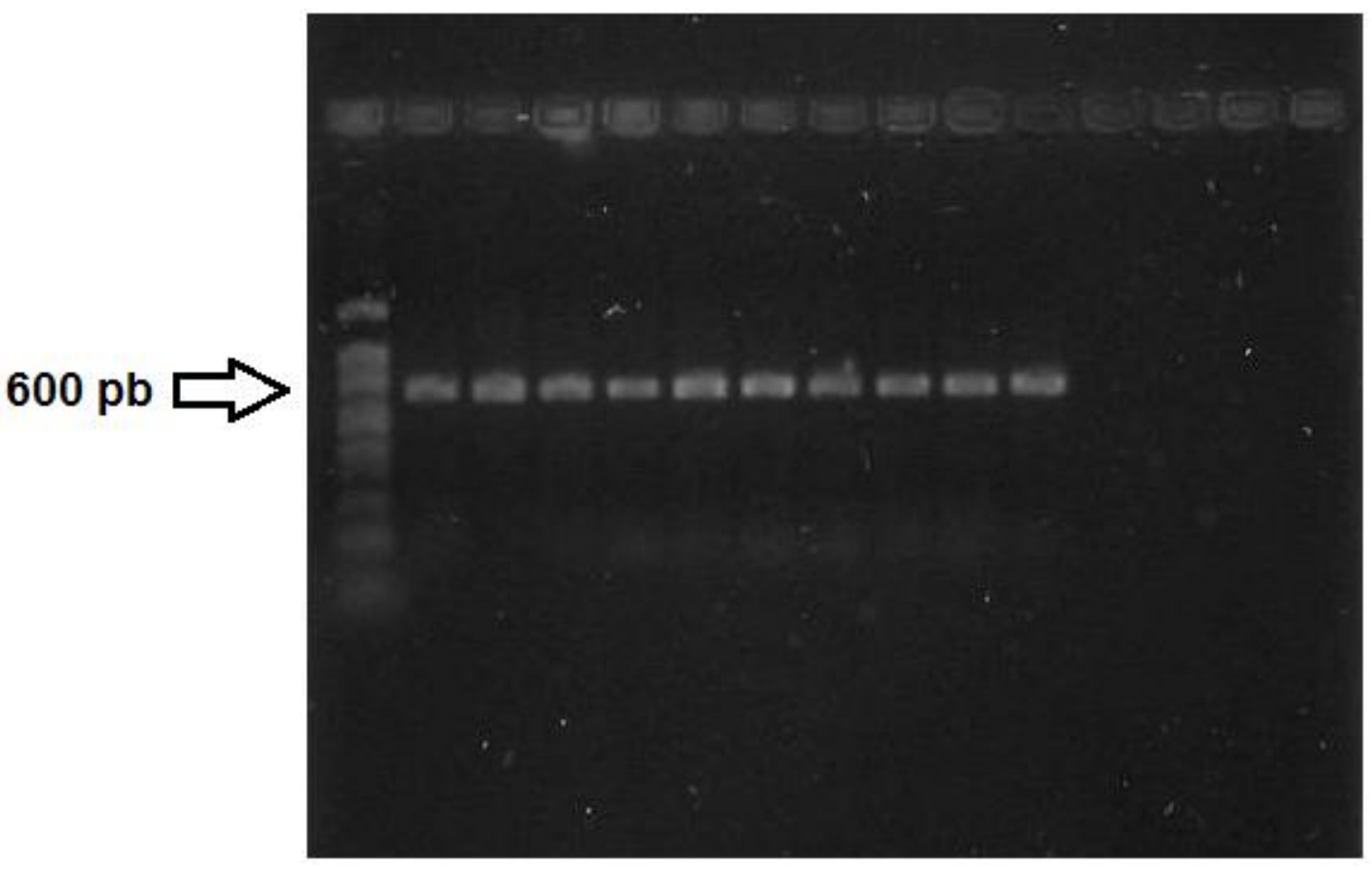

3.4.4 Purificação do produto da PCR e Sequenciamento

Para purificação do produto de PCR foi usado um kit comercial da Invitrogen (Invitrogen Corporation, Melle, Alemanha. PureLink ${ }^{T M}$ PCR Purification Kit), com os procedimentos descritos a seguir: Para cada 1 volume do produto de PCR adicionou-se 4 volumes de PureLink ${ }^{\mathrm{TM}}$ Binding Buffer com isopropanol. Centrifugouse a $10.000 \mathrm{~g}$ durante $1 \mathrm{~min}$ e descartou-se o lavado. Depois se adicionou $650 \mu \mathrm{l}$ de 
Wash Buffer com etanol e foi centrifugado novamente a $10.000 \mathrm{~g}$ por $1 \mathrm{~min}$. Para remover qualquer resíduo de Wash Buffer, centrifugou-se mais uma vez durante 3 min na velocidade máxima da centrífuga. Posteriormente o DNA que restou foi eluído com $50 \mu \mathrm{l}$ de Elution Buffer e centrifugado durante 2min. A solução final purificada foi armazenada em freezer de $-20^{\circ} \mathrm{C}$.

O DNA foi sequenciado nos sentidos forward e reverse com o auxílio do kit comercial ABI Prism dGTP BigDye $\AA$ (Lincoln Centre Drive, Foster, EUA) Terminator v3. Para realizar cada reação utilizou-se 1,0 $\mu \mathrm{l}$ do PCR, 2,0 $\mu \mathrm{l}$ de BigDye, 1,0 $\mu \mathrm{l}$ de tampão, 1,0 $\mu \mathrm{l}$ de iniciadores (UEA 7 ou UEA 10) e água estéril para completar o volume de $10 \mu \mathrm{l}$. As reações foram realizadas em termociclador com os ciclos de temperaturas de: $96{ }^{\circ} \mathrm{C}$ por 2 min e 35 ciclos de 45 segundos a $96 \stackrel{\circ}{\circ}$, 30 segundos a $50{ }^{\circ} \mathrm{C}$ e $4 \mathrm{~min}$ a $60 \stackrel{\circ}{ } \mathrm{C}$. Após reação de sequenciamento as amostras foram precipitadas com $80 \mu \mathrm{l}$ de isopropanol 75\%. As amostras ficaram $25 \mathrm{~min}$ em temperatura ambiente e depois foram centrifugadas a 12000 RCF por $25 \mathrm{~min}$. Retirou-se o sobrenadante com o auxílio de uma pipeta e adicionou-se $200 \mu \mathrm{l}$ de etanol $70 \%$. Centrifugou-se novamente a 12000 RCF por 5 min e o sobrenadante foi descartado. As amostras secas e precipitadas foram armazenadas a $-20{ }^{\circ} \mathrm{C}$ e sequenciadas pela Genomic Engenharia Molecular por meio do sequenciador modelo 3130xl da Applied Biosystems. Para testar a eficiência das reações de sequenciamento, uma mesma amostra foi submetida a outros dois sequenciadores diferentes: sequenciador automático ABI 3100 do ICB-USP e ABI 3730 do Centro de Estudos do Genoma Humano. Os resultados foram essencialmente os mesmos, variando apenas o tamanho das sequências.

\subsubsection{Análise e alinhamento das sequências}

As sequências de DNA obtidas foram analisadas pelo programa Lasergene $\AA$ Core Suite (DNAstar), sendo alinhadas e editadas com o programa MEGA 5.0 (Tamura et al., 2007). As redes de haplótipos foram construídas através do software Network 4.6 (Polzin, Daneshmand, 2004), que também analisou a diversidade haplotípica e o número de sítios polimórficos nas sequências. Para construção das árvores filogenéticas de Neighbor-joining, matrizes de distâncias genéticas de Kimura e composição nucleotídica das sequências foi utilizado o programa MEGA 
5.0. A percentagem de diferença entre os haplótipos também foi calculada pelo MEGA 5.0, utilizando Kimura-2-parâmeros. O Fst, Nm, testes de Tajima e Fu \& Li foram calculados através do programa DnaSP v5 (Rozas et al., 2003). O $\phi s t$ e a percentagem de diferenciação genética intra e interpopulacionais foram gerados pelo software Arlequim 3.5.2.1 (Excoffier et al., 2005). 


\section{RESULTADOS}

\subsection{Diagnose entre as espécies Anopheles cruzii e An. homunculus}

Nestas análises foi adicionada a espécie An. bellator, que foi capturada em grande número nas coletas e também pertence ao subgênero Kerteszia. Ela é considerada vetor secundário de malária também na região sudeste. Esta parte do projeto gerou um artigo científico que foi submetido e aceito na revista Parasite \& Vectors (Fator de Impacto=2,94), o qual se encontra no APÊNDICE A.

\subsection{Dimorfismo sexual - Morfometria Geométrica Alar}

\subsubsection{Anopheles cruzii}

Foram feitas análises de dimorfismo sexual para o formato alar dentre todas as populações de An. cruzii coletadas, conforme ilustrado na Figura 10. Em todos os casos não houve sobreposição dos dois grupos. Os valores de reclassificação, alometria e distância de Mahalanobis estão descritos na Tabela 4. A Figura 11 descreve um gráfico com as distâncias de Mahalanobis entre machos e fêmeas de todas as populações analisadas.

\subsubsection{Anopheles homunculus}

Para as populações de An. homunculus também foram feitas análises de dimorfismo sexual para formato alar entre as diferentes populações (Figura 12). Não houve sobreposição dos grupos em nenhuma época amostrada. Os valores de reclassificação, alometria e distância de Mahalanobis estão descritos na Tabela 5. 
Figura 11 - Histogramas múltiplos evidenciando a separação entre machos (cinza) e fêmeas (preto) de Anopheles cruzii no morfoespaço de variáveis canônicas.

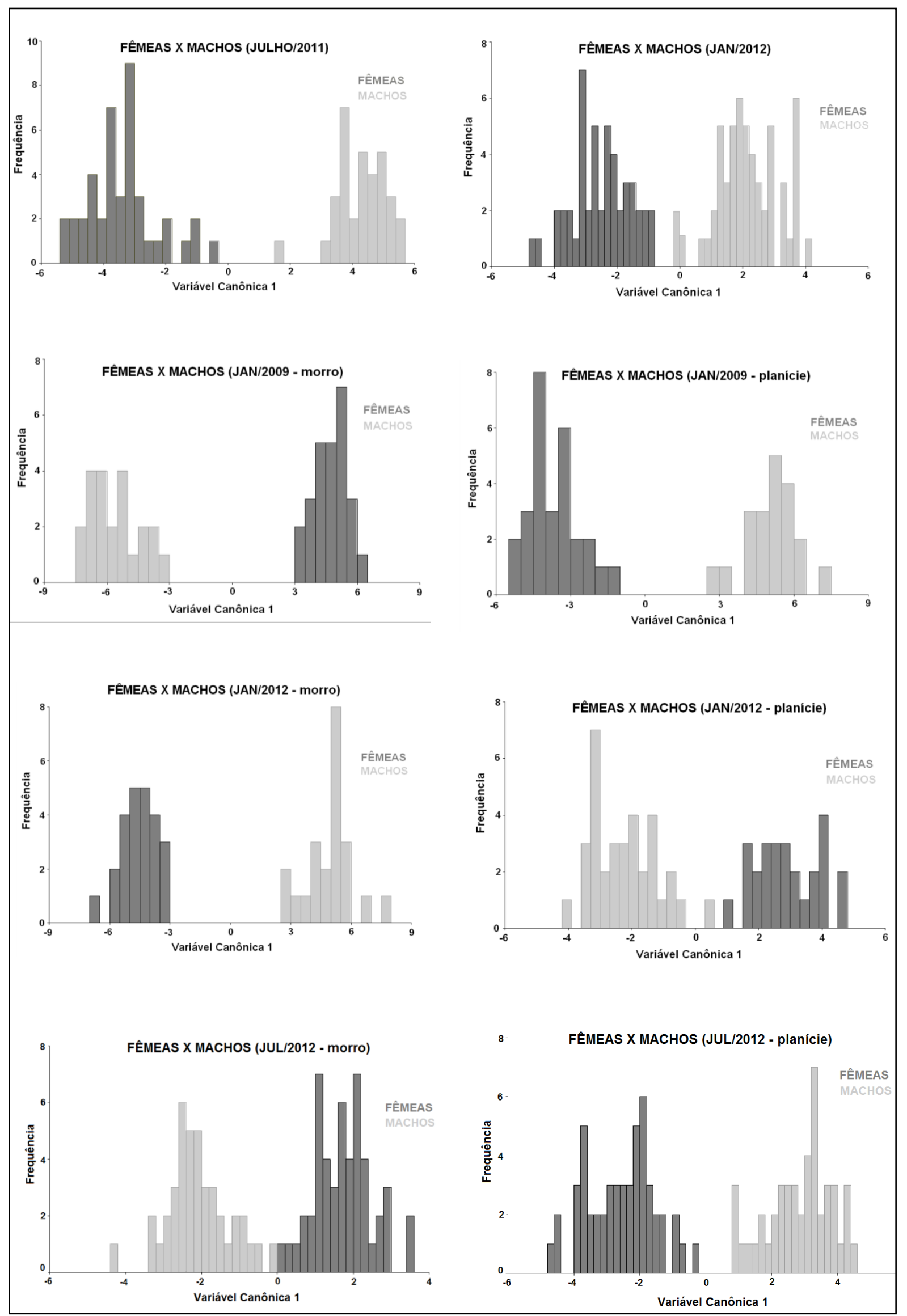


Tabela 3 - Dados relacionados ao dimorfismo sexual das populações de Anopheles cruzii.

\begin{tabular}{|c|c|c|c|c|}
\hline \multirow{2}{*}{ Período } & \multirow{2}{*}{$\begin{array}{c}\text { Distância de } \\
\text { Mahalanobis } \\
\hat{\lambda} \mathbf{x}\end{array}$} & \multirow{2}{*}{$\begin{array}{c}\text { Alometria } \\
(\%)\end{array}$} & \multicolumn{2}{|c|}{$\begin{array}{c}\text { Reclassificação } \\
(\%)\end{array}$} \\
\hline & & & 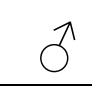 & q \\
\hline $\begin{array}{l}\text { JAN/2009 } \\
\text { (planície) }\end{array}$ & 8,744 & $15,751^{*}$ & 90 & 93 \\
\hline JAN/2009 (morro) & 10,324 & $10,470^{*}$ & 81 & 93 \\
\hline JULHO/2011 & 7,668 & $5,902^{*}$ & 93 & 100 \\
\hline $\begin{array}{l}\text { JAN/2012 } \\
\text { (planície) }\end{array}$ & 5,123 & 2,141 & 80 & 82 \\
\hline JAN/2012 (morro) & 9,507 & $5,853^{*}$ & 87 & 96 \\
\hline $\begin{array}{c}\text { JULHO/2012 } \\
\text { (planície) }\end{array}$ & 5,406 & $5,924^{*}$ & 95 & 92 \\
\hline $\begin{array}{c}\text { JULHO/2012 } \\
\text { (morro) }\end{array}$ & 3,603 & $6,909^{*}$ & 83 & 90 \\
\hline
\end{tabular}

*Valores considerados significativos $(P<0,0001)$

Figura 12 - Representação gráfica das distâncias de Mahalanobis entre machos e fêmeas de cada população. As populações da planície estão representadas em verde, e as do morro, em marrom.

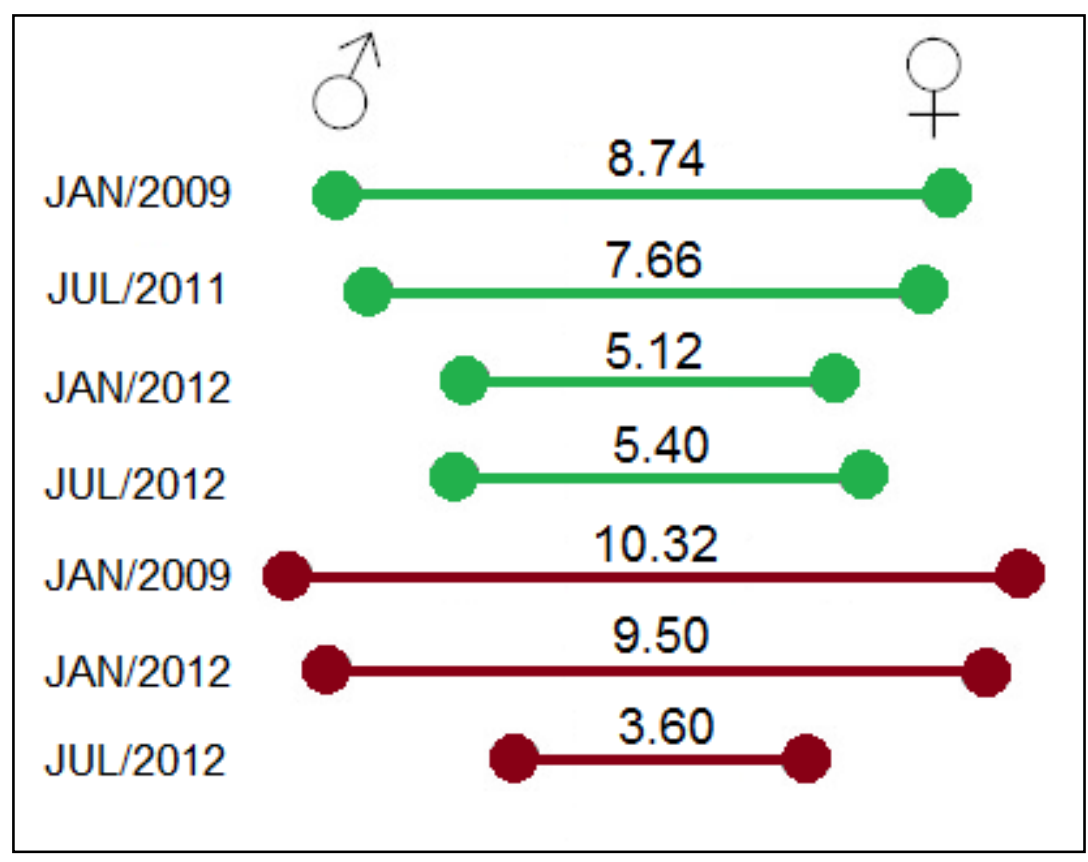


Figura 13 - Histogramas múltiplos evidenciando a separação entre machos (cinza) e fêmeas (preto) de Anopheles homunculus no morfoespaço de variáveis canônicas.

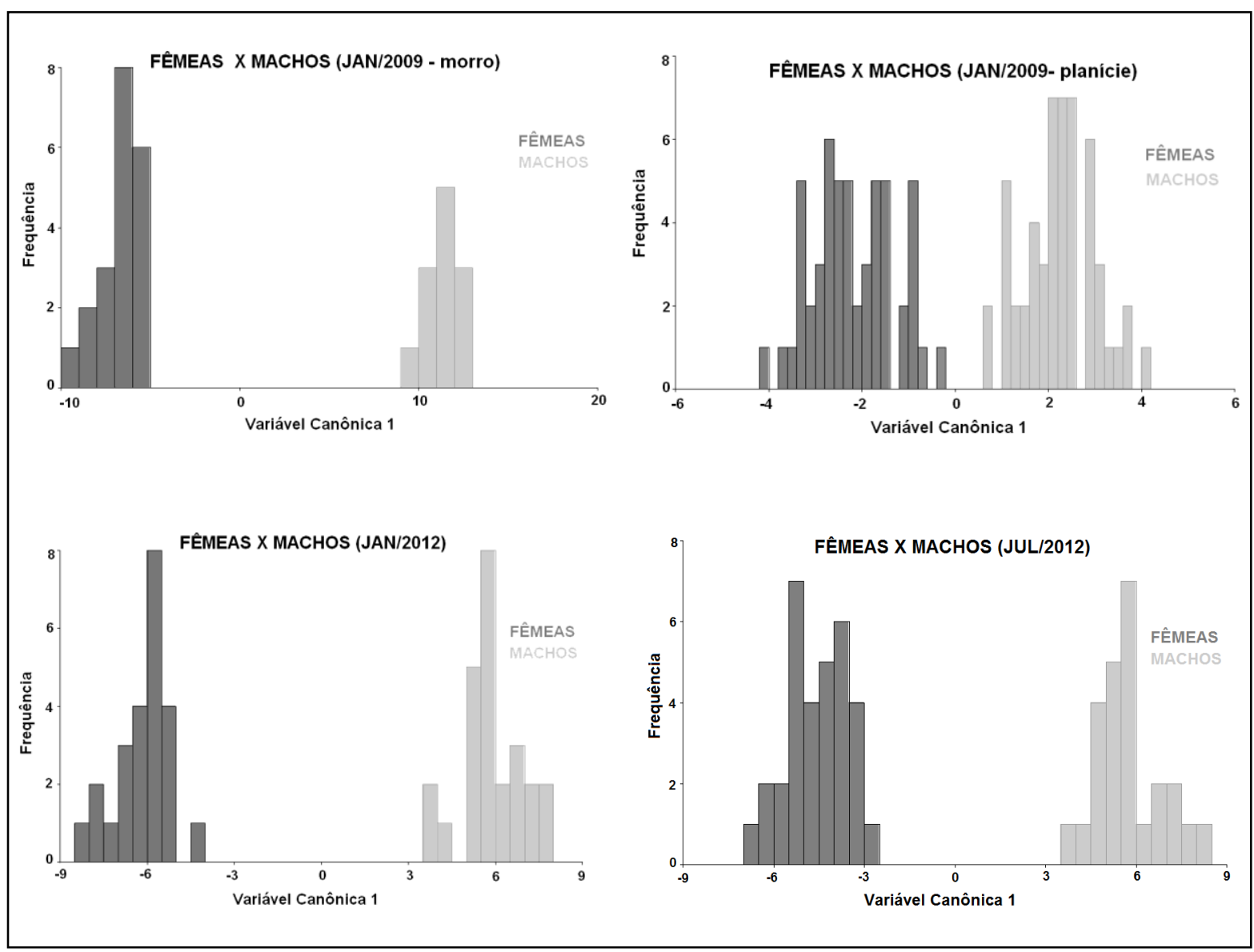

Tabela 4 - Dados relacionados ao dimorfismo sexual das populações de Anopheles homunculus.

\begin{tabular}{ccccc}
\hline Período & $\begin{array}{c}\text { Distância de } \\
\text { Mahalanobis } \\
\lambda \mathbf{x} \%\end{array}$ & $\begin{array}{c}\text { Alometria } \\
(\%)\end{array}$ & \multicolumn{2}{c}{$\begin{array}{c}\text { Reclassificação } \\
\text { (\%) }\end{array}$} \\
\hline $\begin{array}{c}\text { JAN/2009 } \\
\text { (planície) }\end{array}$ & 4,203 & $6,092^{*}$ & 87 & 90 \\
\hline $\begin{array}{l}\text { JAN/2009 } \\
\text { (morro) }\end{array}$ & 29,588 & $16,340^{*}$ & 90 & 95 \\
$\begin{array}{c}\text { JAN/2012 } \\
\text { (morro) }\end{array}$ & 11,984 & $7,761^{*}$ & 92 & 100 \\
$\begin{array}{c}\text { JULHO/2012 } \\
\text { (morro) }\end{array}$ & 10,316 & $7,362^{*}$ & 96 & 100 \\
\hline
\end{tabular}

*Valores considerados significativos $(P<0,0001)$ 


\subsection{Variações sazonais - Inverno x Verão}

\subsubsection{Variações sazonais em Anopheles cruzii}

\subsubsection{Morfometria Geométrica Alar}

Os indivíduos coletados em Julho/2011 (“INVERNO”) e Janeiro/2012 ("VERÃO") apresentaram diferenciação em relação à forma alar nas análises de variáveis canônicas. Há formação de dois grupos distintos para cada época, tanto para fêmeas (Figura 13) como para machos (Figura 14). Após a sobreposição de Procrustes, foi realizado um alinhamento entre os extremos de diferenciação no formato alar de machos e fêmeas em cada estação, conforme ilustrado na Figura 15. O tamanho dos centróides entre fêmeas e machos no inverno foi o único que divergiu significativamente $(P<0,001$; ANOVA, $F=6,76)$. Comparando separadamente machos e fêmeas de cada estação, não houve divergência considerável quanto ao tamanho alar (Fig.16).

Figura 14 - Morfoespaço de variáveis canônicas geradas na comparação somente entre fêmeas de An. cruzii nas duas estações do ano: inverno (azul) e verão (vermelho).

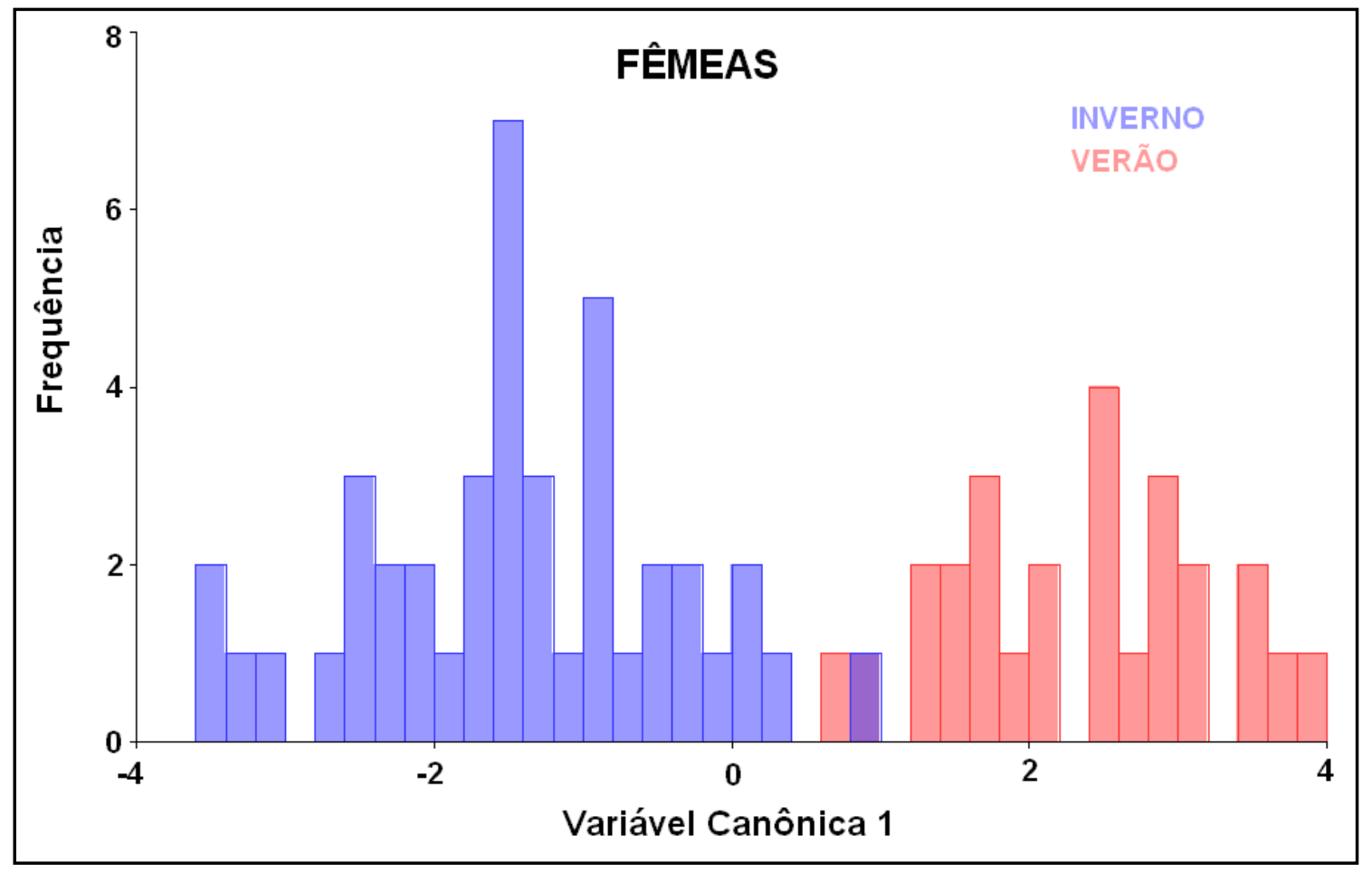


Figura 15 - Morfoespaço de variáveis canônicas geradas na comparação somente entre machos de An. cruzii nas duas estações do ano: inverno (azul) e verão (vermelho).

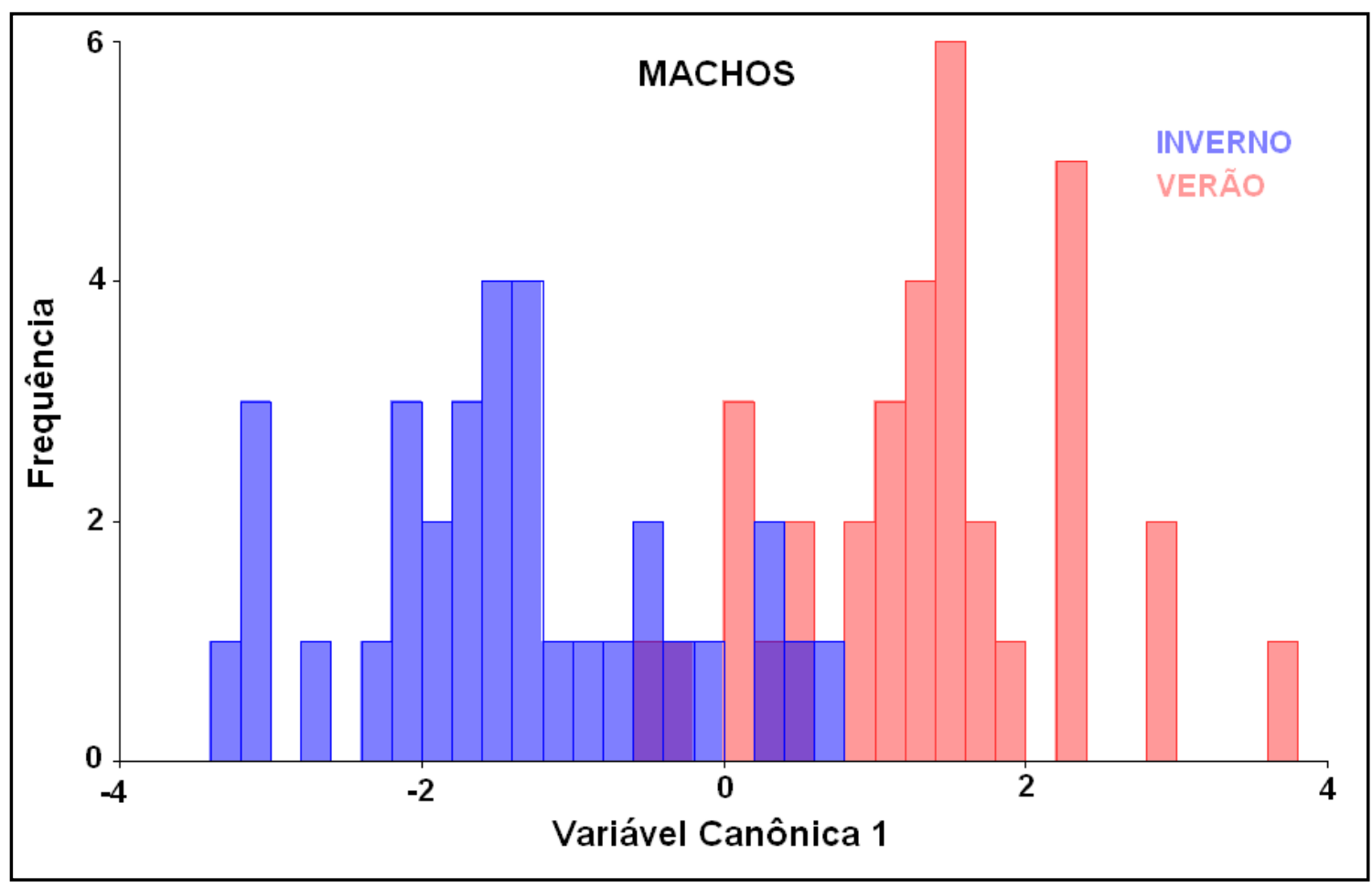

Figura 16 - Consensos alares alinhados de An. cruzii após sobreposição de Procrustes mostrando os extremos de diferenciação entre inverno e verão de (a) fêmeas e (b) machos.

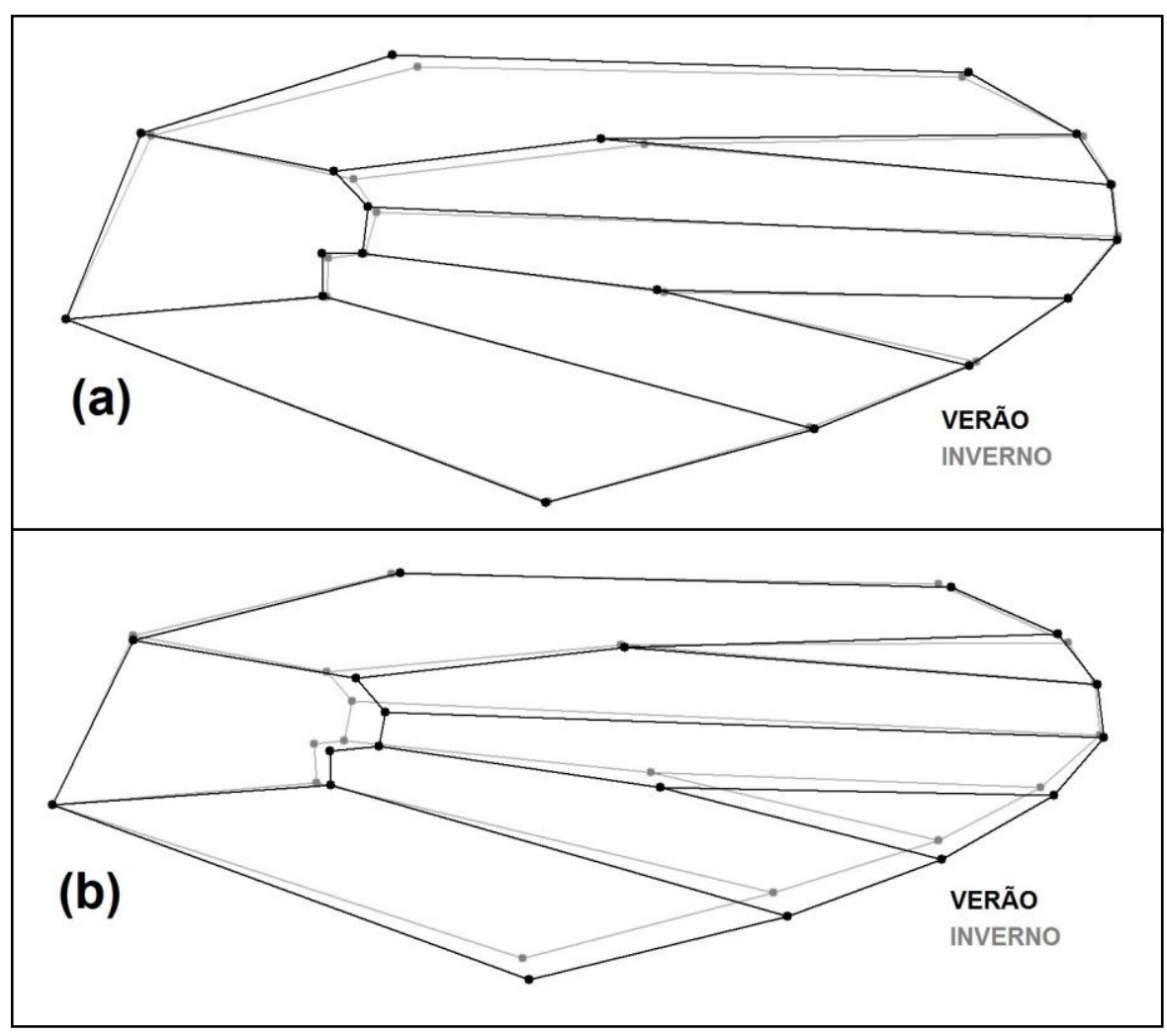


O Qst calculado em fêmeas foi de 0,31 para forma e 0,71 para o tamanho; nos machos esses valores foram de 0,29 para forma e 0,33 para o tamanho.

Figura 17 - Gráfico descritivo do tamanho dos centróides de machos e fêmeas de An. cruzii nas duas estações do ano: inverno e verão. Os valores do eixo Y estão em milímetros.

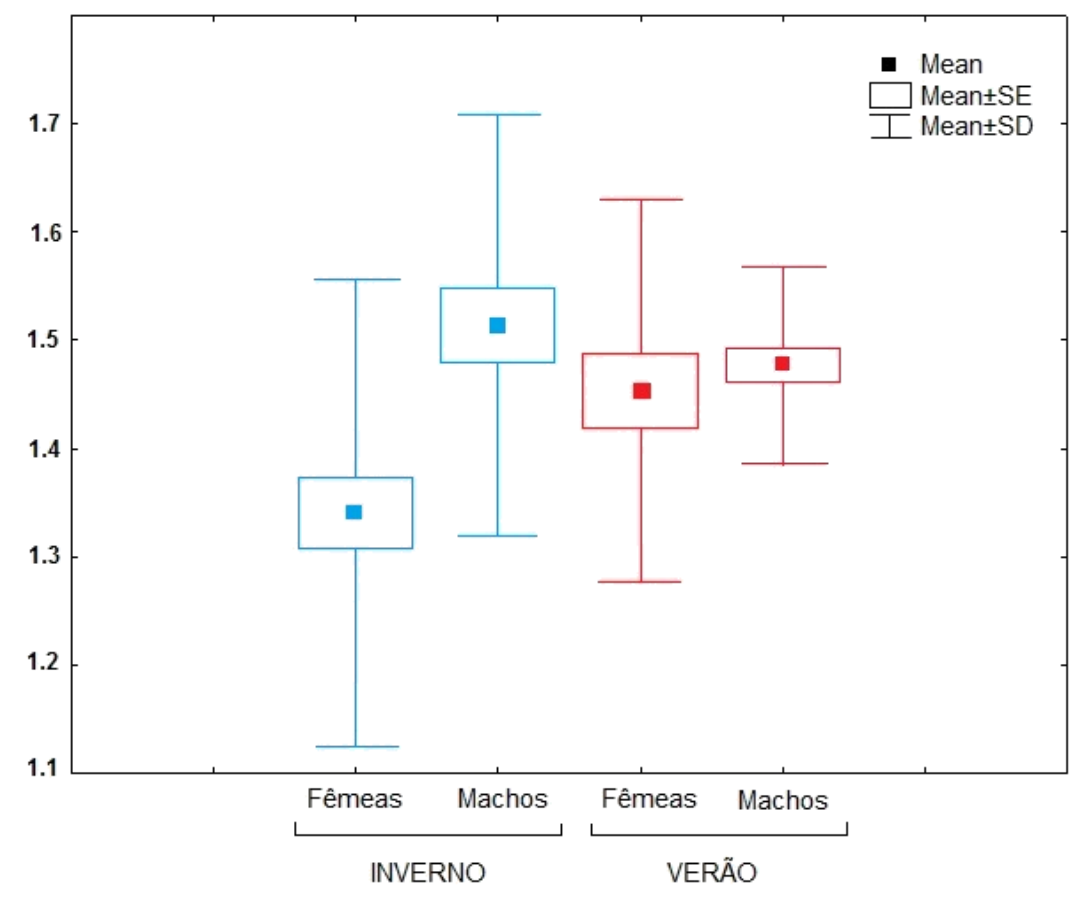

\subsubsection{Gene Mitocondrial CO-I}

Nestas análises foi utilizado um fragmento da porção final do gene COI com 390 pb. A similaridade de todos os haplótipos encontrados nesta comparação está demonstrada na Figura 17. As posições das mudanças nucleotídicas em cada haplótipo encontram-se no APÊNDICE B. Em relação às mutações, 92\% ocorreram na terceira posição do códon e foram sinônimas; a grande maioria é do tipo transição. Dos 50 espécimes amostrados, 24 do inverno e 26 do verão, foram encontrados 33 haplótipos diferentes, sendo que apenas dois deles foram compartilhados entre as estações climáticas $(\mathrm{H}-3$ e $\mathrm{H}-8)$. $\mathrm{O}$ dendrograma de distância genética entre os haplótipos encontrados no inverno e verão está demonstrado na Figura 18. A diferenciação genética intrapopulacional foi de 99,3\% e a interpopulacional foi $0,7 \%$. Os dados genéticos como diversidade haplotípica e nucleotídica estão na Tabela 6; os valores dos testes de Tajima, Fu \& Li, Fst, $\phi s t$, $\mathrm{Nm}$ e a percentagem de diferença entre os haplótipos estão descritos na Tabela 7. 
Tabela 5 - Dados genéticos da comparação Inverno x Verão de Anopheles cruzii.

\begin{tabular}{cccccc}
\hline Comparação & $\mathbf{H} / \mathbf{n}$ & $\begin{array}{c}\mathbf{N}^{\circ} \text { Sítios } \\
\text { Polimórficos }\end{array}$ & Conteúdo A-T & $\mathbf{h}$ & $\mathbf{\pi}$ \\
\hline $\begin{array}{c}\text { Inverno } \\
\mathbf{X} \\
\text { Verão }\end{array}$ & $33 / 50(2)$ & $32 / 390$ & $72 \%$ & 0,97 & 0,012 \\
\hline
\end{tabular}

$\mathrm{H}=$ número de haplótipos; $\mathrm{n}=$ número total de indivíduos; ()$=0$ número entre parênteses representa os haplótipos compartilhados entre as duas populações; $h=$ diversidade haplotípica; $\pi=$ diversidade nucleotídica.

Tabela 6 - Valores de diferenciação genética e número de migrantes da comparação Inverno x Verão de Anopheles cruzii.

\begin{tabular}{ccccccc}
\hline Comparação & $D_{T}$ & $\boldsymbol{F}$ & $\boldsymbol{\phi s t}$ & Fst & Nm & $\%$ Dif. \\
\hline $\begin{array}{c}\text { Inverno } \\
\mathbf{X} \\
\text { Verão }\end{array}$ & $-1,030^{*}$ & $-2,56^{*}$ & 0,007 & 0,003 & 21,60 & 2,82 \\
\hline
\end{tabular}

$D T=$ teste de Tajima; $F=$ teste de $\mathrm{Fu} \& \mathrm{Li} ; \mathrm{Nm}=$ número de migrantes. \%Dif= percentual de diferença entre os haplótipos mais distintos encontrados na população. * Valores significativos $(P<0,001)$

Figura 18 - Rede de haplótipos mostrando a relação entre os indivíduos de An. cruzii coletados no inverno (azul) e verão (vermelho). O tamanho dos círculos é proporcional ao número de indivíduos (o menor círculo equivale a um indivíduo). Os círculos amarelos são haplótipos intermediários hipotéticos.

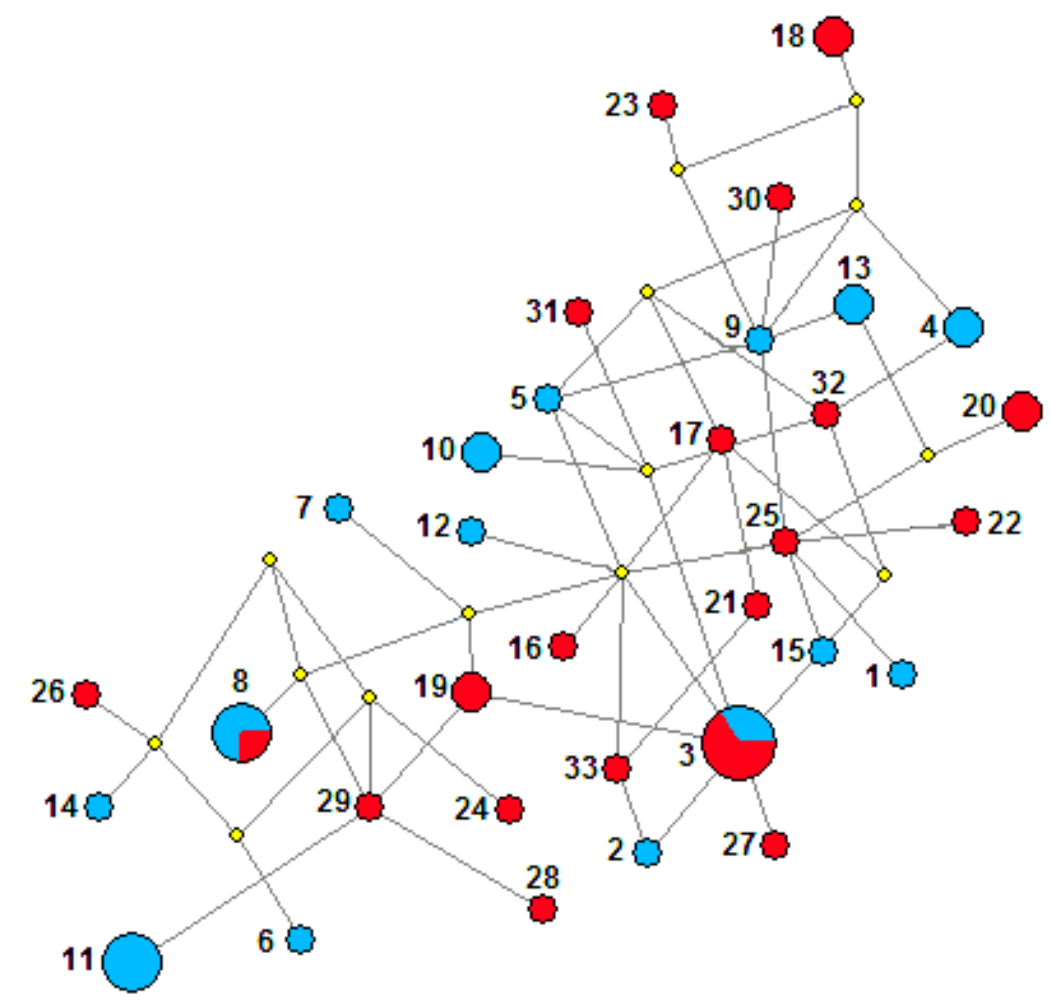


Figura 19 - Dendrograma de distância genética entre os haplótipos do inverno $x$ verão encontrados em Anopheles cruzii construído pelo método Neighbor-joining (NJ). Os quadrados vermelhos indicam haplótipos encontrados no verão; os azuis indicam aqueles encontrados no inverno; a seta aponta os haplótipos compartilhados entre as duas populações.

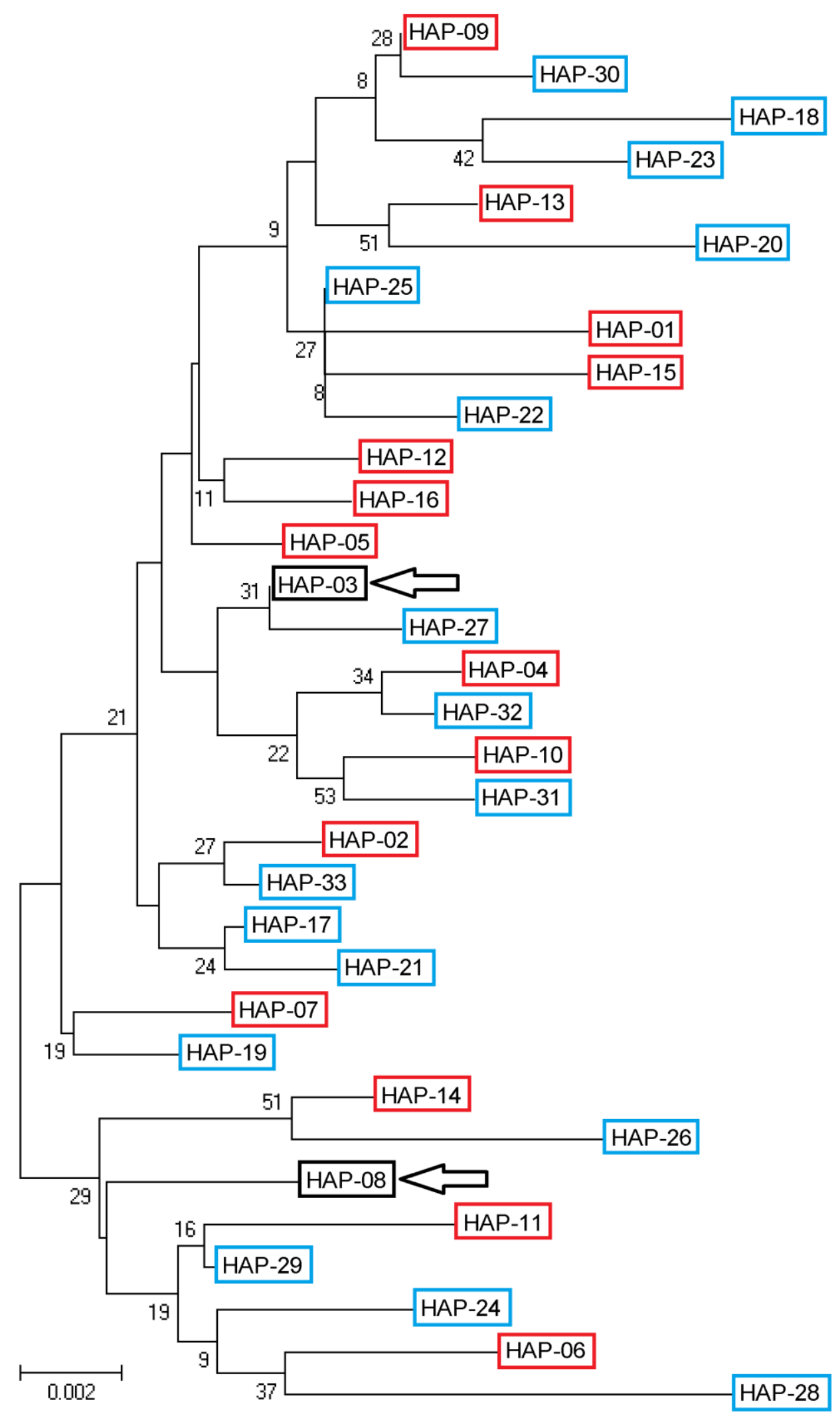




\subsubsection{Variações sazonais em Anopheles homunculus}

\subsubsection{Morfometria Geométrica Alar}

Os indivíduos coletados em Janeiro/2012 ("VERÃO”) e Julho/2012 ("INVERNO") apresentaram uma grande diferenciação da forma alar nas análises de variáveis canônicas. Há formação de dois grupos distintos sem sobreposição para cada época, tanto para fêmeas (Figura 19) como para machos (Figura 20). Após a sobreposição de Procrustes, foi realizado um alinhamento entre os extremos de diferenciação no formato alar de machos e fêmeas em cada estação, conforme ilustrado na Figura 21. O tamanho dos centróides divergiu significativamente em cada época $(\mathrm{P}<0,001$; ANOVA, $F=81,84)$. Comparando separadamente machos e fêmeas de cada estação, houve divergência considerável apenas entre os sexos da população do verão (Figura 22). O índice Qst calculado em fêmeas foi de 0,99 para tamanho e 0,25 para forma; nos machos foi de 0,97 para o tamanho e 0,20 para forma.

Figura 20 - Morfoespaço de variáveis canônicas geradas na comparação somente entre fêmeas de An. homunculus nas duas estações do ano: inverno (azul) e verão (vermelho).

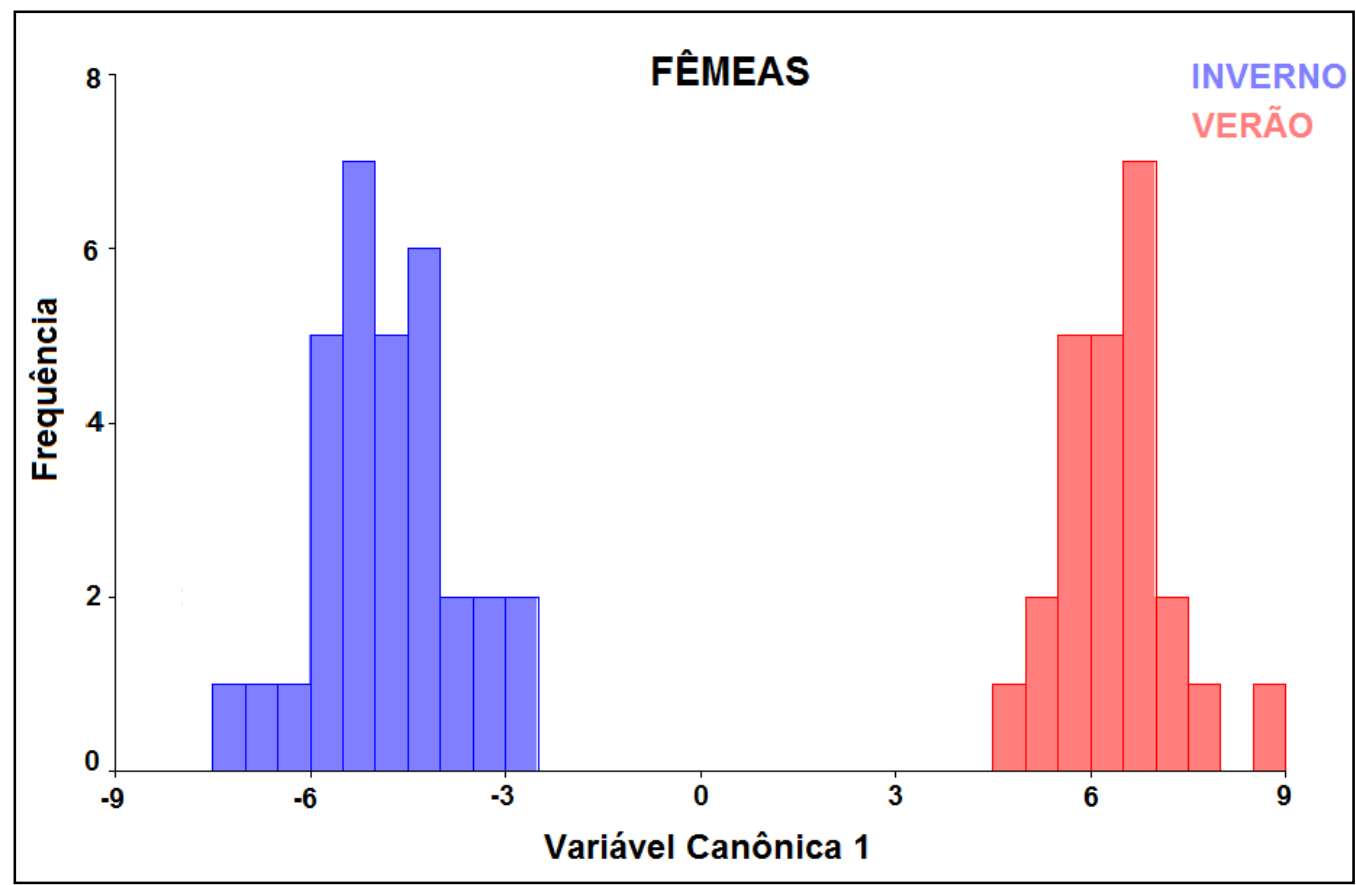


Figura 21 - Morfoespaço de variáveis canônicas geradas na comparação somente entre machos de An. homunculus nas duas estações do ano: inverno (azul) e verão (vermelho).

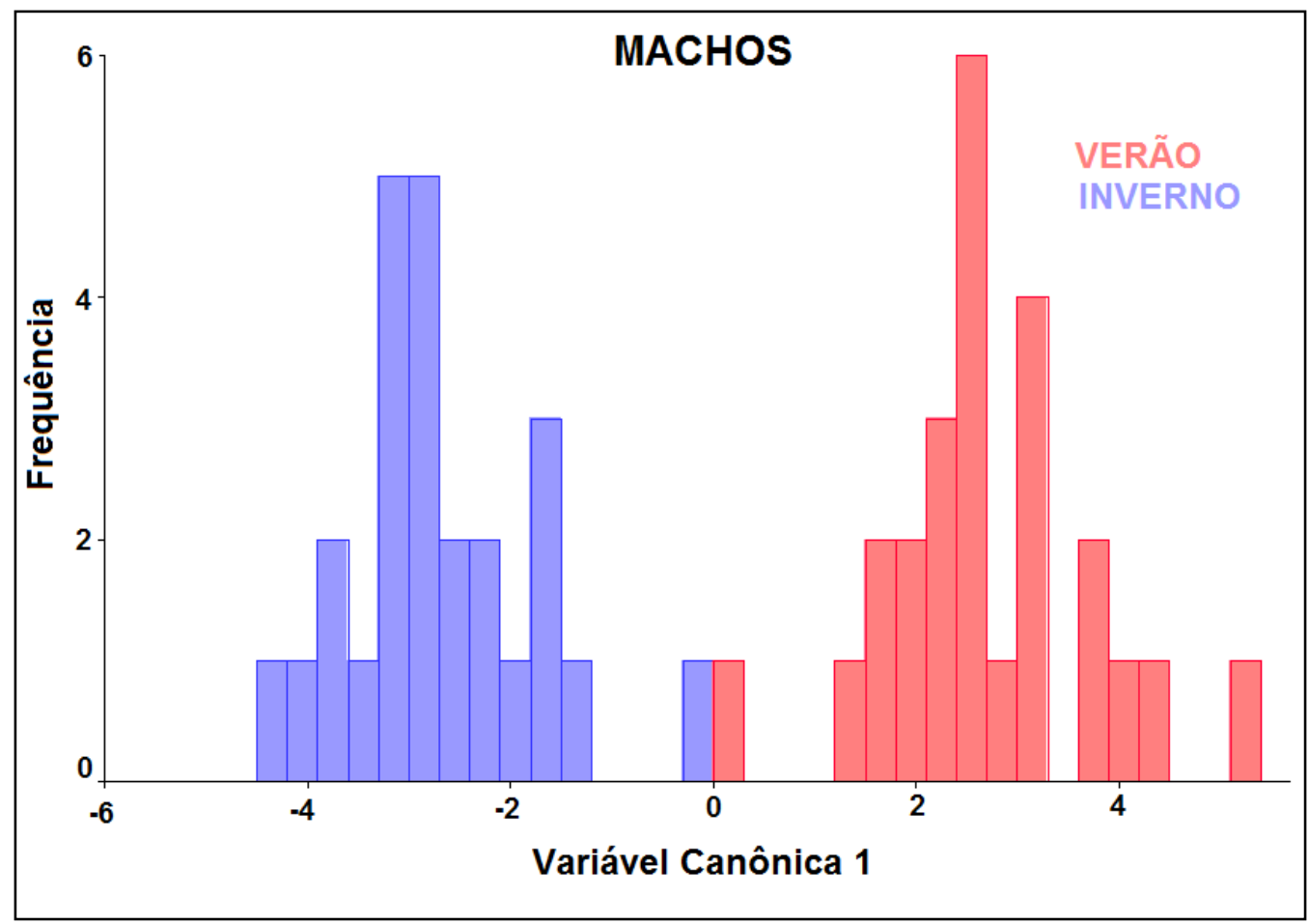

Figura 22 - Consensos alares alinhados de An. homunculus após sobreposição de Procrustes mostrando os extremos de diferenciação entre inverno e verão de (a) fêmeas e (b) machos.

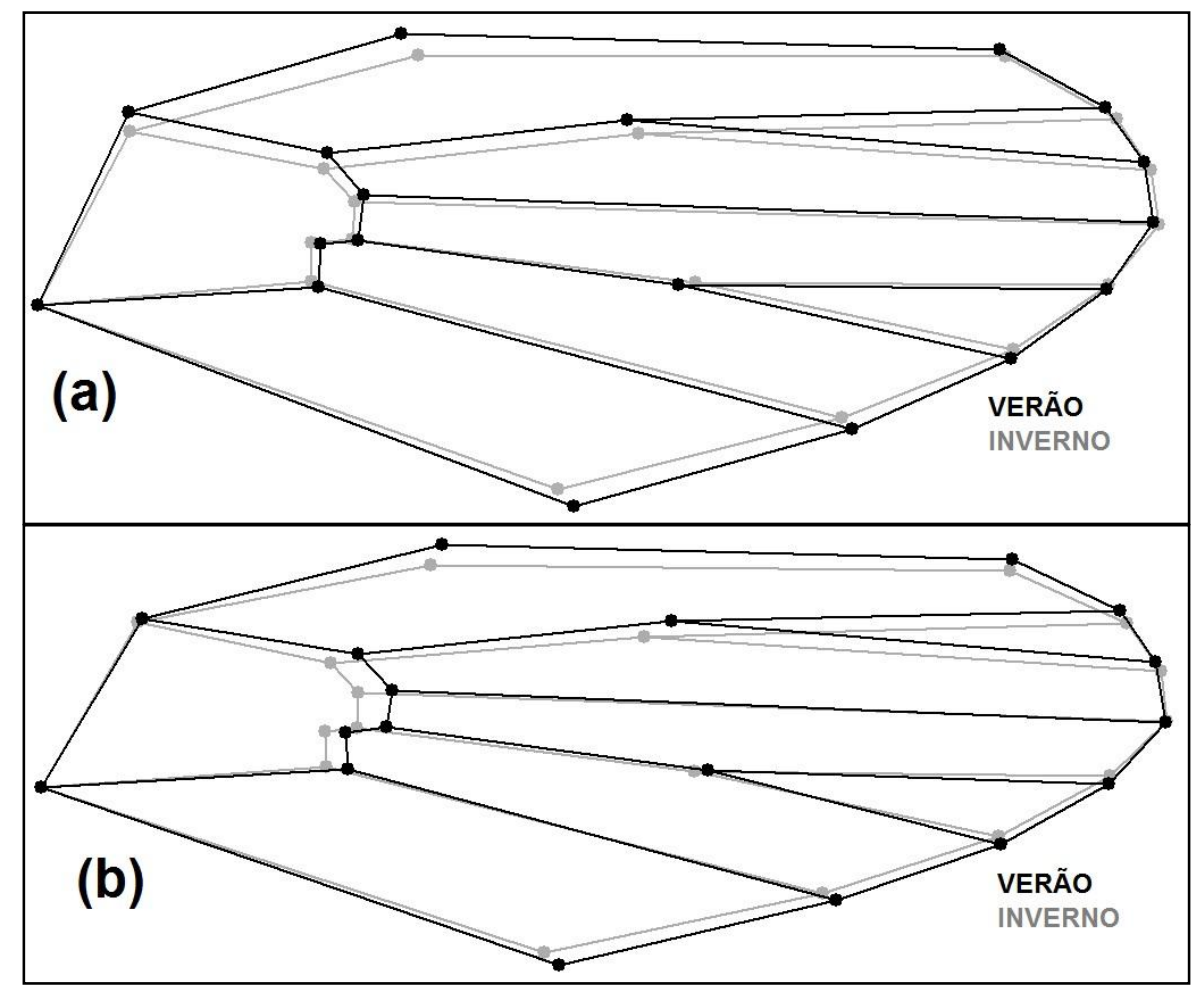


Figura 23 - Gráfico descritivo do tamanho dos centróides de machos e fêmeas de An. homunculus nas duas estações do ano: inverno e verão. Os valores do eixo $Y$ estão em milímetros.

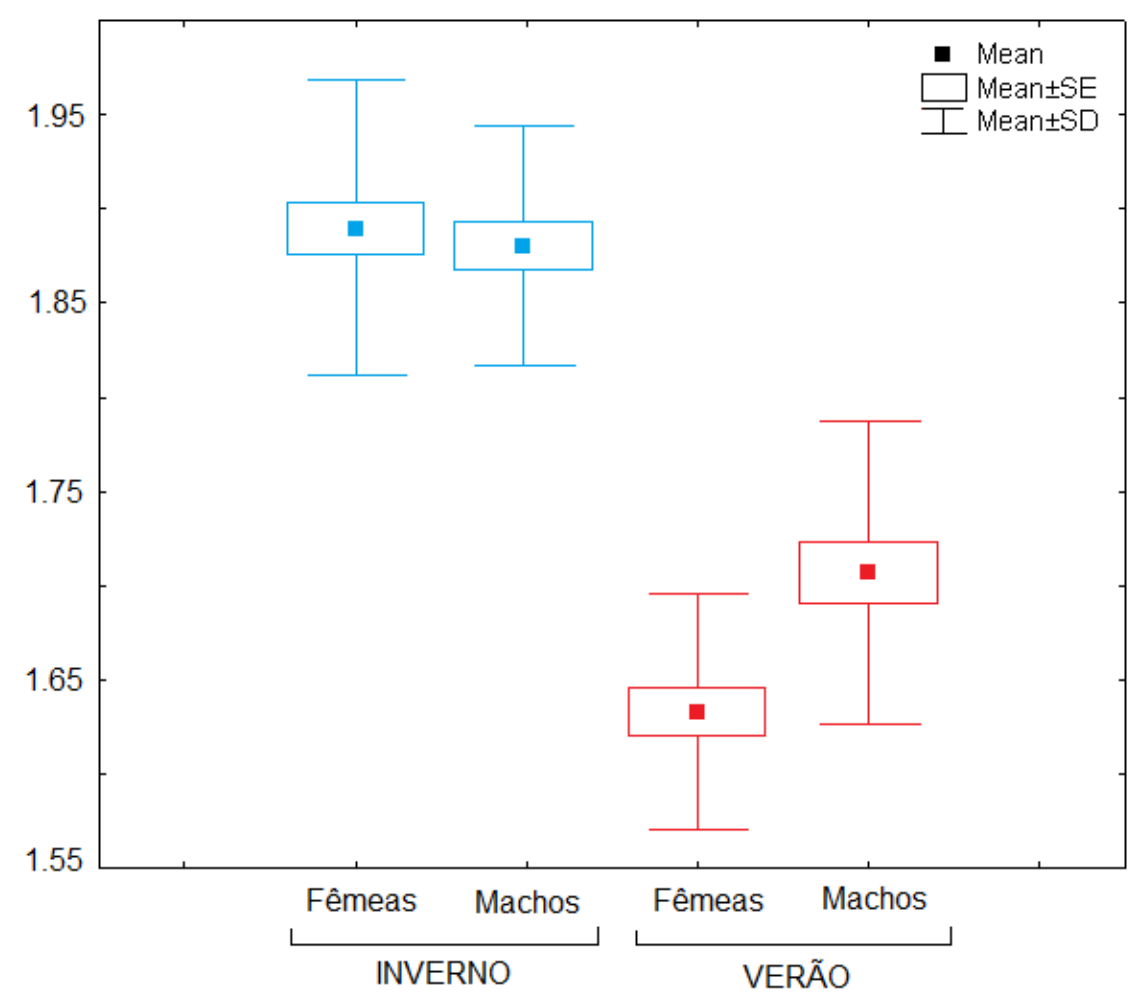

\subsubsection{Gene Mitocondrial CO-I}

Para esta espécie foram analisadas sequências de 513pb, sendo que $87 \%$ das mutações ocorreram na terceira posição do códon e a grande maioria é do tipo transição. Dos 31 espécimes amostrados, 15 do inverno e 16 do verão, foram encontrados 9 haplótipos diferentes, sendo que apenas um deles foi compartilhado entre as estações climáticas $(\mathrm{H}-1)$. Os sítios variáveis em cada haplótipo estão apresentados no APÊNDICE B. A similaridade de todos os haplótipos encontrados está demonstrada na Figura 23. A diferenciação genética intrapopulacional foi de $88,4 \%$ e interpopulacional foi $11,6 \%$. O dendrograma de distância genética entre as haplótipos está demonstrado na Figura 24. Os dados genéticos como diversidade haplotípica e nucleotídica estão na Tabela 8; os valores dos testes de Tajima, Fu \& $\mathrm{Li}$, Fst, $\phi s t, \mathrm{Nm}$ e a percentagem de diferença entre os haplótipos estão descritos na Tabela 9. 
Figura 24 - Rede de haplótipos de Anopheles homunculus mostrando a relação entre os indivíduos coletados no inverno (azul) e verão (vermelho). O tamanho dos círculos é proporcional ao número de indivíduos (o menor círculo equivale a um indivíduo). Os círculos amarelos são haplótipos intermediários hipotéticos.

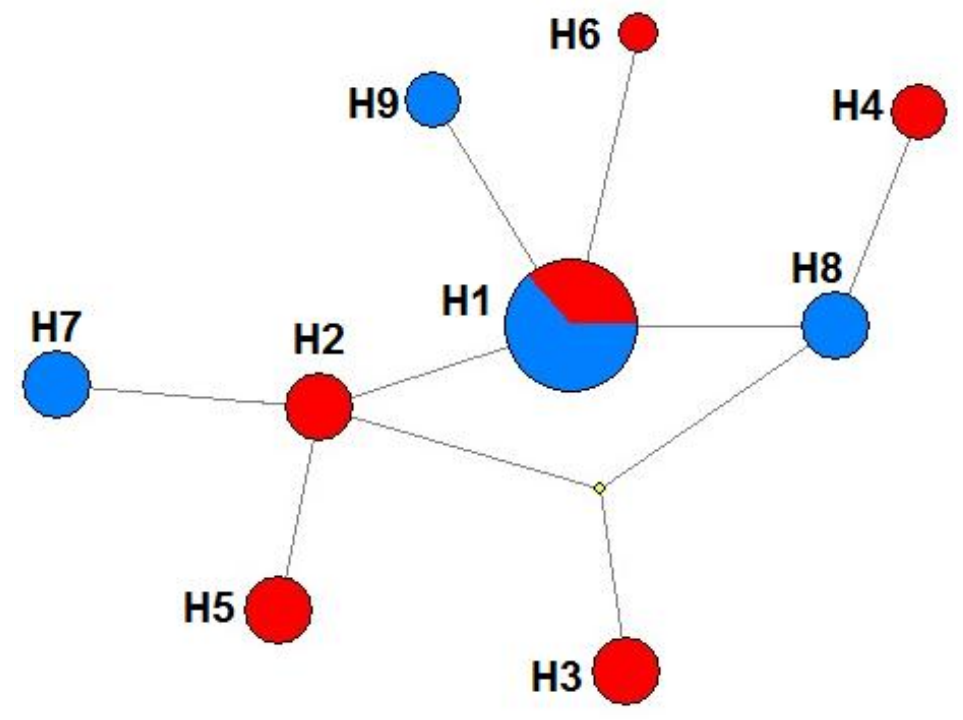

Figura 25 - Dendrograma de distância genética entre os haplótipos encontrados em Anopheles homunculus construído pelo método Neighbor-joining (NJ). Os quadrados vermelhos indicam haplótipos encontrados no verão; os azuis indicam aqueles encontrados no inverno; a seta aponta o haplótipo compartilhado entre as duas populações.

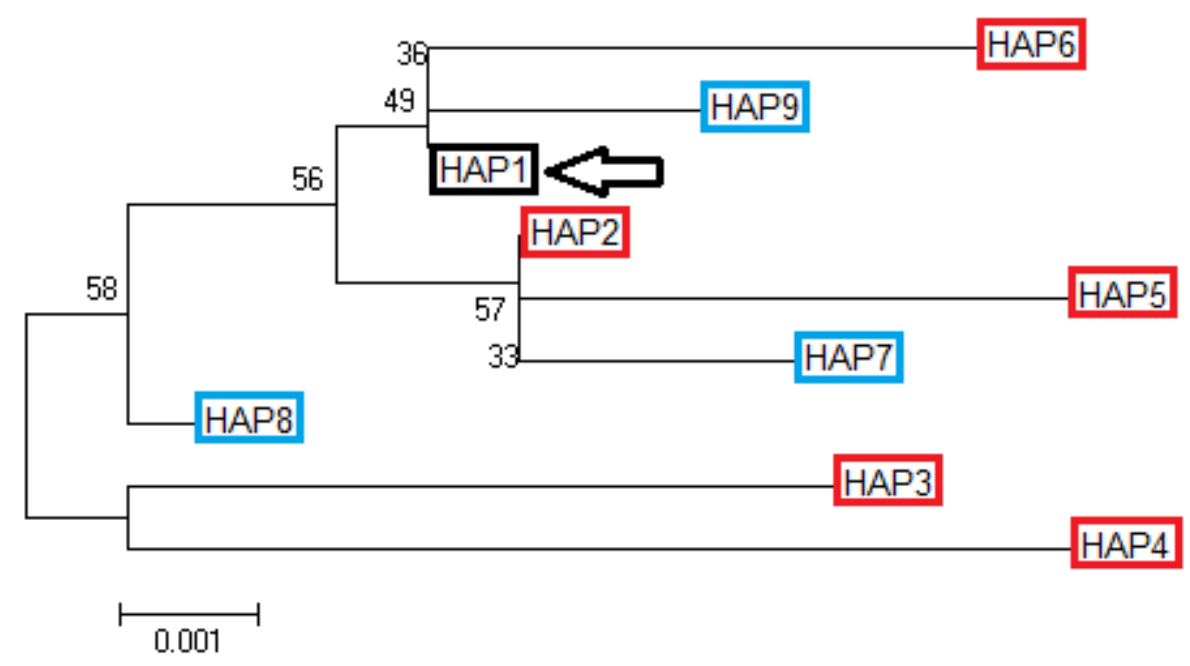


Tabela 7 - Dados genéticos da comparação Inverno x Verão de Anopheles homunculus.

\begin{tabular}{cccccc}
\hline Comparação & $\mathbf{H} / \mathbf{n}$ & $\begin{array}{c}\mathbf{N}^{\circ} \text { Sítios } \\
\text { Polimórficos }\end{array}$ & Conteúdo A-T & $\mathbf{h}$ & $\mathbf{T}$ \\
\hline $\begin{array}{c}\text { Inverno } \\
\mathbf{X} \\
\text { Verão }\end{array}$ & $9 / 31(1)$ & $14 / 513$ & $71,1 \%$ & 0,84 & 0,005 \\
\hline
\end{tabular}

$\mathrm{H}=$ número de haplótipos; $\mathrm{n}=$ número total de indivíduos; ()$=0$ número entre parênteses representa os haplótipos compartilhados entre as duas populações; $h=$ diversidade haplotípica; $\pi=$ diversidade nucleotídica.

Tabela 8 - Valores de diferenciação genética e número de migrantes da comparação Inverno x Verão de Anopheles homunculus.

\begin{tabular}{ccccccc}
\hline Comparação & $D_{T}$ & $\boldsymbol{F}$ & 申st & Fst & Nm & $\%$ Dif. \\
\hline $\begin{array}{c}\text { Inverno } \\
\mathbf{X} \\
\text { Verão }\end{array}$ & $-0,764$ & $-1,48^{*}$ & $0,116^{*}$ & $0,119^{*}$ & 4,78 & 1,5 \\
\hline
\end{tabular}

$D T=$ teste de Tajima; $F=$ teste de $\mathrm{Fu} \& \mathrm{Li} ; \mathrm{Nm}=$ número de migrantes. $\% \mathrm{Dif}=\%$ de diferença entre os haplótipos mais distintos encontrados na população. * Valores significativos $(P<0,001)$

\subsection{Variações Altitudinais em An. cruzii - Morro x Planície}

\subsubsection{Variações Altitudinais em Janeiro/2009}

Neste grupo foram realizadas apenas análises morfológicas, visto que o DNA estava muito danificado para amplificação do gene CO-I. Quando comparado os microambientes planície e morro, nota-se também que os indivíduos apresentam uma diferenciação no formato alar. Após a CVA aparecem dois grupos distintos no morfoespaço, sendo que entre os machos é possível observar uma separação sem sobreposição entre os espécimes da planície e do morro (Figuras 25 e 26). 
Figura 26 - Morfoespaço de variáveis canônicas geradas na comparação somente entre fêmeas de An. cruzii em Janeiro/2009 nos dois microambientes: planície (verde) e morro (marrom).

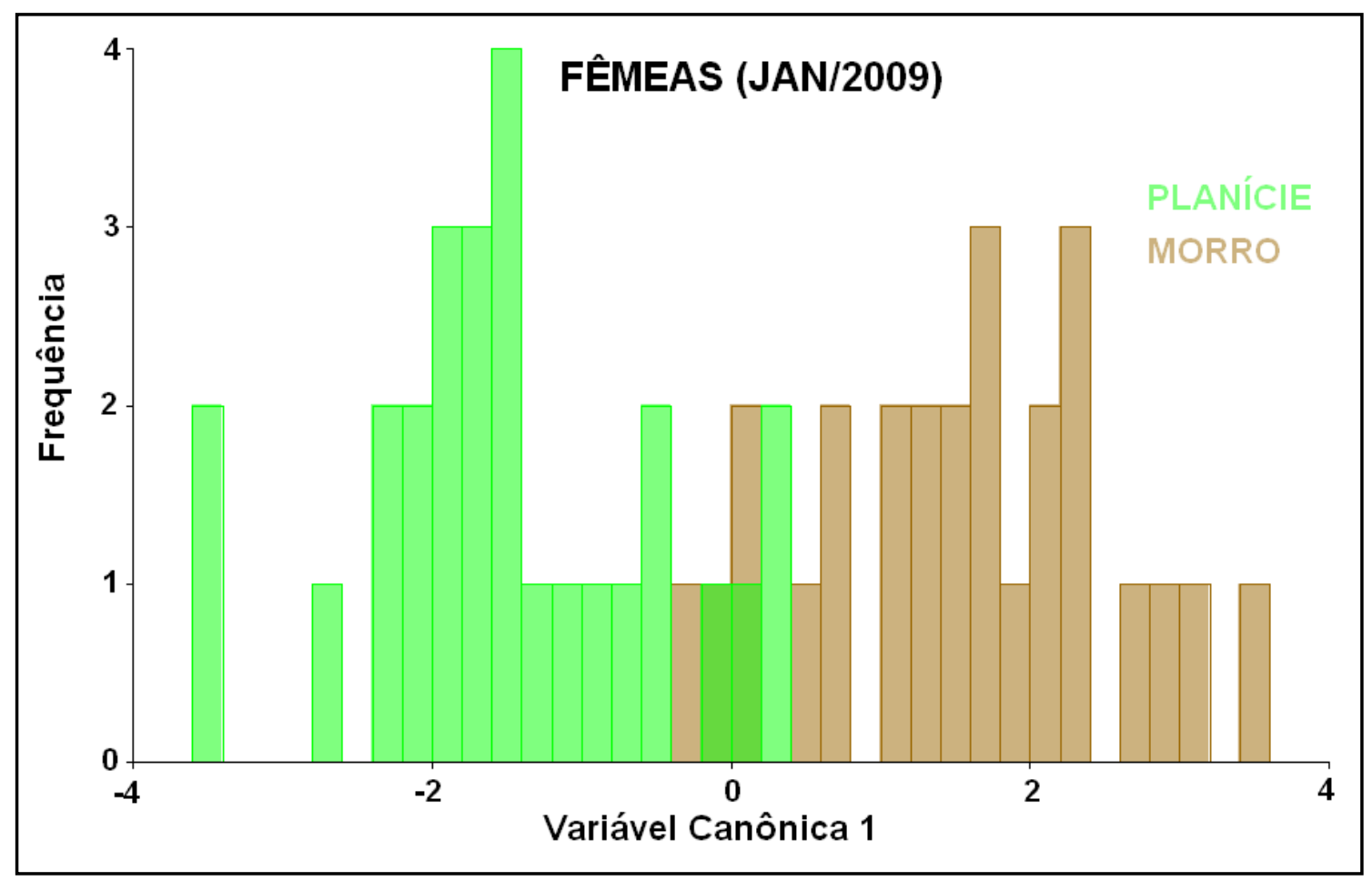

Figura 27 - Morfoespaço de variáveis canônicas geradas na comparação somente entre machos de An. cruzii em Janeiro/2009 nos dois microambientes: planície (verde) e morro (marrom).

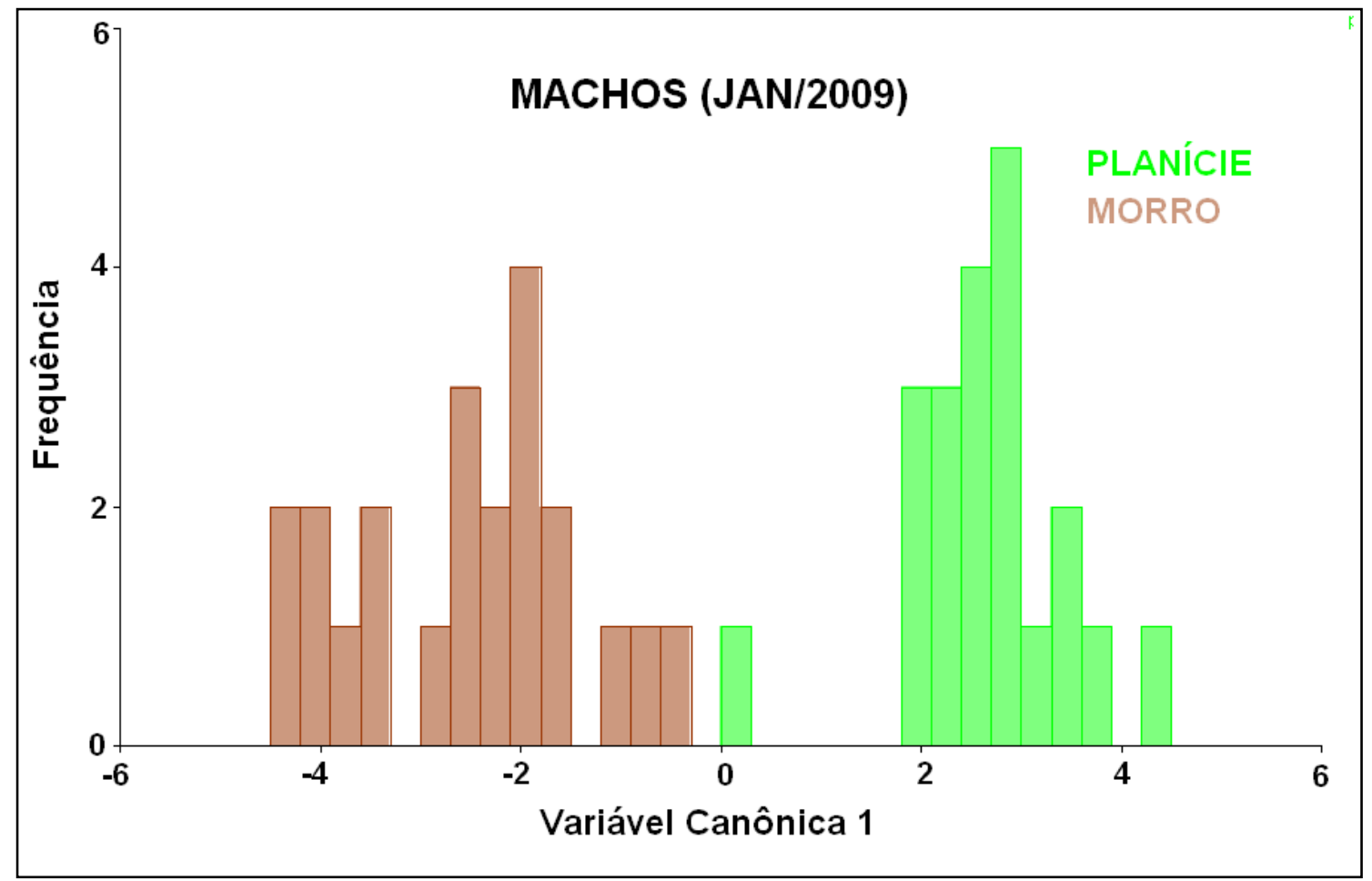


Analisando os consensos alares após a sobreposição de Procrustes foi possível comparar os extremos de diferenciação no formato alar de machos e fêmeas em cada ambiente, como observado na Figura 27. O Qst de forma foi de 0,29 e 0,25 para fêmeas e machos, respectivamente.

Figura 28 - Consensos alares alinhados de An. cruzii em Janeiro/2009 após sobreposição de Procrustes mostrando os extremos de diferenciação entre morro e planície de (a) fêmeas e (b) machos.

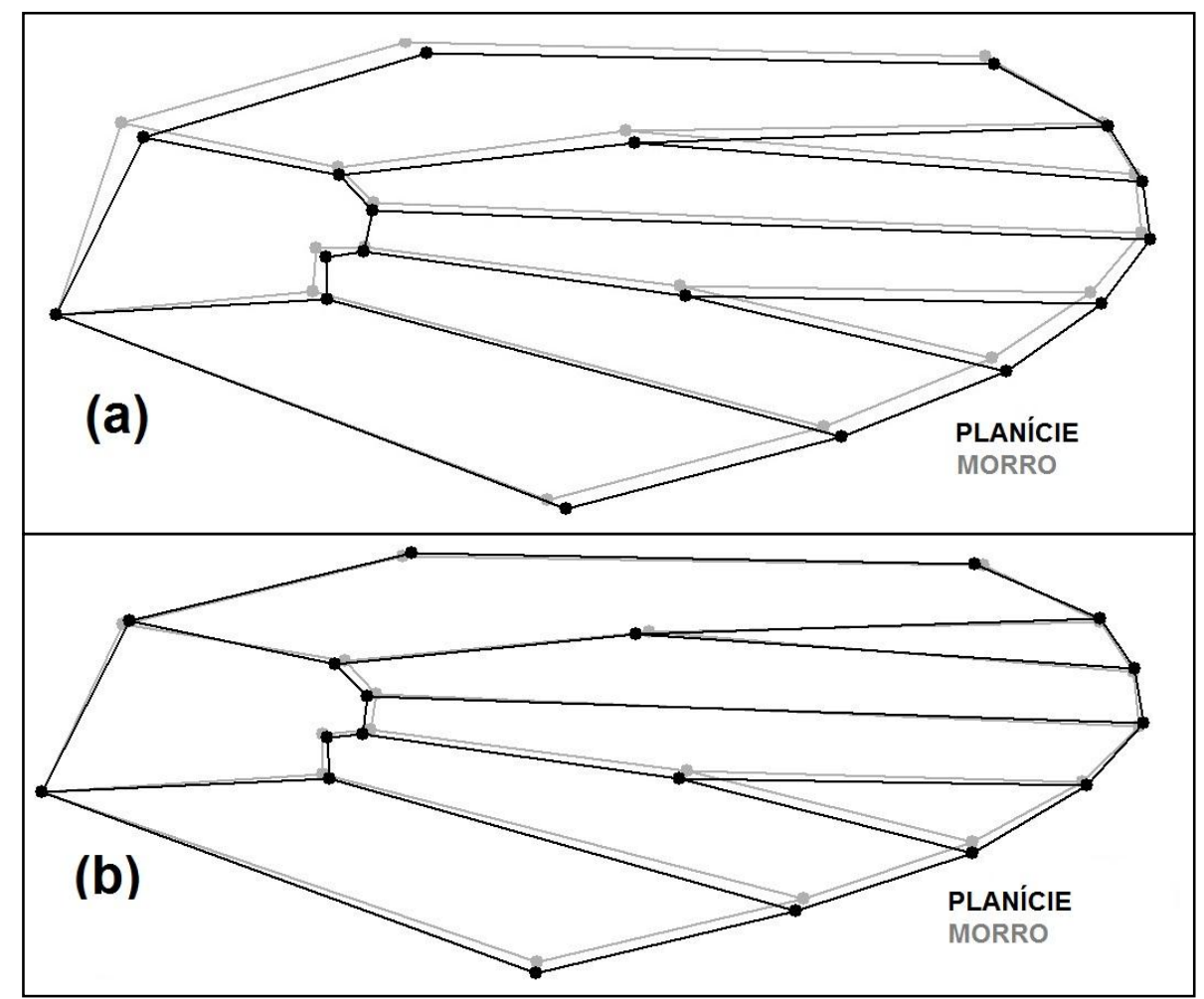

O tamanho dos indivíduos não foi significativamente diferente em nenhum dos microambientes, porém no morro machos e fêmeas são ligeiramente maiores. Também não houve dimorfismo sexual de tamanho entre eles (Figura 28). O Qst de tamanho foi de 0,34 para fêmeas e 0,40 para os machos. 
Figura 29 - Gráfico descritivo do tamanho dos centróides de machos e fêmeas de An. cruzii em Janeiro/2009 nos dois microambientes: planície e morro. Os valores do eixo Y estão em milímetros.

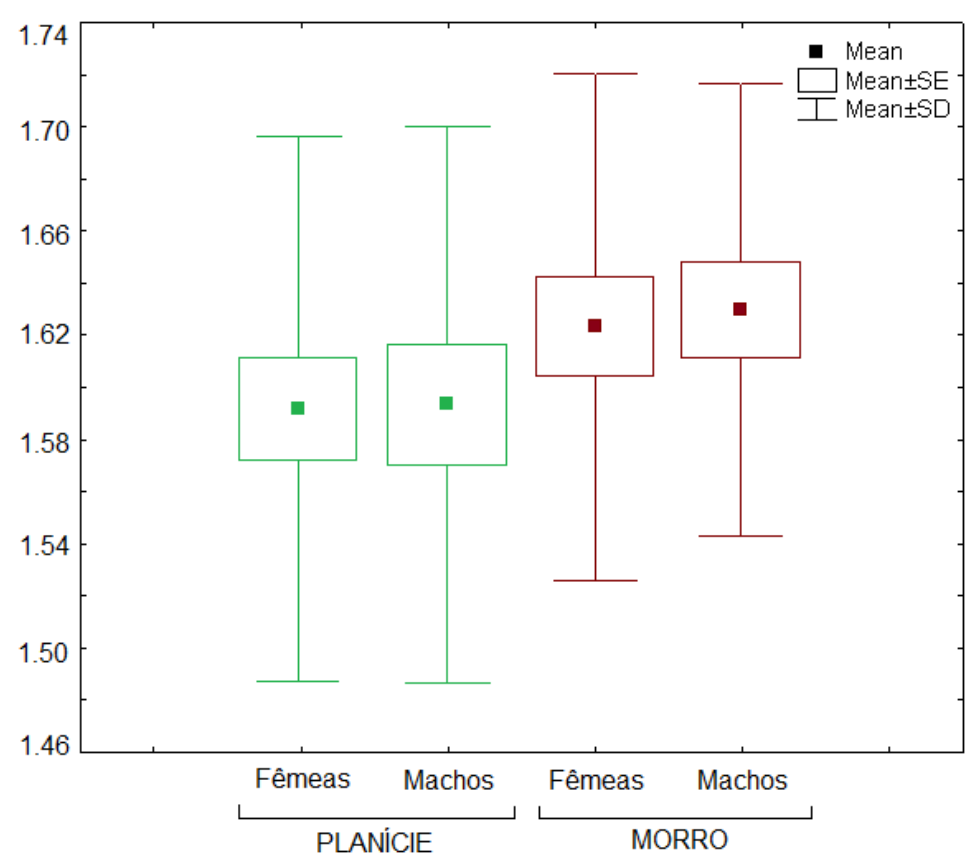

\subsubsection{Variações Altitudinais em Janeiro/2012}

\subsubsection{Morfometria Geométrica Alar}

Comparando os microambientes planície e morro de Janeiro/2012, nota-se também que os indivíduos apresentam uma diferenciação no formato alar. Após a CVA de machos e fêmeas aparecem dois grupos distintos no morfoespaço e é possível observar uma tênue separação entre os espécimes da planície e do morro (Figuras 29 e 30). O tamanho dos indivíduos de um modo geral não apresentou diferenças significativas, exceto comparando os machos do morro e da planície $(P<0,01 ;$ ANOVA, $F=5,62)$. Não houve dimorfismo sexual de tamanho nos dois microambientes (Figura 31). Analisando os consensos alares após a sobreposição de Procrustes foi possível comparar os extremos de diferenciação no formato alar de machos e fêmeas em cada ambiente. Alguns landmarks foram extremamente variáveis nas fêmeas, como observado na Figura 32. Os valores calculados de Qst em fêmeas foram de 0,25 para forma e 0,58 para tamanho; nos machos esses valores foram de 0,27 para forma e 0,91 para tamanho. 
Figura 30 - Morfoespaço de variáveis canônicas geradas na comparação somente entre fêmeas de An. cruzii em Janeiro/2012 nos dois microambientes: planície (verde) e morro (marrom).

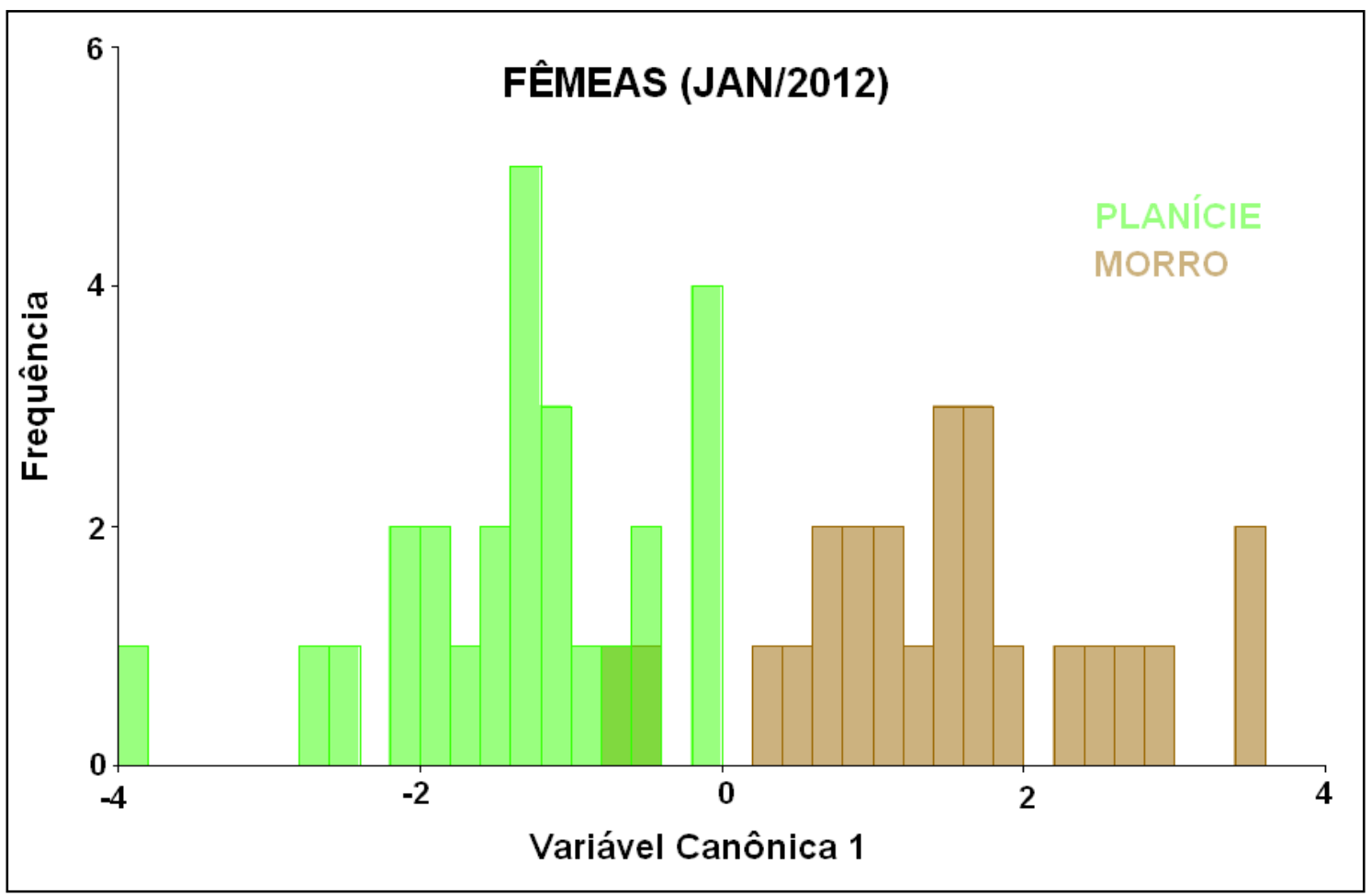

Figura 31 - Morfoespaço de variáveis canônicas geradas na comparação somente entre machos de An. cruzii em Janeiro/2012 nos dois microambientes: planície (verde) e morro (marrom).

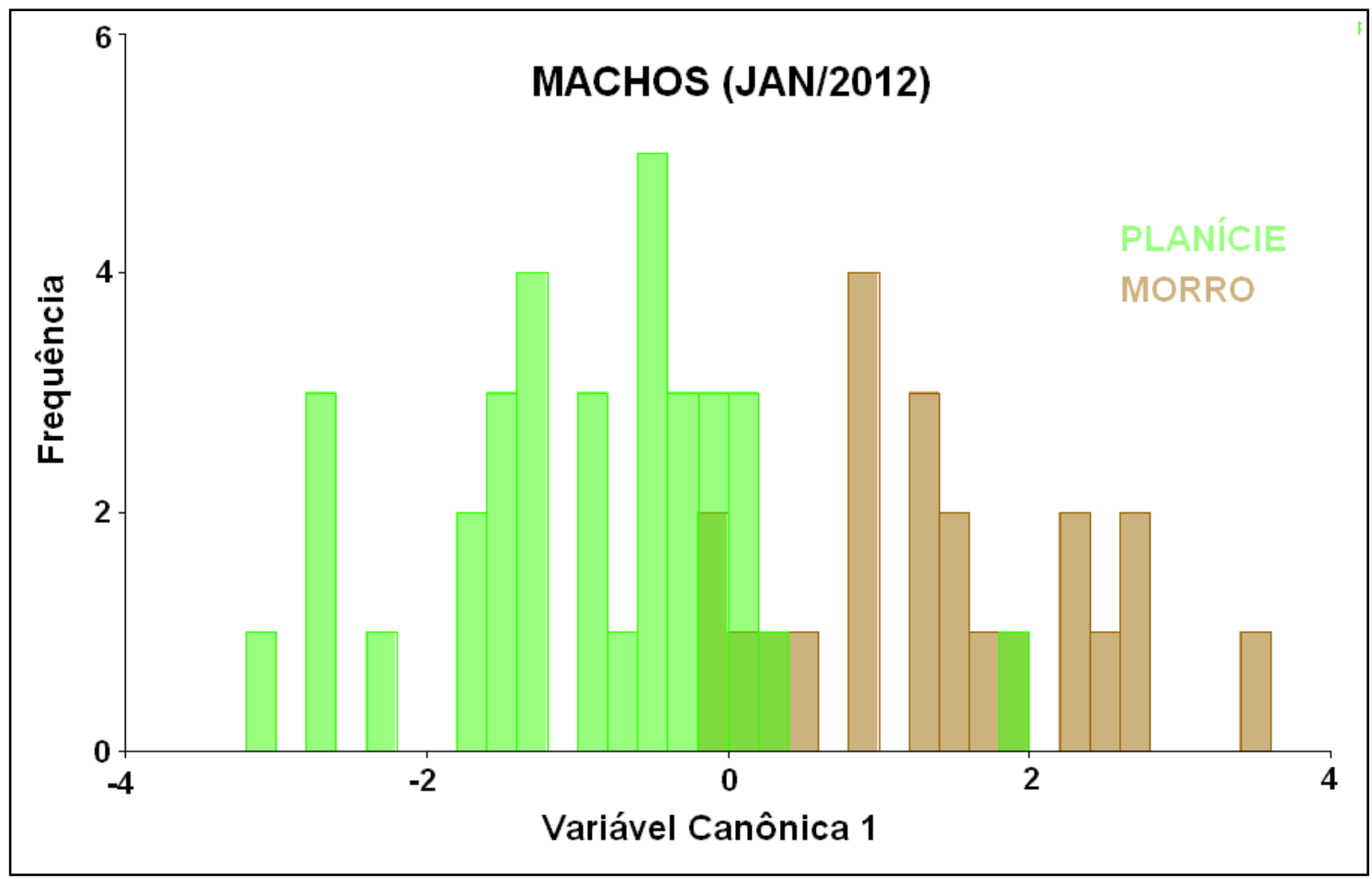


Figura 32 - Gráfico descritivo do tamanho dos centróides de machos e fêmeas de An. cruzii nos dois microambientes: planície e morro em Janeiro/2012. Os valores do eixo Y estão em milímetros.

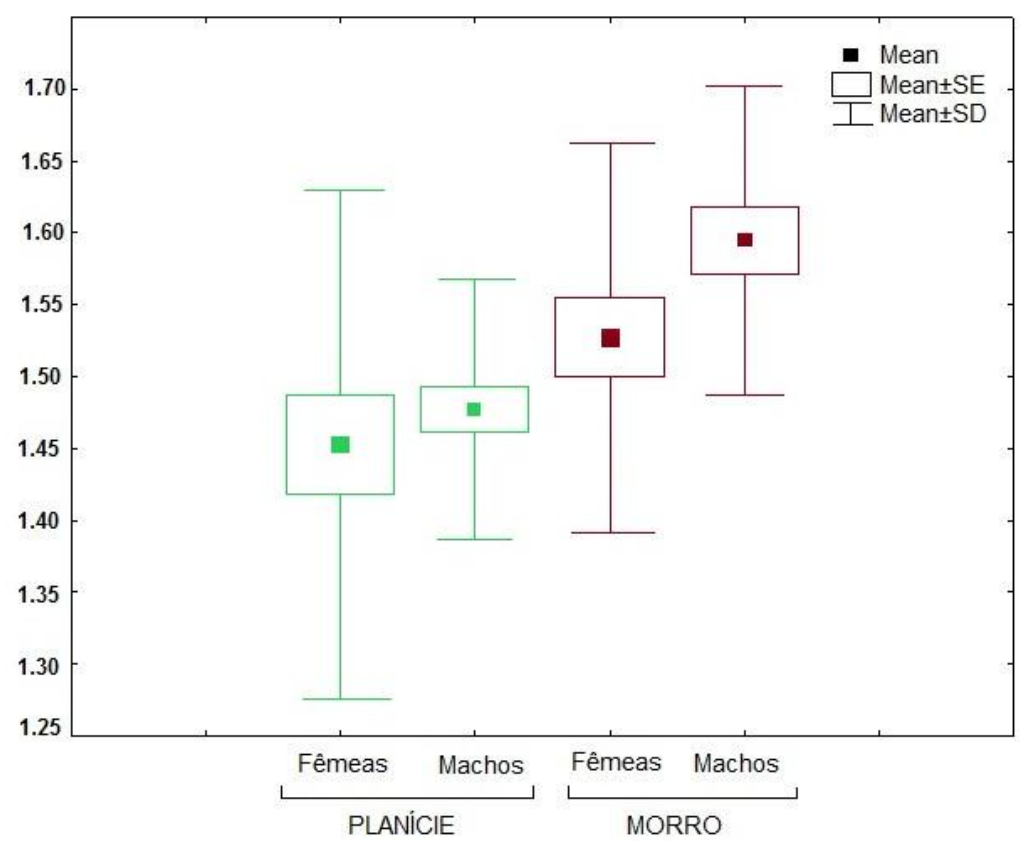

Figura 33 - Consensos alares alinhados de An. cruzii após sobreposição de Procrustes mostrando os extremos de diferenciação entre morro e planície de (a) fêmeas e (b) machos.

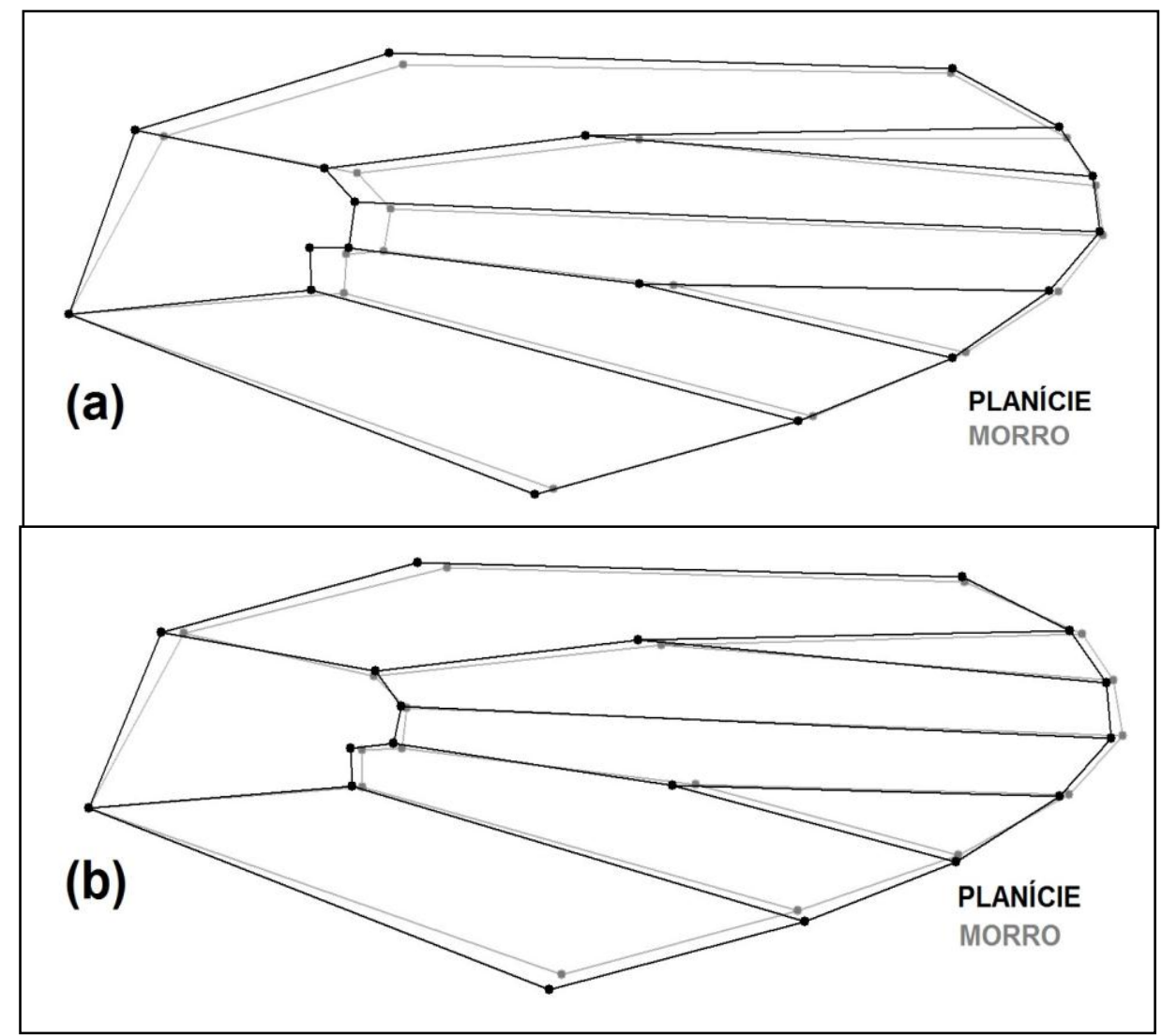




\subsubsection{Gene Mitocondrial CO-I}

Dos 46 espécimes amostrados em Janeiro/2012, 26 da planície e 20 do morro, foram encontrados 33 haplótipos diferentes, sendo que apenas um deles foi compartilhado entre os dois microambientes $(\mathrm{H}-26)$. A rede descritiva da similaridade entre os haplótipos está demonstrada na Figura 33.

Figura 34 - Rede de haplótipos de Anopheles cruzii mostrando a relação entre os indivíduos coletados na planície (verde) e morro (marrom) em Janeiro/2012. O tamanho dos círculos é proporcional ao número de indivíduos (o menor círculo equivale a um indivíduo). Os círculos amarelos são haplótipos intermediários hipotéticos. Os haplótipos em vermelho são os mesmos encontrados no verão.

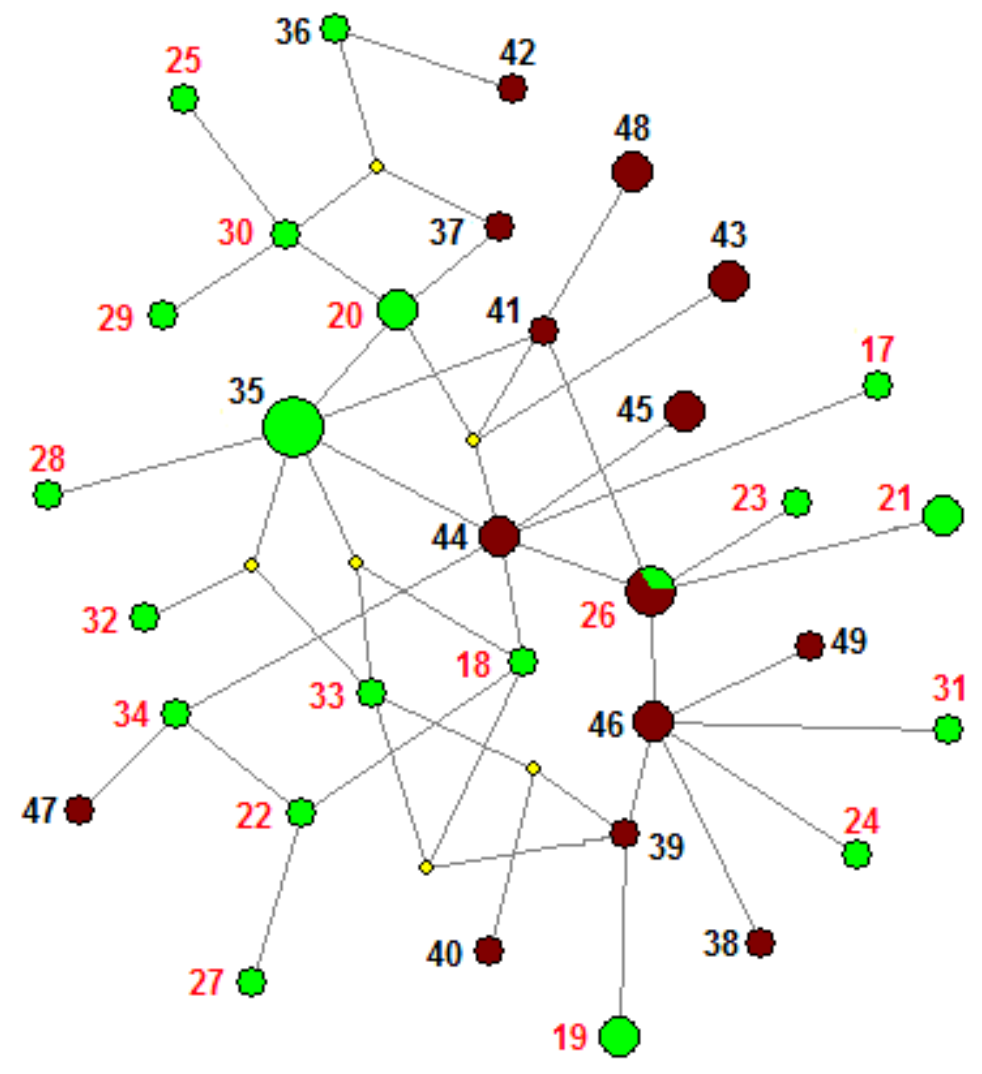

Os sítios variáveis em cada haplótipo estão apresentados no APÊNDICE B. O dendrograma de distância genética entre as haplótipos está demonstrado na Figura 34. Os dados genéticos como diversidade haplotípica e nucleotídica estão na Tabela 10; os valores dos testes de Tajima, Fu \& Li, Fst, $\phi s t, \mathrm{Nm}$ e a percentagem de diferença entre os haplótipos estão descritos na Tabela 11. Os valores de diferenciação genética intra e interpopulacional foram de $97,3 \%$ e 2,7\%, respectivamente. 
Figura 35 - Dendrograma de distância genética entre os haplótipos do morro $x$ planície encontrados em Anopheles cruzii em Janeiro/2012 construído pelo método Neighbor-joining (NJ). Os quadrados verdes indicam haplótipos encontrados na planície; os marrons indicam aqueles encontrados no morro; a seta aponta os haplótipos compartilhados entre as duas populações.

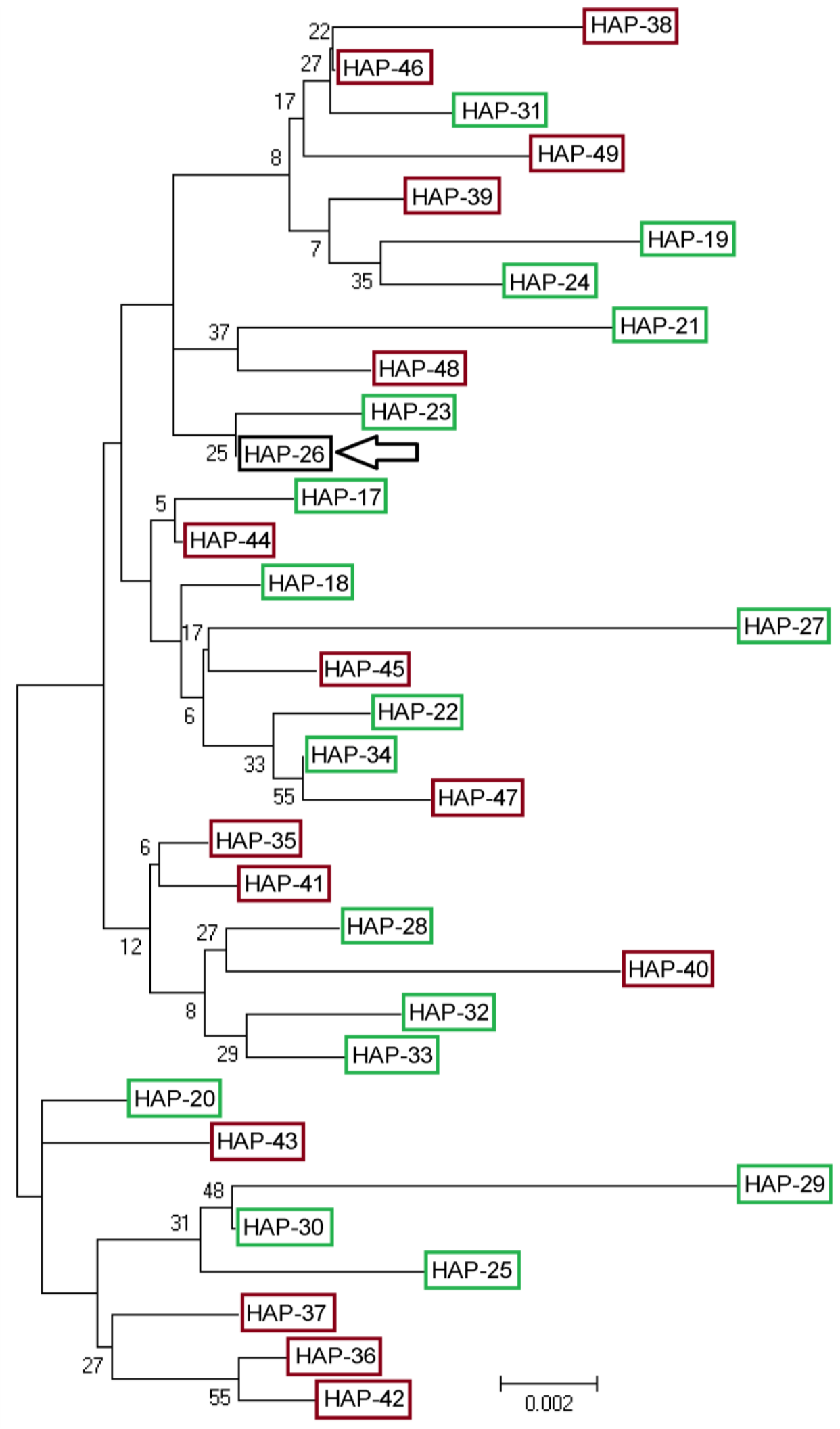


Tabela 9 - Dados genéticos da comparação Morro X Planície de Anopheles cruzii em Janeiro/2012.

\begin{tabular}{cccccc}
\hline Comparação & H/n & $\begin{array}{c}\mathbf{N}^{\circ} \text { Sítios } \\
\text { Polimórficos }\end{array}$ & Conteúdo A-T & $\mathbf{h}$ & $\boldsymbol{\pi}$ \\
\hline $\begin{array}{c}\text { Morro } \\
\mathbf{X} \\
\text { Planície }\end{array}$ & $33 / 46(1)$ & $26 / 390$ & $71,9 \%$ & 0,98 & 0,010 \\
\hline
\end{tabular}

$\mathrm{H}=$ número de haplótipos; $\mathrm{n}=$ número total de indivíduos; ()$=0$ número entre parênteses representa os haplótipos compartilhados entre as duas populações; $h=$ diversidade haplotípica; $\pi=$ diversidade nucleotídica.

Tabela 10 - Valores de diferenciação genética e número de migrantes da comparação Morro X Planície de Anopheles cruzii em Janeiro/2012.

\begin{tabular}{ccccccc}
\hline Comparação & $D_{T}$ & $\boldsymbol{F}$ & $\boldsymbol{\phi s t}$ & $\mathrm{Fst}$ & $\mathrm{Nm}$ & $\%$ Dif. \\
\hline $\begin{array}{c}\text { Morro } \\
\mathbf{X} \\
\text { Planície }\end{array}$ & $-1,024^{*}$ & $-1,29^{*}$ & $0,026^{*}$ & $0,03^{*}$ & 8,08 & 2,82 \\
\hline
\end{tabular}

$D T=$ teste de Tajima; $F=$ teste de $\mathrm{Fu} \& \mathrm{Li} ; \mathrm{Nm}=$ número de migrantes. $\% \mathrm{Dif}=\%$ de diferença entre os haplótipos mais distintos encontrados na população. * Valores significativos $(P<0,001)$

\subsubsection{Variações Altitudinais em Julho/2012}

\subsubsection{Morfometria Geométrica Alar}

Em Julho/2012 os indivíduos do morro e da planície também apresentaram uma diferenciação no formato alar. Após a CVA de machos e fêmeas aparecem dois grupos distintos no morfoespaço e é possível observar uma separação entre os espécimes da planície e do morro (Figuras 35 e 36). O tamanho dos indivíduos divergiu significativamente entre os dois ambientes $(P<0,01$; ANOVA, $F=6,34)$, sendo que no morro foi maior. Entretanto não houve dimorfismo sexual de tamanho nos dois microambientes (Figura 37). Analisando os consensos alares após a sobreposição de Procrustes foi possível comparar os extremos de diferenciação no formato alar de machos e fêmeas. Alguns landmarks foram extremamente variáveis nas fêmeas, como observado na Figura 38. O Qst em fêmeas foi 0,28 para forma e 0,87 para tamanho; nos machos 0,31 para forma e 0,75 para tamanho. 
Figura 36 - Morfoespaço de variáveis canônicas geradas na comparação somente entre fêmeas de An. cruzii em Julho/2012 nos dois microambientes: planície (verde) e morro (marrom).

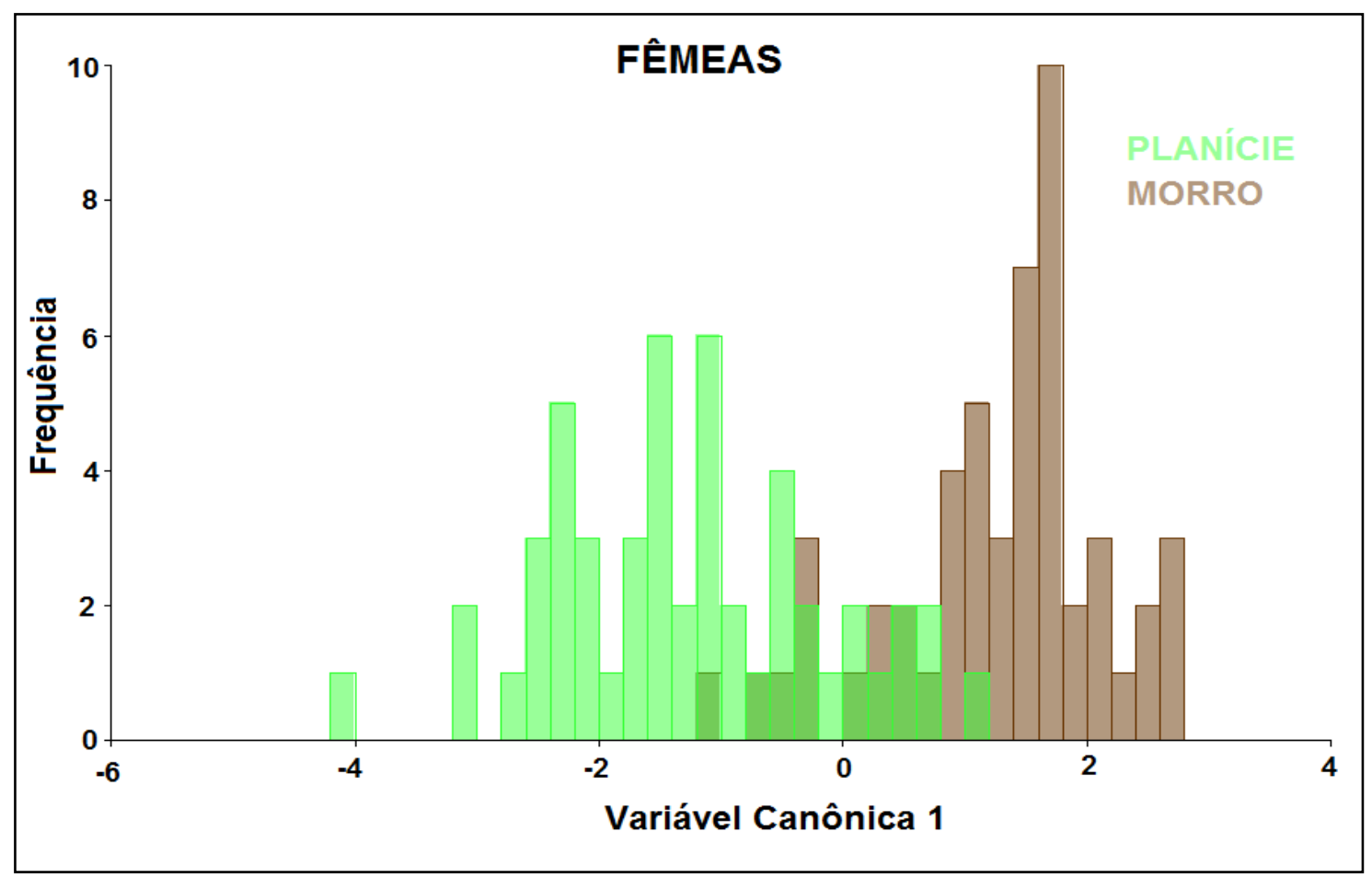

Figura 37 - Morfoespaço de variáveis canônicas geradas na comparação somente entre machos de An. cruzii em Julho/2012 nos dois microambientes: planície (verde) e morro (marrom).

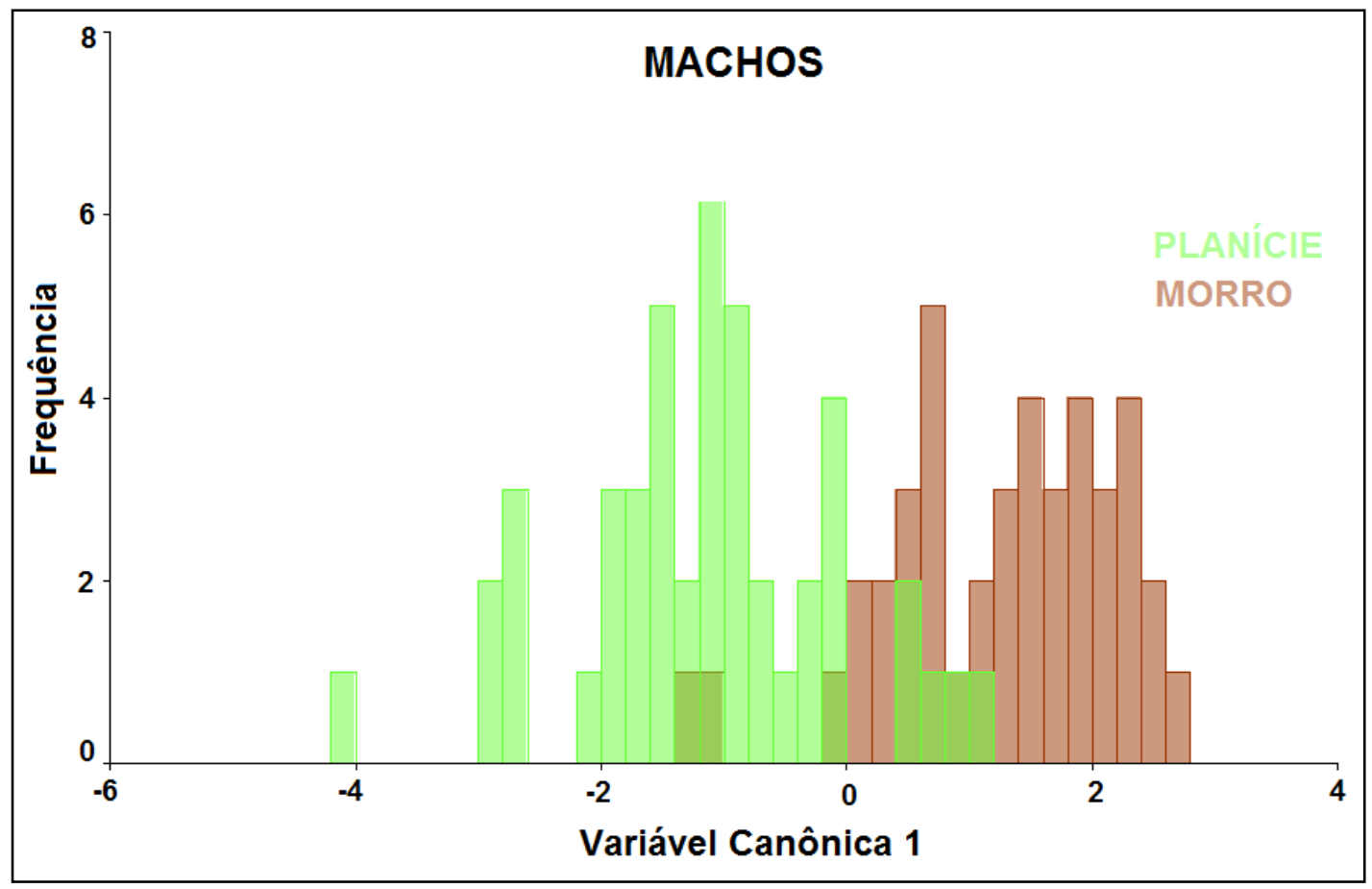


Figura 38 - Gráfico descritivo do tamanho dos centróides de machos e fêmeas de An. cruzii em Julho/2012 nos dois microambientes: planície e morro. Os valores do eixo Y estão em milímetros

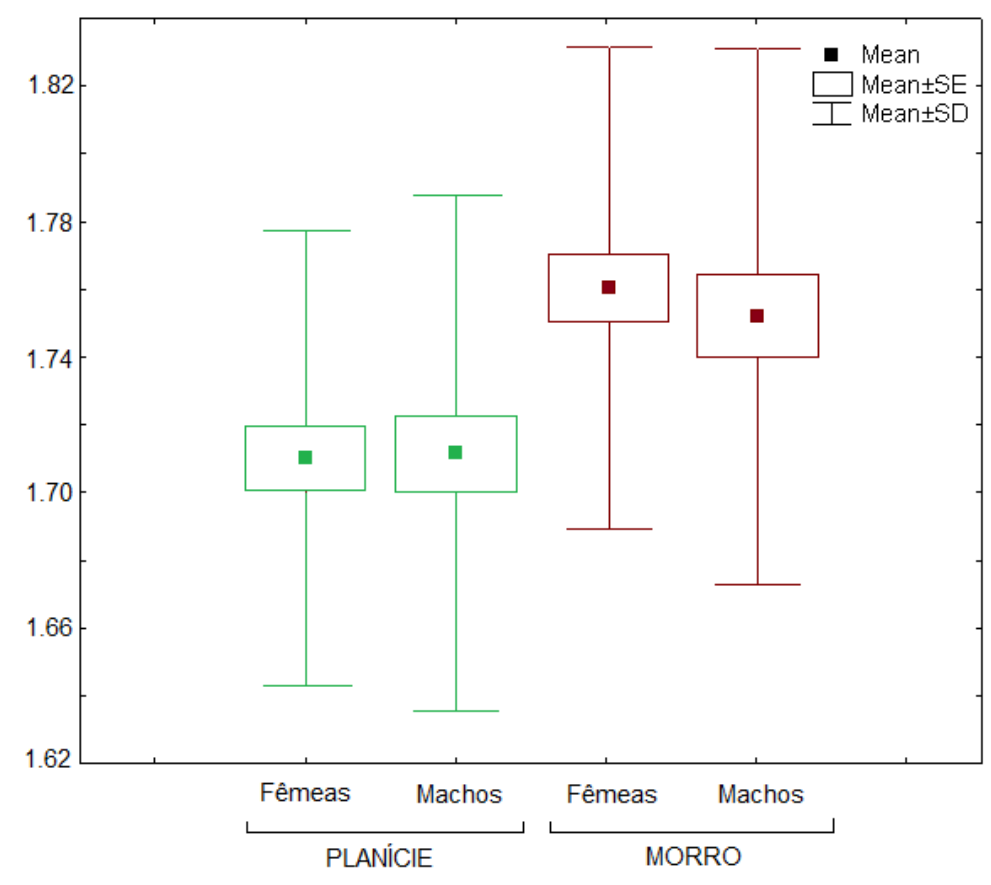

Figura 39 - Consensos alares alinhados de An. cruzii após sobreposição de Procrustes mostrando os extremos de diferenciação entre morro e planície de (a) fêmeas e (b) machos.

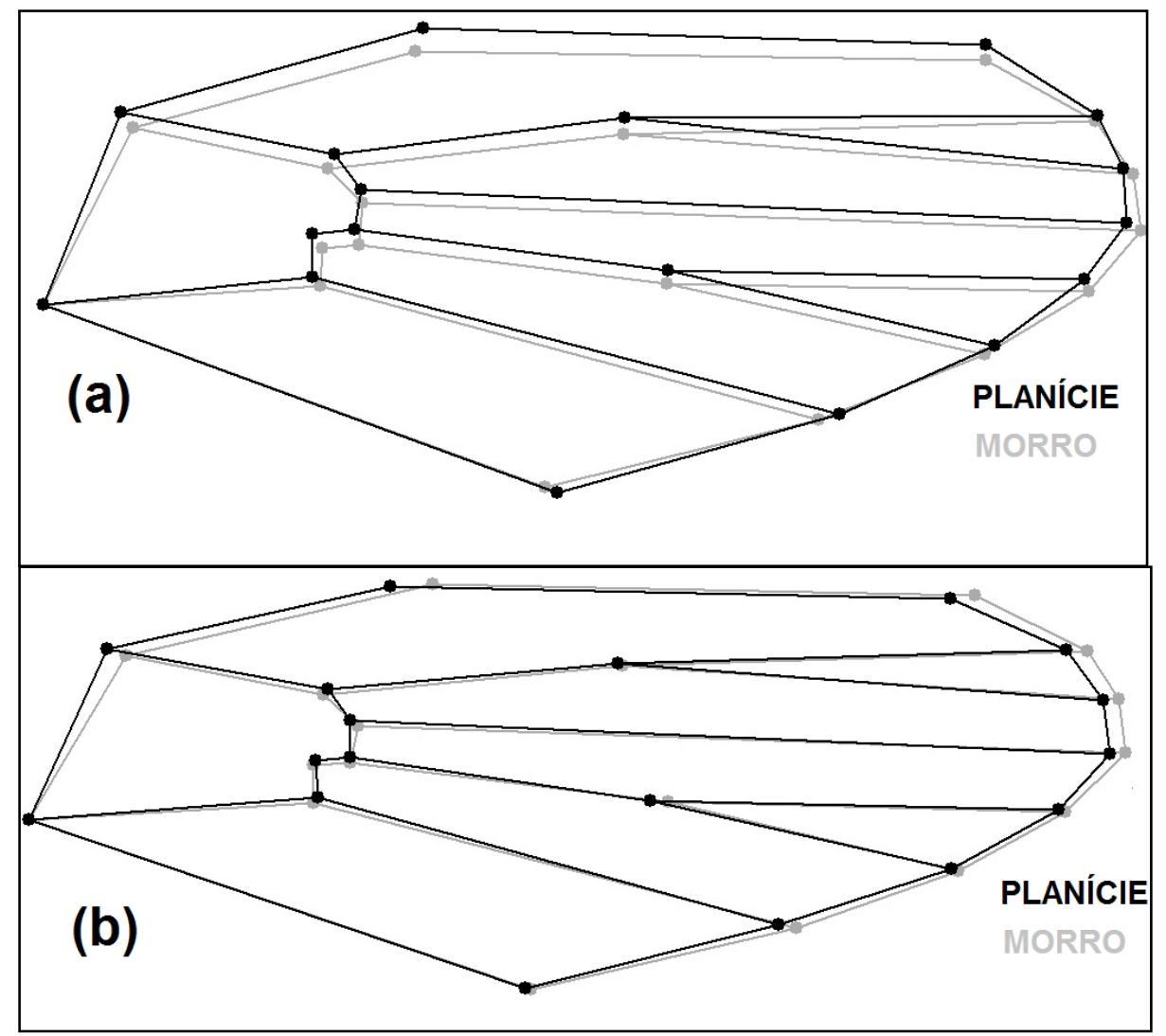




\subsubsection{Gene Mitocondrial CO-I}

Dos 42 espécimes amostrados em Julho/2012, 21 da planície e 21 do morro, foram encontrados 23 haplótipos diferentes, sendo que apenas um deles foi compartilhado entre os dois microambientes $(\mathrm{H}-58)$. A rede descritiva da similaridade entre os haplótipos está demonstrada na Figura 39.

Figura 40 - Rede de haplótipos de Anopheles cruzii mostrando a relação entre os indivíduos coletados na planície (verde) e morro (marrom) em Julho/2012. O tamanho dos círculos é proporcional ao número de indivíduos (o menor círculo equivale a um indivíduo). Os círculos amarelos são haplótipos intermediários hipotéticos.

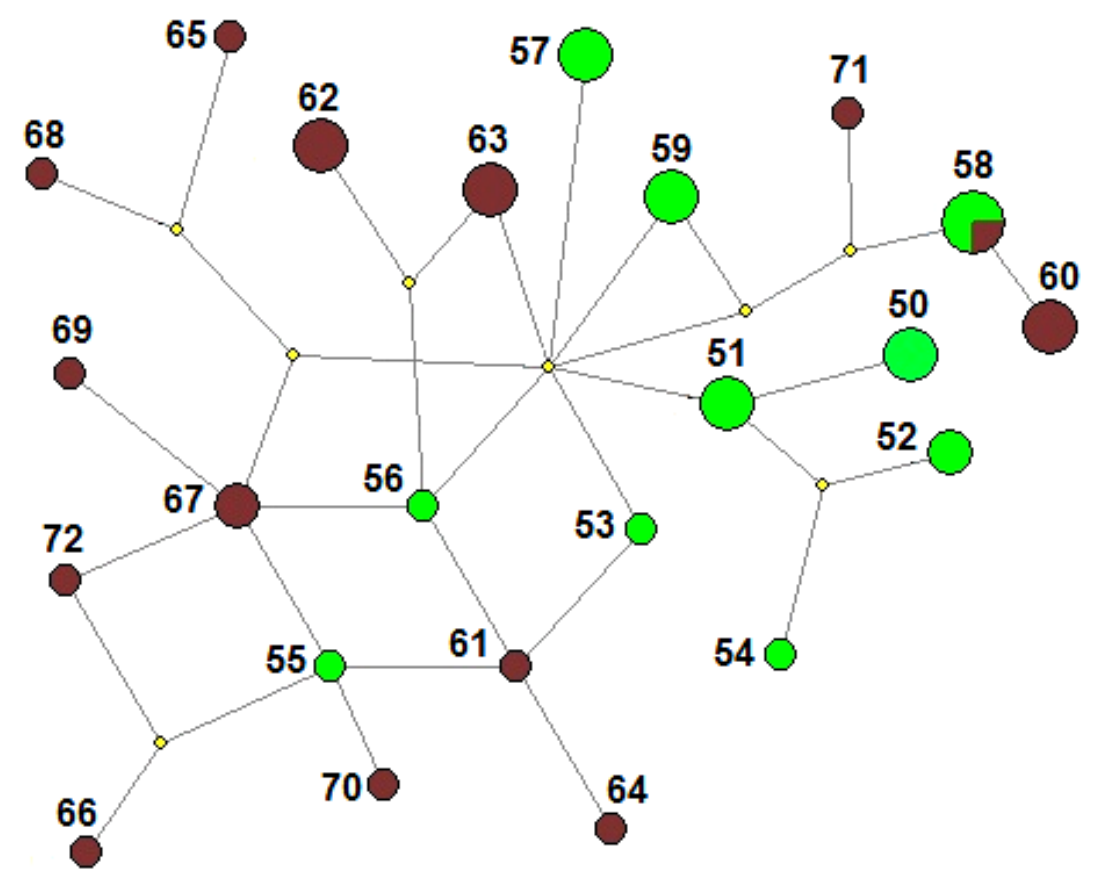

Os sítios variáveis em cada haplótipo estão apresentados no APÊNDICE B. O dendrograma de distância genética entre as haplótipos está demonstrado na Figura 40. Os dados genéticos como diversidade haplotípica e nucleotídica estão na Tabela 12; os valores dos testes de Tajima, Fu \& Li, Fst, $\phi s t, \mathrm{Nm}$ e a percentagem de diferença entre os haplótipos estão descritos na Tabela 13. A diferenciação genética dentro da população foi de $79,6 \%$; entre as populações de morro e planície foi de $20,4 \%$. 
Figura 41 - Dendrograma de distância genética entre os haplótipos do morro $\mathrm{x}$ planície encontrados em Anopheles cruzii em Julho/2012 construído pelo método Neighbor-joining (NJ). Os quadrados verdes indicam haplótipos encontrados na planície; os marrons indicam aqueles encontrados no morro; a seta aponta os haplótipos compartilhados entre as duas populações.

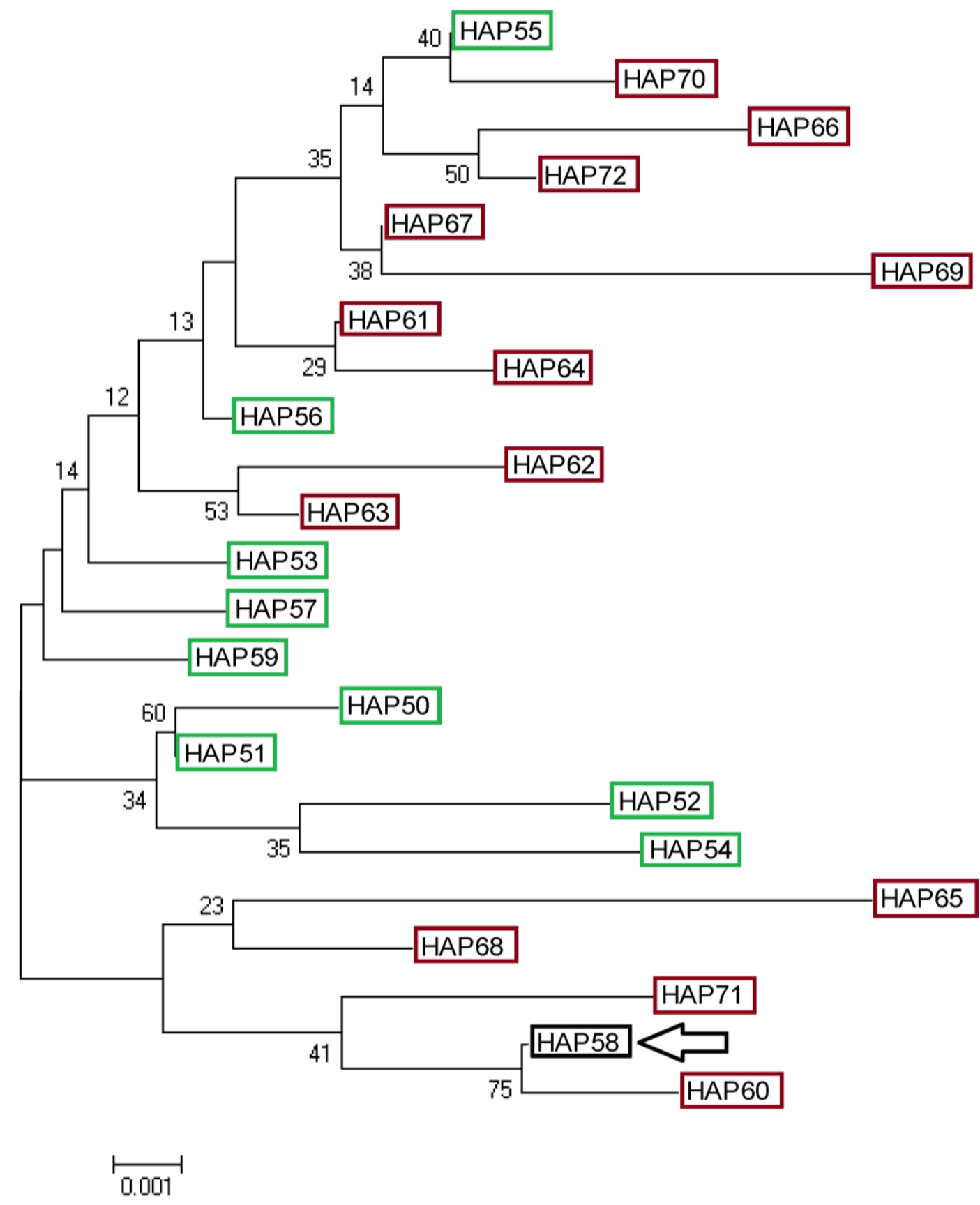


Tabela 11 - Dados genéticos da comparação Morro X Planície de Anopheles cruzii em Julho/2012.

\begin{tabular}{cccccc}
\hline Comparação & $\mathbf{H} / \mathbf{n}$ & $\begin{array}{c}\mathbf{N}^{\circ} \text { Sítios } \\
\text { Polimórficos }\end{array}$ & Conteúdo A-T & h & $\mathbf{\pi}$ \\
\hline $\begin{array}{c}\text { Morro } \\
\mathbf{X} \\
\text { Planície }\end{array}$ & $23 / 42(1)$ & $23 / 421$ & $70,9 \%$ & 0,97 & 0,010 \\
\hline
\end{tabular}

$\mathrm{H}=$ número de haplótipos; $\mathrm{n}=$ número total de indivíduos; ()$=0$ número entre parênteses representa os haplótipos compartilhados entre as duas populações; $h=$ diversidade haplotípica; $\pi=$ diversidade nucleotídica.

Tabela 12 - Valores de diferenciação genética e número de migrantes da comparação Morro X Planície de Anopheles cruzii em Julho/2012.

\begin{tabular}{ccccccc}
\hline Comparação & $\boldsymbol{D}_{\boldsymbol{T}}$ & $\boldsymbol{F}$ & $\boldsymbol{\phi s t}$ & Fst & Nm & \% Dif. \\
\hline $\begin{array}{c}\text { Morro } \\
\mathbf{X} \\
\text { Planície }\end{array}$ & $-0,635$ & $-1,32$ & $0,121^{*}$ & $0,125^{*}$ & 1,67 & 2,14 \\
\hline
\end{tabular}

$D T=$ teste de Tajima; $F=$ teste de Fu \& Li; $N m=$ número de migrantes. \%Dif= \% de diferença entre os haplótipos mais distintos encontrados na população. * Valores significativos $(P<0,001)$

\subsection{Variações Temporais - 2009 x 2012}

\subsubsection{Variações Temporais em Anopheles cruzii}

Foram realizadas análises temporais no morro e na planície para An. cruzii, pois esses dois microambientes apresentam alto grau de diferenciação (como visto anteriormente) e devem ser analisados de forma separada. Foram realizadas apenas análises morfológicas nestas comparações pela ausência de DNA das populações de 2009.

\subsubsection{Variações temporais no microambiente morro}

Ao realizar a CVA foi possível evidenciar em machos e fêmeas uma separação dos grupos de 2009 e 2012 no morfoespaço, com nenhuma sobreposição entre eles (Figuras 41 e 42). $O$ tamanho do centróide das fêmeas nesses dois anos divergiu de maneira significativa $(\mathrm{P}<0,05 ;$ ANOVA, $F=4,44)$. Os demais não apresentaram diferenças consideráveis (Figura 43). 
Figura 42 - Morfoespaço de variáveis canônicas geradas na comparação somente entre fêmeas de An. cruzii do morro nos dois períodos: 2009 (cinza) e 2012 (amarelo).

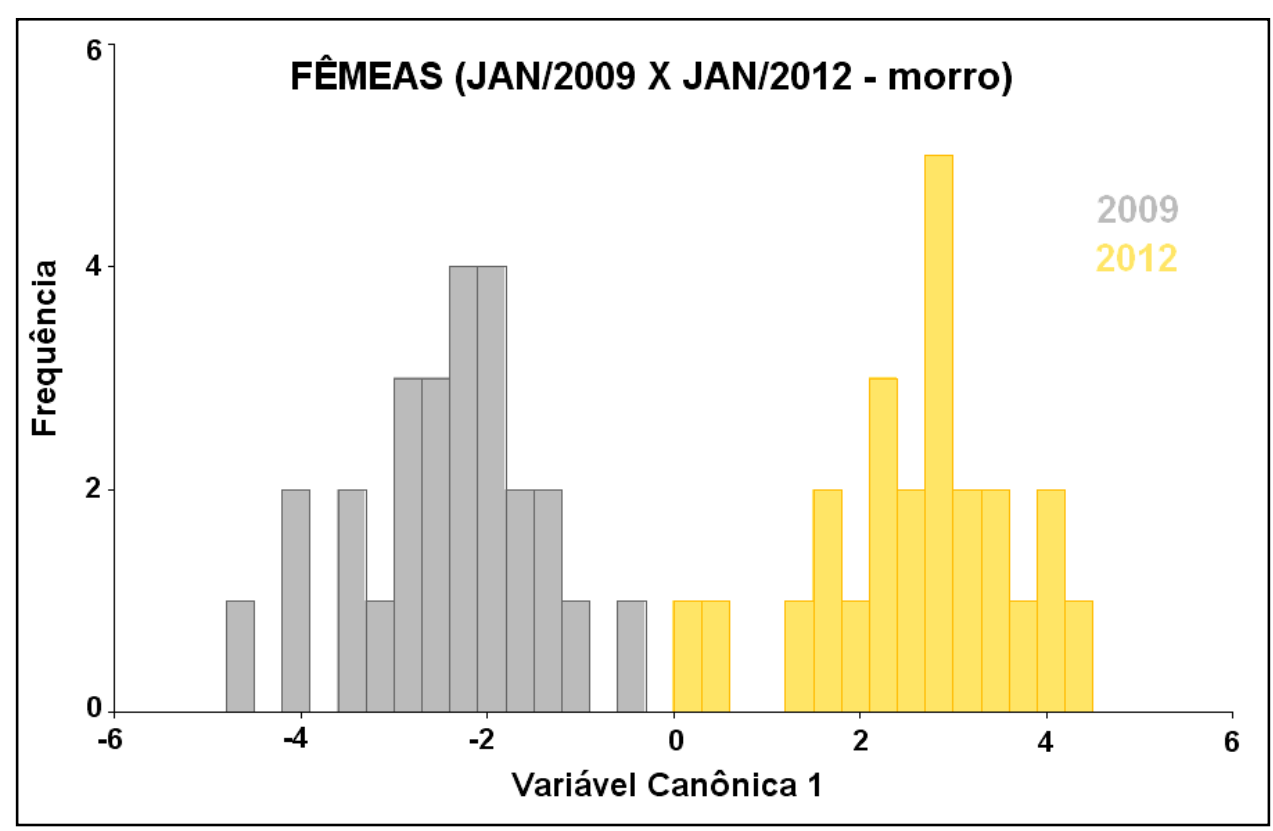

Figura 43 - Morfoespaço de variáveis canônicas geradas na comparação somente entre machos de An. cruzii do morro nos dois períodos: 2009 (cinza) e 2012 (amarelo).

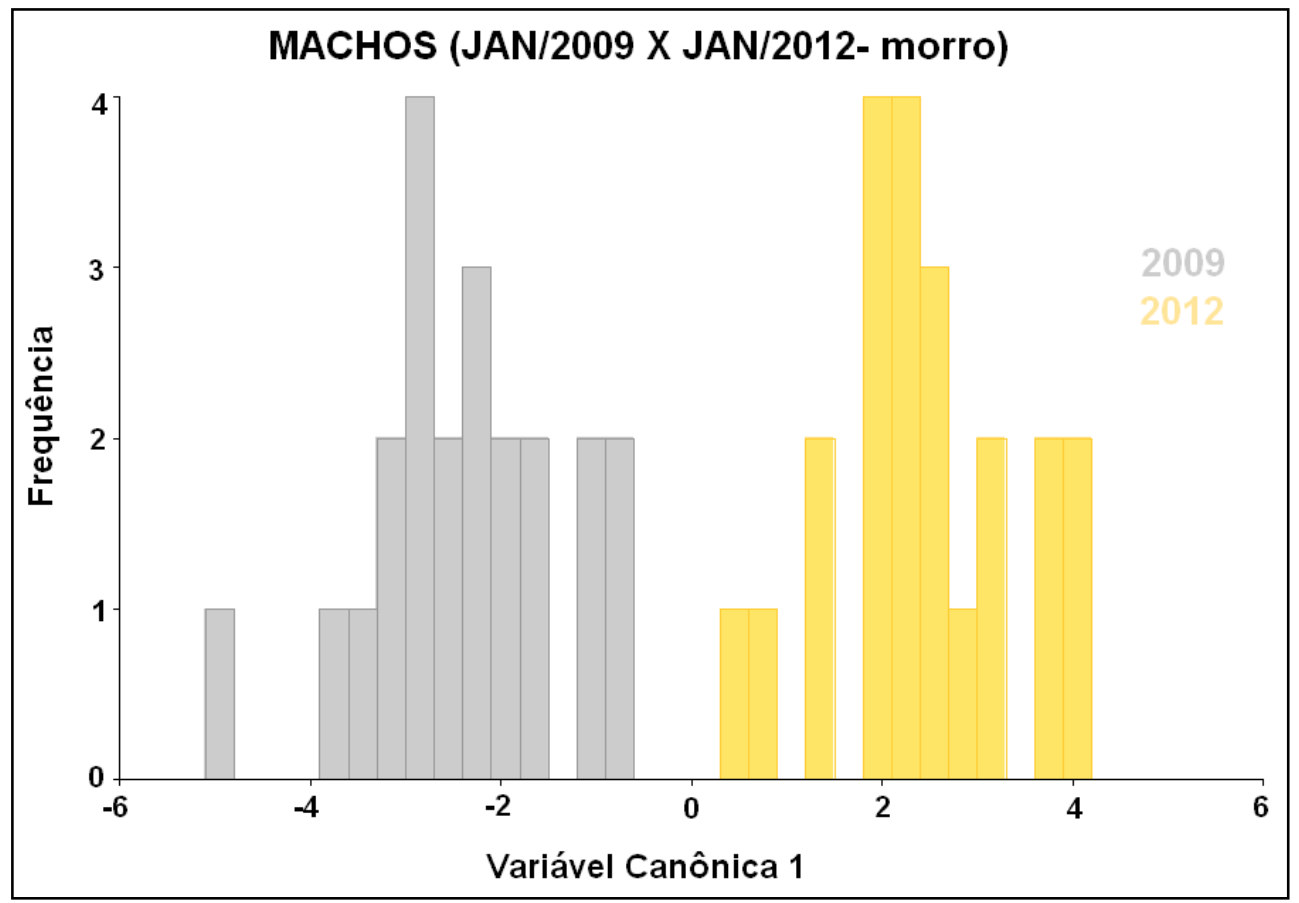


Figura 44 - Gráfico descritivo do tamanho dos centróides de machos e fêmeas do morro nos dois períodos: 2009 e 2012. Os valores do eixo Y estão em milímetros.

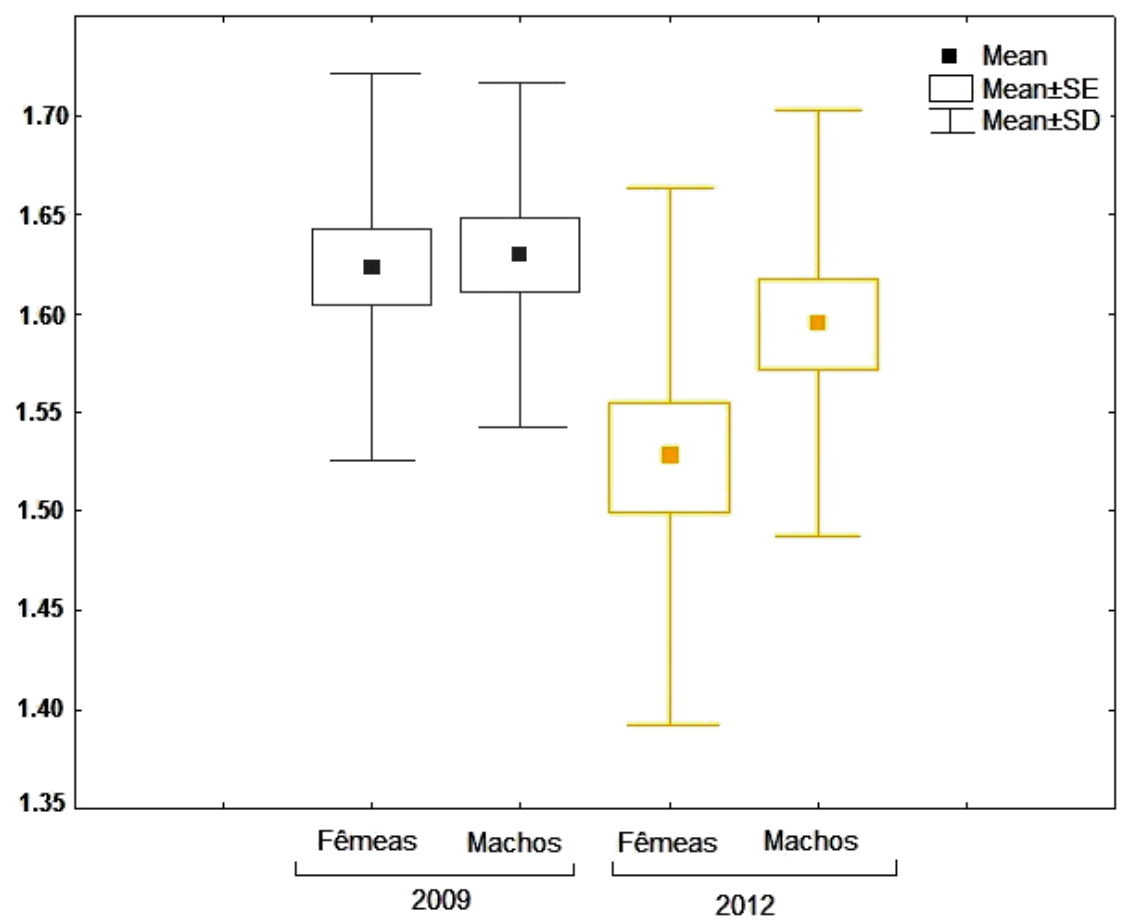

Comparando os extremos de diferenciação em cada ano, as fêmeas mostraram uma maior variabilidade nos landmarks (Figura 44) no alinhamento após a sobreposição de Procrustes. 
Figura 45 - Consensos alares alinhados de An. cruzii após sobreposição de Procrustes mostrando os extremos de diferenciação no morro entre os anos de 2009 e 2012 de (a) fêmeas e (b) machos.

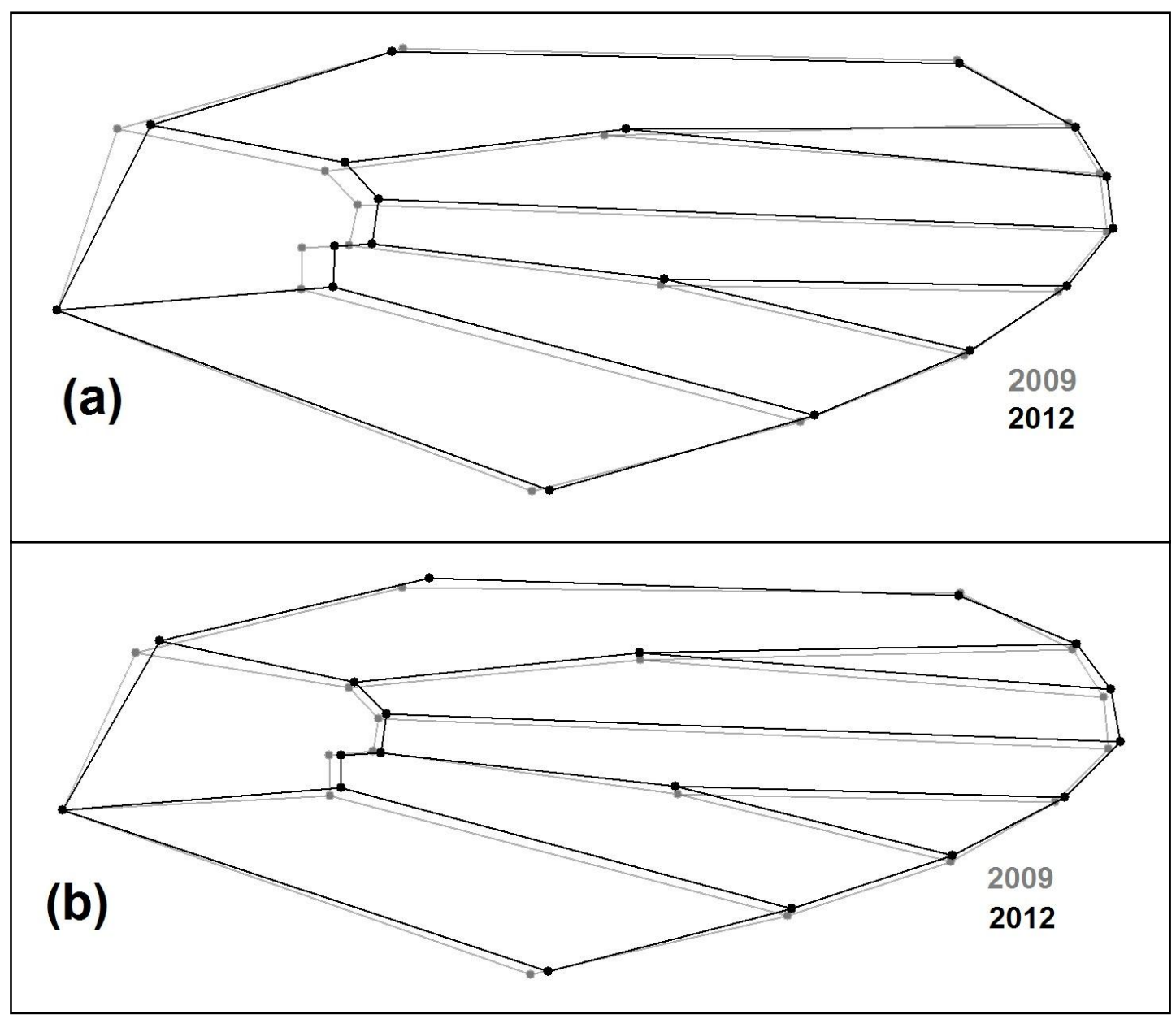

\subsubsection{Variações temporais no microambiente planície}

No ambiente de planície os indivíduos também apresentaram uma diferenciação acentuada no morfoespaço. Tanto machos quanto fêmeas dos períodos de 2009 e 2012 ficaram agrupados em conjuntos bem separados, evidenciando mais uma vez a microevolução no formato alar. Os espécimes coletados nos anos de 2009 e 2012 parecem seguir um padrão de diferenciação, não apresentando nenhuma sobreposição entre eles (Figuras 45 e 46). 
Figura 46 - Morfoespaço de variáveis canônicas geradas na comparação somente entre fêmeas de An. cruzii da planície nos dois períodos: 2009 (cinza) e 2012 (amarelo).

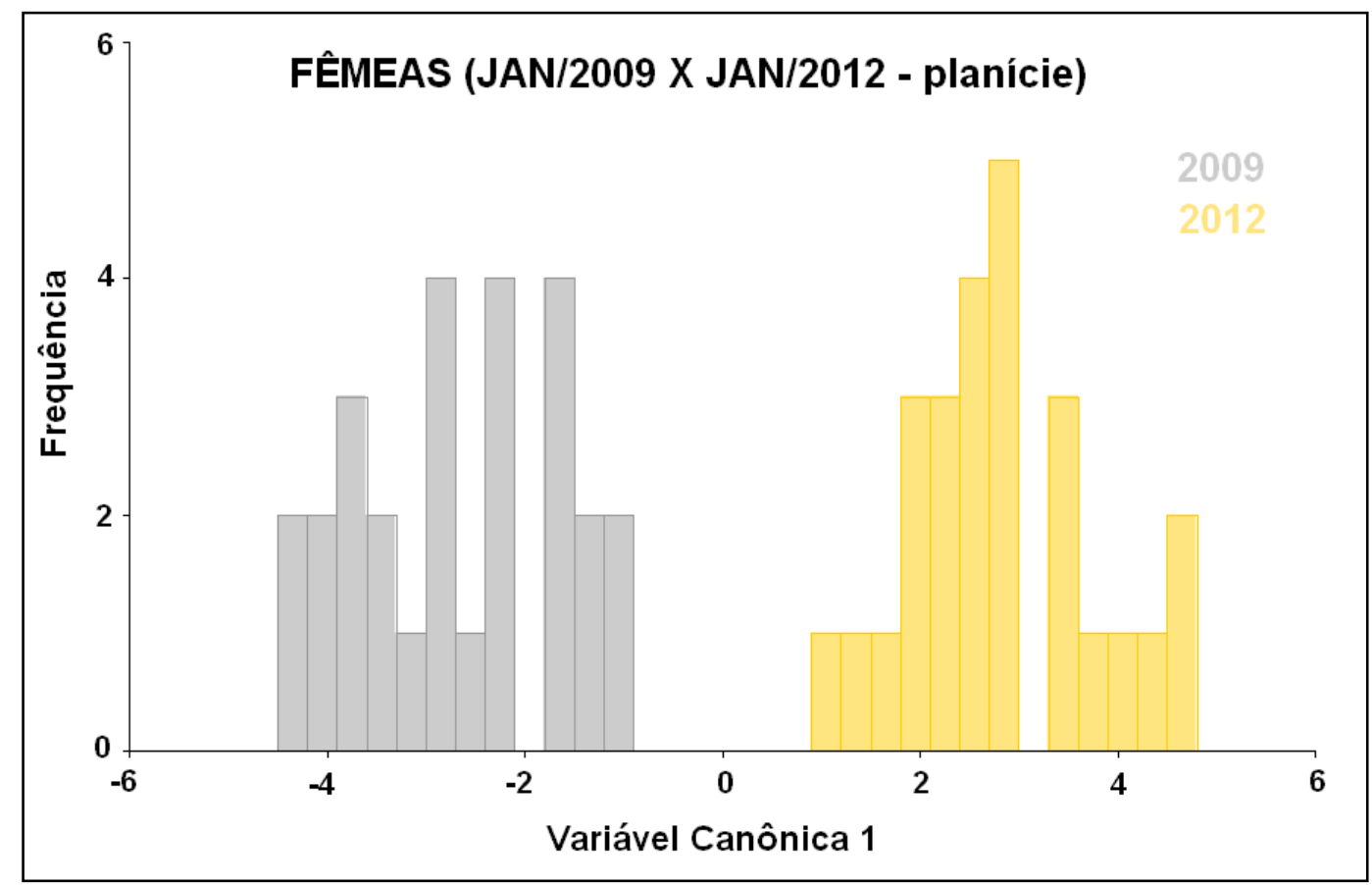

Figura 47 - Morfoespaço de variáveis canônicas geradas na comparação somente entre machos de An. cruzii da planície nos dois períodos: 2009 (cinza) e 2012 (amarelo).

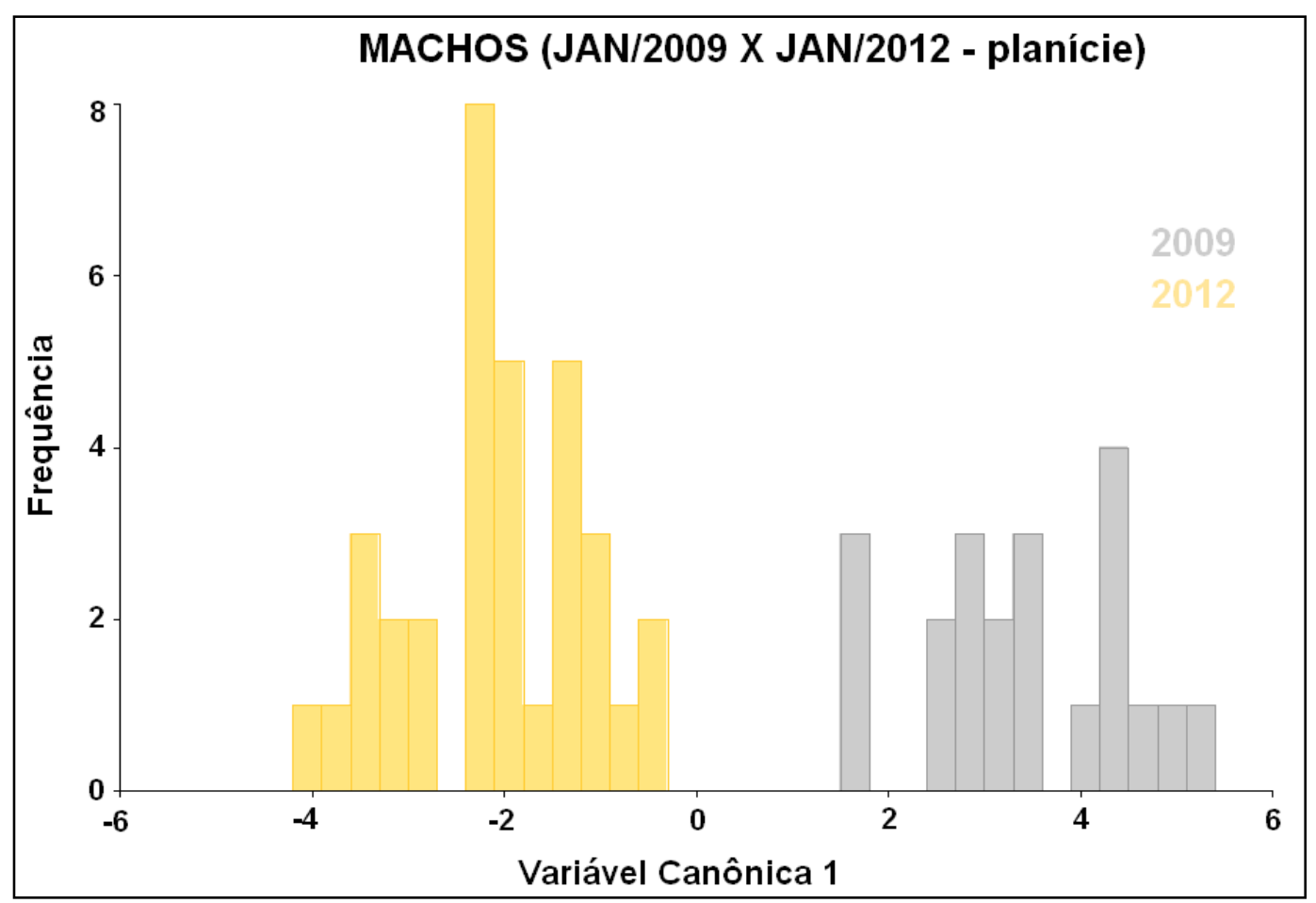


O tamanho do centróide entre machos e fêmeas do mesmo ano não apresentou diferenças consideráveis, mas comparando os grupos de 2009 e 2012 esses valores foram significativos, sendo o maior deles entre fêmeas $(P<0,001$; ANOVA, $F=9,66$ ) (Figura 47). Há uma tendência de diminuição do tamanho alar em ambos os sexos nesses dois anos.

Figura 48 - Gráfico descritivo do tamanho dos centróides de machos e fêmeas de An. cruzii do morro nos dois períodos: 2009 e 2012. Os valores do eixo Y estão em milímetros.

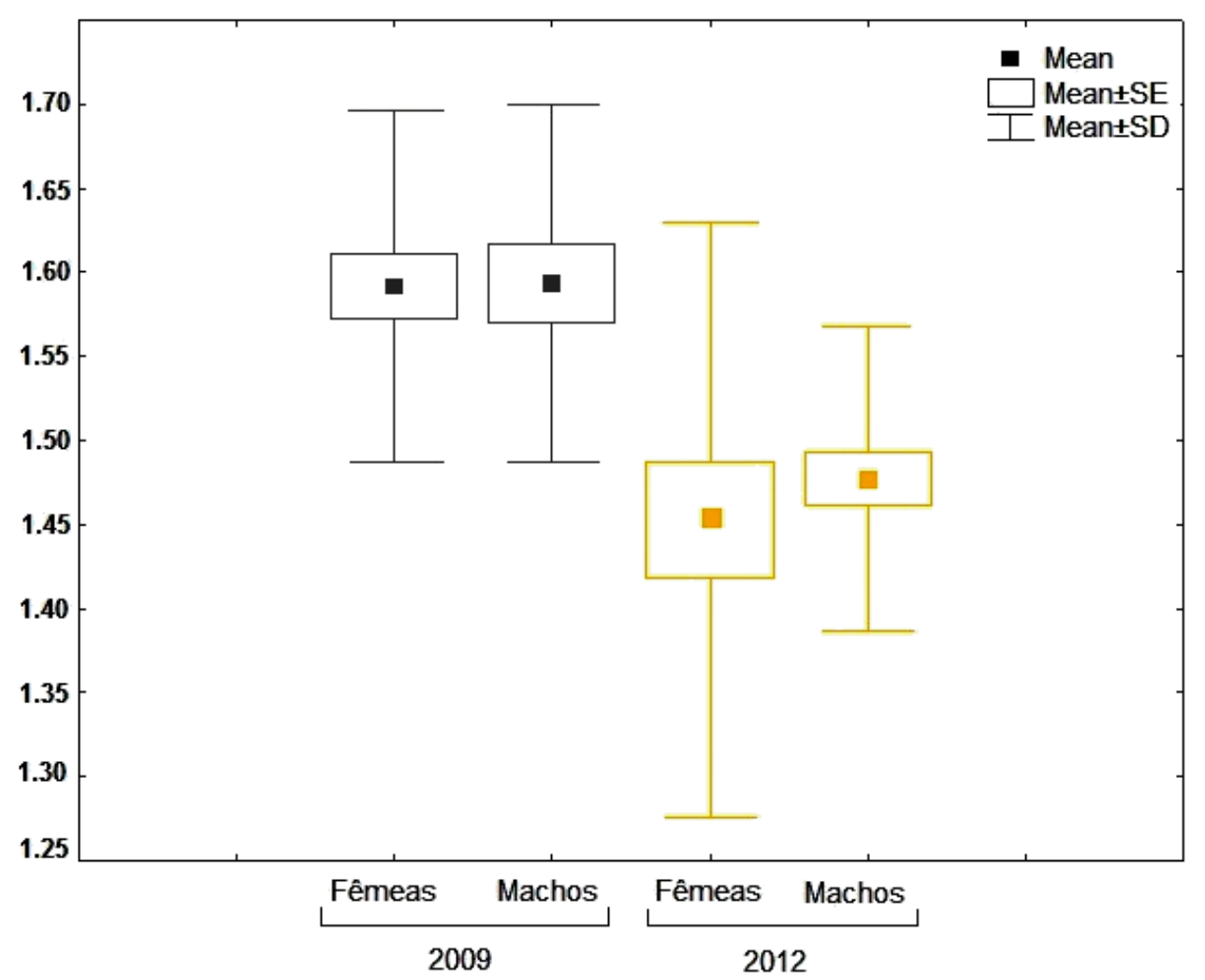

Nos alinhamentos após a sobreposição de Procrustes os machos e as fêmeas de cada ano também apresentaram diferenças em relação ao formato alar, como mostrado na Figura 48. 
Figura 49 - Consensos alares alinhados após sobreposição de Procrustes mostrando os extremos de diferenciação no morro entre os anos de 2009 e 2012 de (a) fêmeas e (b) machos.

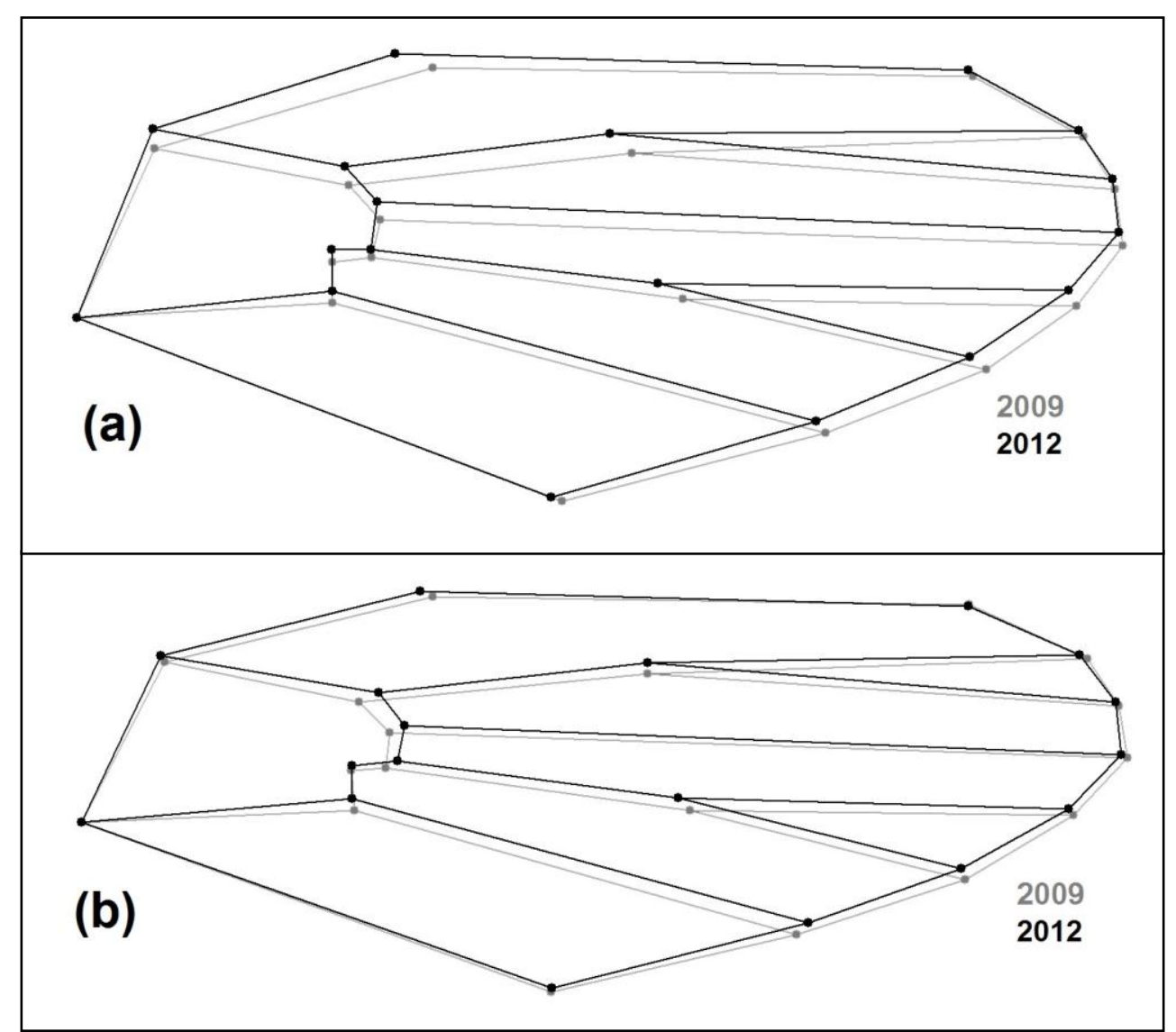

\subsubsection{Variações temporais em Anopheles homunculus}

Em An. homunculus foram feitas comparações apenas no microambiente de morro, visto que não havia amostras em 2012 na planície. Ao realizar a CVA foi possível observar uma evidente separação dos grupos de 2009 e 2012 no morfoespaço, com nenhuma sobreposição entre eles tanto em machos como em fêmeas (Figuras 49 e 50). O tamanho do centróide não divergiu consideravelmente nos dois anos de coleta, porém houve dimorfismo sexual de tamanho em cada grupo $(\mathrm{P}<0,05$; ANOVA, $F=5,05)$, sendo os machos maiores que as fêmeas (Figura 51). Comparando os extremos de diferenciação em cada ano, os machos mostraram uma asa mais alongada do que as fêmeas (Figura 52) no alinhamento após a sobreposição de Procrustes. 
Figura 50 - Morfoespaço de variáveis canônicas geradas na comparação somente entre fêmeas de An. homunculus nos dois períodos: 2009 (cinza) e 2012 (amarelo).

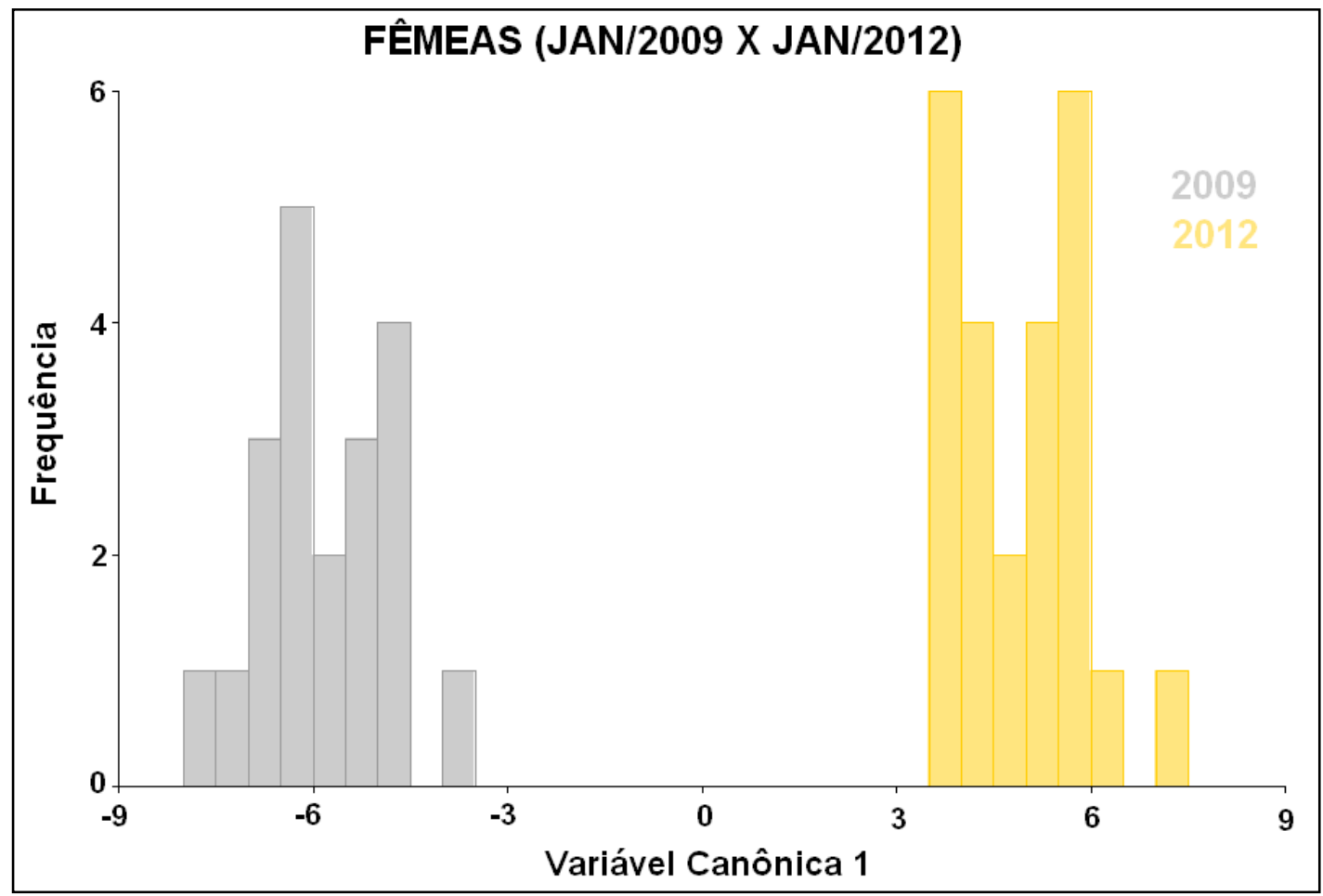

Figura 51 - Morfoespaço de variáveis canônicas geradas na comparação somente entre machos de An. homunculus nos dois períodos: 2009 (cinza) e 2012 (amarelo).

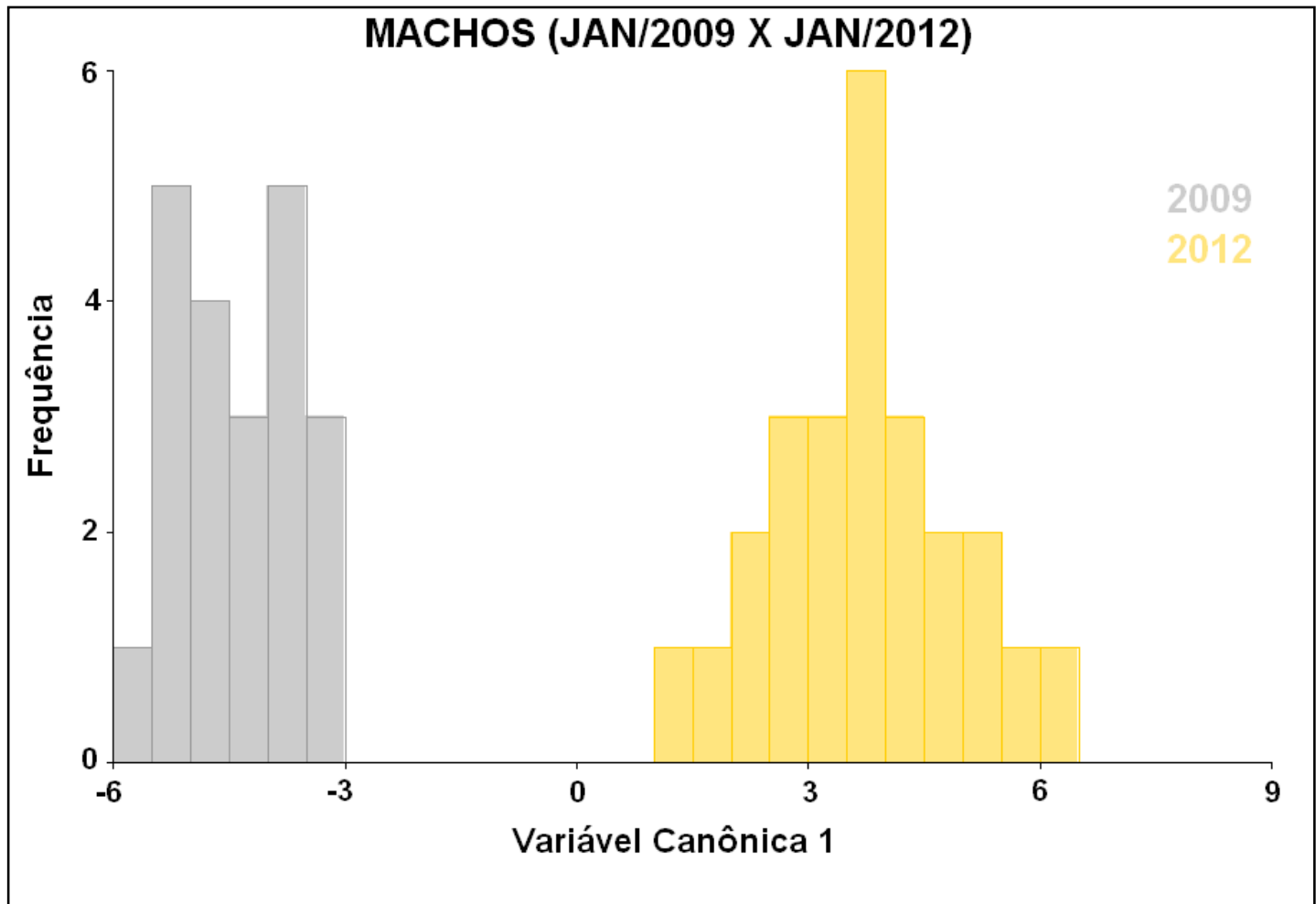


Figura 52 - Gráfico descritivo do tamanho dos centróides de machos e fêmeas de An. homunculus do morro nos dois períodos: 2009 e 2012. Os valores do eixo Y estão em milímetros.

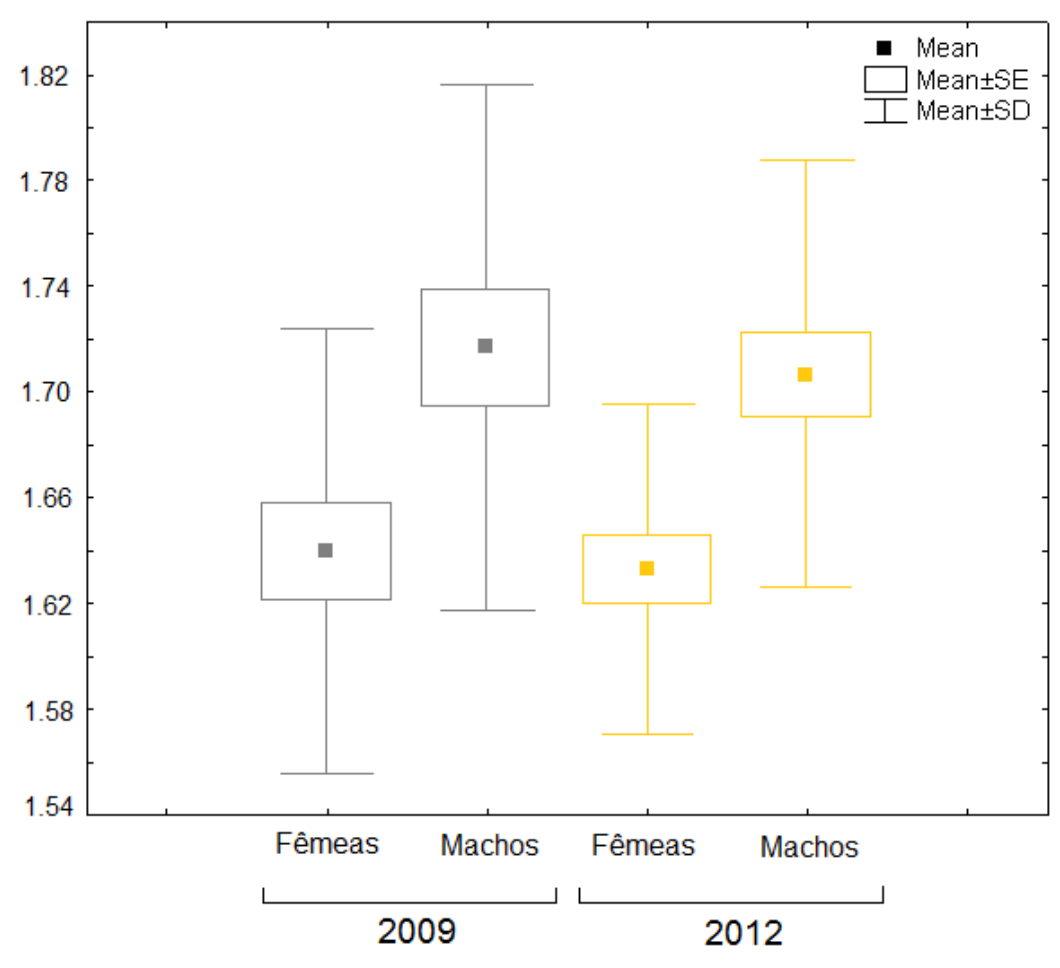

Figura 53 - Consensos alares alinhados de An. homunculus após sobreposição de Procrustes mostrando os extremos de diferenciação entre os anos de 2009 e 2012 de (a) fêmeas e (b) machos.

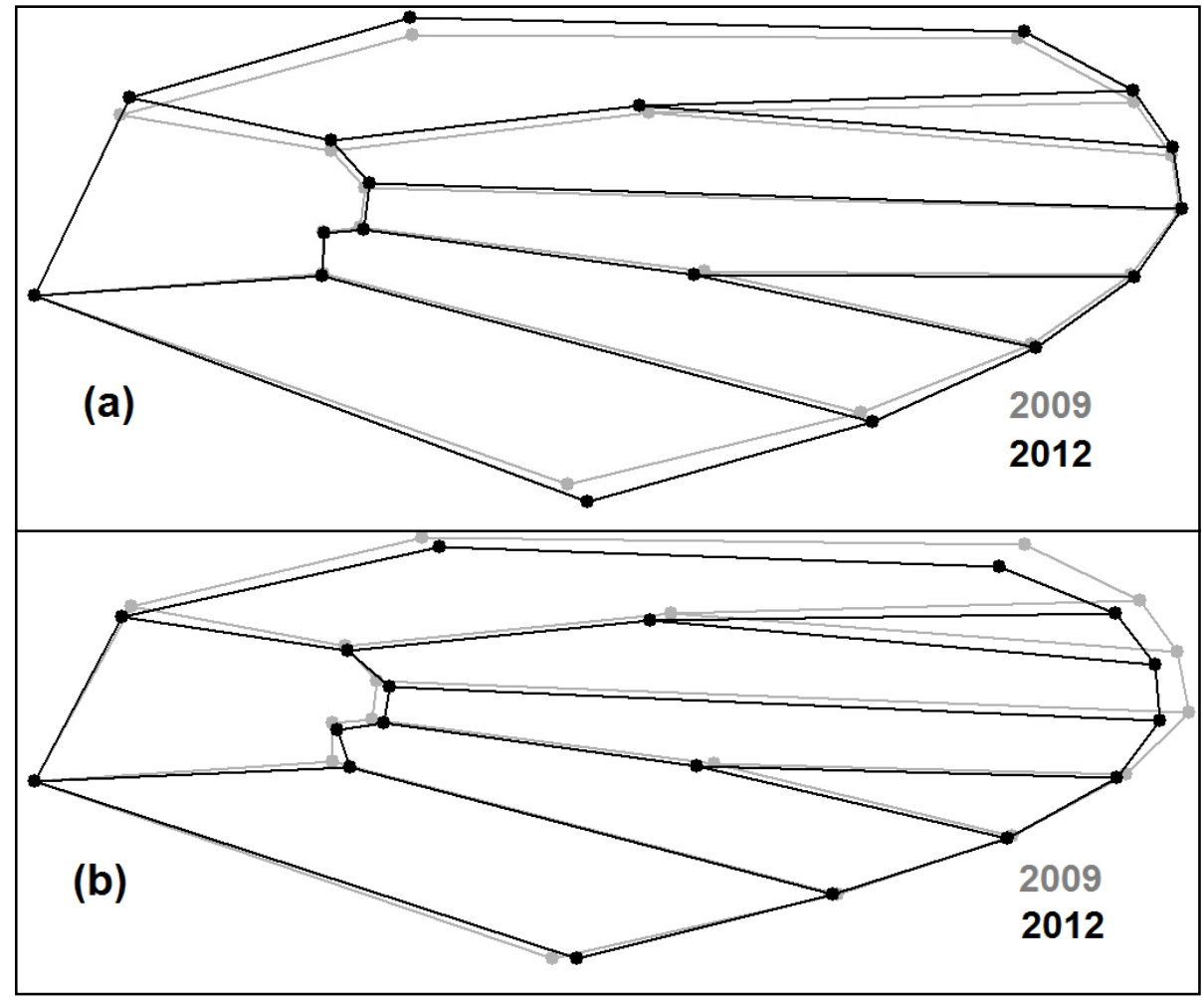




\subsection{Tamanho do Centróide e Correlações}

O tamanho do centróide, já apresentado nas seções anteriores em cada comparação, os scores de reclassificação e a distância de Mahalanobis foram sintetizados e apresentados em conjunto na Tabela 14, para An. cruzii, e na Tabela 15 para An. homunculus. Para a espécie An. cruzii também foi construído um gráfico correlacionando tamanho do centróide, precipitação e temperatura de machos (Figura 53) e fêmeas (Figura 54) na planície e no morro.

Tabela 13 - Tamanhos do centróide, em milímetros, de machos e fêmeas de Anopheles cruzii de cada população analisada. Os índices de reclassificação e valores das distâncias de Mahalanobis estão mostrados em colunas separadas.

\begin{tabular}{|c|c|c|c|c|c|c|}
\hline \multirow[t]{2}{*}{ Grupo Amostral } & \multicolumn{2}{|c|}{$\begin{array}{c}\text { Tamanho do Centróide } \\
(\mathrm{mm})\end{array}$} & \multicolumn{2}{|c|}{$\begin{array}{c}\text { Reclassificação } \\
(\%)\end{array}$} & \multicolumn{2}{|c|}{$\begin{array}{l}\text { Distância de } \\
\text { Mahalanobis }\end{array}$} \\
\hline & $\hat{0}$ & q & $\hat{0}$ & q & $\hat{0}$ & + \\
\hline Inverno(Jul/2011) & 1,513 & 1,340 & 67 & 74 & & \\
\hline Verão (Jan/2012) & 1,477 & 1,453 & 59 & 73 & 2,786 & 3,767 \\
\hline Morro (Jan/2009) & 1,622 & 1,623 & 60 & 58 & & \\
\hline Planície(Jan/2009) & 1,601 & 1,591 & 62 & 63 & 5,164 & 3,002 \\
\hline Morro (Jan/2012) & 1,594 & 1,527 & 50 & 53 & & \\
\hline Planície(Jan/2012) & 1,477 & 1,453 & 52 & 54 & 2,329 & 2,818 \\
\hline Morro(Jul/012) & 1,752 & 1,760 & 69 & 75 & & 0 \\
\hline Planície (Jul/2012) & 1,711 & 1,710 & 72 & 73 & $2,3 / 9$ & 2,542 \\
\hline 2009 (planície) & 1,601 & 1,591 & 85 & 74 & 5177 & 5510 \\
\hline 2012 (planície) & 1,477 & 1,453 & 79 & 77 & $5,4 / 2$ & 5,519 \\
\hline 2009 (morro) & 1,622 & 1,623 & 59 & 70 & 170 & $\mathrm{c}$ \\
\hline 2012 (morro) & 1,594 & 1,527 & 54 & 80 & 92 & $0<6$ \\
\hline
\end{tabular}

Tabela 14 - Tamanhos do centróide, em milímetros, de machos e fêmeas de Anopheles homunculus de cada população analisada. Os índices de reclassificação e valores das distâncias de Mahalanobis estão mostrados em colunas separadas.

\begin{tabular}{|c|c|c|c|c|c|c|}
\hline \multirow[t]{2}{*}{ Grupo Amostral } & \multicolumn{2}{|c|}{$\begin{array}{c}\text { Tamanho do Centróide } \\
\text { (mm) }\end{array}$} & \multicolumn{2}{|c|}{$\begin{array}{c}\text { Reclassificação } \\
(\%)\end{array}$} & \multicolumn{2}{|c|}{$\begin{array}{l}\text { Distância de } \\
\text { Mahalanobis }\end{array}$} \\
\hline & 0 & o & 0 & o & $\hat{0}$ & o \\
\hline Verão(Jan/2012) & 1,706 & 1,632 & 64 & 100 & $=107$ & 11010 \\
\hline Inverno(Jul/2012) & 1,880 & 1,889 & 76 & 97 & , & 3 \\
\hline $2009(r$ & 1,717 & 1,639 & 79 & 89 & 13389 & 12319 \\
\hline 2012 (morro) & 1,706 & 1,632 & 84 & 87 & & \\
\hline
\end{tabular}


Figura 54 - Tamanho do centróide de machos de Anopheles cruzii da planície (verde) e morro (marrom) nos meses de JAN/2009, JAN/2012 e JUL/2012. Os valores de temperatura (linha sólida) e precipitação (linha tracejada) desse período também estão representados com escala na parte direita do gráfico.

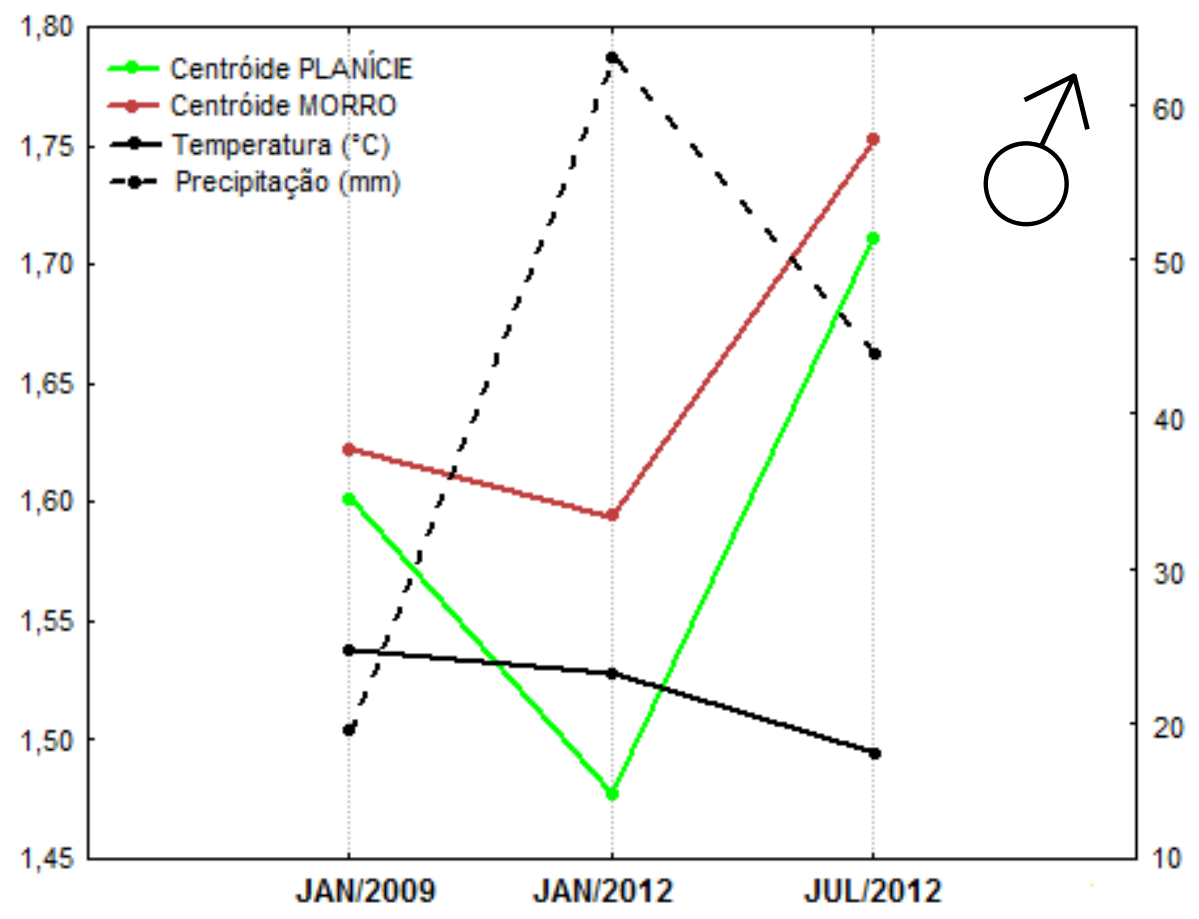

Figura 55 - Tamanho do centróide de fêmeas de Anopheles cruzii da planície (verde) e morro (marrom) nos meses de JAN/2009, JAN/2012 e JUL/2012. Os valores de temperatura (linha sólida) e precipitação (linha tracejada) desse período também estão representados com escala na parte direita do gráfico.

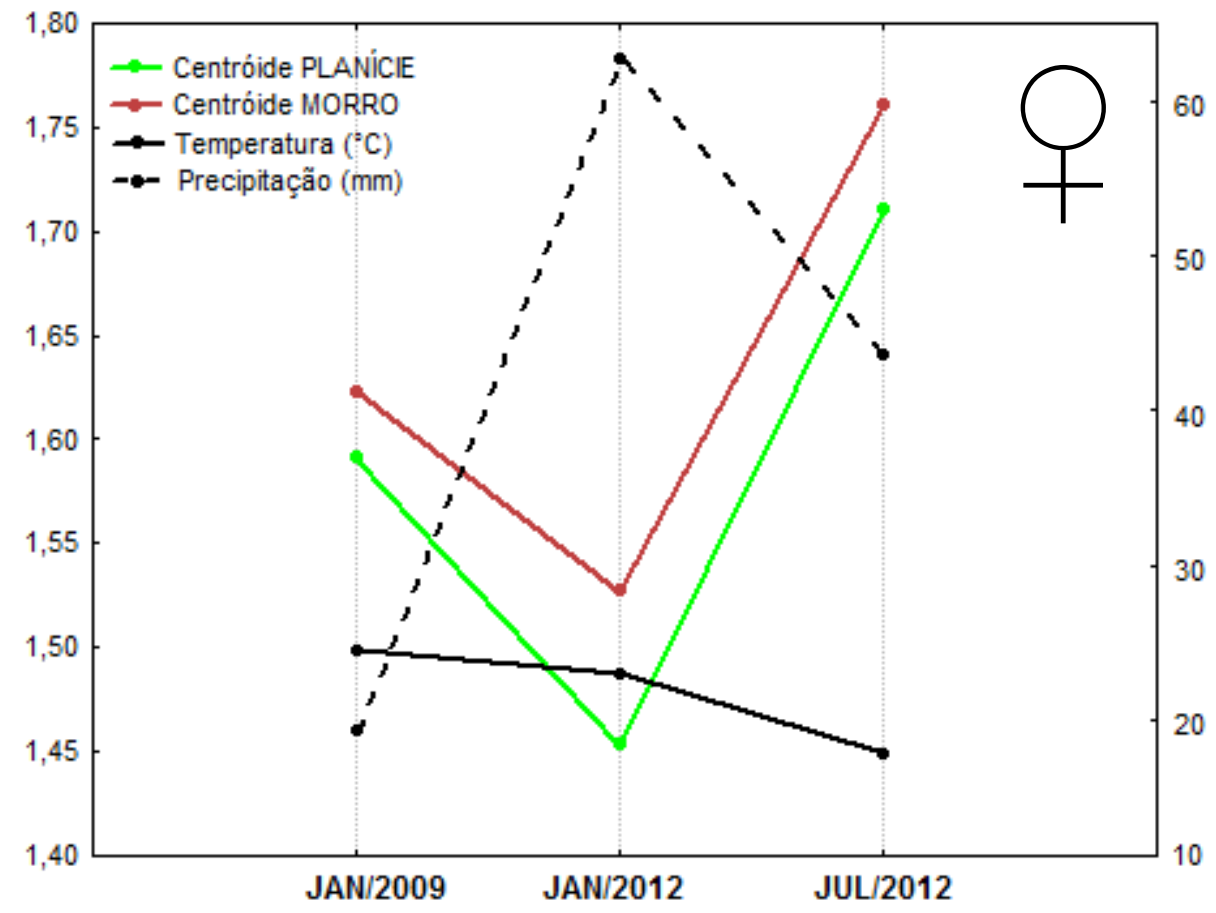




\section{DISCUSSÃo}

\subsection{Dimorfismo Sexual}

Em todas as análises, machos e fêmeas de todas as populações das duas espécies apresentaram grande diferença no formato alar, ficando evidente a separação em grupos distintos sem sobreposição no morfoespaço de variáveis canônicas. Em An. homunculus esses grupos de machos e fêmeas se mostraram mais distantes no morfoespaço, indicando que parece haver um dimorfismo sexual maior nesta espécie. Sendo assim, a morfometria geométrica se mostrou uma ferramenta útil na separação dos sexos nas duas espécies. A forma alar é determinada por herança quantitativa poligênica (Dujardin, 2008), e sofre menos efeito ambiental que o tamanho. Ele também pode deformar a asa por alometria, mas aqui esse efeito foi removido através da regressão entre os componentes de forma e o centróide.

Exceto na população de An. cruzii de JAN/2012 da planície, todas as outras apresentaram índices de alometria significativamente altos no formato alar, sendo o maior deles cerca de 16\% (Tabelas 4 e 5). Em alguns casos, o dimorfismo sexual tem sido relacionado diretamente ao efeito alométrico, pois o sexo de maior tamanho pode ser uma versão alometricamente reescalonada do sexo de menor tamanho (Gidaszewski et al., 2009; Klingenberg, 2010). Entretanto, mesmo retirando esse efeito das análises houve clara separação entre os sexos das duas espécies, o que indica que a alometria não parece ser um fator que influencia de maneira significativa a evolução desse caráter.

Os machos de um modo geral pareceram ser mais estáveis na forma alar, pois analisando os consensos nota-se que a asa da fêmea possui uma quantidade maior de landmarks variáveis. Na grande maioria dos casos, os índices de reclassificação são maiores para as fêmeas nas duas espécies, indicando que o formato alar desse sexo evolui de forma distinta e parece seguir um padrão onde os indivíduos ficam mais agrupados no morfoespaço. Essa variação morfológica diferencial para cada sexo pode ser fruto de pressões seletivas diferentes e isso pode moldar as asas de acordo com adaptações ou restrições pertinentes de cada um (Klingenberg, 2010). Caso a interpretação esteja correta, esses resultados 
podem ser indícios de seleção sexual na espécie. Machos e fêmeas possuem papéis ecológicos distintos dentro do ambiente, assim como o uso de suas asas, e isso poderia ser um motivador da seleção natural específica para sexo (tradução literal de sex-specific).

No presente estudo foi possível observar que os machos de todas as populações possuem asas mais estreitas que as fêmeas; isto pode estar relacionado à função alar, onde machos as utilizam para produção de sons na côrte sexual e fêmeas em vôos precisos durante a oviposição e busca de alimento (Wekesa et al., 1998). Na Figura 11 nota-se que as distâncias de Mahalanobis em An. cruzii parecem seguir uma tendência, ainda que inicial, e diminuem ao longo do tempo, tanto no morro quanto na planície. Ou seja, nas populações amostradas o formato alar de machos e fêmeas ficou mais semelhante com o passar dos meses. BitnerMathé e Klaczko (1999) comprovaram a alta herdabilidade desse caráter, o que indica que o componente genético está atuando nesta aproximação da forma alar entre os sexos. Isso pode ser indício de algum tipo de seleção onde há pouca variação no fenótipo dentro da população (Templeton, 2011). Entretanto, vários estudos com espécies de Drosophila também relataram a variação no formato alar (Bublii et al, 1996; Cavicchi et al, 1991; Haas, Tolley, 1998; Huey et al., 2000) mas há pouca evidência de que isso seja adaptativo naquela espécie.

$\mathrm{Na}$ maioria das comparações entre os sexos de An. cruzii, o tamanho de machos e fêmeas foi semelhante, divergindo do padrão encontrado na maioria dos culicídeos em que a fêmea é maior. Todos os indivíduos utilizados nestas análises foram mantidos em laboratório sob as mesmas condições externas, pois o tamanho alar é uma característica que sofre plasticidade podendo variar dependendo das condições ambientais (Dujardin, 2008). Mesmo os imaturos sendo coletados em ambiente silvestre, a maior parte do seu ciclo de vida ocorreu sob condições externas constantes do laboratório, já que a maioria deles eram ovos ou larvas L1 e L2. Por essa razão, a variação de tamanho observada aqui parece ter grande contribuição do componente genético de cada população.

Apesar das diferenças bem evidentes no formato alar de machos e fêmeas, 0 padrão geral de venação alar é comum a toda família Culicidae (Stark et al., 1999; Wooton, 1992). A forma de um modo geral parece ser altamente conservada e possui uma "limitação filogenética" (Gilchrist, Partridge, 2001) para mudanças muito 
drásticas, isto é, a própria arquitetura gênica das espécies restringe as variações no formato alar. O dimorfismo sexual de forma observado em An. cruzii e An. homunculus é maior que a variação intrapopulacional que ocorre nessas espécies; portanto, mesmo havendo microevolução e sendo analisados microambientes e estações do ano diferentes, ainda assim há diferença alar entre machos e fêmeas.

\subsection{Variações Sazonais}

Em An. cruzii as análises de inverno x verão mostraram uma divergência entre os grupos, principalmente das fêmeas, com base no formato alar. O Qst de forma e tamanho para machos e fêmeas foi semelhante, indicando que a variação da asa nas duas épocas ocorre de forma parecida para ambos os sexos. O intervalo de coleta entre aquelas duas estações climáticas, aproximadamente seis meses, já foi suficiente para mostrar algum padrão de diferenciação. Para ambos os sexos, o tamanho do centróide apresentou correlação inversa com os índices de precipitação, como pode ser observado nas Figuras 36 e 37. Em JAN/2012, quando ocorreram os maiores índices pluviométricos, as populações do morro e da planície apresentaram um tamanho alar muito reduzido. Esse fato pode estar relacionado com o ciclo de vida da espécie, que, como outros representantes do subgênero Kerteszia, ovopositam em bromélias e dependem diretamente da quantidade de água armazenada nessas plantas (Zavortink, 1993). Uma grande quantidade de chuva pode fazer transbordar os criadouros bromeliáceos e, desta forma, reduzir muito a população de larvas e de nutrientes disponíveis. Como as larvas de anofelinos são essencialmente filtradoras e não possuem sifão respiratório (Forattini, 2002), elas necessitam que o alimento fique disponível na lâmina d'água. Quando há um período chuvoso, esses nutrientes são diluídos ou lançados para fora da bromélia, dificultando a alimentação e o consequente crescimento dessas larvas.

Analisando os dados genéticos, foi possível constatar que houve um rico patrimônio haplotípico dentro das populações de An. cruzii, mesmo sendo analisado um fragmento do gene $\mathrm{COI}$ (cerca de 390 pb). Foi encontrado um alto índice de diversidade haplotípica $(0,97)$ em ambas as estações climáticas, e apenas dois deles foram compartilhados entre elas. Isto pode ser produto de deriva genética que ocorreu entre o inverno e o verão, que entretanto não alterou quantitativamente a 
diversidade haplotípica. Pode ser também que o padrão aqui observado seja uma oscilação natural da espécie An. cruzii, que ainda é pouco estudada e não se conhece muito sobre seu ciclo sazonal. A diversidade nucleotídica também foi alta $(0,012)$, indicando que para esta espécie a porção final do gene COl é bastante polimórfica. Os valores negativos dos índices de Tajima e Fu \& Li demonstram que a população está em expansão e que há alta taxa de polimorfismos, respectivamente. Apesar dos poucos haplótipos compartilhados, a diferenciação genética entre as duas populações é muito baixa ( $F s t=0,003$ e $\phi s t=0,007)$ e o número de migrantes é considerado extremamente alto $(\mathrm{Nm}=21,60)$. Para algumas espécies de Culicidae, 0 inverno é um período severo e responsável pelo efeito bottleneck em algumas populações (Taylor et al., 1993). No presente estudo não há tal evidência, visto que a diversidade haplotípica permanece alta nas duas estações climáticas e o há uma alta taxa de migrantes entre elas. A diferenciação intrapopulacional (99,3\%) foi muito maior do que a interpopulacional $(0,7 \%)$, indicando que talvez a diversidade haplotípica seja tão grande que a suficiência amostral ainda não tenha sido atingida. Nagylaki (1998) revela que talvez o índice Fst não seja adequado quando há grande diversidade intrapopulacional, pois a diferença entre as populações pode estar mascarada. Entretanto os dados indicam ligeiramente para uma diferenciação rápida na passagem das duas estações climáticas; pode ser que se tratem de populações com rápida renovação demográfica.

Em An. homunculus as análises morfométricas também revelaram diferenciação alar entre inverno e verão, inclusive mais evidente do que em $A n$. cruzii. Entre as fêmeas os scores de reclassificação sazonal alcançaram 100\% e não houve sobreposição dos grupos no morfoespaço de variáveis canônicas. O tamanho dos indivíduos divergiu de forma muito significativa nos dois sexos (Qst=0,99 e 0,97) e teve correlação inversa com a temperatura, como previsto na regra de Bergman* (1847 apud Ridley, 1993, p.124) onde espécimes de regiões mais frias apresentam tamanho corporal maior. Como todos os indivíduos foram mantidos em laboratório sob as mesmas condições, a variação no tamanho parece ter mais influência do componente genético de cada população do que pela influência do meio ambiente. $A$ diversidade haplotípica foi alta nesta espécie $(\mathrm{dH}=0,84)$, embora menor do que em

\footnotetext{
* Bergman, 1847 apud Ridley, 1993, p. 124
} 
An. cruzii e foram encontrados somente nove haplótipos ao todo nessas duas amostras populacionais sazonais. Mesmo analisando uma sequência maior que a de

An. cruzii (513 pb) foram encontrados poucos sítios polimórficos (cerca de 14), indicando que o gene $\mathrm{COI}$ nesta espécie parece estar mais conservado. Os valores moderados de Fst $(0,119)$ e $\phi s t(0,116)$ indicam que as populações de inverno e verão são geneticamente diferentes. Os índices de Tajima e Fu \& Li foram negativos, e assim como em An. cruzii, indica que a população está em expansão e há polimorfismos.

Apesar de morfologica e filogeneticamente muito próximas, as espécies $A n$. homunculus e An. cruzii apresentam padrões genéticos muito distintos, já que $A n$. homunculus não possui um patrimônio haplotípico tão rico quanto sua congênere, e as populações sazonais apresentam moderada diferenciação genética. Possivelmente, as fêmeas de An. homunculus sejam menos dispersivas que as de An. cruzii e tendam a depositar seus ovos em criadouros próximos. O grau de parentesco entre os indivíduos de An. homunculus parece ser maior que os da outra espécie, já que a taxa de compartilhamento de haplótipos por indivíduo também foi superior. Outra explicação provável seria que a arquitetura genética de $A n$. homunculus não permita uma grande variação dentro da espécie, o que limitaria sua diversidade haplotípica. Entretanto, pouco se sabe sobre a biologia e dispersão dessa espécie, o que dificulta formular uma hipótese mais consistente. A rápida renovação demográfica observada nas duas espécies sugere que medidas de controle sejam específicas para cada época do ano, pois assim como o DNA mitocondrial foi alterado, pode estar ocorrendo alguma mudança no comportamento, na suscetibilidade a métodos de controle ou na competência vetorial de cada espécie. Mesmo o inverno não sendo tão severo na região de Cananéia (temperatura média de $17,5^{\circ} \mathrm{C}$ ), há mudança dos recursos disponíveis no ambiente, o que pode alterar o ciclo de vida dos culicídeos (Vezzani et al., 2004). Com temperaturas mais baixas, geralmente os mamíferos e aves ficam mais reclusos e evitam sua exposição direta ao ambiente (Jacobs, 1996), dificultando o repasto sanguíneo para algumas espécies anofelinas. A temperatura também pode mudar a densidade populacional das espécies e desse modo afetar seus status vetoriais (Aytekin et al., 2009), já que vetores secundários podem se tornar primários. 


\subsection{Variações Temporais 2009 x 2012}

Em An. cruzii, a distância entre os grupos de 2009 e 2012 no morfoespaço das variáveis canônicas, originadas da comparação entre ambos, indicou uma grande variação temporal dentro da espécie, sem sobreposição dos grupos. A microevolução foi rápida o bastante para ser detectada na morfologia em períodos curtos de tempo. O ciclo de vida dos culicídeos é bastante curto, podendo chegar a várias gerações em poucos meses (Forattini, 2002), o que acentuaria essa rápida manifestação do processo microevolutivo. É possível que essa grande diferença encontrada tenha sido devido à deriva genética, recebimento de migrantes ou até mesmo por pressão seletiva frente às mudanças ambientais ocorridas no período. $\mathrm{Na}$ comparação temporal da planície, ambos os sexos apresentaram uma diminuição significativa do tamanho após os três anos comparados. Isso pode indicar a atuação de outra variável ambiental reconhecidamente influente sobre o tamanho ou possivelmente alguma pressão seletiva. O microambiente de planície sofre mais efeitos antrópicos do que o morro, justamente pela sua proximidade com as casas de moradores e estradas, o que poderia justificar essa variação. Jirakanjanakit et al. (2008) observou uma tendência de diminuição do tamanho alar em Aedes aegypti ao longo de quinze gerações mantidas em laboratório.

Em An. homunculus foi possível observar uma variação no formato alar entre os grupos de 2009 e 2012 mais evidente do que em An. cruzii. As distâncias de Mahalanobis entre as duas populações foram extremamente altas, indicando que ocorreu uma microevolução drástica nesse período de tempo. O tamanho do centróide permaneceu estável entre as populações de machos e fêmeas nesse período. Houve um dimorfismo sexual inesperado em 2009 e 2012, quando o macho apresentou tamanho maior que a fêmea, diferentemente do que é observado em outros culicídeos (Moratore, 2010; Peruzin, 2011).

Comparando 2009 e 2012, nota-se que a temperatura permaneceu estável no verão (época de comparação das amostras), porém os índices pluviométricos triplicaram (19,1mm em 2009 e 67,3 em 2012). Isso pode ser a causa dessa mudança tão acentuada observada nas populações, visto que a umidade é um dos fatores que comprovadamente influenciam no formato e tamanho alar (Jirakanjanakit et al., 2007). No presente estudo, a variação temporal dos caracteres alares foi 
detectada de maneira bem acentuada nas duas espécies, fato que deve ser levado em consideração quando asas forem utilizadas na taxonomia. As populações de uma mesma espécie podem apresentar formatos alares distintos se forem coletadas em épocas muito distantes. Apesar de haver forte microevolução nesse caráter, o padrão geral de formato alar para cada espécie não se altera com o tempo a ponto de prejudicar a diagnose entre espécies, como comprovado por Henry et al. (2010).

\subsection{Variações Microambientais}

Em An. cruzii, as populações do morro e planície apresentaram um padrão de divergência alar entre elas em todas as épocas amostradas. A distância mínima entre essas duas regiões é de aproximadamente $60 \mathrm{~m}$, e dessa forma os mosquitos poderiam transitar entre elas. Veloso (1958) observou que a espécie An. cruzii é indiferente a microclimas especiais, sendo encontrado em grande quantidade nos diversos tipos de biótopos. Se os indivíduos estivessem sob uma pressão seletiva estabilizadora, como já foi observado em outras espécies de culicídeos, haveria uma tendência à redução da variabilidade desse caráter (Dujardin, 2009), o que parece não ser o caso aqui encontrado. Entretanto, a separação dos grupos pelo formato alar indica que ocorreu uma tênue divergência dentro desta espécie. A preferência por biótopos e bromélias específicas dentro de cada microambiente pode ser diferencial em cada população, o que explicaria a variação morfológica encontrada. Estudando este mesmo local, Marques (2010) constatou que o volume hídrico das bromélias presentes na planície é significativamente maior do que no morro; isso poderia ser um fator determinante na preferência de cada população. Apesar do ambiente de planície estar muito próximo do mar e, consequentemente, da água salobra quando há maré alta, o pH do conteúdo hídrico das bromélias do morro e da planície é essencialmente o mesmo (Marques, 2010). Em todas as comparações, o tamanho do centróide parece seguir um padrão, ainda que incipiente, onde machos e fêmeas são maiores no morro (Figuras 19, 22 e 26). O Qst de tamanho foi alto para fêmeas de Janeiro/2012 e machos de Julho/2012, indicando que houve grande variação nessas populações. Segundo Gilchrist e Partridge (2001), a variação no tamanho alar de populações naturais pode ser causada por uma pressão seletiva direcional, onde um único fenótipo é favorecido e o alelo mais vantajoso aumenta de 
frequência na população. O tamanho alar também pode estar diretamente relacionado com o fitness do indivíduo, que varia e é dependente do ambiente em que ele está inserido (Reeve et al., 2000). As paisagens do morro e planície são diferentes: os níveis de luz solar, a cobertura vegetal, a umidade relativa e as espécies vegetais presentes podem estar atuando na preferência das populações de anofelinos e, consequentemente, na sua diferenciação.

No presente estudo foi encontrado um número muito alto de haplótipos para cada microambiente nas duas épocas amostradas $(\mathrm{dH}=0,98$ e $\mathrm{dH}=0,97)$, sendo que apenas um deles foi compartilhado entre morro e planície. A diversidade nucleotídica também foi alta, indicando que o fragmento de COI analisado é extremamente polimórfico em An. cruzii. No mês de JUL/2012, as populações apresentaram um Fst moderado ( $F s t=0,125)$ segundo Wright (1998), indicando alguma estruturação populacional. A diferenciação genética interpopulacional nessa época $(20,4 \%)$ também foi maior do que em JAN/2012 (0,7\%), revelando que as populações do morro e planície estão mais separadas. Comparando o Nm em JAN/2012 e JUL/2012, nota-se que há mais migrantes no período de verão. Em laboratório, o alcance médio de voo de um Anopheles é cerca de 1000m; logo, teoricamente, seria possível ele se deslocar do morro até a planície (diferença mínima de $60 \mathrm{~m}$ ). No período de verão, onde as chuvas são mais frequentes, é possível que a superpopulação de mosquitos e a falta de nichos direcione algumas fêmeas para um microambiente menos ocupado, o que explicaria o número de migrantes observado. O grande número de haplótipos encontrado diverge de outros trabalhos com anofelinos utilizando o gene mitocondrial CO-I. Oshagui et al. (2006) encontraram 8 haplótipos em 20 indivíduos analisados e Patsoula et al. (2007) encontraram apenas 9 sequências diferentes em 38 indivíduos.

Os dados de formato, tamanho alar e gene COI foram concordantes, o que indica que provavelmente ocorre uma estratificação vertical em An. cruzii na região de Cananéia. As populações do morro e planície divergem em vários aspectos, o que talvez seja refletido também na sua capacidade vetorial. Os dados desta pesquisa sugerem que pode estar se iniciando uma especiação parapátrica, onde não há barreira extrínseca específica para fluxo gênico. A população é contínua, mas ainda assim os indivíduos não cruzam aleatoriamente (Templeton, 2011). Eles são mais propensos a cruzar com seus vizinhos geográficos do que com indivíduos 
de uma parte diferente de um grupo da população. Neste modo, divergências podem ocorrer por causa do reduzido fluxo gênico entre as populações e as diferentes pressões de seleção em toda a faixa vertical do ambiente. Há uma continuidade paisagística entre os microambientes, pois os criadouros bromeliáceos estão presentes por toda a extensão da mata e não há barreiras físicas entre morro e planície; entretanto, as evidências morfológicas e moleculares apontam que os anofelinos não transitam aleatoriamente pelo estrato vertical.

Estudos com Culex (Demirci et al., 2011) e Aedes (Kuclu et al., 2011) já demonstraram haver uma estratificação altitudinal que pode ser revelada pela morfologia alar dos indivíduos. Entretanto esses trabalhos compararam populações bem distantes, com altitudes que variavam de 800 a $2130 \mathrm{~m}$. No presente estudo foi observada uma variação entre populações muito próximas, onde a distância geográfica entre os microambientes não foi significativamente grande. Ramírez e Dessen (1994, 2000) encontraram padrões A e B de bandas cromossômicas em populações de An. cruzii, ocorrendo em simpatria em algumas regiões com elevações distintas. Para aqueles autores, também há uma correlação entre a altitude e as diferentes formas cromossômicas.

\subsection{Considerações Finais}

Em todas as análises realizadas comparando populações diferentes, a morfometria geométrica se mostrou uma ferramenta útil na detecção de sensíveis variações intrapopulacionais. A asa realmente é um bom marcador para revelar padrões microevolutivos, encontrados também em outros estudos com Culicidae (Henry et al., 2010; Jirakanjanakit et al., 2007; Vidal et al., 2012). Análises multivariadas, como a morfometria geométrica aqui empregada, geralmente revelam padrões e tendências não perceptíveis em análises univariadas (Rocha, 2005). A combinação de marcadores morfológicos e moleculares é importante para entender o organismo de maneira holística, pois os caracteres biológicos podem evoluir em velocidades diferentes. O gene $\mathrm{COI}$ se mostrou extremamente polimórfico para a espécie Anopheles cruzii e nota-se uma estruturação populacional quando comparados morro e planície. Devido a sua importância como vetor de Plasmodium, o status taxonômico dessa espécie tem sido investigado por vários estudos recentes 
(Ramirez, Dessen, 2000a, b; Rona et al., 2009, 2010a, b). Para os autores, as diferenças genéticas e cromossômicas encontradas podem indicar o início de uma especiação dentro de $A n$. cruzii, que ocorreu devido às adaptações locais e condições microgeográficas diversas. O fato de An. cruzii representar um complexo explicaria algumas diferenças encontradas na morfologia, comportamento e distribuição das populações (Ramirez, Dessen, 1994, 2000a, b).

Em todas as comparações realizadas, o teor de bases A -T presente nas sequências é semelhante àqueles encontrados no DNA mitocondrial de outros insetos (Bernasconi et al., 2000; Mirabello, Conn, 2006). Por consequência da herança materna desse gene mitocondrial, o tamanho efetivo da população fica menor do que aquele utilizado em análises com genes nucleares. Sendo assim, ele é mais sensível a subdivisões na população (Roderick, 1996). A alta frequência de transições na terceira posição do códon indica que os grupos analisados divergiram recentemente (Simon et al., 1994). Quando analisamos o grau de diferenciação entre os haplótipos mais divergentes encontrados em uma população, nota-se que essa diferença varia de 1,5\% (em An. homunculus) a 2,82\% (em An. cruzii). Segundo Cywinska et al. (2006) a separação em espécies diferentes para Diptera só ocorre se esses valores forem maiores que 4\%; ou seja, populações do morro e planície, apesar de bem distintas genética e morfologicamente, ainda representam uma mesma espécie: An. cruzii.

A grande quantidade de haplótipos encontrada nas comparações sazonais e microambientais podem ser reflexo da proximidade com o centro de origem dessa espécie. Sabe-se que a distribuição de An. cruzii é restrita a América do Sul (Forattini, 2002), então provavelmente seu centro de origem também está localizado nesta região. O tempo de divergência entre as espécies de Kerteszia é maior do que seu grupo-irmão Nyssorhynchus (Sallum et al., 2002), o que poderia explicar a grande diversidade haplotípica encontrada. Motoki (2012) analisou 214 indivíduos de An. darlingi em todo o território brasileiro e encontrou um $\mathrm{dH}=0,977$, muito semelhante aos valores aqui encontrados $(\mathrm{dH}=0,97$ e $\mathrm{dH}=0,98)$. Entretanto, comparativamente, o número amostral utilizado neste trabalho foi muito menor (cerca de 45 espécimes) e a região de estudo foi apenas o município de Cananéia/SP. Os autores Hurst e Jiggins (2005) exploram uma teoria interessante sobre o grande número de haplótipos encontrado em algumas espécies de 
artrópodes. Para eles, pode existir transferência horizontal de DNA através de várias cepas diferentes de bactérias simbiontes, mantendo uma alta diversidade haplotípica dentro da população. Ao menos para An. cruzii essa hipótese não parece provável, já que testes feitos em nosso laboratório mostraram que espécimes de An. cruzii não estavam infectados com Wolbachia (principal bactéria simbionte encontrada em artrópodes).

Alguns autores (Holsinger, Weir, 2009) revelaram que o índice Fst não é o mais indicado para utilizar quando há dados haploides, e sim o $\phi s t$, que mede a diversidade genética através de AMOVA. No presente estudo os valores de Fst e $\phi s t$ foram muito semelhantes, revelando que provavelmente as populações se comportam de acordo com o que eles indicam. Comparando esses índices de diversidade genética com os índices de diversidade morfológica (Qst), nota-se que em todas as populações os valores de Qst, tanto da forma quanto do tamanho, foram maiores. Isso revela que há maior grau de evolução na asa das populações do que no gene COI, portanto, esses marcadores evoluem em velocidades diferentes. Se os marcadores fossem neutros eles deveriam convergir para um mesmo valor (Dujardin, 2008), o que não acontece aqui. Principalmente em An. cruzii o gene COI se mostrou tão polimórfico intrapopulacionalmente que talvez não seja o mais adequado para evidenciar um padrão mais nítido de agrupamento entre as populações, como em Anopheles darlingi (Motoki, 2012; Moutinho et al., 2011) ou Aedes aegypti (Scarpassa et al., 2008). A evolução de uma característica biológica muitas vezes não reflete a verdadeira história evolutiva de seus organismos (Maddison, 1997; Nichols, 2001; Rocha, 2005), por isso inferências sobre a dinâmica populacional de uma espécie devem ser feitas com cautela. Ampliar o número ou combinar marcadores genéticos e morfológicos de diferentes resoluções pode ser uma maneira de abordagem mais confiável.

Os dados aqui apresentados revelam que An. homunculus se trata de uma espécie com rápida microevolução alar e gene COI comparativamente mais conservado que An. cruzii. Embora ambas as espécies aqui estudadas sejam filogeneticamente próximas e compartilhem semelhantes nichos ecológicos, aspectos diferenciais da sua genética populacional são indicativos de histórias evolutivas diferenciadas e que talvez reflitam em peculiaridades ecológicas ainda não descritas. As diferenças populacionais encontradas tanto em An. cruzii quanto 
em An. homunculus sugerem que a utilização de métodos de controle podem ser mais eficientes se forem considerados os diversos perfis da população do vetor, sazonais ou microambientais (Motoki, 2012). 


\section{CONCLUSÕES}

- É possível diferenciar Anopheles cruzii de An. homunculus utilizando somente morfometria geométrica alar.

- Há dimorfismo sexual de forma para todas as populações analisadas de An. cruzii e An. homunculus.

- Populações de An. cruzii do inverno e do verão apresentaram diferenciação no formato alar. O gene CO-I mostrou-se altamente polimórfico com apenas dois compartilhamentos entre as populações, porém com baixo nível de divergência genética ( $F s t=0,003$, $\Phi s t=0,007)$.

- Houve altos valores de diferenciação genéticas intrapopulacional em todos os grupos amostrados $(79,6 \%$ a $99,3 \%)$

- Populações de An. homunculus do inverno também apresentaram alta diferenciação no formato alar em relação às do verão. Nesta espécie o gene CO-I parece estar mais conservado do que em An. cruzii, pois há reduzido número de haplótipos e baixa diversidade nucleotídica $(\pi=0,005)$.

- Populações de An. homunculus do inverno apresentam tamanho alar significativamente maior de que aquelas do verão.

- As populações de An. cruzii do morro e planície também apresentaram variação no formato alar. O tamanho do centróide nos indivíduos do morro foi ligeiramente maior em todas as comparações.

- Houve compartilhamento de apenas um haplótipo entre populações de An. cruzii do morro e planície. Há evidência de alguma estruturação populacional ( $F s t=0,125$; $\Phi s t=0,121)$ e baixo número de migrantes $(\mathrm{Nm}=1,67)$ entre os microambientes analisados em Julho/2012. 
- As informações derivadas da morfologia e genética foram concordantes para morro e planície, o que atesta que a geometria alar pode ser empregada como indicador de microevolução também nessas espécies.

- As comparações temporais tanto em An. cruzii como em An. homunculus mostraram evidente diferenciação morfológica, ou seja, os caracteres das asas são acusativos de microevolução.

- A diversidade haplotípica foi alta em todas as populações de An. cruzii analisadas, com poucos haplótipos compartilhados entre as amostras temporais e geográficas.

- Os marcadores morfológicos e moleculares utilizados neste estudo parecem evoluir em velocidades diferentes, pois os valores Qst são maiores que os Fst em todas as populações. Podem estar ocorrendo diferentes pressões seletivas na asa e no gene CO-I. 


\section{REFERÊNCIAS*}

Amaral J. Infecção natural de Nyssorhynchus (Kerteszia) cruzii e bellator (Diptera, Culicidae). A Folha Médica. 1942;28(15):1-9.

Arruda M, Carvalho MB, Nussenzweig RS, Maracic M, Ferreira AW, Cochrane AH. Potential vectors of malaria and their different susceptibility to Plasmodium falciparum and Plasmodium vivax in northern Brazil identified by immunoassay. American Journal of Tropical Medicine and Hygiene. 1986;35:873-81.

Aytekin S, Aytekin M, Alten B. Effect of different larval rearing temperatures on the productivity (Ro) and morphology of the malaria vector Anopheles superpictus Grassi (Diptera: Culicidae) using geometric morphometrics. Journal of Vector Ecology. 2009;34:32-42.

Bernasconi MV, Valsangiacomo C, Piffaretti JC and Ward PI. Phylogenetic relationships among Muscoidea (Diptera: Calyptratae) based on mitochondrial DNA sequences. Insect Mol Biol. 2000;9:67-74.

Bona ACD. Culicidae (Diptera) em Floresta Ombrófila Densa de Terras Baixas e Análise da idade fisiológica, sobrevivência diária e duração do ciclo gonotrófico da população de Anopheles (Kerteszia) cruzii Dyar \& Knab, 1908. [dissertação (Mestrado em Ciências Biológicas)]. Curitiba: Universidade Federal do Paraná; 2008. $78 \mathrm{f}$.

Branquinho MS, Marrelli MT, Curado I, Natal D, Barata JMS, Tubaki R, Carréri-Bruno GC, Menezes RT, Kloetzel JK. Infecção do Anopheles (Kerteszia) cruzii por Plasmodium vivax e Plasmodium vivax variante VK247 nos Municípios de São Vicente e Juquitiba, São Paulo. Rev Panam Salud Publica. 1997;2:122-34.

Brasil. Ministério da Saúde. Coordenação Geral do Programa Nacional de Controle da Malária. SVS Malária. Brasília; 2010. 48 p.

Brogdon WG. Measurement of flight tone differences between female Aedes aegypti and A. albopictus (Diptera: Culicidae) J Med Entomol. 1994;31(5):700-3

Bublii O, Imasheva AG, LAZEBNY OE. Variation of a set of wing characters in natural populations of Drosophila melanogaster. Genetika. 1996;32:1513-20.

Calado DC, Navarro-Silva MA. Identificação de Anopheles (Kerteszia) cruzii Dyar \& Knab e Anopheles (Kerteszia) homunculus Komp (Diptera, Culicidae, Anophelinae) através de marcadores moleculares (RAPD e RFLP). Revista Brasileira de Zoologia. 2005;22:1127-33.

\footnotetext{
* De acordo com:

International Committee of Medical Journal Editors. [Internet]. Uniform requirements for manuscripts submitted to Biomedical Journal: sample references. [update 2011 Jul 15]. Available from: http://www.icmje.org.
} 
Calado DC. Polimorfismos em Anopheles cruzii Dyar \& Knab, 1908 detectados através de marcadores moleculares (RAPD e RFLP) e comparação com Anopheles bellator Dyar \& Knab, 1906 e Anopheles homunculus Komp, 1937 (Diptera, Culicidae, Anophelinae). [tese (Doutorado em Ciências Biológicas)] Curitiba: Universidade Federal do Paraná; 2005. 132 f.

Carvalho ME, Glasser CM, Ciaravolo RMC, Etzel A, Santos LA, Ferreira CS. Sorologia da malária vivax no foco Aldeia dos Índios, município de Peruíbe, São Paulo, de 1984 a 1986. Cadernos de Saúde Pública. 1998;4:276-92.

Cavicchi S, Giorgi G, Natali V, Guerra D. Temperature-related divergence in experimental populations of Drosophila melanogaster III. Fourier and centroid analysis of wing shape and relationship between shape variationand fitness. J. Evol. Biol. 1991;4:141-59.

Centro de Pesquisas Meteorológicas e Climáticas aplicadas à Agricultura (CEPAGRI) [homepage na internet]. Campinas: Meteorologia Universidade Estadual de Campinas - UNICAMP. Disponível em: http://cpa.unicamp.br/outrasinformacoes/clima_muni_113.html [2012 out. 17].

Centro Integrado de Informações Agrometeorológicas (ClIAGRO) [homepage na internet]. São Paulo: Governo do Estado de São Paulo. Disponível em http://www.ciiagro.sp.gov.br/ciiagroonline/Listagens/BH/LBalancoHidricoLocal.asp [2012 out. 17].

Collins FH, Paskewitz SM. A review of the use of ribosomal DNA (rDNA) to differentiate among cryptic Anopheles species. Insect Molecular Biology. 1996;5:1-9.

Collucci E, Sallum MAM. Phylogenetic analysis of the subgenus Kerteszia of Anopheles (Diptera: Culicidae: Anophelinae) based on morphological characters. Insect Syst Evol. 2003;34(4):361-72.

Consoli RAGB, Lourenço-de-Oliveira R. Principais mosquitos de importância sanitária no Brasil. Rio de Janeiro: Fiocruz Press; 1994. 228 p.

Consolim J, Luz E, Vieira AM, Borba AM. Alguns aspectos epidemiológicos sobre a persistência de transmissão de malária no litoral paranaense. III. Entrada e permanência de Anopheles cruzii na habitação humana (Diptera, Culicidae). Arquivos de Biologia e Tecnologia. 1979;22(2):173-9.

Coutinho JO, Rachou R, Ricciardi I. Contribuição para o conhecimento dos transmissores de malária no Brasil . A. (K.) cruzi e A. (K) bellator. Arquivos de Higiene. 1943;13(2):115-27.

Cywinska A, Hunter F, Hebert P. Identifying Canadian mosquito species through DNA barcodes. Medical and Veterinary Entomology. 2006;20:413-24.

Davidson G. The five mating-types in the Anopheles gambiae complex. Riv Malariol. 1964;43:167. 
Deane LM, Ferreira-Neto JA, MOURA LM. The vertical dispersion of Anopheles (Kerteszia) cruzii in a forest in Southern Brazil suggests that human cases of malaria of simian origin might be expected. Memórias do Instituto Oswaldo Cruz. 1984;79:461-3.

Deane LM. Malaria vectors in Brazil. Memórias do Instituto Oswaldo Cruz. 1986;81(2):5-14.

Deane LM. Simian malaria in Brazil. Memórias do Instituto Oswaldo Cruz. 1992;87(3):1-20.

Demirci B, Lee Y, Lanzaro GC, Alten B. Altitudinal Genetic And Morphometric Variation among populations of Culex theileri Theobald (Diptera: Culicidae) from Northeastern Turkey. Journal of Vector Ecology. 2011;37(1):197-209.

Devicari M. Estudo genético-morfológico de populações de Aedes scapularis (Dipetra: Culicidae). [dissertação (Mestrado em Parasitologia)]. São Paulo: Instituto de Ciências Biomédicas, Universidade de São Paulo; 2010. 65 f.

Dujardin JP, Costa J, Bustamante D, Jaramillo N, Catalá S. Deciphering morphology in Triatominae: The evolutionary signals. Acta Tropica. 2009;110:101-11.

Dujardin JP. Morphometrics applied to medical entomology. Infect Genet Evol. 2008;8:(6):875-90.

Dye C. Vectorial capacity: Must be measured all its components? Parasitology Today. 1986;2:203-9.

Excoffier L, Laval G, Schneider S. Arlequin ver. 3.0: An integrated software package for population genetics data analysis. Evolutionary Bioinformatics Online. 2005;1:4750.

Ferreira E, Castro-Filho J, Tomich A, Sá FT. Estudo da longevidade do Anopheles (Kerteszia) cruzii e do Anopheles (Kerteszia) bellator em condições naturais. Revista Brasileira de Malariologia e Doenças Tropicais. 1969a;21:823-8.

Ferreira E, Castro-Filho J, Tomich A, Sá FT. Estudo sobre o raio de vôo do Anopheles (Kerteszia) cruzii e do Anopheles (Kerteszia) bellator em Guaratuba, litoral do Estado do Paraná, Brasil. Revista Brasileira de Malariologia e Doencas Tropicais. 1969b;21:819-22.

Ferreira SR, Luz N. Malária no estado do Paraná - aspectos históricos e prognose. Acta Biol Par. 2003;32(3):129-56.

Forattini OP, Gomes AC, Natal D, Santos JLF. Observações sobre a atividade de mosquitos Culicidae em matas primitivas da planície e perfis epidemiológicos de vários ambientes do Vale do Ribeira, São Paulo, Brasil. Revista de Saúde Pública. 1986;20:178-203. 
Forattini OP, Kakitani I, Massad E, Marucci D. Studies on mosquitões (Diptera: Culicidae) and anthropic environment. 11 - Biting activity and blood-seeking parity of Anopheles (Kerteszia) in South-Eastern Brazil. Rev Saúde Pública. 1996;30(2):10714.

Forattini OP, Marques GRAM. Nota sobre o encontro de Ae. Aegypti em bromélias. Rev Saúde Pública. 2000;34:543-4.

Forattini OP, Rabello EX, Cotrim MD. Catálogo das Coleções Entomológicas da Faculdade de Saúde Pública da Universidade de São Paulo (1ª Série) Culicidae. Rev Saúde Pública. 1970;4:1-100.

Forattini OP. Culicidologia médica. São Paulo: EDUSP; 2002. 864 p.

Futuyma DJ. Evolutionary Biology. Sunderland, Mass: Sinauer Associates Press; 1997. $763 \mathrm{p}$.

Gidaszewski N, Baylac M, Klingenberg C. Evolution of dimorphism of wing shape in the Drosophila melanogaster subgroup. BMC Evolutionary Biology. 2009;9:110-27.

Gilchrist AS, Partridge L. The contrasting genetic architecture of wing size and shape in Drosophila melanogaster. Hereditary. 2001;86:144-52

Guimarães AE, Gentile C, Lopes CM, Mello RP. Ecology of mosquitoes (Diptera: Culicidae) in areas of Serra do Mar State Park, State of São Paulo, Brazil. II-Habitat distribution. Memórias do Instituto Oswaldo Cruz. 2000;95(1):17-28.

Haas HL, Tolley KA. Geographic variation of wing morphology in three Eurasian populations of the fruit fly Drosophila lummei. J Zool. 1998;245:197-203.

Henry A, Thongsripong P, Fonseca-Gonzalez I, Jaramillo-Ocampo N, Dujardin JP. Wing shape of dengue vectors from around the world. Infect Genet Evol. 2010;10(2):207-14.

Holsinger KE, Weir BS. Genetics in geographically structured populations: defining,

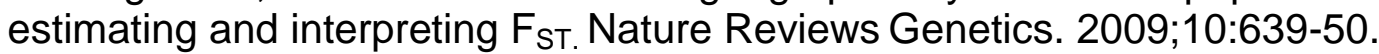

Huey RB, Gilchrist GW, Carlson ML, Berrigan D, Serra L. Rapid evolution of a geographic cline in size in an introduced fly. Science. 2000;287:308-9.

Hurst GDD, Jiggins FM. Problems with mitochondrial DNA as a marker in population, phylogeographic and phylogenetic studies: the effects of inherited symbionts. Proc $R$ Soc B. 2005;272:1525-34.

Jacobs LF. The Economy of Winter: Phenotypic Plasticity in Behavior and Brain Structure. Biol Bull. 1996;191:92-100.

Jirakanjanakit N, Dujardin JP. Discrimination of Aedes aegypti (Diptera: Culicidae) laboratory lines based on wing geometry. Trop Med Public Health. 2005;36(6):85861. 
Jowett T. 1986. Preparation of Nucleic Acids. In: Drosophila, a practical approach. Oxford, U.K. 389 p.

Kakitani I. Observações preliminares sobre a paridade de Anopheles (Kerteszia) cruzii. [dissertação (Mestrado em Ciências)]. São Paulo: Instituto de Ciências Biomédicas, Universidade de São Paulo; 1992. 78 f.

Klingenberg CP. Evolution and development of shape: integrating quantitative approaches. Nature. 2010;(11):623-35.

Kuclu O, Aldemir A, Demirci B. Altitudinal variation in the morphometric characteristics of Aedes vexans Meigen from northeastern Turkey. Journal of Vector Ecology. 2011;(36)30-41.

Lehr MA, Kilpatrick CW, Wilkerson RC, Conn JE. Cryptic species in the Anopheles (Nyssorhynchus) albitarsis (Diptera: Culicidae) complex: incongruence between RAPD-PCR identification and analysis of mtDNA COI gene sequences. Ann Ent Soc Am. 2005;98(6):908-17.

Lima GN. Isolamento, caracterização de locos microssatélites e análise da variabilidade genética de duas populações de Anopheles (N.) darlingi (Diptera: Culicidae) do estado do Amazonas. [dissertação (Mestrado em Genética)]. Manaus: Instituto Nacional de Pesquisas da Amazônia; 2010. 126 f.

Lima MM. Do diagnóstico diferencial entre o Anopheles (Kerteszia) cruzii e o Anopheles (Kerteszia) homunculus na fase larvária. Revista Brasileira de Malariologia e Doenças Tropicais. 1952;4:401-11.

Lozovei AL, Silva MAN. Análise comparativa entre métodos alternativo e convencional para amostras de mosquitos obtidos a partir de habitats fitotélmicos (Bromeliaceae) na Floresta Atlântica, Serra do mar, Paraná, Brasil. Rev Bras Zool. 1999;16:957-66.

Maddison WP. Gene Trees in Species Trees. Syst Biol. 1997;46(3):523-36.

Marques TC, Bourke BP, Laporta GZ, Sallum MAM. Mosquito (Diptera: Culicidae) assemblages associated with Nidularium and Vriesia bromeliads in Serra do mar, Atlantic Forest, Brazil. Parasite \& Vectors. 2012;5:41.

Marques TC. Culicídeos associados às bromélias na Mata Atlântica do município de Cananéia, São Paulo, Brasil. [dissertação (Mestrado em Saúde Pública)]. São Paulo: Faculdade de Saúde Pública da USP, Universidade de São Paulo; 2010. 114 f.

Marrelli MT, Malafronte RS, Flores-Mendoza C, Lourenço-de-Oliveira R, Kloetzel JK, Marinotti O. Sequence analysis of the second internal transcribed spacer (ITS2) of 23 ribosomal DNA in Anopheles oswaldoi (Diptera: Culicidae). Journal Med Entomol. 1999;36:679-84. 
Marrelli MT. Anopheles oswaldoi (Diptera: Culicidae): Análise do Segundo espaçador interno transcrito (ITS2) do DNA ribossômico e da susceptibilidade à infecção com Plasmodium vivax. [tese (Doutorado em Ciências)] São Paulo: Instituto de Ciências Biomédicas, Universidade de São Paulo; 2000. 67 f.

Martins CM. Do diagnóstico diferencial específico entre o Anopheles (Kerteszia) cruzii e o Anopheles (Kerteszia) homunculus pelos caracteres dos adultos fêmeas (Diptera, Culicidae). Revista Brasileira de Malariologia e Doenças Tropicais. 1958;10:429-30.

Matioli SR. Biologia Molecular e Evolução. São Paulo: Holos Editora Press; 2001. $202 \mathrm{p}$.

Mirabello L, Conn JE. Molecular population genetics of the malaria vector Anopheles darlingi in Central and South America. Heredity. 2006;96:311-21.

Monteiro LR, Reis SF. Princípios de morfometria geométrica. Ribeirão Preto: Holos; 1999. 189 p.

Morais SA, Moratore C, Suesdek L, Marreli MT. Genetic-morphometric variation in Culex quinquefasciatus from Brazil and La Plata, Argentina. Mem Instituto Oswaldo Cruz. 2010;105(5):1-5.

Moratore C. Padrões genético-morfológicos em populações de Culex quinquefasciatus (Diptera: Culicidae). [dissertação (Mestrado em Ciências)] São Paulo: Instituto de Ciências Biomédicas, Universidade de São Paulo; 2009. 84 f.

Moritz C, Cícero C. DNA Barcoding: Promise and Pitfalls. PLoS Biol. 2004;2(10):35463.

Motoki MT. Caracterização de populações de Anopheles darlingi (Diptera: Culicidae) do Brasil por estruturas da morfologica externa dos ovos, das asas e por sequências gênicas. [tese (Doutorado em Saúde Pública)]. São Paulo: Faculdade de Saúde Pública, Universidade de são Paulo; 2012. 127 f.

Moutinho PR. Dinâmica e estrutura populacional do Anopheles darlingi em um assentamento rural na floresta amazônica, Acre, Brasil. [dissertação (Mestrado em Ciências Biológicas)] Botucatu: Instituto de Biociências da Universidade Estadual Paulista; 2010. $64 \mathrm{f}$.

Nagylaki T. Fixation indices in subdivided populations. Genetics. 1998;148:1325-32.

Nichols R. Genetrees and speciestrees are not the same. Trends in Ecology and Evolution. 2001;16(7):358-64.

Oshagui MA, Shemshad KH, Yaghobi-Ershadi MR, Pedram M, Vatandoost H, Abaie MR, Akbarzadeh K, Mohtarami F. Genetic structure of the malaria vector Anopheles superpictus in Iran using mitochondrial cytochrome oxidase (COI and COII) and morphologic markers: A new species complex? Acta Tropica. 2006;101:241-8. 
Patsoula E, Samanidou-Voyadjoglou A, Spanakos G, Kremastinou J, Nasioulas G, Vakalis $\mathrm{C}$. Molecular characterization of the Anopheles maculipennis complex during surveillance for the 2004 Olympic Games in Athens. Medical and Veterinary Entomology. 2007;21:36-43.

Peixoto AA, Ronal LDP, Carvalho-Pinto CJ, Gentile C, Grisard EC. Assessing the molecular divergence between Anopheles (Kerteszia) cruzii populations from Brazil using the timeless gene: further evidence of a species complex. Malaria Journal. 2009;8:60. doi:10.1186/1475-2875-8-60.

Peruzin MCJ. Análises comparativas populacionais de Culex quinquefasciatus em dois locais do Estado de São Paulo. [dissertação (Mestrado em Biologia da Relação Patógeno-Hospedeiro)]. São Paulo: Instituto de Ciências Biomédicas, Universidade de São Paulo; 2009. 96 f.

Peyton EL. A new classification for Leucophyrus group of Anopheles (Cellia). Mosquito Systematics. 1990;21:197-205.

Quiñones ML, Ruiz F, Calle DA, Harbach RE, Erazo HF, Linton Y. Incrimination of Anopheles (Nyssorhynchus) rangeli and An. (Nys.) oswaldoi as natural vectors of Plasmodium vivax in Southern Colombia. Mem Inst Oswaldo Cruz. 2006;101(6):61723.

Rachou RG, Ferreira MO. As Kerteszias como grandes responsáveis pela malária no litoral do estado de Santa Catarina. Revista Brasileira de Malariologia e Doenças Tropicais. 1966b;18(3):691-97.

Ramírez CCL, Dessen BEM. Chromosome differentiated populations of Anopheles cruzii: evidence for a third sibling species. Genetica. 2000a;108:73-80.

Ramírez CCL, Dessen EMB. Chromosomal evidence for sibling species of the malaria vector Anopheles cruzii. Genome. 2000b;43:143-51.

Ramirez CCL, Dessen EMB. Cytogenetic analysis of a natural population of Anopheles cruzii. Revista Brasileira de Genética. 1994;17:41-6.

Reeve MW, Fowler K, Partridge J. Increased body size confers greater fitness at lower experimental temperature in male Drosophila melanogaster. J Evol Biol. 2000;13:836-44.

Rezende HR, Soares RM, Cerutti-Junior C, Alves IC, Natal D, Urbinatti PR, Yamasaki T, Falqueto A, Malafronte RS. Caracterização entomológica e infecção natural de anofelinos em área de Mata Atlântica, com casos autóctones de malária, em regiões montanhosas do Espírito Santo. Neotrop. Entomol. 2009;38(2):127-31.

Ridley M. Evolution. Boston: Blackwell Scientific; 2003. 768 p.

Ridley M. Evolution. Oxford: Blackwell Scientific Publications Press; 1993. 768 p. 
Rocha LS. Caracterização de populações de Anastrepha sororcula Zucchi 1979 (Diptera: Tephritidae) por análises cromossômicas, morfométricas e moleculares. [tese (Doutorado em Genética e Biologia Evolutiva)] São Paulo: Instituto de Biociências, Universidade de São Paulo; 2005. 127 f.

Roderick GK. Geographic structure of insect populations: gene flow, phylogeography, and their uses. Annu. Rev. Entomol. 1996;41:325-52.

Rohlf FJ. Relative warp analysis and example of its application to mosquito wings. Contributions to morphometrics. Monografias, Museo Nacional de Ciencias Naturales, Madrid. 1993;135-59.

Rohlf FJ. TpsDig, digitize landmarks and outlines [Computer program]. Version 2.05. Department of Ecology and Evolution, State University of New York. Stony Brook; 2005.

Rohlf FJ. TpsRegr, shape regression [Computer program]. Version 1.28. Department of Ecology and Evolution, State University of New York. Stony Brook; 2003b.

Rohlf FJ. TpsRelw, relative warps analysis [Computer program]. Version 1.36. Department of Ecology and Evolution, State University of New York. Stony Brook; 2003a.

Rohlf FJ. TpsUtil, file utility program [Computer program]. Version 1.26. Department of Ecology and Evolution, State University of New York. Stony Brook; 2004.

Rona LDP, Carvalho-Pinto CJ, Gentile C, Grisard EC, Peixoto AA. Assessing the molecular divergence between Anopheles (Kerteszia) cruzii populations from Brazil using the timeless gene: further evidence of a species complex. Malar J. 2009;8:60.

Rona LDP, Carvalho-Pinto CJ, Mazzoni CJ, Peixoto AA. Estimation of divergence time between two sibling species of the Anopheles (Kerteszia) cruzii complex using a multilocus approach. BMC Evol Biol. 2010a;10:91.

Rona LDP, Carvalho-Pinto CJ, Peixoto AA. Molecular evidence for the occurrence of a new sibling species within the Anopheles (Kerteszia) cruzii complex in South-east Brazil. Malar J. 2010b;9:33.

Rosa-Freitas MG, Lourenco-de-Oliveira R, Carvalho-Pinto CJ, Flores-Mendoza C, Silva-do-Nascimento TF. Anopheline species complexes in Brazil. Current knowledge of those related to malaria transmission Source. Memórias Do Instituto Oswaldo Cruz. 1998;93(5):651-55.

Rozas J, Sánchez-DelBarrio JC, Messeguer X, Rozas R. DnaSP, DNA polymorphisms analyses by the coalescente and other Methods. Bioinformatics Application Note. 2003;19(18):2496-97.

Sallum MAM, Bergo ES, Flores DC, Forattini OP. Systematic studies on Anopheles galvaoi Causey, Deane \& Deane from the subgenus Nysssorhynchus blanchard (Diptera: Culicidae). Mem Inst Oswaldo Cruz. 2002;97(8):1177-89. 
Sallum MAM, Urbinatti PR, Malafronte RS, Resende HR, Cerutti-Junior C, Natal D. Primeiro registro de Anopheles (Kerteszia) homunculus Komp (Diptera, Culicidae) no Estado do Espírito Santo, Brasil. Revista Brasileira de Entomologia. 2008;52(4):67173.

Sambrook J, Fritsch EF, Maniatis T. Molecular Cloning: a laboratory manual. Cold Londres. Springs Harbor Laboratory Press; 1989. 65 p.

São Paulo. Prefeitura Municipal da Estância de Cananéia. Mapa de Cananéia. Disponível em: http://www.cananeia.sp.gov.br/index.php?exibir=secoes \&ID=50 [2012 set. 17].

Scarpassa VM, Cardoza TB, Cardoso RP. Population Genetics and Phylogeography of Aedes aegypti (Diptera: Culicidae) from Brazil. Am J Trop Med Hyg. 2008;78(6):895-903.

Service MW. Medical Entomology. London: Chapman \& Hall Press. 1996. 165 p.

Seto MI. Ocorrência de mosquitos (Diptera: Culicidae) em bromélias da localidade de Aldeia dos Índios, área endêmica de malária no município de Peruíbe (SP), no período de julho de 1985 a julho de 1987 [dissertação (Mestrado em Ciências)]. São Paulo: Instituto de Ciências Biomédicas, Universidade de São Paulo; 1992. 105 f.

Simon C, Frati F, Beckenbach A, Crespi B. Evolution, weighting, and phylogenetic utility of mitochondrial gene sequences and a compilation of conserved polymerase chain reaction primers. Ann. Entomol. Soc. Am. 1994;87:651-701.

Singhaniyom C, Bellec, Dujardin JP. Influence of larval density or food variation on the geometry of the wing of Aedes (Stegomyia) aegypti. Trop Med Int Health. 2007;12(11):1354-60.

Stark J, Bonacum J, Remsen J, DeSalle R. The evolution and development of Dipteran wing veins: A Systematic Approach. Annual Review of Entomology. 1999;44:97-129

StatSoft, Inc. Statistica for Windows [Computer program manual]. Tulsa, OK:

StatSoft, Inc;. Available from: http://www.statsoft.com. 2004. [2010 ago 13].

Stegnii VN. Genetic adaptation and speciation in sibling species of the Eurasian maculipennis complex. Recent Developments in the Genetics of Insect Disease Vectors. 1982;(3)454-64.

Tadei WP, Dutary-Thatcher B. Malaria vectors in the Brazilian Amazon: Anopheles of the subgenus Nyssorhynchus. Revista Inst Med Tropical. 2000;42(2):87-94.

Tamura K, Dudley J, Nei M, Kumar S. MEGA 5.0: Molecular Evolutionary Genetics Analysis (MEGA) software version 5.0. Molecular Biology and Evolution. 2007;24:1596-99. 
Taylor CE, Toure YT, Coluzii M, Petrarca V. Effective population size and persistence of Anopheles arabiensis during the dry season in West Africa. Medical and Veterinary Entomology. 1993;7(4):351-57.

Templeton AR. Genética de populações e teoria microevolutiva. Ribeirão Preto, SP: Holos; 2011. 705 p.

Veloso HP, Moura JV, Klein RM. Delimitação Ecológica dos anofelinos do subgênero Kerteszia na região costeira do sul do Brasil. Memórias do Instituto Oswaldo Cruz.1956;54(3):517-20.

Veloso HP. Considerações Gerais sobre os Biótopos e Habitats dos Anofelinos do Subgênero Kerteszia. Mem Inst Oswaldo Cruz. 1958;56:165-79.

Vezzani D, Velásquez SM, Schweigmann N. Seasonal Pattern of Abundance of Aedes aegypti (Diptera: Culicidae) in Buenos Aires City, Argentina. Mem Inst Oswaldo Cruz. 2004;99(4):351-56.

Vidal PO, Rocha LS, Peruzin MCJ. Wing diagnostic characters for mosquitoes Culex quinquefasciatus and Culex nigripalpus (Diptera; Culicidae). Revista Brasileira de Entomologia. 2011;55:132-42.

Vidal PO, Carvalho E, Suesdek L. Temporal variation on wing geometry of Aedes albopictus. Mem Inst Oswaldo Cruz. 2012. In press.

Walsh JF, Molyneux DH, Birley MH. Deforestation: effects on vector-borne disease. Parasitology. 1993;196:55-75.

Wekesa JW, Brogdon WG, Hawley WA, Besansky NJ. Flight tone of field collected populations of Anopheles gambie and An. arabiensis (Diptera: Culicidae). Physiol Entomol. 1998;23(3):289-94.

White GB. Malaria vectors ecology and genetics. British Medical Bulletin. 1982;38:207-12.

World Health Organization (WHO) [homepage on the internet]. Malaria Media Center. Available from: http://www.who.int/mediacentre/factsheets/fs094/en/index.html). [2012 Sep 17].

Wilkerson RC, Peyton EL. The brazilian malaria vector Anopheles (Kerteszia) cruzii: life stages and biology (Diptera: Culicidae). Mosquito Systematics. 1991;23(2):11022.

Wooton RJ. Functional morphology of insects wings. Annu. Rev Entomol. 1992; 37:113-40.

Wright S. Evolution and genetics of populations. Chicago: University of Chicago Press; 1978. $511 \mathrm{p}$. 
Zavortink TJ. Mosquito studies (Diptera: Culicidae) XXIX. A review of the subgenus Kerteszia of Anopheles. Contribution of the American Entomological Institute. 1973;9:1-54.

Zhang DX, Hewitt E. Assessment of the universality and utility of a set of conserved mitochondrial COI primers in insects. Insect Molecular Biology. 1996;6:143-50. 
APÊNDICE A - Artigo de Periódico 
[Artigo in press, Parasite \& Vectors]

\title{
Morphometrical diagnosis of the malaria vectors Anopheles cruzii, An. homunculus and An. bellator
}

\author{
Camila Lorenz ${ }^{1}$, Tatiani Cristina Marques ${ }^{2}$, Maria Anice Mureb Sallum², Lincoln Suesdek ${ }^{1 /+}$. \\ 1 Programa de Pós-graduação (Mestrado) em Ciências (Biologia da Relação Patógeno-Hospedeiro), \\ Instituto de Ciências Biomédicas, Universidade de São Paulo, Brazil. \\ 2 Departamento de Epidemiologia, Faculdade de Saúde Pública, Universidade de São Paulo \\ 3 Laboratório de Parasitologia, Instituto Butantan, Avenida Vital Brasil, 1500, 05509-300 São Paulo- \\ SP, Brazil. \\ + Corresponding author: linrocha@butantan.gov.br
}

\begin{abstract}
Background: Anopheles (Kerteszia) cruzii is a primary vector of Plasmodium parasites in Brazil's Atlantic Forest. Adult females of An. cruzii and An. homunculus, which is a secondary malaria vector, are morphologically similar and difficult to distinguish when using external morphological characteristics only. These two species may occur syntopically with An. bellator, which is also a potential vector of Plasmodium species and is morphologically similar to An. cruzii and An. homunculus. Identification of these species based on female specimens is often jeopardised by polymorphisms, overlapping morphological characteristics and damage caused to specimens during collection. Wing geometric morphometrics has been used to distinguish several insect species; however, this economical and powerful tool has not been applied to Kerteszia species. Our objective was to assess wing geometry to distinguish An. cruzii, An. homunculus and An. bellator. Methodology: Specimens were collected in an area in the Serra do Mar hotspot biodiversity corridor of the Atlantic Forest biome (Cananeia municipality, State of Sao Paulo, Brazil). The right wings of females of $A n$. cruzii $(n=40)$, An. homunculus $(n=50)$ and An. bellator $(n=27)$ were photographed. For each individual, 18 wing landmarks were subjected to standard geometric morphometrics. Discriminant analysis of Procrustean coordinates was performed to quantify wing shape variation. Results: Individuals clustered into three distinct groups according to species with a slight overlap between representatives of An. cruzii and An. homunculus. The Mahalanobis distance between An. cruzii and An. homunculus was consistently lower (3.50) than that between An. cruzii and An. bellator (4.58) or An. homunculus and An. bellator (4.32). Pairwise cross-validated reclassification showed that geometric morphometrics is an effective analytical method to distinguish between $A n$. bellator, An. cruzii and $A n$. homunculus with a reliability rate varying between $78-88 \%$. Shape analysis revealed that the wings of An. homunculus are narrower than those of An. cruzii and that An. bellator is different from both of the congeneric species. Conclusion: It is possible to distinguish among the vectors An. cruzii, An. homunculus and An. bellator based on female wing characteristics.
\end{abstract}

Keywords: Culicidae, Kerteszia, wing geometric morphometrics, identification, malaria vectors, Atlantic Forest. 


\section{BACKGROUND}

The genus Anopheles of the family Culicidae contains species that are widely distributed throughout South America [1]. These species are commonly associated with watercourses and forests, frequently in coastal areas. In Brazil, the primary anopheline species involved in Plasmodium transmission belong to two subgenera, i.e., Nyssorhynchus (Anopheles darlingi, An. aquasalis, An. nuneztovari s.l., An. oswaldoi, An. triannulatus s.l. and species of the An. albitarsis complex) [2, 3] and Kerteszia (An. cruzii, An. bellator and An. homunculus) [4], with An. cruzii and An. darlingi as the primary vectors of Plasmodium species [5]. The autochthonous transmission of extra-Amazonian malaria occurs mainly in areas of the Southeastern coastal Serra do Mar mountain range, where An. cruzii is a primary vector [6]. Anopheles homunculus and An. bellator are also important secondary vectors of human Plasmodium in that region [7, 8]. In this region, An. bellator, An. cruzii and An. homunculus occur in sympatry and are somewhat morphologically similar. Most Kerteszia species use bromeliad phytothelmata as larval habitats, with the exception of $A n$. bambusicolus, whose habitat is water accumulated inside bamboo internodes [9].

According to Harrison et al. [10], the females of An. cruzii and An. homunculus can be distinguished by the scaling on maxillary palpomeres 3 and 4 . In addition, Martins [11] showed that the integument of the abdominal terga in An. cruzii females are uniformly reddish or reddish with lighter portions, whereas the abdominal integument of $A n$. homunculus are blackish with whitish areas. For larval differentiation, Lima [12] observed that the saddles of segment $X$ are lightly sclerotised in An. cruzii, with either yellowish or reddish integument. By contrast, the larvae of An. homunculus have strongly pigmented saddles of segment X, with dark brown to blackish integument [13]. Anopheles bellator can be distinguished from $A n$. cruzii and An. homunculus by the narrow apical pale bands on hindtarsomeres 2-4 (Figure 1), which are $30 \%$ or less of the length of the tarsomeres, and the typically entirely dark colouration of hindtarsomere 5; by contrast, hindtarsomeres $2-5$ are $50 \%$ basal black and 50\% apical pale in An. cruzii and An. homunculus [10]. The morphological identification of these species is often hampered by variability in the diagnostic characteristics and by damage to insect body parts caused by the capture procedure [13].

Recently published literature shows an increasing tendency towards assessing medically important insect species using geometric morphometrics [14-18], an analytical tool that allows for multivariate statistical descriptions of biological structures [19]. In insects, the wings are the main target for morphometrics because of their two-dimensional form and homologous vein patterns. In the present study, we used geometric morphometrics as a complementary and low-cost tool to identify vector species of the subgenus Kerteszia, focusing on three species that occur in areas of the coastal Atlantic Forest.

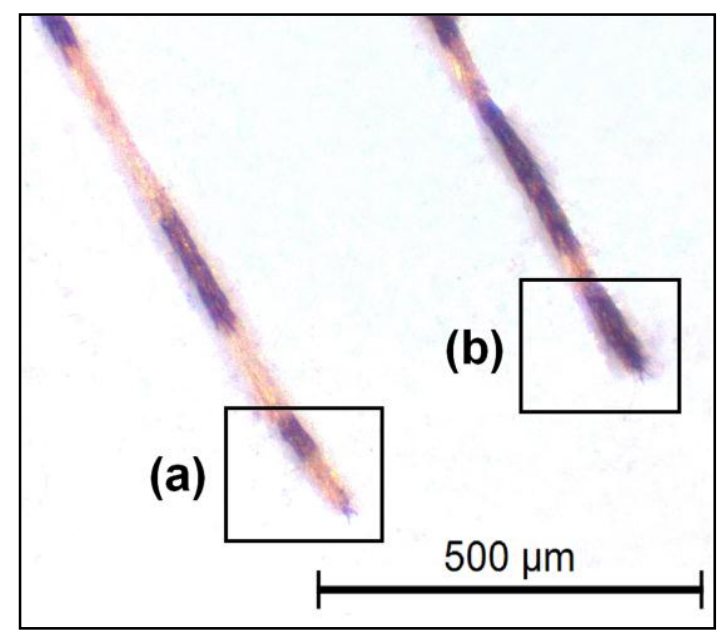

Figure 1 - Morphological differentiation of $5^{\circ}$ posterior tarsomere visualized in adults of $A n$. cruzii (a) and An. bellator (b). 


\section{MATERIAL AND METHODS}

\section{Biological sampling}

All of the specimens were collected in an area of the Atlantic Forest biome in the municipality of Cananeia, State of São Paulo, Brazil, more specifically in the neighborhood of

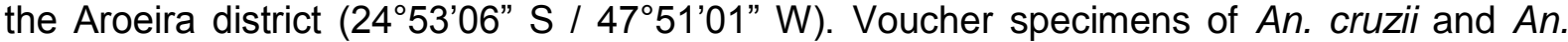
homunculus were deposited in the Coleção Entomológica de Referência, Faculdade de Saúde Pública, Universidade de São Paulo (FSP-USP), Brazil. Mosquito larvae and pupae were taken from water that had accumulated in bromeliad tanks in 2009 and reared in the laboratory until adult emergence under standard conditions of temperature, food availability and container size. Adult females of An. bellator were captured in July and November 2011 with Shannon traps and preserved in plastic vials with silica gel. Species were identified based on colour pattern of larvae, according to Lima [12].

\section{Material preparation and data acquisition}

The right wings of females of An. cruzii $(\mathrm{n}=40)$, An. homunculus $(\mathrm{n}=50)$ and $A n$. bellator $(n=27)$ were removed from adults and cured before being mounted on microscope slides. The wings were soaked for 12 hours in a $10 \%$ potassium hydroxide $(\mathrm{KOH})$ solution at room temperature to remove the wing scales. The potassium hydroxide was removed by washing the wings in a $20 \%$ solution of acetic acid. The wings were dyed with acid fuchsin for 60 minutes and then dehydrated in a series of ethanol concentrations ranging from $80 \%$ to $98 \%$. Images of the wings were captured using a Leica DFC320 digital camera coupled to a Leica S6 microscope with 40X magnification. Eighteen wing landmarks (Figure 2) of each individual were digitised using the TpsDig software V.1.40 (QSC - James Rohlf), and the coordinate images were plotted onto a Cartesian plane for geometric descriptions. All of the wings were scanned twice, and the repeatability of the digitising procedure was assessed using statistical tests [20, 21]. The wing pictures were deposited in the CLIC Image Bank (http://bioinfo-prod.mpl.ird.fr/morphometrics/clic/declic/list.html).
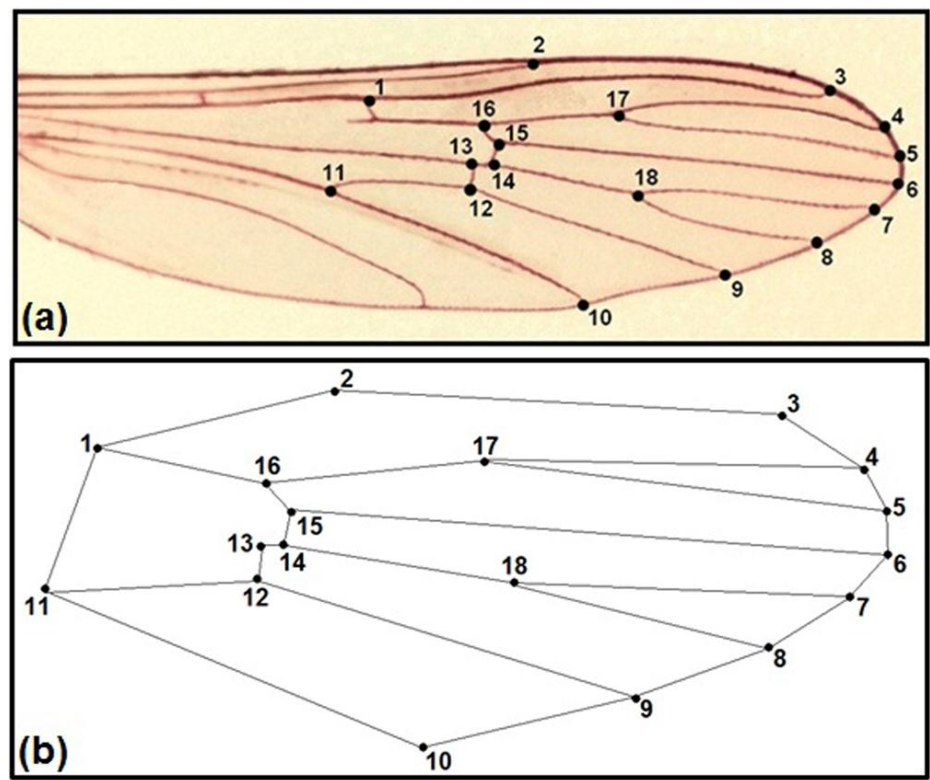

Figure 2 - (a) Wing of female Anopheles bellator colored with acid fuchsin showing the 18 landmarks selected for geometric morphometrics. (b) Diagram of immaginary links between landmarks used to depict wing consensus. 
Geometric morphometrics analysis

The wing size was estimated using isometric measurements of the centroid size [15, 22]. Generalised Procrustes analysis was performed to assess the wing shape. To describe the shape variation without the effects of allometry, a regression analysis was performed between the coordinates of the landmarks and the centroid size for each of the three species.

Discriminant analysis of the canonical variables was performed. To test the accuracy of species classification yielded by morphometrics, each individual was reclassified by comparing the shape with the overall mean wing size of each species using the Mahalanobis distances. The reclassification was cross-validated, and the distances were estimated in discriminant axes in the absence of the individual to be classified. Thin-plate splines were obtained by regression of the canonical scores versus the shape components. The morphometric statistical analyses were conducted with the software TpsUtil 1.29, TpsRelw 1.39 (QSC - James Rohlf), MorphoJ 1.02 and Statistica 7.0. The graphics were generated using Statistica and MorphoJ 1.02.

\section{RESULTS}

The mean centroid size of $A n$. cruzii was $1.62 \mathrm{~mm}$ (range $1.45-1.77 \mathrm{~mm}$ ), that of $A n$. homunculus was $1.71 \mathrm{~mm}$ (range $1.60-1.93 \mathrm{~mm}$ ), and that of An. bellator was $1.59 \mathrm{~mm}$ (range $1.46-1.77 \mathrm{~mm}$ ). Only the mean centroid size of An. homunculus (Figure 3) was significantly different from those obtained for the other two species $(\mathrm{P}<0.001$; ANOVA + Tukey-Kramer post-hoc test). The allometric effect was low $(5.47 \%)$ but statistically significant $(P<0.0001)$ and was removed from the shape analyses. A second round of analyses were conducted, with the allometric effect included, however, the results were essentially similar.

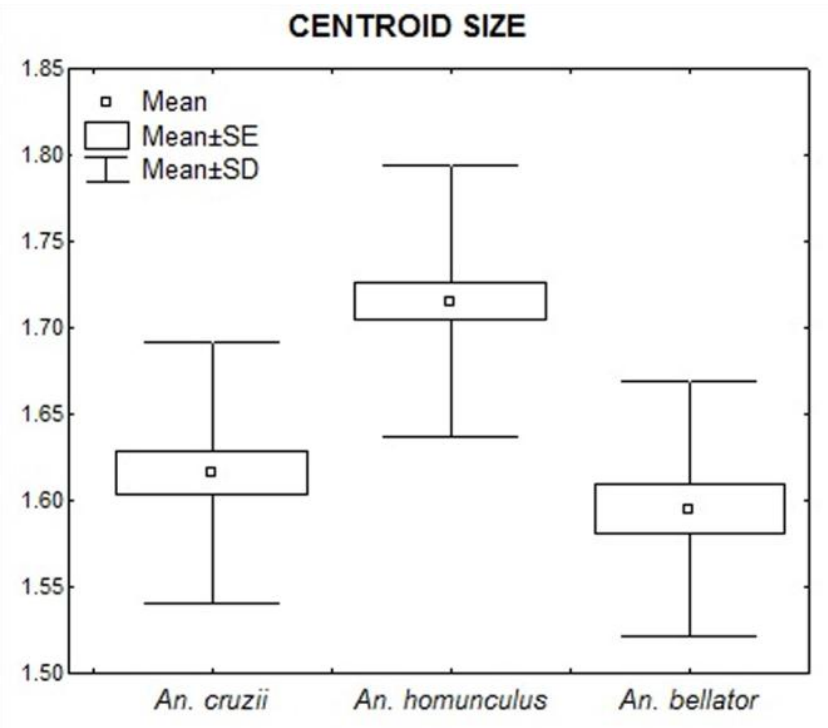

Figure 3 - Descriptive statistics of centroid sizes (in $\mathrm{mm}$ ). 
The canonical variate analysis for the wing shape showed that individuals clustered into distinct groups in the morphospace according to each species (Figure 4). Anopheles bellator was found to be isolated from the other species, whereas An. cruzii and An. homunculus slightly overlapped. The Procrustes distance between these two species was lower (3.50) than between An. cruzii and An. bellator (4.58) or between An. homunculus and An. bellator (4.32). The accuracy scores after a cross-validated reclassification test ranged from $78 \%$ to $88 \%$ (Table 1 ).

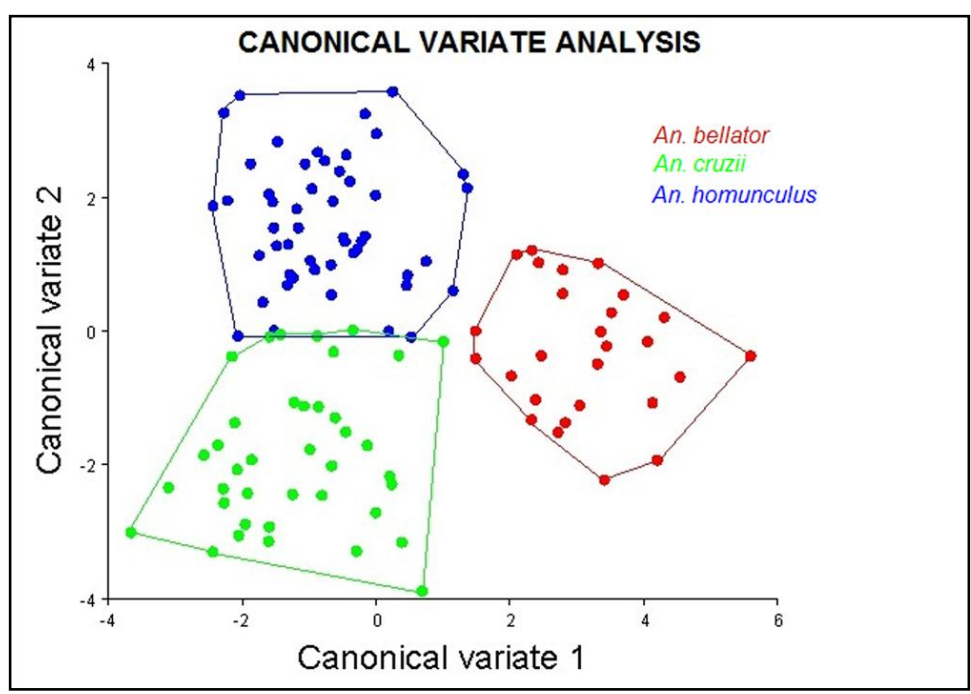

FIG.4 - Morphological space of canonical variates resulting from comparison among the three species.

Table 1- Validated reclassification accuracies of each species derived from the three pairwise comparisons.

\section{Compared species Reclassification Scores}

\begin{tabular}{cc}
\hline An. cruzii & $82 \%$ \\
An. homunculus & $82 \%$ \\
\hline An. cruzii & $82 \%$ \\
An. bellator & $88 \%$ \\
\hline An. homunculus & $78 \%$ \\
An. bellator & $84 \%$ \\
\hline
\end{tabular}

Thin-plate splines with pairwise comparison of species evidenced higher displacement of certain landmarks that were more informative for species identification (Figure 5). The greatest distinction between An. bellator and An. cruzii was found with landmarks 1, 17 and 18, whereas the distinction between An. bellator and An. homunculus was most clear using landmarks 1, 2, 3, 17 and 18. The main shape differences when comparing An. cruzii and An. homunculus were observed in landmarks 1, 2, 3, 12 and 13.

We noted that distances between some most-influential landmarks were also conspicuously distinct between species: distance between landmarks 13-14 (distance $\mathrm{x}$ ); 1213 (distance y); 2-13 (distance z); and 15-18 (distance w). Ratios between those distances are depicted in Figure 6, which allow one to diagnose the species based on a single value. The mean ratio between dimensions $\mathrm{x}$ and y was 0.97 for An. cruzii, 0.94 for An. homunculus and 0.61 for An. bellator (Figure 7), with An. bellator being significantly different from the other species (T-test, $\mathrm{P}<0.0001$ ). The $\mathrm{z} / \mathrm{w}$ ratio was 0.72 for $A n$. cruzii, 0.74 for An. bellator 
and 0.63 for An. homunculus, with An. homunculus being significantly different from the other species (T-test, $\mathrm{P}<0.0001$ ) (Figure 8).

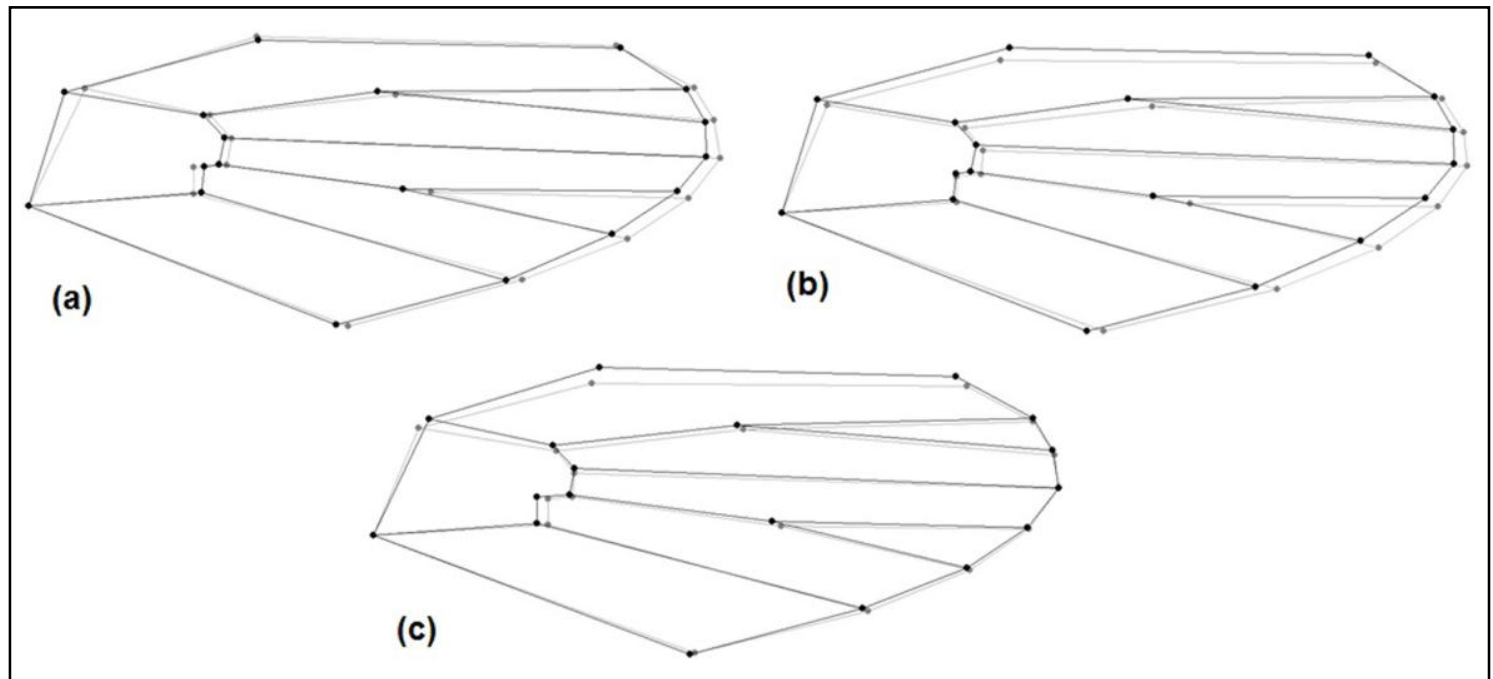

Figure 5 - Pairwise comparison of thin plate spline between species. Landmarks displacement correspond to extreme of diferentiation in each species. (a) An. cruzii (gray) and An. bellator (black);

(b) An. bellator (black) and An. homunculus (gray) and (c) An. homunculus (gray) and An. cruzii (black).

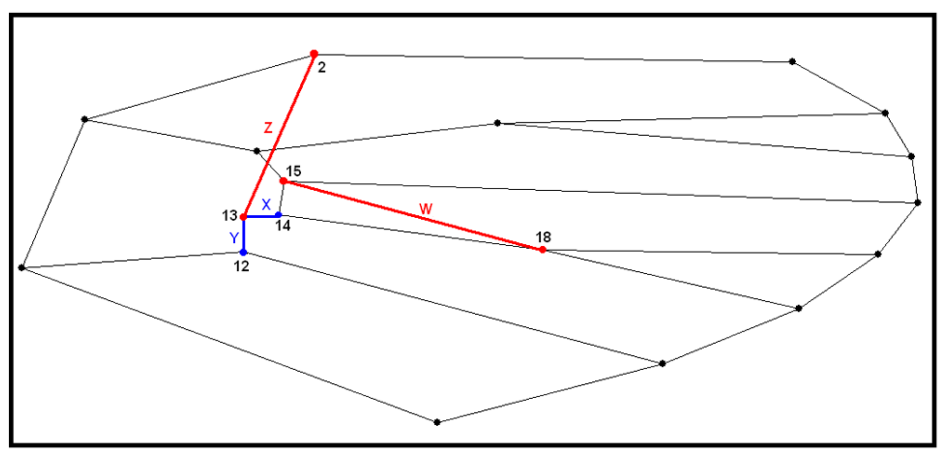

Figure 6 - Graphical presentation of the distance between landmarks used for ratios x/y and z/w.

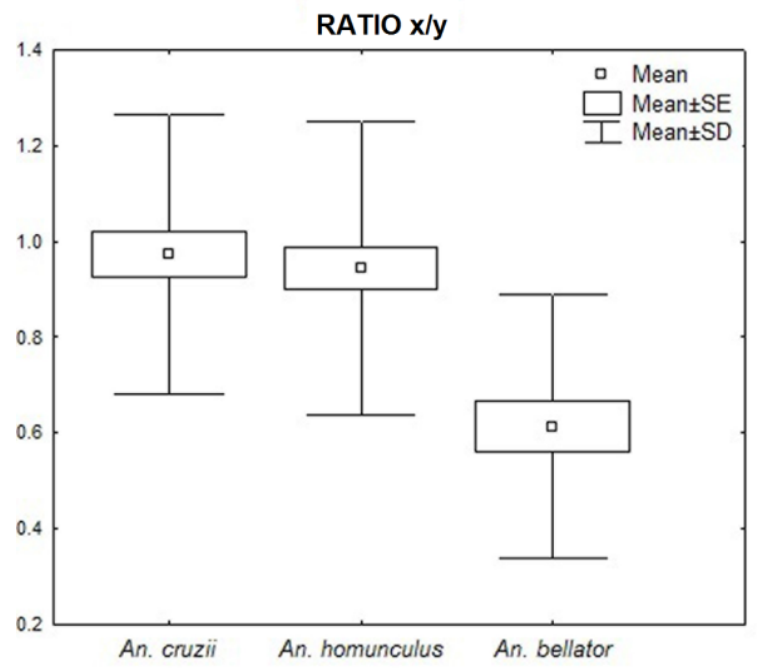

Figure 7 - Descriptive statistics of ratio x/y (in mm). 


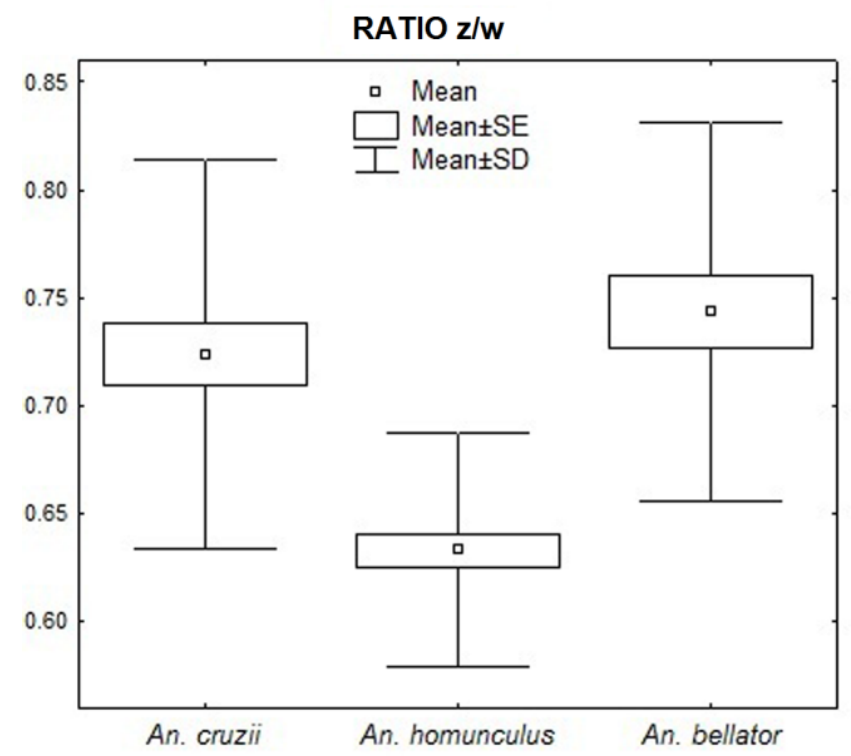

Figure 8 - Descriptive statistics of ratio $\mathrm{z} / \mathrm{w}$ (in $\mathrm{mm}$ ).

\section{DISCUSSION}

Adult females of An. homunculus and An. cruzii are morphologically similar; consequently, distinction between these species is generally problematic when using only the classical morphological characteristics described in identification keys [13]. The correct identification of species is essential for recognition of the vectors involved in the transmission of malaria and for helping researchers to develop control strategies [7]. Geometric morphometrics analyses revealed that An. homunculus, An. cruzii and An. bellator can be distinguished based on wing characteristics.

The results of the discriminant analysis showed that An. bellator is well separated from both An. cruzii and An. homunculus in the morphospace of the canonical variables. This finding is consistent with previous results indicating that $A n$. bellator can be easily distinguished by the adult external morphology (hindtarsomere 5). However, one would expect higher phenotypic similarity between An. bellator and An. homunculus if the wing shape is directly associated with the close phylogenetic relationships between the species [23]. An. cruzii and An. homunculus, which are occasionally misidentified [9], were also discriminated despite partial overlapping in the morphospace of canonical variables.

The wing shape divergence among these three species was not as significant as that for species of the genera Culex and Aedes [16, 24], which may be a result of recent diversification of the subgenera [23] or due to evolutionary constraints. The close evolutionary relationships among Kerteszia representatives might be reflected in the wing shape because of the heritability of this organ, as proposed for other insects [12]. Anopheles bellator and An. homunculus can coexist in bromeliads and compete for resources [25], and this close association could impose constraints or favour canalisation to the observed phenotype.

Considering that the results obtained either with or without allometry were similar, we conclude that size variation did not interfere with species delimitation. Anopheles homunculus had the largest size among species in this study; however, we cannot ascertain that this comparison holds in nature because size is commonly subject to plasticity $[15,24$, 26]. At least for An. homunculus and An. cruzii, it is plausible to consider that the size disparity may be associated with genetic determinism because both species were collected in the larval stage and reared to adults in the laboratory under similar environmental conditions and food resource availability. 
Specimen collectings were not simultaneous (years 2009 and 2011), what could lead us to believe that interespecific wing shape divergency may be partly a result of assynchronic sampling and microevolutionary changes. Such idea is unlikely because the three-years interval is extremely shorter than the divergence time among the Anopheles species involved [23]. It has been recently reported wing shape variation in Aedes albopictus within four years [27] however such variation is slight in comparison to macroevolutionary changes. Additionally, phenetic distance between Ae. aegypti and Ae. albopictus based on wing shape remained equivalent over several years [24].

In addition to helping taxonomists identify species, geometric morphometrics maybe used by health professionals to identify species in the future. This technique will not end up with other methods of identifying, such as those based on the costal wing spots, but will complement them. Whereas present work was essentially based on wing landmarks, papers from Wilkerson and Peyton (1990) [28] and Motoki et al (2009) [29] successfully used wing spots relative sizes to identify Anopheles species. Although it is not an easy task to simultaneously analise landmarks and dark spots in Anopheles wing, we hope in a future to combine landmark and spot-based morphometrics, as suggested by Garros \& Dujardin (in prep).

The mean ratio of dimensions $x$ and $y$ is $2 / 3$ in $A n$. bellator, whereas this ratio is nearly $1 / 1$ in $A n$. cruzii and An. homunculus. Remarkably, the length of segment 13-14 (distance $\mathrm{x}$ ) in some individuals of $A n$. bellator is so short that the segment is almost nonexistent. As far as we know, such vein pattern has not been observed in other culicids. Although the occasionally vestigial segment does not directly contribute to the diagnosis proposed here, it may be worth an investigation. As an example, the absence of a wing vein in Drosophila melanogaster was characterised as an informative mutation named crossveinless [30]. Additionally, the mean ratio $\mathrm{z} / \mathrm{w}$ of $A n$. homunculus was lower than those of the other two species. Accordingly, as shown in Figure 5, the wings of Anopheles homunculus are narrower anteroposteriorly.

Apart from the morphological characteristics used in this study, molecular taxonomic markers have been developed for Kerteszia species [13], facilitating species identification and delimitation. The employment of geometric morphometric methods in taxonomic studies is promising and should be performed in conjunction with other methods to facilitate the correct identification of anopheline species.

Acknowledgements

This investigation has financial support from the Fundação de Amparo à Pesquisa do Estado de São Paulo, FAPESP (Grants no. 2011/20397-7; 2005/53973-0), CAPES (Grant no. 23038.005274/2011-24), and CNPq (BPP no. 301666/2011-3 to MAMS). CL is a master recipient of a CNPq scholarship no. 135207/2011-8.

\section{REFERENCES}

1. Consoli RAGB, Lourenço-de-Oliveira R: Principais mosquitos de importância sanitária no Brasil. Fiocruz: Rio de Janeiro, Brasil Press; 1994.

2. Marrelli MT, Malafronte RS, Flores-Mendoza C, Lourenço-de-Oliveira R, Kloetzel JK, Marinotti O: Sequence analysis of the second internal transcribed spacer (ITS2) of 23 ribosomal DNA in Anopheles oswaldoi (Diptera: Culicidae). Journal Med. Entomol 1999, 36: 679-684.

3. Tadei WP, Dutary-Thatcher B: Malaria vectors in the Brazilian Amazon: Anopheles of the subgenus Nyssorhynchus. Rev Inst Med Trop 2000, 42: 87-94.

4. Ramirez CCL, Dessen EMB: Cytogenetic analysis of a natural population of Anopheles cruzii. Rev Bras Gen 1994, 17: 41-46. 
5. Ferreira SR, Luz N: Malária no estado do Paraná - Aspectos históricos e prognose. Acta Biol Par 2003, 32: 129-156.

6. Arruda M, Carvalho MB, Nussenzweig RS, Maracic M, Ferreira AW, Cochrane AH: Potential vectores of malaria and their different susceptibility to Plasmodium falciparum and Plasmodium vivax in northern Brazil identified by immunoassay. Am J Trop Med Hyg 1986, 35: 873-881.

7. Forattini OP: Culicidologia Médica. São Paulo: Editora da Universidade de São Paulo Press; 2002.

8. Rezende HR, Junior $\mathrm{CC}$, dos Santos $\mathrm{CB}$ : Aspectos atuais da distribuição demográfica de Anopheles (Kerteszia) cruzii Dyar \& Knab (1908) no Estado do Espírito Santo, Brasil. Entomologia y Vectores 2005, 12: 123-126.

9. Sallum MAM, Urbinatti PR, Malafronte RS, Resende HR, Cerutti-Junior C, Natal D: Primeiro registro de Anopheles (Kerteszia) homunculus Komp (Diptera, Culicidae) no Estado do Espírito Santo, Brasil. Rev Bras Entomol 2008, 52: 671-673.

10. Harrison BA, Ruiz-Lopez F, Falero GC, Savage HM, Pecor JE, Wilkerson RC: Anopheles (Kerteszia) lepidotus (Diptera: Culicidae), not the malaria vector we thought it was: Revised male and female morphology; larva, pupa and male genitalia characters; and molecular verification. Zootaxa 2012, 3228:1-17.

11. Martins CM: Do diagnóstico diferencial específico entre o Anopheles (Kerteszia) cruzii e o Anopheles (Kerteszia) homunculus pelos caracteres dos adultos fêmeas (Diptera, Culicidae). Rev Bras Malario e D Trop 1958, 10: 429-430.

12. Lima MM: Do diagnóstico diferencial entre o Anopheles (Kerteszia) cruzii e o Anopheles (Kerteszia) homunculus na fase larvária. Rev Bras Malario e D Trop 1952, 4: 401-411.

13. Calado DC, Navarro-Silva MA: Identificação de Anopheles (Kerteszia) cruzii Dyar \& Knab e Anopheles (Kerteszia) homunculus Komp (Diptera, Culicidae, Anophelinae) através de marcadores moleculares (RAPD e RFLP). Rev Bras Entomol 2005, 22:1127-1133.

14. Jirakanjanakit N, Dujardin JP: Discrimination of Aedes aegypti (Diptera: Culicidae) laboratory lines based on wing geometry. Trop Med Public Health 2005, 36: 858-861.

15. Dujardin JP: Morphometrics applied to medical entomology. Infect Genet Evol 2008, 8: 875890.

16. Vidal PO, Rocha LS, Peruzin MC: Wing diagnostic characters for mosquitoes Culex quinquefasciatus and Culex nigripalpus (Diptera; Culicidae). Rev Bras Entomol 2011, 55: 134137.

17. Dujardin JP, Le Pont F: Geographic variation of metric properties within the neotropical sandflies. Infect Genet Evol 2004, 4: 353-359.

18. Motoki MT, Suesdek L, Bergo ES, Sallum MAM: Wing geometry of Anopheles darlingi (Diptera: Culicidae) in five major Brazilian ecoregions. Infect Genet Evol 2012, in press.

19. Monteiro LR, Reis SF: Princípios de morfometria geométrica. Ribeirão Preto: Holos Press; 1999.

20. ASQC / AIAG: Fundamental statistical process control reference manual. Troy, MI: AIAG Press; 1991.

21. Arnqvist G, Mårtensson $T$ : Measurement error in geometric morphometrics: empirical strategies to assess and reduce its impact on measure of shape. Acta Zool. 1998, 44: 73-96 
22. Rohlf FJ: Shape statistics: Procrustes superimpositions and tangent spaces. Journal of Classification 1999, 16: 197-223.

23. Colucci E, Sallum MAM: Phylogenetic analysis of the subgenus Kerteszia of Anopheles (Diptera: Culicidae: Anophelinae) based on morphological characters. Insect System Evol 2003, 3:372-373.

24. Henry A, Thongsripong P, Fonseca-Gonzalez I, Jaramillo-Ocampo N, Dujardin JP: Wing shape of dengue vectors from around the world. Infect Genet Evol 2010, 10: 207-214.

25. Pittendrigh CS: The Ecotopic Specialization of Anopheles homunculus and Its Relation to Competition with A. bellator. Evolution 1949, 4: 64-78.

26. Hernández ML, Abrahan LB, Dujardin JP, Gorla DE, Catalá SS: Phenotypic Variability and Population Structure of Peridomestic Triatoma infestans in Rural Areas of the Arid Chaco (Western Argentina): Spatial Influence of Macro- and Microhabitats. Vector-Borne and Zoonotic Diseases 2011, 5: 503-513.

27. Vidal PO, Carvalho E, Suesdek L: Temporal variation on wing geometry of Aedes albopictus. Mem Inst Oswaldo Cruz 2012, in press.

28. Wilkerson RC, Peyton EL: Standardized Nomenclature for the Costal Wing Spots of the Genus Anopheles and Other Spotted-Wing Mosquitoes (Diptera: Culicidae). Journal of Medical Entomology 1990, 27: 207-224.

29. Motoki MT, Wilkerson RC, Sallum MAM: The Anopheles albitarsis complex with the recognition of Anopheles oryzalimnetes Wilkerson and Motoki, n. sp. and Anopheles janconnae Wilkerson and Sallum, n. sp. (Diptera: Culicidae). Mem Inst Oswaldo Cruz 2009, 104: 823-850.

30. Bridges CB: The Mutant Crossveinless in Drosophila melanogaster. Proc Natl Acad Sci U S A. 1920, 6: 660-663 
APÊNDICE B - Quadros de haplótipos 
Quadro A.1 - Sítios variáveis dos 49 haplótipos encontrados no gene CO-I em An. cruzii no inverno x verão e no morro x planície de JAN/12. Os números em negrito representam o local na sequência que ocorreu a mudança. As bases em cinza são aquelas variáveis nas sequências.

\begin{tabular}{|c|c|c|c|c|c|c|c|c|c|c|c|c|c|c|c|c|c|c|c|c|c|c|c|c|c|c|c|c|c|c|c|c|c|}
\hline \multirow[b]{2}{*}{ Haplotipo } & \multirow[b]{2}{*}{13} & \multirow[b]{2}{*}{46} & \multirow[b]{2}{*}{49} & \multirow[b]{2}{*}{50} & \multicolumn{29}{|c|}{ Posições das mudanças nucleotidicas em An. cruzii } \\
\hline & & & & & 70 & 73 & 85 & 97 & 100 & 106 & 112 & 121 & 124 & 139 & 142 & 143 & 154 & 166 & 171 & 196 & 226 & 244 & 253 & 256 & 259 & 277 & 289 & 292 & 314 & 316 & 337 & 345 & 376 \\
\hline H1 & G & $\mathrm{T}$ & A & c & A & $\mathrm{T}$ & $\mathrm{T}$ & G & A & G & $T$ & $T$ & A & $\mathrm{c}$ & $\mathrm{T}$ & G & A & $T$ & G & A & $\mathrm{c}$ & A & G & A & $\mathrm{c}$ & $T$ & $T$ & G & $\mathrm{c}$ & $A$ & $T$ & $\mathrm{c}$ & $G$ \\
\hline $\mathrm{H} 2$ & $A$ & $T$ & $A$ & c & $A$ & $T$ & $T$ & $G$ & $A$ & $A$ & $T$ & $T$ & $A$ & $\mathrm{c}$ & $T$ & $A$ & A & $T$ & $G$ & $A$ & c & $A$ & $A$ & A & $T$ & $T$ & $T$ & G & c & $A$ & $T$ & c & G \\
\hline H3 & A & $T$ & $A$ & $c$ & A & $\mathrm{T}$ & $T$ & $G$ & $A$ & $G$ & $T$ & $T$ & $A$ & $\mathrm{c}$ & $\mathrm{T}$ & $A$ & $A$ & $T$ & $G$ & $A$ & $c$ & $A$ & $A$ & $A$ & $T$ & $T$ & $T$ & $G$ & c & $A$ & $T$ & $\mathrm{c}$ & $G$ \\
\hline $\mathrm{H} 4$ & $A$ & $T$ & $A$ & $\mathrm{c}$ & $A$ & $T$ & $T$ & $G$ & $A$ & $G$ & $T$ & $T$ & $A$ & $\mathrm{c}$ & $T$ & $A$ & A & $T$ & $G$ & $A$ & $T$ & $A$ & $G$ & A & $T$ & $T$ & $T$ & $G$ & c & $A$ & $T$ & c & A \\
\hline H5 & G & $T$ & $A$ & c & A & $\mathrm{T}$ & $T$ & $G$ & A & $G$ & $T$ & $T$ & $A$ & c & $\mathrm{T}$ & $A$ & A & $T$ & $G$ & $A$ & $T$ & $A$ & $A$ & $A$ & $T$ & $T$ & $T$ & G & c & $A$ & $T$ & c & G \\
\hline H6 & $A$ & $T$ & $A$ & c & A & $T$ & $T$ & G & $G$ & $A$ & $T$ & $T$ & $A$ & $\mathrm{c}$ & $T$ & $A$ & $A$ & $T$ & $G$ & $A$ & c & $A$ & $A$ & $A$ & $T$ & c & $T$ & $A$ & c & $A$ & $T$ & c & $A$ \\
\hline $\mathrm{H} 7$ & $G$ & $T$ & $A$ & $c$ & $A$ & $T$ & $T$ & $G$ & $A$ & $G$ & $T$ & $T$ & $A$ & $\mathrm{c}$ & $T$ & $A$ & A & $\mathrm{c}$ & $G$ & $A$ & c & $A$ & $A$ & $A$ & $T$ & $T$ & $T$ & $A$ & c & $A$ & $T$ & c & G \\
\hline H8 & G & $T$ & A & c & A & $\mathrm{T}$ & $T$ & $G$ & $A$ & $G$ & $T$ & $T$ & A & $\mathrm{c}$ & $\mathrm{T}$ & $A$ & A & $T$ & $G$ & $A$ & $c$ & $A$ & $A$ & A & $\mathrm{T}$ & $c$ & $T$ & $A$ & $T$ & $A$ & $T$ & $c$ & G \\
\hline Н9 & $G$ & $T$ & $A$ & $\mathrm{c}$ & $A$ & $T$ & $T$ & G & A & $G$ & $T$ & $T$ & $A$ & $\mathrm{c}$ & $T$ & $A$ & A & $T$ & $G$ & $A$ & $T$ & $A$ & $G$ & A & $T$ & $T$ & $T$ & G & c & $A$ & $T$ & c & G \\
\hline H10 & $A$ & $T$ & $A$ & c & A & $\mathrm{T}$ & $T$ & G & $A$ & $G$ & $T$ & $T$ & $A$ & c & $\mathrm{T}$ & $A$ & A & $T$ & $G$ & $A$ & $T$ & $A$ & $A$ & A & $T$ & $T$ & $T$ & G & c & $A$ & c & c & $G$ \\
\hline H11 & $A$ & $T$ & $A$ & c & A & $\mathrm{T}$ & $T$ & A & $A$ & $G$ & $T$ & $T$ & $A$ & c & $\mathrm{T}$ & $A$ & A & $T$ & $G$ & $A$ & c & $A$ & A & A & $T$ & c & $T$ & A & c & $A$ & $T$ & c & G \\
\hline $\mathrm{H} 12$ & G & $T$ & $T$ & c & A & $T$ & $T$ & $G$ & A & $G$ & $T$ & $T$ & $A$ & $\mathrm{c}$ & $T$ & $A$ & A & $T$ & $G$ & $A$ & c & $A$ & $A$ & $A$ & $T$ & $T$ & $T$ & G & $\mathrm{c}$ & $A$ & $T$ & $\mathrm{c}$ & G \\
\hline $\mathrm{H} 13$ & $G$ & $T$ & $A$ & $c$ & A & $\mathrm{T}$ & $T$ & $A$ & $A$ & $G$ & $T$ & $T$ & $A$ & $\mathrm{c}$ & $\mathrm{T}$ & $A$ & $A$ & $T$ & $G$ & $A$ & $T$ & $A$ & $G$ & $A$ & $T$ & $T$ & $T$ & G & c & $A$ & $T$ & c & $G$ \\
\hline H14 & G & $T$ & $A$ & c & A & $T$ & $T$ & G & $A$ & $A$ & $T$ & $T$ & $A$ & $\mathrm{c}$ & $T$ & $A$ & A & $T$ & $G$ & $A$ & $c$ & $A$ & $G$ & $A$ & $T$ & $\mathrm{c}$ & $T$ & $A$ & $c$ & A & $T$ & $c$ & $A$ \\
\hline H15 & $G$ & $T$ & $A$ & $T$ & $A$ & $\mathrm{~T}$ & $T$ & G & $A$ & $G$ & $T$ & $T$ & $A$ & $\mathrm{c}$ & $\mathrm{T}$ & $A$ & $G$ & $T$ & $G$ & $A$ & $c$ & $A$ & $G$ & $A$ & $T$ & $T$ & $T$ & $G$ & $c$ & $A$ & $T$ & $\mathrm{c}$ & $G$ \\
\hline $\mathrm{H} 16$ & G & $T$ & $A$ & c & A & $\mathrm{T}$ & $T$ & $G$ & G & $G$ & $T$ & $T$ & $A$ & $\mathrm{c}$ & $\mathrm{T}$ & $A$ & $A$ & $T$ & $G$ & $A$ & c & $A$ & $A$ & $A$ & $T$ & $T$ & $T$ & G & c & $A$ & $T$ & c & G \\
\hline H17 & $G$ & $T$ & $A$ & c & A & $T$ & $T$ & G & $A$ & $G$ & $T$ & $T$ & $A$ & $\mathrm{c}$ & $T$ & $A$ & $A$ & $T$ & $G$ & $A$ & $c$ & $A$ & A & $A$ & $T$ & $T$ & $T$ & $G$ & $\mathrm{c}$ & $A$ & $T$ & $\mathrm{c}$ & $A$ \\
\hline $\mathrm{H} 18$ & $G$ & $T$ & $A$ & $c$ & $A$ & $T$ & $T$ & G & $G$ & $G$ & $T$ & $T$ & $A$ & $\mathrm{c}$ & $T$ & $A$ & $A$ & $T$ & $G$ & $A$ & $T$ & $G$ & $G$ & $A$ & $T$ & $T$ & $T$ & G & c & $A$ & $T$ & c & $A$ \\
\hline H19 & $A$ & $T$ & $A$ & $c$ & $A$ & $T$ & $T$ & $G$ & $A$ & $G$ & $T$ & $T$ & $A$ & $\mathrm{c}$ & $T$ & $A$ & $A$ & $T$ & $G$ & $A$ & $c$ & $A$ & $A$ & $A$ & $T$ & $T$ & $T$ & $A$ & $c$ & $A$ & $T$ & $\mathrm{c}$ & G \\
\hline $\mathrm{H} 20$ & $G$ & c & A & $\mathrm{c}$ & A & $T$ & $T$ & A & A & $G$ & $T$ & $T$ & A & $\mathrm{c}$ & $T$ & A & A & $T$ & $G$ & A & $\mathrm{c}$ & $A$ & $G$ & A & $\mathrm{T}$ & $T$ & $T$ & G & $\mathrm{c}$ & $A$ & $T$ & $T$ & $G$ \\
\hline $\mathrm{H} 21$ & G & $T$ & $A$ & $\mathrm{c}$ & A & $T$ & $T$ & G & $A$ & $A$ & $T$ & $T$ & $A$ & $\mathrm{c}$ & $T$ & $A$ & $A$ & $T$ & $G$ & $A$ & $\mathrm{c}$ & $A$ & $A$ & A & $T$ & $T$ & $T$ & G & $\mathrm{c}$ & $A$ & $\mathbf{T}$ & $\mathrm{c}$ & A \\
\hline $\mathrm{H} 22$ & $G$ & $T$ & $A$ & c & $A$ & $T$ & $T$ & $G$ & $A$ & $G$ & $\mathrm{c}$ & $T$ & $A$ & $\mathrm{c}$ & $T$ & $A$ & $A$ & $T$ & $G$ & $A$ & c & $A$ & $G$ & $A$ & $T$ & $T$ & $T$ & $G$ & $\mathrm{c}$ & $A$ & $T$ & c & G \\
\hline $\mathrm{H} 23$ & G & $T$ & $A$ & c & A & $\mathrm{T}$ & $T$ & $G$ & $A$ & $G$ & $T$ & $T$ & $A$ & c & $T$ & $A$ & $A$ & $T$ & $G$ & $A$ & $T$ & G & $G$ & $A$ & $T$ & $T$ & $T$ & $A$ & c & $A$ & $T$ & c & G \\
\hline $\mathrm{H} 24$ & $A$ & $T$ & $A$ & $\mathrm{c}$ & $A$ & $T$ & $T$ & G & $A$ & $G$ & $T$ & $T$ & $A$ & $\mathrm{c}$ & $T$ & $A$ & $A$ & $T$ & $A$ & $A$ & $\mathrm{c}$ & $A$ & $A$ & $A$ & $T$ & c & $T$ & $A$ & $\mathrm{c}$ & $A$ & $T$ & c & $A$ \\
\hline $\mathrm{H} 25$ & $G$ & $T$ & $A$ & $\mathrm{c}$ & A & $T$ & $T$ & G & $A$ & $G$ & $T$ & $T$ & $A$ & $\mathrm{c}$ & $T$ & $A$ & $A$ & $T$ & $G$ & $A$ & $\mathrm{c}$ & $A$ & $G$ & $A$ & $T$ & $T$ & $T$ & G & $\mathrm{c}$ & $A$ & $T$ & $\mathrm{c}$ & G \\
\hline $\mathrm{H} 26$ & G & $T$ & $A$ & $\mathrm{c}$ & A & $T$ & $T$ & $G$ & $A$ & $A$ & $T$ & $c$ & $A$ & $\mathrm{c}$ & $T$ & $A$ & A & $T$ & $G$ & $A$ & $\mathrm{c}$ & $A$ & $A$ & G & $\mathrm{T}$ & c & $T$ & A & $\mathrm{c}$ & $A$ & $T$ & $\mathrm{c}$ & A \\
\hline $\mathrm{H} 27$ & $A$ & $T$ & $A$ & $\mathrm{c}$ & A & $T$ & $T$ & G & $A$ & $G$ & $T$ & $T$ & $G$ & $\mathrm{c}$ & $T$ & $A$ & $A$ & $T$ & $G$ & $A$ & $c$ & $A$ & $A$ & $A$ & $T$ & $T$ & $T$ & G & $c$ & $A$ & $T$ & $\mathrm{c}$ & G \\
\hline $\mathrm{H}_{28}$ & $A$ & $T$ & $A$ & $\mathrm{c}$ & A & $\mathbf{T}$ & c & G & $G$ & $G$ & $T$ & $T$ & $A$ & $T$ & $\mathbf{T}$ & $A$ & $A$ & $T$ & $G$ & $G$ & $c$ & $A$ & $A$ & $A$ & $\mathrm{~T}$ & $\mathrm{c}$ & $T$ & A & $c$ & $A$ & $\mathrm{~T}$ & $\mathrm{c}$ & G \\
\hline $\mathrm{H} 2 \mathrm{~g}$ & $A$ & $T$ & $A$ & $e$ & $A$ & $T$ & $T$ & $B$ & $A$ & $G$ & $T$ & $T$ & $A$ & $\mathrm{e}$ & $T$ & $A$ & $A$ & $T$ & $G$ & $A$ & $\mathrm{e}$ & $A$ & $A$ & $A$ & $\mathrm{~T}$ & c & $T$ & A & $\mathrm{e}$ & $A$ & $T$ & e & G \\
\hline $\mathrm{H} 3 \mathrm{O}$ & $G$ & $T$ & $A$ & $\mathrm{c}$ & $A$ & $T$ & $T$ & $G$ & $A$ & $G$ & $T$ & $T$ & $A$ & $\mathrm{c}$ & $T$ & $A$ & $A$ & $T$ & $A$ & $A$ & $T$ & $A$ & $G$ & $A$ & $T$ & $T$ & $T$ & $G$ & c & $A$ & $T$ & c & $G$ \\
\hline
\end{tabular}




\begin{tabular}{|c|c|c|c|c|c|c|c|c|c|c|c|c|c|c|c|c|c|c|c|c|c|c|c|c|c|c|c|c|c|c|c|c|c|}
\hline Haplotipo & 13 & 46 & 49 & 50 & 70 & 73 & 85 & 97 & 100 & 106 & 112 & 121 & 124 & 139 & 142 & 148 & 154 & 166 & 171 & 196 & 226 & 244 & 253 & 256 & 259 & 277 & 289 & 292 & 314 & 316 & 337 & 343 & 376 \\
\hline HS1 & A & $T$ & A & c & $A$ & $T$ & $T$ & G & $A$ & $G$ & $T$ & $T$ & $A$ & c & $T$ & $A$ & $A$ & $T$ & G & A & $T$ & A & $A$ & A & $T$ & $T$ & $T$ & G & c & c & $T$ & c & G \\
\hline H32 & $A$ & $T$ & A & c & $A$ & $T$ & $T$ & G & $A$ & $G$ & $T$ & $T$ & $A$ & $\mathrm{c}$ & $T$ & $A$ & $A$ & $\mathrm{~T}$ & $G$ & A & $\mathrm{T}$ & A & $A$ & A & $T$ & $T$ & $T$ & G & c & $A$ & $T$ & $\mathrm{c}$ & $A$ \\
\hline HSS & G & $T$ & A & c & $A$ & $\mathrm{~T}$ & $T$ & G & $A$ & $A$ & $T$ & $T$ & $A$ & c & $T$ & $A$ & $A$ & $T$ & G & A & c & A & $A$ & A & $T$ & $T$ & $T$ & G & c & A & $T$ & c & G \\
\hline H34 & G & $T$ & A & c & $A$ & $\mathrm{~T}$ & $T$ & G & $A$ & $A$ & $T$ & $T$ & $A$ & $c$ & $T$ & $A$ & $A$ & $T$ & G & A & $c$ & A & $A$ & A & $T$ & $T$ & $T$ & G & c & A & $T$ & c & $G$ \\
\hline H35 & A & $T$ & A & c & $A$ & $T$ & $T$ & G & $A$ & $G$ & $T$ & $T$ & $A$ & c & $T$ & $A$ & $A$ & $T$ & $G$ & $A$ & $c$ & A & $A$ & A & $T$ & $T$ & $T$ & G & c & $A$ & $T$ & c & $G$ \\
\hline H36 & G & $T$ & A & c & $A$ & $\mathrm{~T}$ & $T$ & G & $A$ & $G$ & $T$ & $T$ & $A$ & c & $T$ & A & $A$ & $T$ & G & A & c & A & $A$ & A & $T$ & c & $T$ & $A$ & $\mathrm{~T}$ & $A$ & $T$ & c & $G$ \\
\hline H37 & A & $T$ & A & c & $A$ & $T$ & $T$ & G & $A$ & $G$ & $T$ & $T$ & $A$ & c & $T$ & $A$ & $A$ & $T$ & G & A & c & $A$ & A & $A$ & $T$ & $T$ & $T$ & A & $T$ & $A$ & $T$ & $\mathrm{c}$ & $G$ \\
\hline H38 & G & $T$ & A & c & $A$ & $T$ & $T$ & G & $A$ & $G$ & $T$ & $c$ & $A$ & c & c & A & $A$ & $T$ & G & A & $T$ & $A$ & $G$ & A & $T$ & $T$ & $T$ & $G$ & c & $A$ & $T$ & c & $G$ \\
\hline H39 & G & $T$ & A & c & $A$ & $T$ & $T$ & G & $A$ & G & $T$ & $T$ & $A$ & c & $T$ & $A$ & $A$ & $T$ & $G$ & A & $T$ & A & $G$ & A & $T$ & $T$ & $T$ & $G$ & c & $A$ & $T$ & c & $A$ \\
\hline $\mathrm{H} 40$ & A & $T$ & A & c & c & $T$ & $T$ & G & $A$ & $G$ & $T$ & $T$ & $G$ & $\mathrm{c}$ & $T$ & $A$ & $A$ & $\mathrm{~T}$ & $G$ & A & $\mathrm{T}$ & A & G & A & $T$ & $T$ & $T$ & G & c & $A$ & $T$ & $\mathrm{c}$ & $A$ \\
\hline H41 & A & $T$ & A & c & $A$ & $T$ & $T$ & G & $A$ & $G$ & $T$ & $T$ & $A$ & $\mathrm{c}$ & $T$ & $A$ & $A$ & $T$ & $G$ & A & $\mathrm{c}$ & $A$ & G & A & $T$ & $T$ & $T$ & G & $\mathrm{c}$ & $A$ & $T$ & $\mathrm{c}$ & $G$ \\
\hline $\mathrm{H} 42$ & G & $T$ & $A$ & c & $A$ & $T$ & $T$ & G & $A$ & G & $T$ & $T$ & $A$ & $\mathrm{c}$ & $T$ & $A$ & $A$ & $T$ & G & $A$ & $\mathrm{c}$ & $A$ & G & $A$ & $T$ & c & $T$ & $A$ & $\mathrm{~T}$ & $A$ & $T$ & $\mathrm{c}$ & G \\
\hline $\mathrm{H} 4 \mathrm{~s}$ & G & $T$ & $A$ & $c$ & $A$ & $T$ & $T$ & G & $A$ & G & $T$ & $\mathrm{~T}$ & $A$ & $\mathrm{c}$ & $T$ & $A$ & $A$ & $T$ & G & $A$ & $\mathrm{c}$ & $A$ & A & $A$ & $T$ & $\mathrm{~T}$ & c & A & $\mathrm{c}$ & $A$ & $T$ & $\mathrm{c}$ & $G$ \\
\hline $\mathrm{H} 44$ & G & $T$ & A & c & $A$ & $T$ & $T$ & G & $A$ & $G$ & $T$ & $\mathrm{~T}$ & A & $\mathrm{c}$ & $T$ & A & A & $T$ & G & $A$ & $\mathrm{c}$ & $A$ & A & $A$ & $T$ & $\mathrm{~T}$ & $T$ & G & $\mathrm{c}$ & $A$ & $T$ & $\mathrm{c}$ & $G$ \\
\hline H45 & G & $T$ & A & c & $A$ & $T$ & $\mathrm{~T}$ & G & $A$ & G & $T$ & $T$ & $A$ & c & $T$ & $A$ & $A$ & $\mathrm{~T}$ & G & $A$ & c & $A$ & $A$ & G & $T$ & $T$ & $T$ & G & c & $A$ & $T$ & c & $G$ \\
\hline $\mathrm{H} 46$ & G & $T$ & $A$ & c & $A$ & $T$ & $T$ & G & $A$ & G & $T$ & $T$ & $A$ & c & $T$ & $A$ & $A$ & $T$ & G & $A$ & $T$ & $A$ & G & $A$ & $T$ & $T$ & $T$ & G & c & $A$ & $T$ & c & G \\
\hline $\mathrm{H} 47$ & G & $T$ & A & c & $A$ & c & $T$ & G & $A$ & $A$ & $T$ & $T$ & $A$ & $\mathrm{c}$ & $T$ & A & $A$ & $T$ & $G$ & $A$ & c & $A$ & $A$ & $A$ & $T$ & $T$ & $T$ & G & c & $A$ & $T$ & $\mathrm{c}$ & $G$ \\
\hline $\mathrm{H} 43$ & G & $T$ & A & c & $A$ & $T$ & $T$ & A & $A$ & $G$ & $T$ & $T$ & $A$ & $\mathrm{c}$ & $T$ & $A$ & $A$ & $T$ & G & $A$ & $\mathrm{c}$ & A & $A$ & $A$ & $T$ & $T$ & $T$ & $A$ & c & $A$ & $T$ & c & $G$ \\
\hline $\mathrm{H} 4 \mathrm{~g}$ & G & $T$ & $A$ & c & $A$ & $T$ & $T$ & G & $A$ & $A$ & $T$ & $T$ & $A$ & $\mathrm{c}$ & $T$ & $A$ & $A$ & $T$ & G & $A$ & $T$ & $A$ & $G$ & $A$ & $T$ & $T$ & $T$ & $G$ & $T$ & $A$ & $T$ & $c$ & $G$ \\
\hline
\end{tabular}


Quadro A.2 - Sítios variáveis dos 23 haplótipos encontrados no gene CO-I em An. cruzii morro x planície de JUL/12. Os números em negrito representam o local na sequência que ocorreu a mudança. As bases em cinza são aquelas variáveis nas sequências.

\begin{tabular}{|c|c|c|c|c|c|c|c|c|c|c|c|c|c|c|c|c|c|c|c|c|c|c|c|}
\hline \multicolumn{24}{|c|}{ Posições das mudanças nucleotidicas em Anopheles cruzii } \\
\hline Hapiotipo & 24 & 26 & 58 & 64 & 87 & 109 & 124 & 139 & 145 & 148 & 157 & 176 & 239 & 282 & 303 & 309 & 312 & 315 & 396 & 349 & 379 & 385 & 398 \\
\hline $\mathrm{H} 50$ & $\mathrm{c}$ & $A$ & $G$ & $A$ & $G$ & $T$ & $A$ & $T$ & $T$ & $T$ & $T$ & $G$ & $G$ & $A$ & $\mathrm{c}$ & $T$ & $c$ & $T$ & $A$ & $A$ & $T$ & A & $\mathrm{c}$ \\
\hline H51 & $\mathrm{c}$ & $T$ & $G$ & $A$ & $G$ & $T$ & $A$ & $T$ & $T$ & $T$ & $T$ & G & $G$ & $A$ & $\mathrm{c}$ & $T$ & $\mathrm{c}$ & $T$ & $A$ & $A$ & $T$ & A & $\mathrm{c}$ \\
\hline H52 & $T$ & $T$ & $G$ & $A$ & $G$ & $T$ & $A$ & $T$ & $T$ & $T$ & c & $G$ & $G$ & $A$ & $\mathrm{c}$ & c & $c$ & $T$ & $A$ & $A$ & $T$ & A & $\mathrm{c}$ \\
\hline H5s & $c$ & $T$ & $G$ & $A$ & $G$ & $T$ & A & $T$ & $T$ & $T$ & $T$ & A & $A$ & $A$ & $\mathrm{c}$ & $T$ & $c$ & $T$ & $A$ & $A$ & $T$ & A & $\mathrm{c}$ \\
\hline $\mathrm{H} 54$ & $T$ & $T$ & A & $T$ & $G$ & $T$ & A & $T$ & $T$ & $T$ & $T$ & $G$ & $G$ & $A$ & $\mathrm{c}$ & $T$ & $\mathrm{c}$ & $T$ & $A$ & $A$ & $T$ & A & $\mathrm{c}$ \\
\hline H55 & $\mathrm{c}$ & $T$ & $G$ & $A$ & $G$ & $c$ & $A$ & $T$ & $T$ & $\mathrm{c}$ & $T$ & $A$ & $A$ & $A$ & c & $T$ & $\mathrm{c}$ & $T$ & $A$ & $A$ & $T$ & A & $\mathrm{c}$ \\
\hline H56 & $\mathrm{c}$ & $T$ & $G$ & A & $G$ & c & $A$ & $T$ & $T$ & $T$ & $T$ & G & A & A & $\mathrm{c}$ & $T$ & $c$ & $T$ & $A$ & A & $T$ & A & $\mathrm{c}$ \\
\hline H57 & $\mathrm{c}$ & $T$ & $G$ & A & $G$ & $T$ & $A$ & $T$ & $T$ & $T$ & $T$ & $G$ & A & A & $\mathrm{c}$ & $T$ & $c$ & $T$ & $A$ & A & A & A & $\mathrm{c}$ \\
\hline H58 & $\mathrm{c}$ & $T$ & $G$ & A & A & $T$ & $G$ & $T$ & $T$ & $T$ & $T$ & G & $A$ & $A$ & c & $T$ & $\mathrm{c}$ & $T$ & $A$ & $A$ & $T$ & $A$ & $T$ \\
\hline H59 & $\mathrm{c}$ & $T$ & $G$ & A & A & $T$ & $A$ & $T$ & $T$ & $T$ & $T$ & $G$ & A & $A$ & c & $T$ & $\mathrm{c}$ & $T$ & $A$ & $A$ & $T$ & A & $\mathrm{c}$ \\
\hline $\mathrm{H} 60$ & $\mathrm{c}$ & $T$ & $G$ & A & $A$ & $T$ & $G$ & $T$ & $T$ & $T$ & $T$ & $G$ & A & A & c & $T$ & $T$ & $T$ & A & A & $T$ & A & $T$ \\
\hline H61 & $\mathrm{c}$ & $T$ & $G$ & A & $G$ & c & $A$ & $T$ & $T$ & $T$ & $T$ & A & A & A & c & $T$ & $c$ & $T$ & A & A & $T$ & A & c \\
\hline $\mathrm{H} 62$ & $\mathrm{c}$ & $T$ & $G$ & A & $G$ & c & $A$ & $T$ & $\mathrm{c}$ & $T$ & $T$ & $G$ & A & $A$ & c & $T$ & $c$ & $T$ & $G$ & $A$ & $T$ & A & $c$ \\
\hline $\mathrm{H} 63$ & $\mathrm{c}$ & $T$ & $G$ & A & $G$ & $T$ & $A$ & $\mathrm{~T}$ & c & $T$ & $T$ & $G$ & A & A & c & $T$ & $\mathrm{c}$ & $T$ & A & A & $T$ & A & $\mathrm{c}$ \\
\hline HG4 & $\mathrm{c}$ & $T$ & $G$ & A & $G$ & $c$ & $A$ & $T$ & $T$ & $T$ & $T$ & A & A & A & $T$ & $T$ & $c$ & $T$ & A & $A$ & $T$ & A & c \\
\hline $\mathrm{H} 65$ & $T$ & $T$ & $A$ & A & $G$ & $T$ & $G$ & $T$ & $T$ & $\mathrm{c}$ & $T$ & $G$ & A & A & $T$ & $T$ & $\mathrm{c}$ & $T$ & $A$ & $A$ & $T$ & $T$ & $\mathrm{c}$ \\
\hline H66 & $\mathrm{c}$ & $T$ & $G$ & A & $G$ & $c$ & $A$ & c & $T$ & $\mathrm{c}$ & $T$ & A & $A$ & $A$ & c & c & $\mathrm{c}$ & $T$ & $A$ & $A$ & $T$ & A & $\mathrm{c}$ \\
\hline $\mathrm{H} 67$ & $\mathrm{c}$ & $T$ & $G$ & A & $G$ & c & $A$ & $T$ & $T$ & c & $T$ & $G$ & A & A & c & $T$ & $c$ & $T$ & A & $A$ & $T$ & A & c \\
\hline $\mathrm{H} 68$ & $\mathrm{c}$ & $T$ & $G$ & A & $G$ & $T$ & G & $T$ & $T$ & $\mathrm{c}$ & $T$ & G & $A$ & $A$ & c & $T$ & $c$ & $T$ & $A$ & A & $T$ & A & $T$ \\
\hline $\mathrm{H} 69$ & $\mathrm{c}$ & $T$ & $G$ & A & $G$ & $c$ & $A$ & $T$ & $T$ & $\mathrm{c}$ & $T$ & $G$ & A & $G$ & c & $T$ & $T$ & c & $A$ & $A$ & $T$ & A & $\mathrm{c}$ \\
\hline $\mathrm{H} 70$ & $c$ & $T$ & $G$ & A & $G$ & c & $A$ & $\mathrm{~T}$ & $T$ & c & $T$ & A & A & $A$ & c & $T$ & $c$ & $T$ & A & $G$ & $T$ & A & $c$ \\
\hline H71 & $\mathrm{c}$ & $T$ & $G$ & A & $G$ & $T$ & $G$ & $T$ & $T$ & $T$ & c & $G$ & A & $A$ & c & $c$ & $c$ & $T$ & A & A & $T$ & A & c \\
\hline $\mathrm{H} 72$ & $\mathrm{c}$ & $T$ & $G$ & $A$ & $G$ & c & $A$ & $T$ & $T$ & $c$ & $T$ & $G$ & $A$ & $A$ & c & $c$ & c & $T$ & $A$ & $A$ & $T$ & $A$ & c \\
\hline
\end{tabular}

Quadro A.3 - Sítios variáveis dos 9 haplótipos encontrados no gene CO-I em An. homunculus no inverno $x$ verão. Os números em negrito representam o local na sequência que ocorreu a mudança. As bases em cinza são aquelas variáveis nas sequências.

\begin{tabular}{|c|cccccccccccccc|}
\multicolumn{10}{|c|}{ Posições das mudanças nucleotídicas em Anopheles homunculus } \\
\hline Haplótipo & 215 & 224 & 245 & 292 & 293 & 302 & 364 & 380 & 413 & 464 & 470 & 491 & 494 & 512 \\
\hline H1 & T & T & G & G & T & G & C & A & A & T & T & T & A & A \\
H2 & T & C & G & G & T & G & C & A & A & T & T & T & A & A \\
H3 & C & C & G & G & C & G & C & C & A & T & T & T & A & C \\
H4 & C & T & G & G & T & G & T & C & A & T & A & A & A & A \\
H5 & T & C & A & G & T & G & C & A & G & T & T & T & A & A \\
H6 & T & T & G & A & T & G & C & A & A & T & T & T & C & A \\
H7 & T & C & G & G & T & G & C & A & A & C & T & T & A & A \\
H8 & C & T & G & G & T & G & C & A & A & T & T & T & A & A \\
H9 & T & T & G & G & T & A & C & A & A & T & T & T & A & A \\
\hline
\end{tabular}

